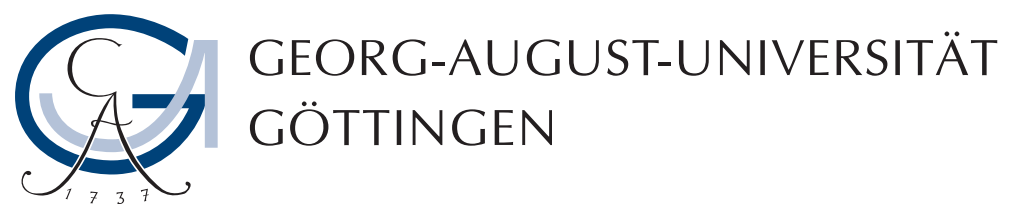

\title{
PROMISES AND PERILS OF GLOBALIZATION
}

\author{
A thesis submitted for the degree of \\ "Dr. rerum politicarum" \\ from the Faculty of Economic Sciences at the \\ Georg-August-Universität Göttingen
}

\author{
Submitted by \\ Lennart Christian Kaplan \\ born in Osterode am Harz, Germany
}

October 2018 



\title{
First Examiner: Professor Dr. Axel Dreher
}

Professor of Economics

Chair of International and Development Politics

Alfred-Weber-Institute for Economics

Ruprechts-Karls-Universität Heidelberg

Affiliated Professor

Department of Economics

Georg-August-Universiät Göttingen

\author{
Second Examiner: \\ Professor Dr. Stephan Klasen \\ Professor of Economics \\ Chair of Development Economics \\ Department of Economics \\ Georg-August-Universiät Göttingen
}

\section{Third Examiner: \\ Professor Dr. Krisztina Kis-Katos \\ Professor of Economics \\ Chair of International Economics \\ Department of Economics \\ Georg-August-Universiät Göttingen}





\section{Contents}

$\begin{array}{ll}\text { List of Figures } & \text { VI }\end{array}$

List of Tables IX

$\begin{array}{lr}\text { Introduction } & 1\end{array}$

1 Your neighbor's aid helps you upgrade?

$\begin{array}{ll}\text { Third-country effects of development aid on sectoral exports } & 9\end{array}$

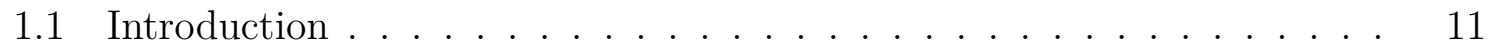

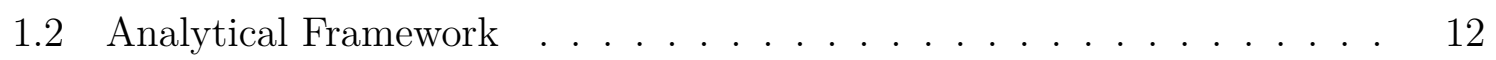

1.3 Empirical Implementation . . . . . . . . . . . . . . . . . . . . . . . . . 14

1.4 Data \& Descriptives $\ldots \ldots \ldots \ldots$

1.5 Results . . . . . . . . . . . . . . . . . . . . . . . . . . . . . . . . . . . . . . . . 18

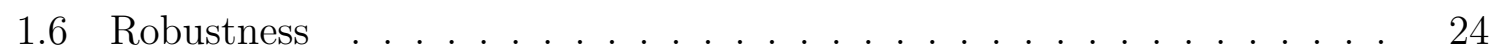

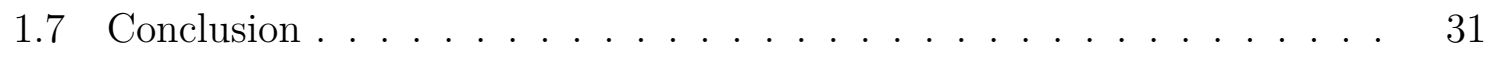

1. A Data Sources . . . . . . . . . . . . . . . . . . . . . . . . . 32

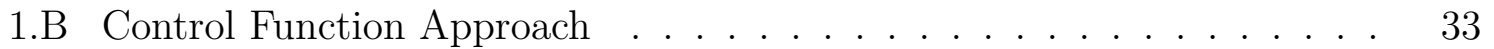

1.C Segment Specific Trends . . . . . . . . . . . . . . . . . . . . . . . 33

$1 . \mathrm{D}$ Tables and Figures $\ldots \ldots \ldots \ldots \ldots$

\begin{tabular}{|ll|}
\hline 2 & Unequal Gains from Trade \\
\hline \hline & The Role of Political Biases
\end{tabular}

2.1 Introduction . . . . . . . . . . . . . . . . . . . . . . . . . . . . . . 44

2.2 Literature . . . . . . . . . . . . . . . . . . . . . . . . . . 45

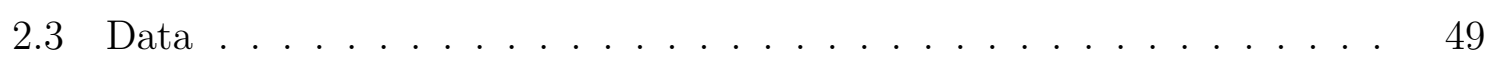

$2.4 \quad$ Empirical Approach $\ldots \ldots \ldots \ldots \ldots \ldots$

2.4 .1 Model $\ldots \ldots \ldots \ldots \ldots$

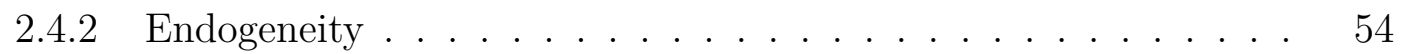

2.5 Results . . . . . . . . . . . . . . . . . . . . . . . 57

$2.5 .1 \quad$ Channels and Heterogeneities . . . . . . . . . . . . . 59

2.5 .2 Robustness . . . . . . . . . . . . . . . . . . . . . . . 62

2.6 Discussion and Conclusion . . . . . . . . . . . . . . . . . . . . . . 63

2. A Appendix . . . . . . . . . . . . . . . . . . . . 65 
2. A.1 Data Appendix . . . . . . . . . . . . . . . . . . . 65

2. A.2 Analytical Appendix $\ldots \ldots \ldots \ldots \ldots$

3 Aid and conflict at the subnational level - Evidence from World Bank and Chinese development projects in Africa 84

3.1 Introduction . . . . . . . . . . . . . . . . 86

3.2 Existing Literature and theoretical considerations . . . . . . . . . . 88

3.2 .1 Literature and theories . . . . . . . . . . . . . . . . 88

3.2 .2 Two Types of Donors: China versus the World Bank . . . . . 92

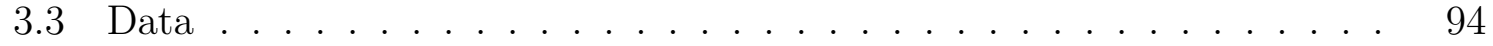

3.3.1 Aid Data $\ldots \ldots \ldots \ldots$

3.3 .2 Conflict Measures . . . . . . . . . . . . . . . . . . . . . . . . 98

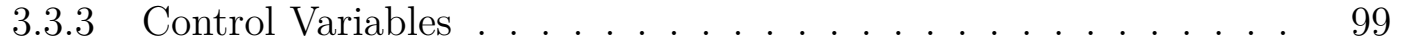

3.4 Empirical Strategy $\ldots \ldots \ldots$

3.4.1 Linear Models - Fixed Effects, Time Trends and Control Variables 100

3.4 .2 Instrumental Variable Approach . . . . . . . . . . . . . . . . . 101

3.5 Results . . . . . . . . . . . . . . . . . . . . . . . 105

3.5.1 OLS, Fixed Effects and Time Trends . . . . . . . . . . . 105

3.5 .2 Instrumental Variable Results . . . . . . . . . . . . . . . 108

3.5 .3 Channels - Aid Subtypes . . . . . . . . . . . . . . . . . . . . . 110

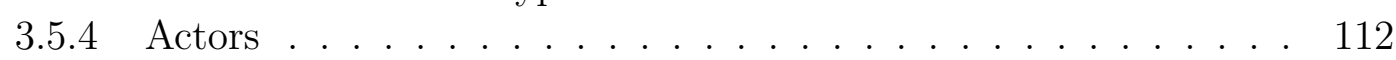

3.5 .5 Types of Violence . . . . . . . . . . . . . . . . . . . . . . . . . 114

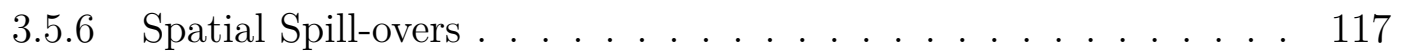

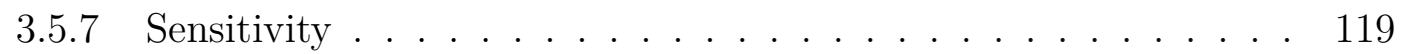

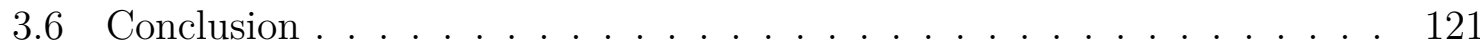

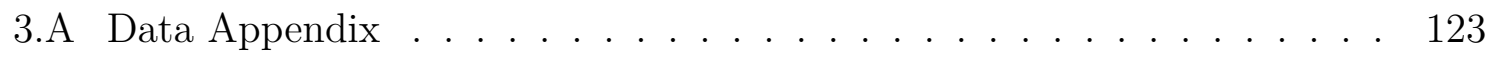

3.A.1 Sources . . . . . . . . . . . . . . . . . . . . . . . . . . . 123

3.A.2 Independent Variables (Development Aid) . . . . . . . . . . . 124

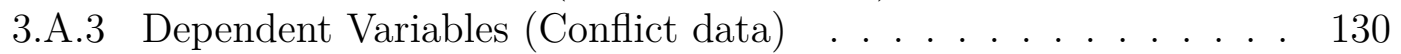

$3 . \mathrm{B}$ Analytical Appendix $\ldots \ldots \ldots \ldots \ldots$

3. B.1 Instrumental Variable . . . . . . . . . . . . . . . . . . . . . 132

3.B.2 Alternative Outcome Variables . . . . . . . . . . . . . . 144

3.B.3 Channels - Ethnic Groups, Governing Coalition and Aid Types 157

3.B.4 Estimations - Miscellaneous . . . . . . . . . . . . . . 164

4 What Makes a Successful Development Intervention? The Theory of Planned Behavior - An Application to Implementation Research 178

$4.1 \quad$ Introduction . . . . . . . . . . . . . . . . . . . . . . . . . . . . 180

$4.2 \quad$ Research Design and Data . . . . . . . . . . . . . . . . . . . . . . . 182

4.2 .1 The TPB in the Setting of the SCC Intervention . . . . . . . 183

$4.2 .2 \quad$ What Shapes Attitudes? A Framing Experiment. . . . . . . . . 187 
4.3 Method . . . . . . . . . . . . . . . . . . . . . . . . . . . . . . . . . . 193

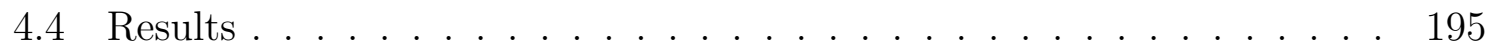

4.5 Discussion and Conclusion . . . . . . . . . . . . . . . . . . . . 204

4. A Appendix . . . . . . . . . . . . . . . . . . . . . . . 206

4. A.1 $\quad$ Experimental Protocol $\ldots \ldots \ldots \ldots$

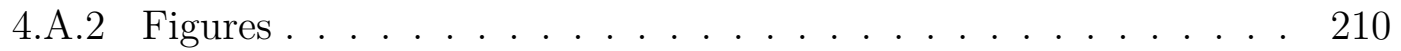

4. A.3 Tables . . . . . . . . . . . . . . . . . . . . . . . . 211

\begin{tabular}{ll}
\hline Bibliography & 251
\end{tabular}

\begin{tabular}{ll}
\hline Acknowledgments & 252
\end{tabular} 


\section{List of Figures}

I Perils and Promises of Globalization . . . . . . . . . . . . . . 4

$1.1 \quad$ Average DORCA Scores . . . . . . . . . . . . . . . . . . 17

A.1 Trends in Aid and Trade . . . . . . . . . . . . . . . . . . . 34

A.2 Average WDORCA Scores. . . . . . . . . . . . . . . . . . . . . 36

$2.1 \quad$ Poverty and Local Producer Price Indices . . . . . . . . . . . . . . 51

a $\quad$ Average Poverty Indices $\ldots \ldots \ldots \ldots$. . . . . . . . . . 51

b $\quad$ Local Producer Price Indices . . . . . . . . . . . . . . . . . . . 51

$2.2 \quad$ Leader Birth Regions and Coethnicity . . . . . . . . . . . . . . 52

a $\quad$ Leader Birth Regions $\ldots \ldots \ldots \ldots \ldots$. . . . . . . . . . 52

b $\quad$ Coethnics of Leader. . . . . . . . . . . . . . . . . . . . 52

$2.3 \quad$ Cash Crop Trends . . . . . . . . . . . . . . . . . . 55

$2.4 \quad$ Trends in Producer Prices and Trends in Poverty across Power Status 56

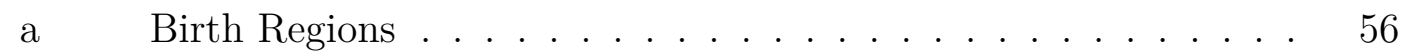

b $\quad$ Ethnic Groups $\ldots \ldots \ldots \ldots \ldots \ldots$

B.1 Regional and Ethnic Affiliation of Respondents . . . . . . . . . . . 70

B.2 Randomization Inference - Producer Prices and Coethnicity . . . . . . 77

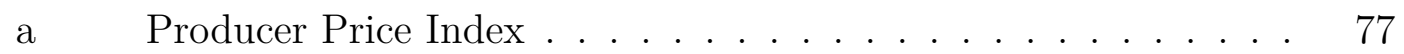

b Leader Coethnicity . . . . . . . . . . . . . . . . . 77

B.3 $\quad$ Partial Regression Plots . . . . . . . . . . . . . . . . . . . . . . . . 79

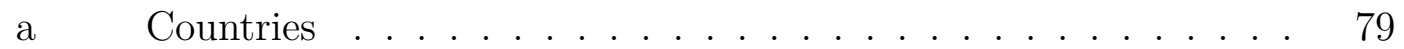

b $\quad$ Years . . . . . . . . . . . . . . . . . . . . . . . . . 79

$3.1 \quad$ Scenarios Linking Aid to Conflict . . . . . . . . . . . . . . . . . . . 89

$3.2 \quad$ Distribution of Georeferencing Precision . . . . . . . . . . . . . . . . 95

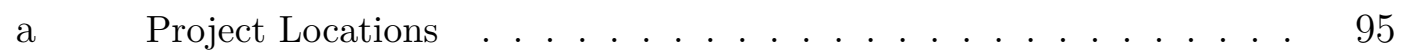

b $\quad$ Disbursement / Commitment Amounts . . . . . . . . . . . 95

$3.3 \quad$ Maps: Conflict and Aid in Africa . . . . . . . . . . . . . . . . . . . 99

a conflict. . . . . . . . . . . . . . . . . . . . . . . . . . 99

b Development Aid . . . . . . . . . . . . . . . . . . . . . . 99

$3.4 \quad$ Deviations from Chinese Steel Production Trend \& Battle-Related Deaths 104

a Mean Battle-Related Deaths (raw) . . . . . . . . . . . . . . . . 104

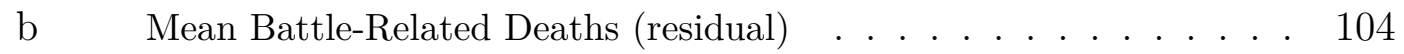


$3.5 \quad$ World Bank IDA funding Position \& Battle-Related Deaths . . . . . . 105

a $\quad$ Mean Battle-Related Deaths (raw) . . . . . . . . . . . . . . 105

b Mean Battle-Related Deaths (residual) . . . . . . . . . . . . . 105

C.1 Chinese Aid ADM1 Spatial Join . . . . . . . . . . . . . . . . . . . . 126

C.2 $\quad$ Sectoral Distribution of Aid . . . . . . . . . . . . . . . . . . . . . . . . 127

a $\quad$ World Bank's IDA . . . . . . . . . . . . . . . . . . . . . . . . 127

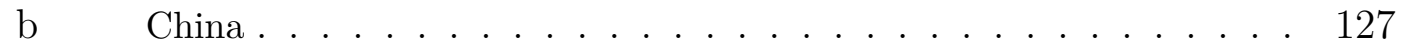

C.3 IDA Funding Position - Time Series . . . . . . . . . . . . . . . . . . . 132

C.4 Donor Funding Positions and Aid . . . . . . . . . . . . . . . . . . . . 132

a $\quad$ World Bank IDA Funding Position and $\ln$ (World Bank Aid) . . . . 132

b Deviations from Trend in Steel Production and $\ln$ (Chinese Aid) . . . 132

C.5 SCAD Data for Precision Codes 1-4 . . . . . . . . . . . . . . 144

$4.1 \quad$ Applying the TPB to the SCC Intervention . . . . . . . . . . . . . . . 184

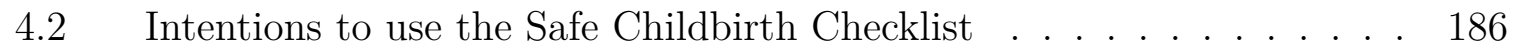

a $\quad$ Intentions - Indonesia . . . . . . . . . . . . . . . . . 186

b $\quad$ Intentions - Pakistan . . . . . . . . . . . . . . . . . . 186

$4.3 \quad$ Actual use of the Safe Childbirth Checklist . . . . . . . . . . . . . . . 186

a $\quad$ Behavior - Indonesia . . . . . . . . . . . . . . . 186

b $\quad$ Behavior - Pakistan . . . . . . . . . . . . . . 186

$4.4 \quad$ Framing Experiment - Previous Experience . . . . . . . . . . . . . . . 202

D.1 $\quad$ SCC Leaflet . . . . . . . . . . . . . . . . . . . . . . . . 207

D.2 $\quad$ Study Design Flow Chart . . . . . . . . . . . . . . . . . . . . . . 210

D.3 Distribution of "International" Country Perceptions . . . . . . . . . . 210 


\section{List of Tables}

$1.1 \quad$ Spearman's $\rho \ldots \ldots \ldots \ldots \ldots \ldots$

$1.2 \quad$ DORCA Baseline . . . . . . . . . . . . . . . . . . . . . . . . . . . . . 19

1.3 PRODY Baseline. . . . . . . . . . . . . . . . . . . . . . . . . . . . . . 20

$1.4 \quad$ DORCA (Dis-)Advantage . . . . . . . . . . . . . . . . . . . . . . . . 22

$1.5 \quad$ PRODY (Dis-)Advantage $\ldots \ldots \ldots \ldots \ldots$

$1.6 \quad$ DORCA (Dis-)Advantage - Control Function . . . . . . . . . . . . 28

$1.7 \quad$ DORCA (Dis-)Advantage - pre 2005 . . . . . . . . . . . . . . . . . . . 29

$1.8 \quad$ DORCA (Dis-)Advantage - post $2005 \ldots \ldots \ldots$

A.1 Countries in Sample . . . . . . . . . . . . . . . . . . . . . . . . . . . 32

A.2 $\quad$ Synthetic Aid - First Stage . . . . . . . . . . . . . . . . . . . . . 33

A.3 DORCA (Dis-)Advantage - Segment Specific Trends . . . . . . . . . . 35

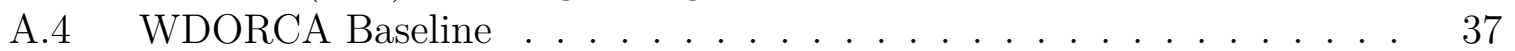

A.5 WDORCA (Dis-)Advantage. . . . . . . . . . . . . . . . . . . 38

A.6 $\quad$ PRODY (Dis-)Advantage - Control Function . . . . . . . . . . . . . . . 39

A.7 $\quad$ PRODY (Dis-)Advantage - pre 2005 . . . . . . . . . . . . . . . . . . 40

A.8 $\quad$ PRODY (Dis-)Advantage - post $2005 \ldots \ldots \ldots$

$2.1 \quad$ Descriptives - Main Variables . . . . . . . . . . . . . . . . . . 52

$2.2 \quad$ Different Types of Favoritism - Baseline Results . . . . . . . . . 57

$2.3 \quad$ Channels - Tax Support . . . . . . . . . . . . . . . . . . . . . . 60

$2.4 \quad$ Heterogeneous Effects across Regime Types . . . . . . . . . . . . . 61

$2.5 \quad$ Robustness - Placebo Test . . . . . . . . . . . . . . . . . . . . 62

B.1 Afrobarometer - Sampled Countries and Years . . . . . . . . . . . 65

B.2 Data Sources . . . . . . . . . . . . . . . . . . . . . . . 66

B.3 African Leaders in the Sample . . . . . . . . . . . . . . . . . . . 68

B.4 $\quad$ African Leaders in the Sample (continued) . . . . . . . . . . . . . . . . 69

B.5 $\quad$ Balance Test - Leader Birth Region \& Leader Ethnicity . . . . . . . . 70

B.6 Inequality \& Poverty Perceptions . . . . . . . . . . . . . . . 71

B.7 $\quad$ Agricultural and Mineral Commodities . . . . . . . . . . . . . . . 72

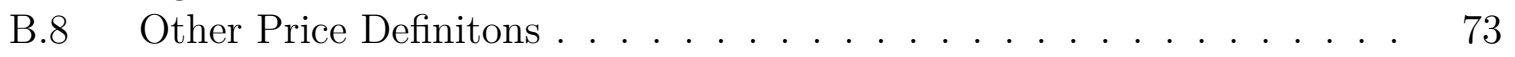

B.9 Urban-Rural Divide . . . . . . . . . . . . . . . . . . . . . . . . 75

B.10 Poverty - Binary Outcome Measure . . . . . . . . . . . . . . . 75

B.11 Robustness - Perceived Honesty $\ldots \ldots \ldots \ldots \ldots$ 
B.12 Robustness - Leave One Commodity Out . . . . . . . . . . . . . . . . 78

B.13 Robustness - Without Price Makers . . . . . . . . . . . . . . . . . . . 79

B.14 Leverage - Top 20 Observations . . . . . . . . . . . . . . . . . . . 80

B.15 $\quad$ Robustness - Excluding High Leverage Observations . . . . . . . . . . 81

B.16 Heterogeneous Effects across Regime Types - Sample Split . . . . . . 81

B.17 $\quad$ Pre Trends of Power Status and Producer Prices . . . . . . . . . . . . 82

B.18 Correlation - Lights \& Producer Prices . . . . . . . . . . . . . . . . . 82

B.19 Correlation of Poverty Index and Expenditure . . . . . . . . . . . . . . 83

B.20 $\quad$ Robustness - Controlling for Conflict . . . . . . . . . . . . . . . . . 83

$3.1 \quad$ Donor Comparison - WB versus China . . . . . . . . . . . . . . 96

$3.2 \quad$ Descriptive statistics - ADM1 Region . . . . . . . . . . . . . . . . . . 97

$3.3 \quad$ OLS Results - Aid and Conflict at the Local Level . . . . . . . . . . . 106

$3.4 \quad$ IV Results - Aid and Conflict at the Local Level . . . . . . . . . . . . 109

$3.5 \quad$ Results - Aid Subtypes . . . . . . . . . . . . . . . . . . . . 111

3.6 IV Results - Actors . . . . . . . . . . . . . . . . . . . . . . . . . 113

$3.7 \quad$ IV Results - Riots, Demonstrations \& Strikes [SCAD] . . . . . . . . . 115

$3.8 \quad$ IV Results - Non-lethal pro-government Violence [SCAD] . . . . . . . 116

3.9 OLS Results - Spill-Overs from Coalition to Non-Coalition Regions . . 118

3.10 OLS Results - Aggregate Cross-Country Analysis . . . . . . . . . . . . 119

C.1 Data Sources . . . . . . . . . . . . . . . . . . 123

C.2 Data Sources (continued) . . . . . . . . . . . . . . . . . . . . 124

C.3 Aid Allocation Formula Example . . . . . . . . . . . . . . . . . . . . . 129

C.4 Leads and Further Lags . . . . . . . . . . . . . . . . . . . . . . . . . . 133

C.5 IV Results - First Stage: Extensive Margin . . . . . . . . . . . . . . . 134

C.6 IV Results - First Stage: Intensive Margin . . . . . . . . . . . . . . . 135

C.7 IV Results - First Stage with Probability Constituent Term . . . . . . 136

C.8 IV Results - Reduced Form . . . . . . . . . . . . . . . . . . . . . . 137

C.9 Placebo-Instrumented Lead of Aid . . . . . . . . . . . . . . . . . . . 138

C.10 IV Results - IDA-Position ${ }_{t-1}$. . . . . . . . . . . . . . . . . . . . 139

C.11 IV Results - Without high Leverage Regions . . . . . . . . . . . . . . 140

C.12 IV Results - Excluding First Year . . . . . . . . . . . . . . . . . . . . 141

C.13 IV Results - WB Aid detrended \& Chinese Aid not detrended. . . . . . 142

C.14 IV Results - Initial Probability . . . . . . . . . . . . . . . . . 143

C.15 OLS Results - Riots, Demonstrations \& Strikes [SCAD] . . . . . . . . 145

C.16 IV Results - Riots, Demonstrations \& Strikes [SCAD] . . . . . . . . . 146

C.17 OLS Results - Demonstrations [SCAD] . . . . . . . . . . . . . 147

C.18 OLS Results - Riots $[\mathrm{SCAD}]$. . . . . . . . . . . . . . . . . . . 148

C.19 OLS results - Strikes [SCAD] . . . . . . . . . . . . . . . . . . . 149

C.20 IV Results - Repression (non-lethal) without UCDP Violence . . . . . 150

C.21 IV Results - Count of non-lethal pro-government Violence [SCAD] . . 151

C.22 OLS Results - Actors . . . . . . . . . . . . . . . . 152

C.23 OLS Results - Battle-Related Deaths . . . . . . . . . . . . . . . . 153 
C.24 IV Results - Battle-Related Deaths . . . . . . . . . . . . . . . . . 154

C.25 OLS Results - Intensity $2(\mathrm{BRD} \geq 25)$. . . . . . . . . . . . . . . . 155

C.26 IV Results - Intensity $2(\mathrm{BRD} \geq 25)$. . . . . . . . . . . . . . 156

C.27 Sample split - Mean of Fractionalization. . . . . . . . . . . . . . . 158

C.28 Sample-split - Median Fractionalization . . . . . . . . . . . . . . . 159

C.29 IV/OLS Results - Coalition Groups, Fractionalization as Control . . . 160

C.30 OLS/IV Results - Coalition Group, Fractionalization as Control . . . 161

C.31 IV Results - Coalition Group, Fractionalization not as Control . . . . 162

C.32 Robustness - Aid Subtypes . . . . . . . . . . . . . . . . . . . . . 163

C.33 IV Results - ADM2 Regions . . . . . . . . . . . . . . . . . . . . . . 164

C.34 OLS Results - ADM2 Regions . . . . . . . . . . . . . . . . . . . . 165

C.35 OLS Results - Population Weighted Aid Allocation. . . . . . . . . . . 166

C.36 $\quad$ IV Results - Population Weighted Aid Allocation . . . . . . . . . . . . 167

C.37 OLS Results - Spill-Overs from Capital to Non-Capital . . . . . . . . 169

C.38 OLS Results - Clustering at Regional Level . . . . . . . . . . . . . . . 170

C.39 IV Results - Clustering at Regional Level . . . . . . . . . . . . . . . . 171

C.40 OLS Results - Lagged Dependent Variable . . . . . . . . . . . . . . . 172

C.41 Robustness - Poisson Pseudo-Maximum Likelihood . . . . . . . . . . . 173

C.42 OLS Results - World Bank Aid in Same Years as Chinese Aid . . . . . 174

C.43 IV Results - World Bank Aid in Same Years as Chinese Aid . . . . . . 175

C.44 OLS Results - Both Donors . . . . . . . . . . . . . . . . . 176

C.45 IV Results - Both Donors . . . . . . . . . . . . . . . . . . . 177

4.1 Theory of Planned Behavior - Intended SCC uptake . . . . . . . . . 196

4.2 Theory of Planned Behavior - Actual SCC uptake . . . . . . . . . . 197

$4.3 \quad$ Framing Experiment - Main Results . . . . . . . . . . . . . . . . 200

D.1 $\quad$ Experimental Balance - Full Sample . . . . . . . . . . . . . . . . . . 211

D.2 $\quad$ Experimental Balance - Reduced Sample . . . . . . . . . . . . . . . . 212

D.3 $\quad$ Experimental Balance - Reduced Sample \& SCC intervention . . . . . 213

D.4 $\quad$ Summary Statistics for Indonesian data . . . . . . . . . . . . . . . . . 214

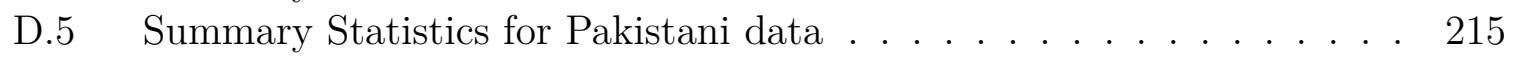

D.6 $\quad$ TPB - Intentions and Behavior: Wild Bootstrapped SE . . . . . . . . 216

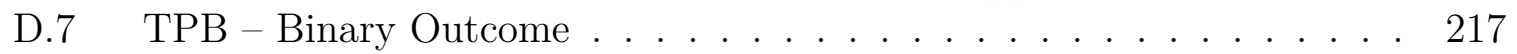

D.8 $\quad$ Framing Experiment - Wild Bootstrapped SE . . . . . . . . . . . . 218

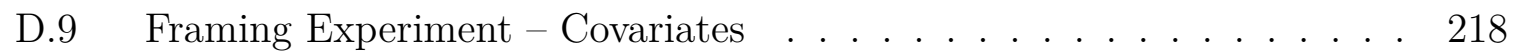

D.10 $\quad$ Framing Experiment - Elicitation as Control . . . . . . . . . . . . . . 219

D.11 Framing Experiment - Alternative Outcomes . . . . . . . . . . . . 220

D.12 $\quad$ Framing Experiment - Prior Contact as Control . . . . . . . . . . . . 220

D.13 Framing Experiment - Interaction with Prior Contact . . . . . . . . . 221

D.14 Association between Previous Project Participation and Trust . . . . . 221

D.15 $\quad$ Framing Experiment - Ordered Probit Results . . . . . . . . . . . 222

D.16 Framing Experiment - Association with Potential Channel Variables . 222

D.17 $\quad$ Framing Experiment - Previous Experience (Point Estimates) . . . . . 224 


\section{Introduction}





\section{Introduction}

Globalization and Development: The start of modern globalization is often said to date back to the 19th century (Daudin et al., 2008). This process gained further trajectory during the 20th century due to several innovations in transportation and communication technology. In this regard, globalization shapes economic development and is not a mono-causal process, but rather multi-facetted encompassing political, social, and economic aspects (Dreher, 2006). Global political institutionalization, including the UN system, fosters peace (Hultman et al., 2014). Socially, gobalization leads to a spread of ideas and people, which affects norms (Barsbai et al., 2017; Kis-Katos et al., 2018), technology (Kanwar, 2012) and skill complementarities between workers of different origin (Alesina et al. 2016). While global value chains offer opportunities for economic upgrading among economic latecomers (Gereffi and Fernandez-Stark, 2016), financial flows - if allocated prudently - can foster growth (Galiani et al., 2017; Harms and Méon, 2018).

Recently, the financial crisis in 2007/08 has demonstrated the perilous effects of globalization, inducing strong increases in globalization criticism and discontent. Yet, there were several forceful criticisms of globalization prior to this recent economic downturn. This includes Keynes, who stated in 1933 experiencing the great depression that he would sympathize "with those who would minimize, rather than with those who would maximize economic entanglement among nations" (Keynes, 1933). And indeed there are several challenges and trade-offs linked to global integration, which affect domestic economic development.

For instance, the spread of ideas can have adverse consequences, exemplified by the adaptation of Western lifestyles leading to a rise in non-communicable diseases and large associated costs for national health systems (Demmler et al., 2017; Bommer et al., 2017). While an effective international refugee regime does not exist, high-skilled migration often hurts the migrants' home countries in terms of brain drain (Beine et al. 2008). Further, trade integration might lead to an offshoring of environmental pollution (Baghdadi et al., 2013). What is more, the public and academic discourse associates globalization with rising inequality (Milanovic, 2007; Dreher and Gaston, 2008; Lang and Tavares, 2018) and job insecurity (Autor et al., 2013). This gives rise to a political backlash in terms of increasing populism (Ballard-Rosa et al., 2017), nationalism (Acemoglu and Yared, 2010) and global de-integration, exemplified by Brexit and the policies of the Trump administration (Piketty, 2016; Brakman et al., 2018).

Considering the promises of economic development, globalization is not a "yes" or "no" issue, but rather asks for well crafted and evidence-based policies to reduce potential perils. Consequently, decisions have to build on a deliberate societal discourse and one should be allowed to question if "globalization has gone too far?" (Rodrik, 1998).

Here, academic research can make a substantial contribution to an informed debate. Against this background, this thesis provides insights into globalization's implications for economic development with a special focus on politico-economic factors. Due to the multi-dimensional nature of globalization it is necessary to focus on certain aspects. This thesis focuses on two major fields of globalization - development cooperation and 
trade. Billions of foreign dollars are invested every year into development cooperation, but evidence on its effectiveness is at best mixed (Doucouliagos and Paldam, 2008; Galiani et al., 2017; Dreher and Langlotz, 2017). In contrast, trade offers opportunities for low and lower middle income countries to achieve economic development on their own. However, international and national policy making can constrain or enhance potential gains. The following chapters take multiple perspectives to study constraints and opportunities as described subsequently.

Level of Analysis: One striking feature of globalization is that it involves processes on the international stage which feed back into the national development of countries. Taking either a macro-economic or a micro-economic perspective, one faces a trade-off between deriving broader implications versus gaining more detailed insights in terms of mechanisms. Thus, it is essential to adjust the empirical lense to a suitable level. As Figure I Illustrates, different chapters of the thesis focus on the macro (Chapter 1), meso (Chapter 2 and 3) and micro (Chapter 4) levels of analysis.

Figure I Perils and Promises of Globalization

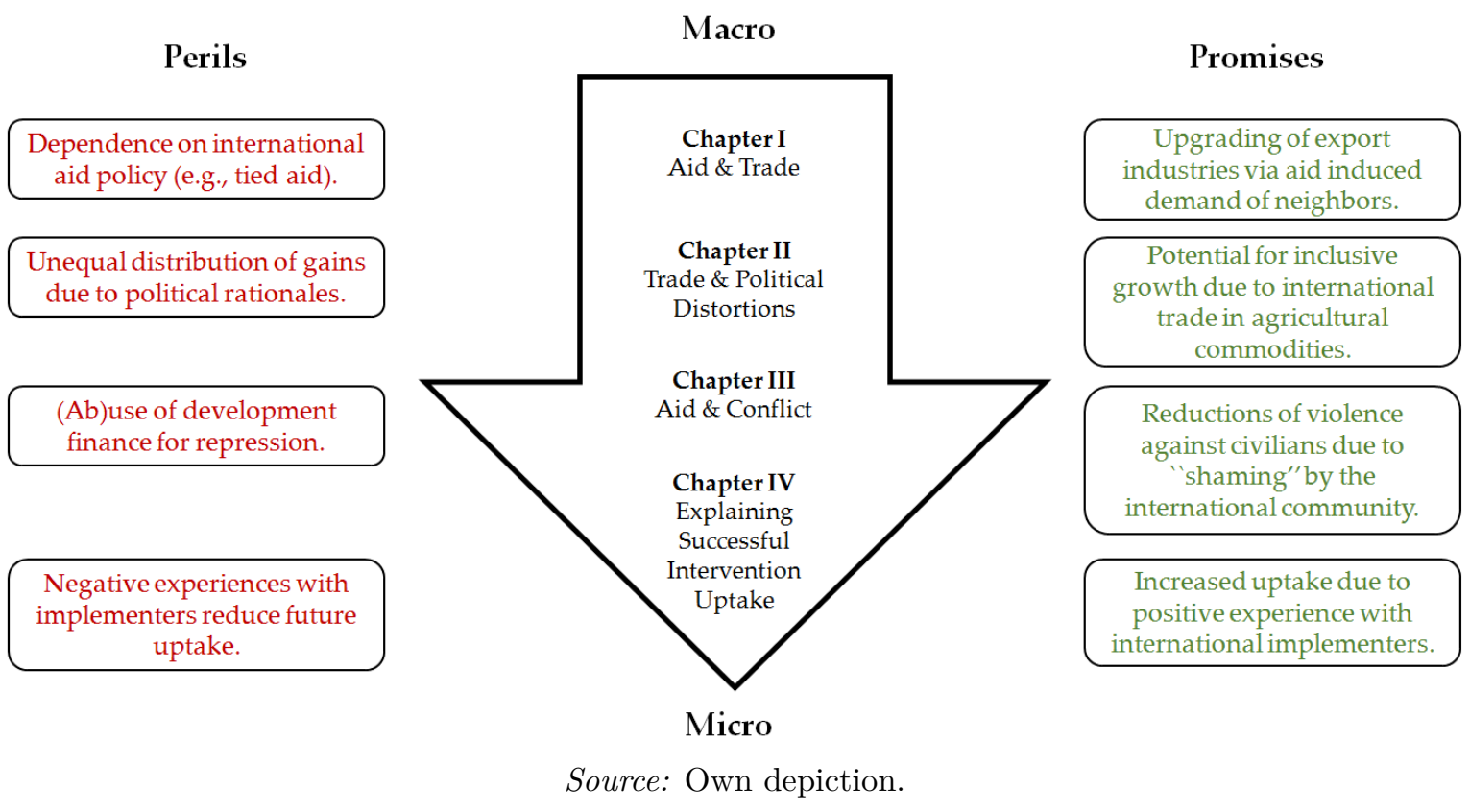

Chapter 1 investigates the role of globalized flows of finance (development aid) and goods (trade). Both factors are of international character and relate to the global perspective. Thus, we choose macro lenses and combine the well-established economic theory of comparative advantage with a spatial perspective on trade costs in order to study third-country effects of development aid.

Although economic theories stress the potential of trade for sustainable and inclusive economic growth, actual outcomes depend crucially on how gains from globalization are 


\section{Introduction}

shared. Political interest groups have a large influence on the distribution, which can be conceptualized by an economic quid pro quo model, where groups are targeted in turn for their electoral support (Dixit and Londregan, 1996, Franck and Rainer, 2012, Bueno De Mesquita, 2005). In- and out-groups can be constructed along visible traits, for instance regional and ethnic lines. In order to examine these group level differences, Chapter 2 zooms into the meso level considering subnational data and the distribution of gains from trade.

Group level inequalities, e.g., "grievances" (Cederman et al., 2013), are a recurring theme in political science, and often thought to be a main driver of conflict in contrast to purely economic greed (Collier and Hoeffler, 2004). Returning to the effects of aid, Chapter 3 considers those group level inequalities also from a subnational meso perspective. Yet when considering aid projects, it is of utmost importance to be aware of heterogeneities. If the development projects are successful and contribute to growth, the projects could be in theory a promising tool to reduce conflict risk by increasing economic opportunity costs of fighting.

However, many of the projects remain unfinished (Williams, 2017) or fail (Müller and Pape, 2018) in low resource or fragile contexts. Success of development projects might highly depend on targeted populations' uptake. Thus, the final chapter of the thesis considers individual level data and zooms into the micro level of development economics to evaluate the support of the Safe Childbirth Checklist intervention in Indonesia and Pakistan. For this purpose, we consider a framework grounded in social psychology "The Theory of Planned Behavior" (Ajzen, 1985). This framework identifies three main determinants - perceived behavioral control, subjective norms, and individual attitudes towards behavior - which we consider to explain intervention uptake.

Data: As the following chapters are located at different levels of analysis, they build on various different datasets. Those data include well-established macro datasets like the World Bank's World Development Indicators or UN Comtrade's information on trade flows. Meso level analyses build on innovative geospatial datasets on aid (Strange et al., 2017; Dreher et al., 2016, Strandow et al., 2011), conflict (Croicu and Sundberg, 2015: Hendrix and Haggard, 2015), as well as individual opinions (Afrobarometer, 2018). Finally, we also use self-collected survey questionnaires and experimental data from Pakistan and Indonesia.

Methods: In order to provide relevant advice for effective decisions, we carefully chose suitable methods for the context and level of analysis in question. More specifically, it is important to consider several factors which might drive both outcome and explanation as dynamics are intertwined in the multi-causal settings of globalization and development. For this purpose, panel data approaches are applied, which help to control for various unobserved factors. As outcomes could be subject to endogenously determined processes, all chapters make use of empirical strategies to identify sources of exogenous variation. 


\section{Introduction}

In three of the four chapters we identify plausibly exogenous effects by interacting external global variation with country or region specific scaling variables. In this regard, the analysis in Chapter 1 builds on an interaction of aggregate donor budgets with a pre-determined country-level recipient probability to estimate a synthetic measure of aid due to Temple and Van de Sijpe (2017) in a control function approach (Wooldridge, 2015). In Chapter 2, I exploit variation of global commodity price changes, which should have differential effects on the regional level depending on local capacities to extract these goods. Chapter 3 involves an instrumental variable approach, where we interact donors' aid budgets with regional recipient probabilities.

Finally, we induce external variation in Chapter 4 by randomizing one subdeterminant of the theory of planned behavior - namely attitudes - in a framed field experiment. More specifically, we expose respondents randomly to information on the implementers' origin in order to carve out how changes in individual attitudes affect support for the intervention. While we analyze the causal mechanisms quantitatively, the micro level analysis also allows us to provide supportive evidence from qualitative research.

Findings: Chapter 1 considers development aid as a financial transfer from the global North to the global South. Based on the theoretical model by Trionfetti (2017), we develop predictions on how this would translate into positive implications for neighboring countries of recipients. More specifically, we hypothesize that aid leads to a higher demand by recipient nations for goods, for which they themselves have no comparative advantage (e.g., goods that are produced typically by richer countries). Assuming that trade costs are lower with regard to proximate countries, aid induces a higher demand for more advanced products from neighbors, which can help neighboring countries to upgrade their export portfolio. However, this is by no means a mechanistic pattern. In contrast, intra-regional transport costs need to be low enough to make products from neighbors in the global South more attractive than products from the global North. Moreover, neighboring countries need to have sufficient capacities to produce those more advanced products in order to meet the growing demand by neighbors. We illustrate this with subsample regressions for Asia and Africa. Several Asian governments promoted export-led growth strategies via preferential treatment for manufacturing sectors and targeted investments in infrastructure. Of course there are also several African success stories to be named - e.g., the Rwandan coffee sector or the Kenyan flower industry. However, transport costs (Storeygard, 2016) and the shortage of human capital (Page, 2012) are still a constraint for many African states. National policy making could, thus, potentially enhance third country effects via complementary investments in education and infrastructure. Moreover, global development policy can make a substantial difference as the results indicate that the manifestation of the pattern in Asia is driven by the period after the Paris Declaration in 2005. The Paris Declaration concluded an untying of development aid from donor exports despite the antagonism of commercial interest groups in donor countries. However, economic development is not only influenced by global politics. 
Also domestic politics can distort the participation in economic development. Against this background Chapter 2 studies domestic politico-economic factors, which distort gains from agricultural commodity trade in African countries. Agriculture is a particularly relevant case to study as it constitutes the main employment base for several African countries The high labor intensity of agriculture increases its potential for inclusive growth, in contrast to more easily appropriable natural resources or development aid. However, political distortions reduce agriculture's potential for pro-poor growth. Theory and empirics are ambiguous whether affiliations with the current national leader have positive or negative effects on participation in agricultural commodity trade (Kasara, 2007; Bates and Block, 2010). Combining high-resolution geospatial data with surveys for 33 African countries, I distinguish ethnic and regional political affiliation to resolve existing ambiguities. Results indicate that ethnic affiliation positively affects gains from trade, while this pattern is further enhanced when living in the leader's birth region. The findings suggest that leaders target coethnics via subsidies and a preferential tax treatment rather than via the provision of public goods. Those individually targeted benefits contrast previous accounts of the windfall-driven provision of regional public goods (Hodler and Raschky, 2014). Democratic institutions counteract but do not offset this pattern.

Chapter 3 also focuses on the meso level by employing subnational data. More specifically, we make use of innovative data on subnational development aid for two major donors - the World Bank and China. While the World Bank is often perceived as a donor who lays great importance on human rights (e.g., in terms of conditionality), China is seen by many as a "rogue donor" (Naím, 2007) who mainly follows its own aims. We link the information on aid provision to subnational occurrences of organized violence and social conflict on the African continent, which was the stage of some of the most intense conflicts including violence in Congo DRC, Rwanda, Somalia, and Sudan. A large strand of literature stresses the conflict fueling role of development aid, but uses macro level data to test theories on individual conflict actors (Collier and Hoeffler, 2004 Nunn and Qian, 2014). Using subnational data enables us to test theories of conflict more carefully by considering aid types, conflict actors, ethnic power groups and spatial spill-overs. The results show that aid projects on average seem to reduce rather than to fuel conflict. We also find no increased likelihood of demonstrations, strikes or riots associated, but a higher likelihood of non-lethal government repression in areas where China is active. While it is in the interest of China to sustain stability in its partner countries, there seems to be a willingness to compromise on political rights in order to guarantee political survival of its partner regimes. For World Bank finance, our analysis indicates that conflict reducing effects are driven by less lethal violence by governments against civilians, and by projects in the transport and financial sectors. Thus, development interventions might have positive effects if they - as suggested by peace and conflict theory - succeed in "winning the hearts and minds" (Berman et al.

\footnotetext{
${ }^{1}$ Although this thesis mainly applies cross-country approaches, country studies constitute a valuable source to understand the heterogeneous effects of globalization. For this reason, the references provide a selection of complementing case studies.
} 
2011) of the local population.

This is only possible if implementers succeed in convincing recipient communities of the use of interventions to change behavior in the long term. Often interventions fail to achieve these aims due to the complex interplay of incentives in developmental contexts (Hanna et al., 2016). While there is a large demand for what works, there is surprisingly little evidence explaining the determinants of behavioral change.

For this reason, Chapter 4 goes one step further on the continuum from the meso to the micro level to understand the drivers of individual behavioral uptake of two comparable health interventions in Indonesia and Pakistan. For this purpose, we borrow from a model grounded in psychological theory called the "Theory of Planned Behavior." The framework suggests the perceived behavioral control, attitudes towards the behavior and subjective norms of important others as main drivers of uptake. Considering data both for Indonesia and Pakistan enables us to understand the context specificity. While in the hierarchical clinical context of Indonesia subjective norms of the superiors play a substantial role, the individual health providers in Pakistan feel constrained due to a limited ease of applying the intervention (behavioral control). In both countries individual attitudes towards behavior are an important driver for both intended and actual uptake. We complement this finding by considering attitudes more carefully. In a framed field experiment, we randomly stress different characteristics of the implementers' origin and examine how Indonesian respondents react. Although international researchers (e.g., institutions of higher education from the Western hemisphere, like JPAL or EPoD) often initially test development interventions, local authorities are responsible for the implementation and roll-out. Our results indicate that Indonesian health workers are significantly more supportive (measured in financial support) when facing international implementers. This pattern is driven by previous experiences with implementers - the greatest difference occurs when respondents have already participated both in local and international projects. On the one hand, this points to the specific experience of the population under observation as a large amount of international aid was disbursed in Aceh after 2004's Tsunami. On the other hand, it enables one to derive some broader implications for international and local policy making. As previous experiences seem to have long-term effects, both local and international policy makers should act in a responsible manner in order to guarantee support.

Summary: The following chapters indicate the politico-economic scope of channelling the gains of globalization. While globalization promises gains such as the upgrading of trade industries and poverty reduction, this is by no means a mechanistic process as many undesirable outcomes around the globe indicate. In contrast, globalization is a perilous process, highly dependent on the different layers of international and national policy making. With this thesis I would like to contribute to a deliberate discourse on how to shape trade and development cooperation in order to realize globalization's promises for economic development. 


\title{
Chapter 1
}

\section{Your neighbor's aid helps you upgrade? \\ Third-country effects of development aid on sectoral exports}

Joint work with Hendrik W. Kruse

\begin{abstract}
In this paper we study third-country effects of foreign development aid on sectoral exports. Based on the recent paper by Trionfetti (2017) we hypothesize that development aid increases exports of neighboring recipient countries in sectors for which donor countries have a revealed comparative advantage, assuming lower trade costs among recipients than with donors. We use a panel of low and lower middle income countries' exports over the 2000-2013 period to test this hypothesis. We find that the predicted pattern materializes only in a subsample for Asia in the period after the Paris declaration.
\end{abstract}



Third-country effects of development aid on sectoral exports

\section{$1.1 \quad$ Introduction}

Transfers such as development aid affect not only the recipient country itself but also affect the size of destination markets for potential exporters. Despite tied aid and project aid relating to projects managed by organizations in donor countries, aid is not entirely spent on imports from the donor country (Kruse and Martínez-Zarzoso, 2016), and some third countries will benefit as well. 1

In this paper, we study the effect that aid can have on the sectoral composition of exports from other low and lower middle income countries. More precisely, based on a recent model by Trionfetti (2017) we hypothesize aid is related to an increase in developing countries' exports of goods in which they have a comparative disadvantage from a global perspective.

The model presented in Trionfetti (2017) has two regions "North" (N) and "South" (S) in which a transfer takes place from $\mathrm{N}$ to $\mathrm{S}$. Intuitively, a transfer leads to an increase in demand in $\mathrm{S}$. In a world with trade costs producers from $\mathrm{S}$ can sell at a cheaper price in $\mathrm{S}$ than in $\mathrm{N}$, because trade costs are lower within $\mathrm{S}$. Thus, a transfer from $\mathrm{N}$ to $\mathrm{S}$ makes producers in $\mathrm{S}$ more competitive. Due to trade costs, products where $\mathrm{S}$ has a comparative disadvantage are more expensive in $\mathrm{S}$ than in $\mathrm{N}$, whereas products where $\mathrm{S}$ has a comparative advantage are cheaper in S. Producers in sectors with a comparative disadvantage would, hence, benefit more because demand shifts to a market where they find it easier to compete. We apply the model to a world with multiple countries and show that its logic applies to exports of recipient countries, as well, if certain conditions are met: trade costs between recipients of transfers have to be smaller on average than between donors and recipients, and recipient countries have to be characterized by similar patterns of comparative advantage.

We use a panel of sectoral export data for 55 low and lower middle income countries from 2000 to 2013. Using a fixed effects approach, we test whether the third-country effects of aid flowing to nearby countries are more pronounced in sectors where donors have a comparative advantage. Since the extent of intra-regional trade costs between recipients matters, we split the sample into Africa and Asia. According to Limao and Venables (2001) and Storeygard (2016), trade costs are still a major impediment in Africa and intra-continental trade is much lower than in other world regions (Sow, 2018). In order to address endogeneity we use a synthetic aid instrument based on donor budgets developed by Temple and Van de Sijpe (2017), in a control function setting.

It is mainly Asian countries enjoying a comparative advantage in similar sectors than donors, which benefit from the shift of purchasing power to less competitive markets. However, this effect is driven by the period after the Paris Declaration in 2005. The latter hallmarked several changes in the international aid regime including reducing the

\footnotetext{
${ }^{1}$ Before concluding the Paris Declaration of Aid Effectiveness in 2005, major donors still tied large shares of aid to the procurement of goods from donor countries (e.g., Australia 37\%, Canada 34\% and the US 54\%) (Martínez-Zarzoso et al., 2014). Since then the tying status was reduced drastically.
} 
Third-country effects of development aid on sectoral exports

share of tied aid.

Our study adds to the vast literature on the effect of development aid on recipient exports. First, several studies are looking at the effect of bilateral aid on bilateral exports to the donor. Pettersson and Johansson (2013) find a positive effect of aid in some sectors, whereas Nowak-Lehmann D. et al. (2013) show that this effect vanishes when using a fixed effects estimator. Second, others study the effect of aggregate aid on aggregate exports. Temple and Van de Sijpe (2017) introduce a new instrument for this purpose. However, they find no significant effect. Calì and te Velde (2011) and Vijil and Wagner (2012) take particular interest in the effect of Aid for Trade (AfT) on aggregate exports. Both studies find that aid for infrastructure, in fact, facilitates trade and has an impact on overall exports. They also study the effect of aid dedicated to specific sectors of the economy on exports in these sectors, but do not find any effect. Rajan and Subramanian (2011) argue that by increasing domestic demand aid leads to increasing wages and appreciation. They find that among manufacturing industries aid leads to a reduction in value added of exportable industries indicating Dutch Disease effects. Note that this is in contrast to Temple and Van de Sijpe (2017) who "do not find symptoms of Dutch Disease."

To the best of our knowledge, there are no studies to assess the sectoral implications of third-country effects of development aid, or explicitly model the link between aid and comparative advantage. Trionfetti (2017) offers an explanation for this gap by showing that in a world without trade frictions transfers do not have differential effects on sectoral demand. Our main contribution is, thus, to provide empirical evidence of such effects.

The existence of such effects has important implications for development policy. A recent strand of literature argues that different sectors may have different potentials for growth. Hausmann et al. (2007) stress the importance of technological sophistication. Rodrik (2013) shows that productivity convergence is higher in manufacturing sectors. In accordance with this, McMillan et al. (2014) stress that when employment shifts to high-productivity sectors, growth prospects increase. Diao et al. (2017) highlight the

role of aid induced domestic demand to achieve those changes. In addition, third-country effects of development aid as described in this study may be important in facilitating structural change.

The remainder of the chapter is structured as follows. Section 1.2 presents our analytical framework and Section 1.3 its empirical implementation. Section 1.4 introduces our data and provides some descriptive information about our main indicators of interest. Our main results and robustness checks are presented in Sections 1.5 and 1.6 . Finally, Section 1.7 concludes.

\subsection{Analytical Framework}

In this section, we sketch a partial equilibrium framework in order to illustrate through which channels development aid may affect third countries' exports. For simplicity, we 
ignore second order effects such as price adjustments. We refer the reader to Trionfetti (2017) for a complete general equilibrium analysis with price adjustments channeled through labor markets. Here, our purpose is merely to make the underlying intuition plausible. Consider a simple sectoral gravity equation as in Larch and Wanner (2017) (see also Yotov et al. 2016). There are $K$ sectors, each of which comprise several differentiated varieties of goods. Within each sector $k \in K$ preferences are characterized by a constant elasticity of substitution (CES). Sectoral preferences are nested within a Cobb Douglas utility function, such that expenditure shares for each sector are given. Then, demand in country $j$ for a sector $k$ variety produced in country $i$, with $i, j \in N$, is given by:

$$
x_{i j}^{k}=\left(\frac{p_{i}^{k} \tau_{i j}^{k}}{P_{j}^{k}}\right)^{1-\sigma^{k}} E_{j}^{k},
$$

where $p_{i}^{k}$ are factory gate prices in country $i, \tau_{i j}^{k}$ are iceberg trade costs between $i$ and $j, P_{j}^{k} \equiv\left(\sum_{i}\left(p_{i}^{k} \tau_{i j}^{k}\right)^{1-\sigma}\right)^{1 /(1-\sigma)}$ is the price index in sector $k$ in country $j$, and $\sigma^{k}$ is the elasticity of substitution. $E_{j}^{k} \equiv \alpha^{k}\left(y_{j}+T F_{j}\right)$ is expenditure from country $j$ in sector $k$. $\alpha^{k}$ is the expenditure share of sector $k$ (assumed to be equal across countries). $y_{j}$ is market income (GDP) and $T F_{j}$ is a transfer, the sum of which is $j$ 's disposable income. Note that transfers have to sum up to zero across countries; i.e., $\sum_{j \in N} T F_{j}=0$.

Aggregating across importers yields total sectoral exports:

$$
x_{i}^{k}=\sum_{j \neq i}\left(\frac{p_{i}^{k} \tau_{i j}^{k}}{P_{j}^{k}}\right)^{1-\sigma^{k}} \alpha^{k}\left(y_{j}+T F_{j}\right)
$$

In turn, in partial equilibrium changes in total sectoral exports due to changes in global transfers can be written as

$$
d x_{i}^{k}=\sum_{j \neq i}\left(\frac{p_{i}^{k} \tau_{i j}^{k}}{P_{j}^{k}}\right)^{1-\sigma^{k}} \alpha^{k} d T F_{j},
$$

without trade costs - i.e., $\tau_{i j}^{k}=1 \forall i, j, k$ - sectoral exports are not affected by a transfer between any two countries other than $i$. The reason is that optimal price indices vary across countries only due to trade costs. Consider for instance a transfer from country $j$ to country $j^{\prime}$; i.e., $d T F_{j}=-d T F_{j^{\prime}}$. Without trade costs, it is possible to factor out $\left(p_{i}^{k} \tau_{i j}^{k} / P_{j}^{k}\right)^{1-\sigma^{k}}$. Then, the effect of a transfer from $j$ to $j^{\prime}$ is $d x_{i}^{k}=\left(p_{i}^{k} / P^{k}\right)^{1-\sigma^{k}} \alpha^{k}\left(d T F_{j^{\prime}}-d T F_{j}\right)=0$.

In reality, of course, trade costs are positive. Under such circumstances, it holds in general that $P_{j}^{k} \neq P_{j^{\prime}}^{k}$. This is due to differences in remoteness across countries, and due to the spatial distribution of factory gate prices across countries. (1.3) shows that a sufficient condition for a transfer from $j$ to $j^{\prime}$ to increase aggregate exports in $i$ is that 
$\tau_{i j^{\prime}}^{k}<\tau_{i j}^{k}$ and that $P_{j^{\prime}}^{k}>P_{j}^{k}$, even though only one of the two conditions necessarily has to be met.

Assuming that $\tau_{i j^{\prime}}^{k}=\tau_{i j^{\prime}}^{k^{\prime}}<\tau_{i j}^{k}=\tau_{i j}^{k^{\prime}}$ the effect of a transfer from $j$ to $j^{\prime}$ on exports from $i$ is going to be higher in sector $k$ compared to $k^{\prime}$ if $P_{j^{\prime}}^{k} / P_{j}^{k}>P_{j^{\prime}}^{k^{\prime}} / P_{j}^{k^{\prime}}$. I.e., the effect is going to be higher in sectors where the donor has a comparative advantage, and the recipient has a comparative disadvantage.

\subsection{Empirical Implementation}

Unfortunately, (1.2) does not provide a direct way to test this hypothesis. The reason is simply that $(1.2)$ is an aggregate gravity model where the only free parameter is the elasticity of substitution. Based on any estimate for $\sigma^{k}$, our hypothesis follows directly from the gravity model, given our assumptions. Instead, we are interested in whether the intersectoral patterns predicted by the gravity model in fact materialize in the data.

For that purpose, we need a variable that captures in which sectors donors have a comparative advantage, and recipients have a comparative disadvantage. We use a variable constructed in a similar way as the PRODY index of technology content due to Hausmann et al. (2007). Like the PRODY index, our measure is based on the revealed comparative advantage (RCA) index due to Balassa (1965). The basic idea behind the RCA index is that countries that have a comparative advantage in certain goods should export relatively more of this good. In turn, the RCA of a country in a given sector is defined as the ratio of the export share of the good in this country and the export share worldwide:

$$
R C A_{i k t}=\frac{x_{i k t} / x_{i t}}{\sum_{i} x_{i k t} / x_{i t}},
$$

where $x_{i k t}$ are country $i$ exports of good $k$ at time $t$. Left out indices indicate totals across the respective dimension. We calculate comparative advantage at some base year $t_{0}$ to avoid endogeneity. The PRODY index is calculated as the weighted average of GDP per capita where sectoral RCAs serve as weights. I.e.,

$$
P R O D Y_{k t}=\sum_{j} \frac{R C A_{j k t_{0}}}{\sum_{j} R C A_{j k t_{0}}} G D P p . c \cdot j t,
$$

where GDPp.c.jt is per capita GDP of country $j$ at time $t$. This index is high in sectors in which rich countries have a comparative advantage and low in sectors in which poor countries have a comparative advantage. It is meant to capture the technology content of a product. One shortcoming of the index for our purposes is that rich countries are not of equal importance as donors, in particular, due to their difference in size. For that reason, we slightly adjust the formula. We use the RCA indices as weights for international transfers to infer whether a given sector is one in which donors tend to have a comparative advantage or recipients. 
Third-country effects of development aid on sectoral exports

$$
\operatorname{DORCA} A_{k t}=-\sum_{j} \frac{R C A_{j k t_{0}}}{\sum_{j} R C A_{j k t_{0}}} T F_{j t}
$$

where $T F_{j t}$ are transfers, which are negative for donor countries. This index is going to be negative if recipients have a comparative advantage and positive if donors enjoy a comparative advantage (DORCA). While the DORCA index provides a major improvement over the PRODY index for our purposes it still neglects one element of the prediction. As trade costs matter, we should only expect to find the effects if relatively nearby donors have an advantage compared to relatively nearby recipients. In order to account for this prediction, we define a weighted DORCA index:

$$
W D O R C A_{i k t}=-\sum_{j} \frac{R C A_{j k t_{0}}}{\sum_{j} R C A_{j k t_{0}}} \frac{T F_{j t}}{D_{i s t_{i j}}}
$$

which is weighted by bilateral distance Dist $_{i j}$ between countries $i$ and $j$. We will employ all three indices but focus on the DORCA and PRODY index for comparability. While the WDORCA and DORCA indices correspond more closely to our hypothesis, the PRODY index is more closely linked to sectoral upgrading and allows a better judgment as to whether the induced shift is likely to benefit the economy. Since the indices are not easy to interpret quantitatively, we use a bin approach. I.e., we divide the distribution of the indices into five different segments separated by quantiles and each represented by a dummy. $\mathbf{B I N}_{i}^{k}$ is a $5 \times 1$ vector indicating into which segment - or bin - of the distribution the respective observation falls ${ }^{2}$

Secondly, we need an estimation equation inspired by $(1.2)$. We estimate the following equation:

$$
x_{i t}^{k}=\beta_{0}+\beta_{G D P} \mathbf{B i n}_{i}^{k} \times\left(\sum_{j \neq i} \frac{y_{j t}}{D i s t_{i j}}\right)+\beta_{A i d} \operatorname{Bin}_{i}^{k} \times\left(\sum_{j \neq i} \frac{T F_{j t}}{D i s t_{i j}}\right)+\psi_{i}^{k}+\theta_{t}+\epsilon_{i t}^{k},
$$

where $x_{i t}^{k}$ are exports from country $i$ in sector $k$ at time $t . \sum_{j \neq i} T F_{j t} / D i s t_{i j}$ is the contribution of development aid to external demand faced by exporter $i$ (i.e., it is aid weighted by the inverse of distance); $\sum_{j \neq i} y_{j t} / D_{i s t}{ }_{i j}$, correspondingly, is the contribution of GDP to external demand, and $\sum_{j \neq i}\left(y_{j t}+T F_{j t}\right) / D_{i s t}$ is a proxy for total market potential. $\beta_{G D P}$ and $\beta_{\text {Aid }}$ are the respective $1 \times 5$ coefficient vectors that vary for each bin. $\psi_{i}^{k}$ are exporter-sector fixed effects, and $\theta_{t}$ are time fixed effects controlling for world market fluctuations.

\footnotetext{
${ }^{2}$ The choice of five bins balances two considerations. On the one hand we want to allow a sufficient degree of heterogeneity in the coefficients. On the other hand, we need sufficient variation within a given bin to be able to identify the distinct effect of our variables of interest. Results using other bin structures are qualitatively similar and available upon request.
} 
Third-country effects of development aid on sectoral exports

\subsection{Data \& Descriptives}

The underlying sectoral export data for the 2000 to 2013 period are obtained from the World Bank's World Integrated Trade Solution Database (WITS: COMTRADE). Exports to the rest of the world and bilateral trade flows are taken as reported by the exporter. Exports are retrieved for 32 sectors using Revision 3 of the ISIC classification. Bilateral distance, used to calculate our market potential measure, is from CEPII. Total GDP and GDP per capita are from the World Bank's World Development Indicators (WDI) [ $^{3}$ We obtain data on our main variable of interest, net aid flows, from the OECD's Development Assistance Committee (OECD, 2015).

Based on these variables we construct the three indices defined above. The PRODY index and the DORCA and WDORCA indices are not quantitatively comparable. The PRODY index is a weighted average of per capita income, whereas DORCA and WDORCA are weighted averages of aggregate net outflows of development aid. We are merely concerned with the ordering these indices imply. For that reason Table 1.1 reports the Spearman rank correlation coefficients. Unsurprisingly, the two indices measuring Donor RCAs, DORCA and WDORCA, are highly correlated, with a rank correlation coefficient of about 90 percent. In accordance with expectations, the relation of both indices to the PRODY index is less strong but still positive (73 percent and 80 percent, respectively) and highly significant. While DORCA and WDORCA on the one hand and PRODY, on the other hand, were designed to capture different aspects of sectors, they are still positively related and one may expect that if exports were to increase in high DORCA sectors, this would typically mean that exports in sectors with a high level of technological sophistication will increase. As WDORCA and DORCA are highly correlated and depict generally similar patterns, the main analysis will focus on the results for the DORCA and PRODY indices. 4

Table 1.1 Spearman's $\rho$

\begin{tabular}{lccc}
\hline & PRODY & DORCA & WDORCA \\
\hline PRODY & 1.0000 & & \\
DORCA & $0.7963^{*}$ & 1.0000 & \\
WDORCA & $0.7306^{*}$ & $0.9038^{*}$ & 1.0000 \\
\hline
\end{tabular}

Note: ${ }^{*} p<0.001$ using Bonferroni correction.

Figure 1.1 depicts average index scores of the DORCA index for various sectors. The results are in accordance with expectations. Donors tend to have a comparative advantage in most manufacturing sectors with the exception of textile, apparel, leather

\footnotetext{
${ }^{3}$ The data have been obtained using the wbopendata command by Azevedo (2011).

${ }^{4}$ The WDORCA index is, however, of specific interest as it implicitly accounts for trade costs via distance. Corresponding estimates using the WDORCA are, thus, for all main regressions depicted in the appendix and fundamental differences between the indices will be noted in the main part.
} 
Third-country effects of development aid on sectoral exports

Figure 1.1 Average DORCA Scores

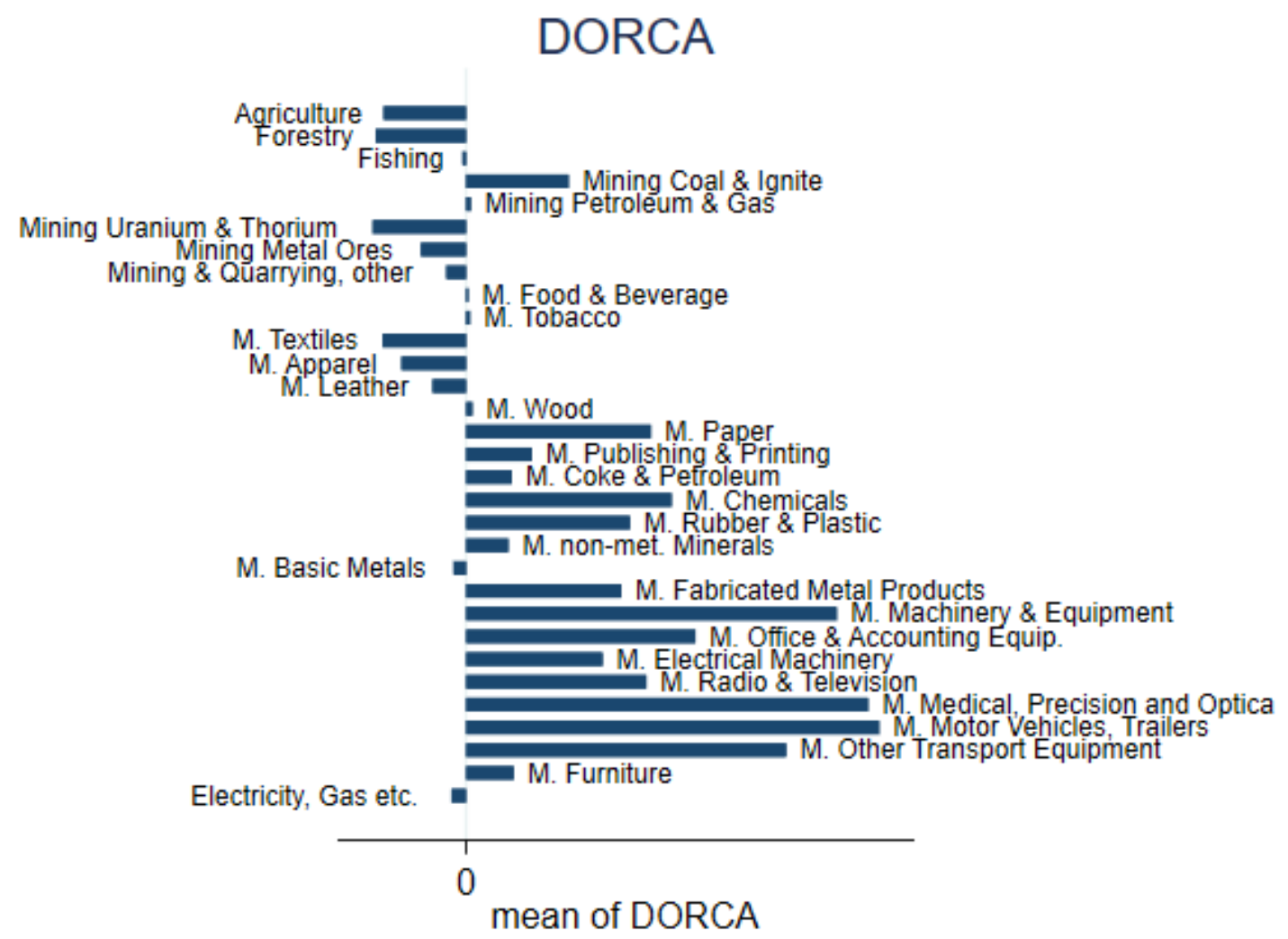

Source: Authors' calculation based on WITS and OECD data.

Note: Averages across countries and time.

and basic metals according to the DORCA index (Figure 1.1). Recipients tend to have a comparative advantage in mining sectors, agriculture and forestry. 
Third-country effects of development aid on sectoral exports

\subsection{Results}

Tables 1.2 and 1.3 present our first set of results. In all three tables, we estimate a simple form of (1.8), using five bins of the respective index. We report the coefficients on the contribution of aid to foreign demand - $\sum_{j \neq i} T F_{i t} / D i s t_{i j}$ - for all five bins, respectively. Moreover, we run the analysis not only for the full sample (column 1 of Tables 1.2 and 1.3), but also for Asia (column 2) and Africa (column 3) separately.

At first sight, the prediction of the model does not seem to be borne out by the data. For the full sample, results are largely statistically insignificant. For Asia, in contrast, coefficients are always significant at the 10 percent level irrespective of the index used. However, equally irrespective of the index the null hypothesis that all coefficients are the same can never be refuted. Africa shows mostly insignificant results, and in some cases, we even obtain negative and statistically significant coefficients.

A key concern regarding these results is the endogeneity of prices $p_{i}^{k} \cdot p_{i}^{k}$ is expected to increase with growing demand from abroad or on the domestic market. This will dampen the effect neighboring countries' aid can have on exports which declines in $p_{i}^{k}$. The standard way in which the gravity literature deals with endogenous prices is by imposing the market clearing condition and conditioning on the sectoral production values (Yotov et al., 2016). Unfortunately, this is not a feasible option here, because in order for the effects to materialize the sectoral production values have to change. In this sense, total sectoral production is a "bad control" (Angrist and Pischke, 2009).

However, using sectoral market clearing conditions one can show that the factory gate price is inversely related to the volume of production when demand is given. Moreover, one can show that the effect of additional demand on the factory gate price is lower the higher the produced quantity $5^{5}$ Thus, exporters that produce a relatively small amount of a given product may be forced to increase their price, which in turn may upset the expected sectoral export patterns. Exporters that produce a relatively large quantity of a given product will find it easier to meet the additional demand. This adversely affects the market prospects of exporters that produce relatively little. This effect is due to heterogeneity within recipient countries or the "South" which is not accounted for in Trionfetti (2017). As a result, countries that are close to recipients and have a comparative advantage in similar sectors as donors should see an increase especially in those sectors. Since they may absorb most of the additional demand in high DORCA/WDORCA sectors, the expected pattern may not necessarily materialize if countries have a comparative disadvantage. Thus, not only the comparative advantage of donor countries matters but also the comparative advantage of the exporting developing country. We allow for this possibility by introducing a dummy variable indicating whether or not a given exporter has a comparative advantage $(R C A>1)$ in a given sector. We augment our estimation equation (1.8) by allowing the intersectoral

\footnotetext{
${ }^{5}$ To see this let $q_{i}^{k}$ denote the quantity supplied. Then, in equilibrium we have $q_{i}^{k}=$ $p_{i}^{k^{-\sigma_{k}}} \sum_{j}\left(\frac{\tau_{i j}^{k}}{P_{j}^{k}}\right)^{1-\sigma_{k}} E_{j}^{k}$ or $p_{i}^{k}=\left(\sum_{j}\left(\frac{\tau_{i j}^{k}}{P_{j}^{k}}\right)^{1-\sigma_{k}} \frac{E_{j}^{k}}{q_{i}^{k}}\right)^{\frac{1}{\sigma_{k}}}$.
} 
Third-country effects of development aid on sectoral exports

Table 1.2 DORCA Baseline

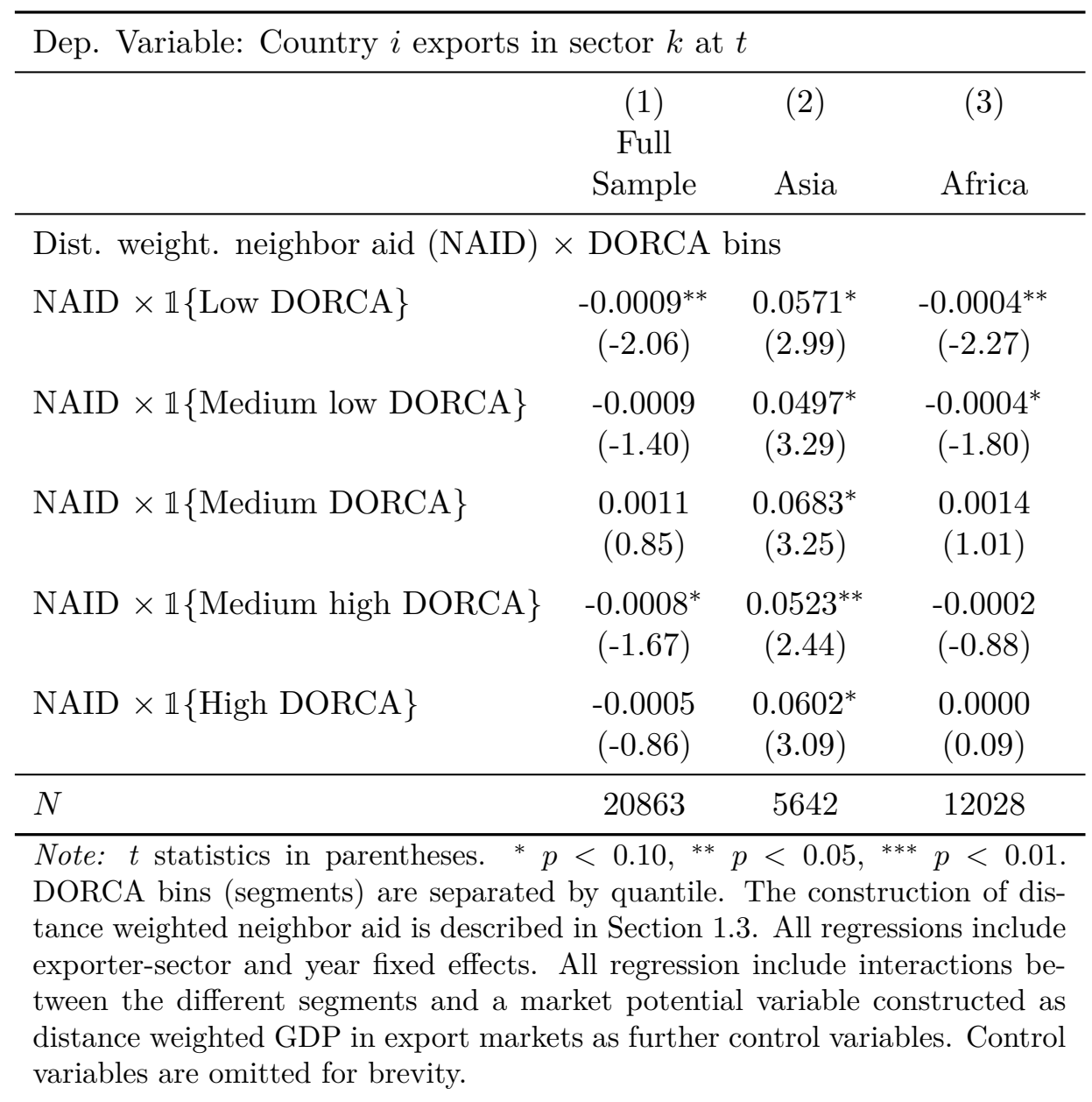


Third-country effects of development aid on sectoral exports

Table 1.3 PRODY Baseline

\begin{tabular}{lccc}
\hline Dep. Variable: Country $i$ exports in sector $k$ at $t$ \\
& $(1)$ & $(2)$ & $(3)$ \\
& Full & & \\
& Sample & Asia & Africa \\
\hline Dist. weight. neighbor aid (NAID) & PRODY & bins & \\
NAID $\times \mathbb{1}\{$ Low PRODY & -0.0005 & $0.0607^{*}$ & -0.0001 \\
& $(-1.64)$ & $(3.56)$ & $(-0.86)$ \\
NAID $\times \mathbb{1}\{$ Medium low PRODY\} & $-0.0010^{* *}$ & $0.0515^{*}$ & -0.0001 \\
& $(-1.98)$ & $(2.83)$ & $(-0.69)$ \\
NAID $\times \mathbb{1}\{$ Medium PRODY $\}$ & -0.0005 & $0.0575^{*}$ & 0.0001 \\
& $(-0.93)$ & $(3.17)$ & $(0.22)$ \\
NAID $\times \mathbb{1}\{$ Medium high PRODY\} & -0.0005 & $0.0493^{*}$ & $-0.0003^{*}$ \\
& $(-1.06)$ & $(2.82)$ & $(-1.76)$ \\
NAID $\times \mathbb{1}\{$ High PRODY $\}$ & 0.0006 & $0.0681^{*}$ & 0.0008 \\
& $(0.55)$ & $(3.17)$ & $(0.79)$ \\
\hline$N$ & 20863 & 5642 & 12028 \\
\hline Note: See Table 1.2 & & &
\end{tabular}

patterns to differ depending on whether the exporter has a comparative advantage. I.e.,

$$
\begin{aligned}
x_{i t}^{k}=\beta_{0} & +\left(\beta_{G D P}^{0} \operatorname{Bin}_{i}^{k} \times \mathbb{1}\left\{R C A_{i t}^{k} \leq 1\right\}+\beta_{G D P}^{1} \mathbf{B i n}_{i}^{k} \times \mathbb{1}\left\{R C A_{i t}^{k}>1\right\}\right) \times\left(\sum_{j \neq i} \frac{y_{j t}}{D_{i s t_{i j}}}\right) \\
& +\left(\beta_{A i d}^{0} \mathbf{B i n}_{i}^{k} \times \mathbb{1}\left\{R C A_{i t}^{k} \leq 1\right\}+\beta_{A i d}^{1} \operatorname{Bin}_{i}^{k} \times \mathbb{1}\left\{R C A_{i t}^{k}>1\right\}\right) \times\left(\sum_{j \neq i} \frac{T F_{j t}}{\text { Dist }_{i j}}\right) \\
& +\psi_{i}^{k}+\theta_{t}+\epsilon_{i t}^{k},
\end{aligned}
$$

where $\beta_{A i d}^{0}\left(\beta_{G D P}^{0}\right)$ is the vector of coefficients for the contribution of aid (GDP) to external demand given that country $i$ has a comparative disadvantage in $k$ and $\beta_{\text {Aid }}^{1}$ $\left(\beta_{G D P}^{1}\right)$ is the vector of coefficients if $i$ enjoys an advantage in $k$. I.e., instead of five we will have ten different coefficients of the contribution of aid to external demand. Based on the reasoning outlined above, we should expect that the pattern emerges for countries with a comparative advantage, but may be weaker or fail to materialize for countries that suffer a comparative disadvantage.

Results for the various indicators are reported in Tables 1.4 and 1.5 . In order to facilitate inspection, we present the results for one regression spread over two columns. 
Third-country effects of development aid on sectoral exports

The vector of coefficients $\beta_{A i d}^{0}\left(R C A_{i t}^{k} \leq 1\right)$ is reported in the first column and the second column reports results for $\beta_{\text {Aid }}^{1}\left(R C A_{i t}^{k}>1\right)$. Apart from that, the tables are structured in line with Tables 1.2 and 1.3 .

For the full sample (columns 1 and 2 in all tables) we find negative coefficients that are statistically significant in the medium-high bins if countries have a comparative disadvantage, respectively. A similar picture emerges for the African subsample, except that results are always insignificant when using the PRODY index.

As before, it is the Asian countries for which we find sizeable and statistically significant coefficients. For disadvantaged country-sector combinations (column 3) we find positive coefficients, statistically significant at least at the ten percent level, in all bins and both tables. No clear pattern emerges and while the coefficients are statistically different from zero, they are not statistically different from each other (with the exception of PRODY's high bin which is significantly smaller than the first and second bin). In accordance with our expectations, this changes when looking at advantaged countrysector combinations. Here, when using the DORCA index, the strongest increases are found in the medium, medium-high and high bin, supporting the hypothesized pattern. Those coefficients are statistically significantly larger than the medium-low bin. ${ }^{6}$ At the median neighbors' aid would induce an export increase of $29 \%$ in the medium-high and of $20 \%$ in the medium DORCA segment, while only leading to an increase by $14 \%$ in the low bin. 7 This is in line with our prediction, and indicates that at least between these three bins the effect is highest in sectors where donors have a comparative advantage. Nonetheless, the results for the two extreme bins - the bins for low and high index values - are not in line with this pattern for the DORCA 8 One possible reason for this could be differences in demand structures between donors and recipients (i.e., our assumption of a constant $\alpha_{k}$ across countries could be violated). The results for the PRODY index, however, partially contradict this interpretation. Surprisingly, the predicted pattern materializes most strongly when using the PRODY index, although it is based on GDP per capita instead of aid and does not account for the distance between donors and recipients. The coefficient in the high bin for advantaged country-sector combinations is statistically significantly larger and almost double in size compared to the medium-high bin.9

These results are in line with Doucouliagos and Paldam (2008) who show that aid is more effective in Asian states. In contrast, one possible explanation for the dismal

\footnotetext{
${ }^{6}$ The comparison of coefficients is based on one-sided t-tests due to our theoretical expectation regarding the estimated pattern.

${ }^{7} \mathrm{We}$ refer to the median as there is a large variation in relative effects due to the heterogeneous sample under observation.

${ }^{8}$ The coefficient structure for the WDORCA in Appendix Table A.5 is similar, although we cannot reject the null hypothesis that the coefficient in the medium-high bin is smaller or equal to the effect in the medium bin. One potential reason for this could be that distance is only an imperfect proxy for trade costs.

${ }^{9}$ Since theory and results suggest that aid to neighboring countries could induce shifts in demand and export structure, one might be concerned about endogeneity of sectoral quantile rankings. Thus, in a further test, the ranking of the initial sampling year 2000 was used. The results are robust.
} 
Third-country effects of development aid on sectoral exports

Table 1.4 DORCA (Dis-)Advantage

\begin{tabular}{|c|c|c|c|c|c|c|}
\hline & \multirow{2}{*}{\multicolumn{2}{|c|}{$\begin{array}{c}\begin{array}{c}\text { Full } \\
\text { sample }\end{array} \\
\text { RCA }\end{array}$}} & \multicolumn{2}{|c|}{ Asia } & \multicolumn{2}{|c|}{ Africa } \\
\hline & & & \multicolumn{2}{|c|}{$\mathrm{RCA}$} & \multicolumn{2}{|c|}{$\mathrm{RCA}$} \\
\hline & $\leq 1$ & $>1$ & $\leq 1$ & $>1$ & $\leq 1$ & $>1$ \\
\hline \multicolumn{7}{|c|}{ Dist. weight. neighbor aid $(\mathrm{NAID}) \times$ DORCA bins } \\
\hline $\mathrm{NAID} \times \mathbb{1}\{$ Low $\mathrm{DORCA}\}$ & $\begin{array}{c}-0.0003 \\
(-1.01)\end{array}$ & $\begin{array}{c}0.0059 \\
(0.56)\end{array}$ & $\begin{array}{c}0.0568^{*} \\
(4.19)\end{array}$ & $\begin{array}{c}0.1023^{*} \\
(1.91)\end{array}$ & $\begin{array}{c}-0.0002^{*} \\
(-1.82)\end{array}$ & $\begin{array}{c}-0.0014 \\
(-0.23)\end{array}$ \\
\hline NAID $\times \mathbb{1}\{$ Med. low DORCA $\}$ & $\begin{array}{c}-0.0002 \\
(-0.89)\end{array}$ & $\begin{array}{c}0.0045 \\
(0.22)\end{array}$ & $\begin{array}{c}0.0619^{*} \\
(4.20)\end{array}$ & $\begin{array}{c}0.0423 \\
(1.39)\end{array}$ & $\begin{array}{c}-0.0003 \\
(-1.35)\end{array}$ & $\begin{array}{c}0.0073 \\
(0.42)\end{array}$ \\
\hline NAID $\times \mathbb{1}\{$ Medium DORCA $\}$ & $\begin{array}{c}0.0015 \\
(1.12)\end{array}$ & $\begin{array}{c}0.0162 \\
(0.94)\end{array}$ & $\begin{array}{c}0.0630^{*} \\
(4.39)\end{array}$ & $\begin{array}{c}0.1505^{* *} \\
(1.99)\end{array}$ & $\begin{array}{c}0.0014 \\
(1.03)\end{array}$ & $\begin{array}{c}0.0068 \\
(0.63)\end{array}$ \\
\hline NAID $\times \mathbb{1}\{$ Med. high DORCA $\}$ & $\begin{array}{c}-0.0010^{* *} \\
(-2.21)\end{array}$ & $\begin{array}{l}0.0485 \\
(1.48)\end{array}$ & $\begin{array}{c}0.0372^{* *} \\
(2.07)\end{array}$ & $\begin{array}{c}0.2211^{* *} \\
\quad(2.19)\end{array}$ & $\begin{array}{c}-0.0002 \\
(-0.78)\end{array}$ & $\begin{array}{c}-0.0331 \\
(-1.19)\end{array}$ \\
\hline NAID $\times \mathbb{1}\{$ High DORCA $\}$ & $\begin{array}{c}-0.0005 \\
(-0.93)\end{array}$ & $\begin{array}{l}0.1147 \\
(1.15)\end{array}$ & $\begin{array}{c}0.0525^{*} \\
(3.74)\end{array}$ & $\begin{array}{c}0.2378 \\
(1.62)\end{array}$ & $\begin{array}{c}0.0002 \\
(0.34)\end{array}$ & $\begin{array}{c}-0.0718^{* *} \\
(-2.11)\end{array}$ \\
\hline$N$ & \multicolumn{2}{|c|}{20863} & \multicolumn{2}{|c|}{5642} & \multicolumn{2}{|c|}{12028} \\
\hline $\begin{array}{l}\text { Note: } t \text { statistics in parentheses. } \\
\text { weighted neighbor aid is described } \\
\text { refer to one regression. All regressior } \\
\text { omitted for brevity. DORCA bins (se } \\
\text { between the different DORCA segme } \\
\text { GDP in export markets as further c }\end{array}$ & $\begin{array}{l}0.10 \text {, } \\
\text { ection } \sqrt{1} \\
\text { clude e } \\
\text { ents) ar }\end{array}$ & $\begin{array}{l}<0.1 \\
\text { he c } \\
\text { er-se } \\
\text { arate }\end{array}$ & $\begin{array}{l}{ }^{* * *} p< \\
\text { ans for s } \\
\text { and yea } \\
\text { quantile }\end{array}$ & $\begin{array}{l}\text { 1. The c } \\
\text { tors with } \\
\text { ixed effect } \\
\text { All regress } \\
\text { construct }\end{array}$ & $\begin{array}{l}\text { truction } \\
A \leq 1 \& \\
\text { Control } \\
\text { include }\end{array}$ & $\begin{array}{l}\text { distance } \\
\{C A>1 \\
\text { iables are } \\
\text { eractions } \\
\text { weighted }\end{array}$ \\
\hline
\end{tabular}


Third-country effects of development aid on sectoral exports

Table 1.5 PRODY (Dis-)Advantage

\begin{tabular}{|c|c|c|c|c|c|c|}
\hline & \multirow{2}{*}{\multicolumn{2}{|c|}{$\begin{array}{c}\begin{array}{c}\text { Full } \\
\text { sample }\end{array} \\
\text { RCA }\end{array}$}} & \multirow{2}{*}{\multicolumn{2}{|c|}{$\begin{array}{l}\text { Asia } \\
\text { RCA }\end{array}$}} & \multirow{2}{*}{\multicolumn{2}{|c|}{$\begin{array}{c}\text { Africa } \\
\mathrm{RCA}\end{array}$}} \\
\hline & & & & & & \\
\hline & $\leq 1$ & $>1$ & $\leq 1$ & $>1$ & $\leq 1$ & $>1$ \\
\hline \multicolumn{7}{|c|}{ Dist. weight. neighbor aid $($ NAID $) \times$ PRODY bins } \\
\hline NAID $\times \mathbb{1}\{$ Low PRODY $\}$ & $\begin{array}{c}0.0000 \\
(0.02)\end{array}$ & $\begin{array}{c}0.0052 \\
(0.82)\end{array}$ & $\begin{array}{c}0.0607^{*} \\
(4.34)\end{array}$ & $\begin{array}{c}0.1135^{*} \\
(2.59)\end{array}$ & $\begin{array}{c}0.0001 \\
(0.55)\end{array}$ & $\begin{array}{c}-0.0001 \\
(-0.04)\end{array}$ \\
\hline NAID $\times \mathbb{1}\{$ Med. low PRODY $\}$ & $\begin{array}{c}-0.0000 \\
(-0.02)\end{array}$ & $\begin{array}{c}0.0031 \\
(0.26)\end{array}$ & $\begin{array}{c}0.0629^{*} \\
(4.14)\end{array}$ & $\begin{array}{c}0.0914^{*} \\
(1.96)\end{array}$ & $\begin{array}{c}0.0000 \\
(0.27)\end{array}$ & $\begin{array}{c}0.0018 \\
(0.23)\end{array}$ \\
\hline NAID $\times \mathbb{1}\{$ Medium PRODY $\}$ & $\begin{array}{c}-0.0001 \\
(-0.29)\end{array}$ & $\begin{array}{c}0.0204 \\
(1.08)\end{array}$ & $\begin{array}{c}0.0568^{*} \\
(3.77)\end{array}$ & $\begin{array}{c}0.1279^{* *} \\
(2.09)\end{array}$ & $\begin{array}{c}0.0002 \\
(0.59)\end{array}$ & $\begin{array}{c}0.0052 \\
(0.35)\end{array}$ \\
\hline NAID $\times \mathbb{1}\{$ Med. high PRODY $\}$ & $\begin{array}{c}-0.0006^{*} \\
(-1.88)\end{array}$ & $\begin{array}{l}0.1357 \\
(1.16)\end{array}$ & $\begin{array}{c}0.0439^{*} \\
(2.97)\end{array}$ & $\begin{array}{c}0.2027^{* *} \\
(2.05)\end{array}$ & $\begin{array}{c}-0.0001 \\
(-0.69)\end{array}$ & $\begin{array}{c}0.1245 \\
(0.83)\end{array}$ \\
\hline NAID $\times \mathbb{1}\{$ High PRODY $\}$ & $\begin{array}{c}0.0005 \\
(0.49)\end{array}$ & $\begin{array}{c}0.0806 \\
(1.16)\end{array}$ & $\begin{array}{c}0.0503^{*} \\
(3.80)\end{array}$ & $\begin{array}{c}0.3971^{* *} \\
(2.47)\end{array}$ & $\begin{array}{c}0.0010 \\
(0.95)\end{array}$ & $\begin{array}{c}0.0139 \\
(0.21)\end{array}$ \\
\hline$N$ & \multicolumn{2}{|c|}{20863} & \multicolumn{2}{|c|}{5642} & \multicolumn{2}{|c|}{12028} \\
\hline
\end{tabular}

Note: See Table 1.4. PRODY bins (segments) are separated by quantile. All regression include interactions between the different PRODY segments and a market potential variable constructed as distance weighted GDP in export markets as further control variables. 
performance of the theory in Africa may be the lack of capacity of the African physical infrastructure. As Brooks and Hummels (2005) and Storeygard (2016) report, trade costs within Africa are much higher than in Asia. This implies that distance is a much greater impediment to regional trade in Africa. Our distance weighted neighbor aid measure may thus exaggerate the extent to which African countries face higher demand. Cameroon and Vietnam can exemplify this difference between the continents. Both had similar income levels, relied largely on exports of primary products at the turn of the century and are neighbored by several major recipients of development aid. While Cameroon is still highly dependent on commodities including petroleum and cocoa, however, Vietnam increased its export sophistication via a shift towards manufacturing of electrical communication equipment during our observation period (WITS, 2018). Although both have concluded trade agreements with their neighbors, the World Bank's Trading across Borders ranking lists Vietnam on rank 94 and Cameroon 186 among 189 countries (World Bank, 2018a) 10

\subsection{Robustness}

Third-country effects are less prone to endogeneity concerns of strategic aid allocation than direct bilateral effects. However, as donors pursue regional development strategies (te Velde, 2007, OECD, WTO, 2013; World Bank, 2018c), the argument of endogenous aid allocation could be extended to the regional level. First, donors might support regions, which already host important supply-chains rather than creating new initiatives for regional integration. In this case, development aid allocation might react to upgrading trajectories rather than causing these developments among neighbors. What is more, donors might allocate aid to neighbors of well-performing states to achieve regional convergence. In this case, we would falsely count aid to more needy neighbors as a reason for upgrading among regional top-performers.

In order to address these concerns, we build on Temple and Van de Sijpe (2017), and construct a synthetic measure of aid based on the overall aid budget of the donor. Temple and Van de Sijpe (2017) use average past values for the share of a given donor country's aid that has gone to a specific recipient in order to get counterfactual synthetic - bilateral aid flows. These bilateral aid flows are then aggregated for each recipient, and the resulting aggregate is used as an instrumental variable (IV) for actual aid flows. We use average bilateral shares for the 1990-1999 period to construct this

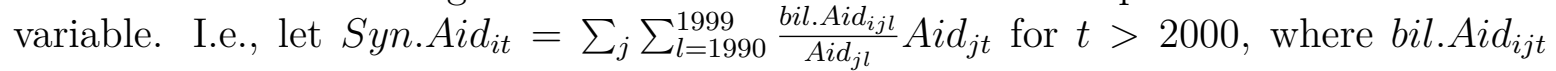
is bilateral aid that $i$ received from $j$ and $A i d_{j t}$ is donor $j$ 's total aid budget. While

\footnotetext{
${ }^{10}$ The Trading across Borders ranking measures costs and time of ex- and import procedures, in terms of "documentary compliance, border compliance and domestic transport" (World Bank, 2018a). The performance of the two countries extends to their regional trading blocks, where ASEAN members rank in the middle and Cameroon's potential trading partners within the CEMAC (Economic and Monetary Community of Central Africa) are to be found at the bottom ranks. In this regard, the WTO indicates that among CEMAC nations "infrastructure (road, rail and port networks) [...] is either lacking or in poor condition" (WTO, 2013).
} 
Third-country effects of development aid on sectoral exports

recipient characteristics may be endogenous determinants of aid, in our setting donor characteristics can arguably be treated as exogenous. Moreover, the synthetic aid variable is also plausibly excludable because it represents merely a counterfactual aid flow.

Instead of applying a standard IV approach, we follow Wooldridge (2015) in using a control function approach. The control function rests on similar identifying assumption as the IV approach, namely excludability and exogeneity of the instrument. We estimate a first stage equation with development aid as our dependent variable:

$$
\ln \left(1+\frac{A i d_{i t}}{y_{i t}}\right)=\alpha_{0}+\alpha_{1} y_{i t}+\alpha_{2} \ln \left(1+\frac{\text { Syn.Aid }}{y_{i t}}\right)+\phi_{i}+\zeta_{t}+v_{i t}
$$

where Syn. Aid $d_{i t}$ denotes our synthetic aid variable, and $\phi_{i}$ are country and $\zeta_{t}$ are year fixed effects. While in an IV setting the predicted value from 1.10 would replace the endogenous regressor in (1.8), in a control function approach we use the predicted error term from (1.10) $\hat{v}_{i t}$ as an additional regressor in (1.8) to properly control for the endogenous variation. Wooldridge (2015) has shown that in a linear model (without interactions) this yields the same point estimates as traditional IVs. One decisive advantage, however, is that the control function approach provides a simple Hausmantest of endogeneity that can be easily made robust to heteroskedasticity. In a control function approach, one can use a robust t-test to test the null hypothesis of exogeneity of the variable of interest. If $\hat{v}_{i t}$ is insignificant the null hypothesis can be accepted. As with a Hausman test, however, the validity of the test hinges on the validity of the chosen instrument.

In a setting with interactions, the control function approach offers additional efficiency gains compared to IV. The difference, as Wooldridge (2015) points out, is that in an IV framework one has to treat every interaction as a single endogenous regressor. In the control function approach, however, it suffices to simply include $\hat{v}_{i t}$, as in the linear case. Intuitively, in an instrumental variable approach, one has to remove the endogeneous variation in the interaction and the parent term. In the control function approach, however, the original variables are not adjusted. Instead, by using the residual from the first stage, one controls for the endogeneous variation. Since the source of the variation is the same, only one variable is required. Note that this is based on the additional assumption that the variable that neighbor aid is interacted with is exogenous (e.g., not determined by the instrument). This is plausibly the case since the DORCA/PRODY indices are not country specific 11

In this setting, we use the donor budget based synthetic aid measure due to Temple and Van de Sijpe (2017) as the excluded instrument. Judging by the first stage Fstatistics, this instrument performs considerably well for the Asian subsamples. However, for the full and African sub sample the corresponding F-statistics are below the

\footnotetext{
${ }^{11}$ Although we do not provide a technical proof, the robustness of results when using advantage indicators from the initial sampling year 2000, reduces concerns that the indices are subject to endogeneity.
} 
Third-country effects of development aid on sectoral exports

rule of thumb value of $10{ }^{12}$ Hence, as the approach is suitable for the subsample where the study's main results are found, we proceed with this strategy.

As suggested by Wooldridge (2015), we include the residual from the first stage $\hat{v}_{2}$ to control for endogeneity. According to Wooldridge (2015), the significance test is tantamount to a heteroskedasticity-robust Hausman test of the null hypothesis that our variable of interest is exogenous, assuming that our instrument is. $\hat{v}_{2}$ is significant in the full and Asian sub sample, which are, hence, subject to endogeneity. Controlling for this endogenous part leaves the main results largely unchanged. The positive coefficient of $\hat{v}_{2}$ suggests that previous fixed effects results were slightly upward biased.

Again, we find for the Asian subsample that in sectors with $R C A \leq 1$ exports increase significantly, but the effects are not significantly larger in sectors with a high DORCA or PRODY. In contrast, for sectors with $R C A>1$ larger coefficients occur among higher DORCA bins in column 4 of Table 1.6. As before, results for the full sample and for Asia are not in line with the predictions of the model. Our findings, thus, seem robust to controlling for endogeneity ${ }^{13}$

During the period between 2000 and 2013 low and lower middle income states in our sample experienced a strong increase in both aid and exports (see Figure A.1 in the Appendix). ${ }^{14}$ Especially, a strong jump occurs around 2005, which was marked by important aid policy forums including the UN Millennium project, the Commission for Africa as well as the OECD's Development Assistance Committee donors' Paris Declaration (PD) on Aid Effectiveness (Minasyan et al., 2017). In the 2005 Paris Declaration donors committed to successively reduce the amount of tied aid, which requires that recipients spend development aid on goods from the donor country (OECD, 2008). Tied aid could potentially undermine our prediction because it changes the effective trade costs of recipients vis-à-vis donors. Neighboring countries may not benefit from aid inflows if they can only be spent on goods from the donor country. In order to assess if this structural break might contribute to the results found, we split the sample into the 2000-2005 and 2006-2013 periods.

In Table 1.7 we conduct the same analysis as in Table 1.4 but restricted to the pre-PD

${ }^{12}$ We also considered potential alternative instrumental variables, which were recently suggested. Galiani et al. (2017) use crossing the International Development Association's gross national income eligibility threshold as an instrument. However, the local average treatment effect in this "Quasiexperiment," which is only experienced for countries on a growth trajectory, is rather specific. This might be problematic for our specific research question as shifts in the export structure are suggested as growth determinants in the literature (Hausmann et al., 2005). Another alternative is Dreher and Langlotz s (2017) instrument, which is based on donor fractionalization and the probability to receive aid. As a large part of the statistical power of this IV is derived from the Cold War period, which is not covered by our sample, this identification strategy is not applicable to our research.

${ }^{13}$ Additionally to concerns of reversed causality, an obvious omitted variable bias could be associated with the correlation of own and neighbors' aid receipts. Further regressions, which include own aid as a control variable, support the previous results found and are available upon request.

${ }^{14}$ One might be concerned that both dependent and independent variable would be driven by secular trends that are due to other global changes, for instance, the rising participation of Asian countries in global value chains (Baldwin and Lopez-Gonzalez, 2015). In order to address this concern, Appendix Table A.3 controls for segment-specific trends and depicts a qualitatively unchanged pattern. 
period. Compared to our previous results neither for the full sample nor for the African subsample does this show a major effect on our results. For the full sample (columns 1 and 2) we only find negative and significant coefficients for disadvantaged sectors, and for Africa (columns 5 and 6) hardly any coefficient is statistically significant. As before, we do not find the predicted pattern in either case. In striking contrast to our earlier results, however, we do not find statistically significant effects of neighbor aid on exports in Asia for advantaged sectors. Hence, the pattern that we find in Section 1.5 does not materialize prior to 2005. But how do the effects change after 2005's high level fora meetings?

In Table 1.8 we restrict the sample to the post-PD period. For the full sample of countries, the mostly negative point estimates are now indistinguishable from zero and would, thus, correspond to neutral effects. The pattern for African countries remains largely unchanged and only an additional significant negative effect in the medium-low DORCA bin for sectors with $R C A>1$ occurs. Among the Asian countries, effects are statistically significant across all bins with $R C A \leq 1$. In contrast to the pre-PD results, we now find the predicted pattern (with the exception of the high DORCA bin) among the sectors with $R C A>1$ with substantially larger and significant effects than in Table 1.4. The results suggest that the policy change 2005 may indeed have allowed some countries to benefit from aid flows to proximate countries. However, the evidence of such an effect is limited to Asia. For African countries, not much seems to have changed after 2005 . 
Third-country effects of development aid on sectoral exports

Table 1.6 DORCA (Dis-)Advantage - Control Function

Dep. Variable: Country $i$ exports in sector $k$ at $t$

\begin{tabular}{|c|c|c|c|c|c|c|}
\hline & \multirow{2}{*}{\multicolumn{2}{|c|}{$\begin{array}{c}\begin{array}{c}\text { Full } \\
\text { sample }\end{array} \\
\text { RCA }\end{array}$}} & \multirow{2}{*}{\multicolumn{2}{|c|}{$\begin{array}{l}\text { Asia } \\
\text { RCA }\end{array}$}} & \multirow{2}{*}{\multicolumn{2}{|c|}{$\frac{\text { Africa }}{\text { RCA }}$}} \\
\hline & & & & & & \\
\hline & $\leq 1$ & $>1$ & $\leq 1$ & $>1$ & $\leq 1$ & $>1$ \\
\hline \multicolumn{7}{|c|}{ Dist. weight. neighbor aid $($ NAID $) \times$ DORCA bins } \\
\hline NAID $\times \mathbb{1}\{$ Low DORCA $\}$ & $\begin{array}{c}-0.0075^{* *} \\
(-2.24)\end{array}$ & $\begin{array}{c}0.0003 \\
(0.02)\end{array}$ & $\begin{array}{c}0.0435^{* * *} \\
(3.57)\end{array}$ & $\begin{array}{l}0.0847 \\
(1.61)\end{array}$ & $\begin{array}{c}0.0003 \\
(0.08)\end{array}$ & $\begin{array}{c}-0.0012 \\
(-0.15)\end{array}$ \\
\hline NAID $\times \mathbb{1}\{$ Med. low DORCA $\}$ & $\begin{array}{c}-0.0074^{* *} \\
(-2.21)\end{array}$ & $\begin{array}{c}-0.0010 \\
(-0.04)\end{array}$ & $\begin{array}{c}0.0491^{* * *} \\
(3.71)\end{array}$ & $\begin{array}{c}0.0243 \\
(0.79)\end{array}$ & $\begin{array}{l}0.0001 \\
(0.04)\end{array}$ & $\begin{array}{c}0.0076 \\
(0.40)\end{array}$ \\
\hline NAID $\times \mathbb{1}\{$ Medium DORCA $\}$ & $\begin{array}{c}-0.0057 \\
(-1.61)\end{array}$ & $\begin{array}{c}0.0100 \\
(0.51)\end{array}$ & $\begin{array}{c}0.0502^{* * *} \\
\quad(3.89)\end{array}$ & $\begin{array}{c}0.1322^{*} \\
(1.76)\end{array}$ & $\begin{array}{c}0.0019 \\
(0.53)\end{array}$ & $\begin{array}{c}0.0071 \\
(0.55)\end{array}$ \\
\hline NAID $\times \mathbb{1}\{$ Med. high DORCA $\}$ & $\begin{array}{c}-0.0081^{\text {** }} \\
(-2.46)\end{array}$ & $\begin{array}{c}0.0430 \\
(1.30)\end{array}$ & $\begin{array}{c}0.0235 \\
(1.37)\end{array}$ & $\begin{array}{c}0.2030^{* *} \\
(2.02)\end{array}$ & $\begin{array}{c}0.0003 \\
(0.08)\end{array}$ & $\begin{array}{c}-0.0330 \\
(-1.17)\end{array}$ \\
\hline NAID $\times \mathbb{1}\{$ High DORCA $\}$ & $\begin{array}{c}-0.0076^{* *} \\
(-2.28)\end{array}$ & $\begin{array}{c}0.1091 \\
(1.10)\end{array}$ & $\begin{array}{c}0.0387^{* * *} \\
\quad(3.01)\end{array}$ & $\begin{array}{c}0.2203 \\
(1.50)\end{array}$ & $\begin{array}{c}0.0006 \\
(0.18)\end{array}$ & $\begin{array}{c}-0.0717^{* *} \\
(-2.10)\end{array}$ \\
\hline$\hat{v}_{2}$ & \multicolumn{2}{|c|}{$\begin{array}{c}0.0079^{* *} \\
(2.19)\end{array}$} & \multicolumn{2}{|c|}{$\begin{array}{c}0.0232^{*} \\
(2.93)\end{array}$} & \multicolumn{2}{|c|}{$\begin{array}{c}-0.0005 \\
(-0.13)\end{array}$} \\
\hline Kleibergen-Paap under-ID p-val. & \multicolumn{2}{|c|}{0.0038} & \multicolumn{2}{|c|}{0.0003} & \multicolumn{2}{|c|}{0.0322} \\
\hline Kleibergen-Paap weak ID F-stat. & \multicolumn{2}{|c|}{8.072} & \multicolumn{2}{|c|}{133.664} & \multicolumn{2}{|c|}{5.139} \\
\hline$N$ & \multicolumn{2}{|c|}{20863} & \multicolumn{2}{|c|}{5642} & \multicolumn{2}{|c|}{12028} \\
\hline
\end{tabular}

Note: See Table 1.4 Correspondingly, the control function approach plugs in $\hat{v}_{2}$ from a specific first stage regression per regional subsample, where first stage results can be found in Table A.2 All regressions include exporter-sector and year fixed effects. All regression include interactions between the different DORCA segments and a market potential variable constructed as distance weighted GDP in export markets as further control variables. Control variables are omitted for brevity. 
Third-country effects of development aid on sectoral exports

Table 1.7 DORCA (Dis-)Advantage - pre 2005

\begin{tabular}{|c|c|c|c|c|c|c|}
\hline & \multicolumn{2}{|c|}{$\begin{array}{c}\text { Full } \\
\text { sample }\end{array}$} & \multicolumn{2}{|c|}{ Asia } & \multicolumn{2}{|c|}{ Africa } \\
\hline & \multicolumn{2}{|c|}{$\mathrm{RCA}$} & \multicolumn{2}{|c|}{$\mathrm{RCA}$} & \multicolumn{2}{|c|}{$\mathrm{RCA}$} \\
\hline & $\leq 1$ & $>1$ & $\leq 1$ & $>1$ & $\leq 1$ & $>1$ \\
\hline \multicolumn{7}{|c|}{ Dist. weight. neighbor aid (NAID) $\times$ DORCA bins } \\
\hline NAID $\times \mathbb{1}\{$ Low DORCA $\}$ & $\begin{array}{c}-0.0023^{* * *} \\
(-3.74)\end{array}$ & $\begin{array}{c}-0.0060^{*} \\
(-1.77)\end{array}$ & $\begin{array}{c}0.0077^{*} \\
(1.75)\end{array}$ & $\begin{array}{c}0.0006 \\
(0.03)\end{array}$ & $\begin{array}{c}-0.0004^{* *} \\
(-2.46)\end{array}$ & $\begin{array}{r}-0.0017 \\
(-1.62)\end{array}$ \\
\hline NAID $\times \mathbb{1}\{$ Med. low DORCA $\}$ & $\begin{array}{l}-0.0007 \\
(-1.10)\end{array}$ & $\begin{array}{c}-0.0067 \\
(-1.23)\end{array}$ & $\begin{array}{c}0.0143^{* *} \\
(2.50)\end{array}$ & $\begin{array}{c}-0.0049 \\
(-0.27)\end{array}$ & $\begin{array}{c}-0.0000 \\
(-0.08)\end{array}$ & $\begin{array}{r}-0.0006 \\
(-0.40)\end{array}$ \\
\hline NAID $\times \mathbb{1}\{$ Medium DORCA $\}$ & $\begin{array}{c}-0.0014^{* * *} \\
(-2.85)\end{array}$ & $\begin{array}{c}-0.0053 \\
(-1.08)\end{array}$ & $\begin{array}{c}0.0106^{* *} \\
(2.01)\end{array}$ & $\begin{array}{c}-0.0048 \\
(-0.32)\end{array}$ & $\begin{array}{l}0.0001 \\
(0.81)\end{array}$ & $\begin{array}{l}0.0001 \\
(0.08)\end{array}$ \\
\hline NAID $\times \mathbb{1}\{$ Med. high DORCA $\}$ & $\begin{array}{c}-0.0033^{* * *} \\
(-2.99)\end{array}$ & $\begin{array}{l}0.0023 \\
(0.22)\end{array}$ & $\begin{array}{c}0.0078 \\
(1.50)\end{array}$ & $\begin{array}{r}-0.0080 \\
(-0.37)\end{array}$ & $\begin{array}{c}-0.0004 \\
(-0.94)\end{array}$ & $\begin{array}{c}-0.0070 \\
(-1.22)\end{array}$ \\
\hline NAID $\times \mathbb{1}\{$ High DORCA $\}$ & $\begin{array}{c}-0.0027^{* * *} \\
(-3.30)\end{array}$ & $\begin{array}{c}-0.0372 \\
(-1.44)\end{array}$ & $\begin{array}{c}0.0098^{* *} \\
(2.31)\end{array}$ & $\begin{array}{c}-0.0264 \\
(-1.40)\end{array}$ & $\begin{array}{c}-0.0001 \\
(-0.43)\end{array}$ & $\begin{array}{l}\text { N.A. } \\
\text { (N.A.) }\end{array}$ \\
\hline$N$ & \multicolumn{2}{|c|}{8990} & \multicolumn{2}{|c|}{2232} & \multicolumn{2}{|c|}{5301} \\
\hline
\end{tabular}

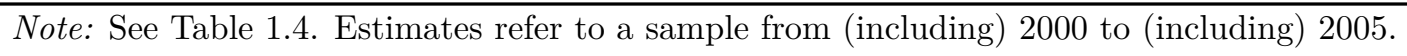


Third-country effects of development aid on sectoral exports

Table 1.8 DORCA (Dis-)Advantage - post 2005

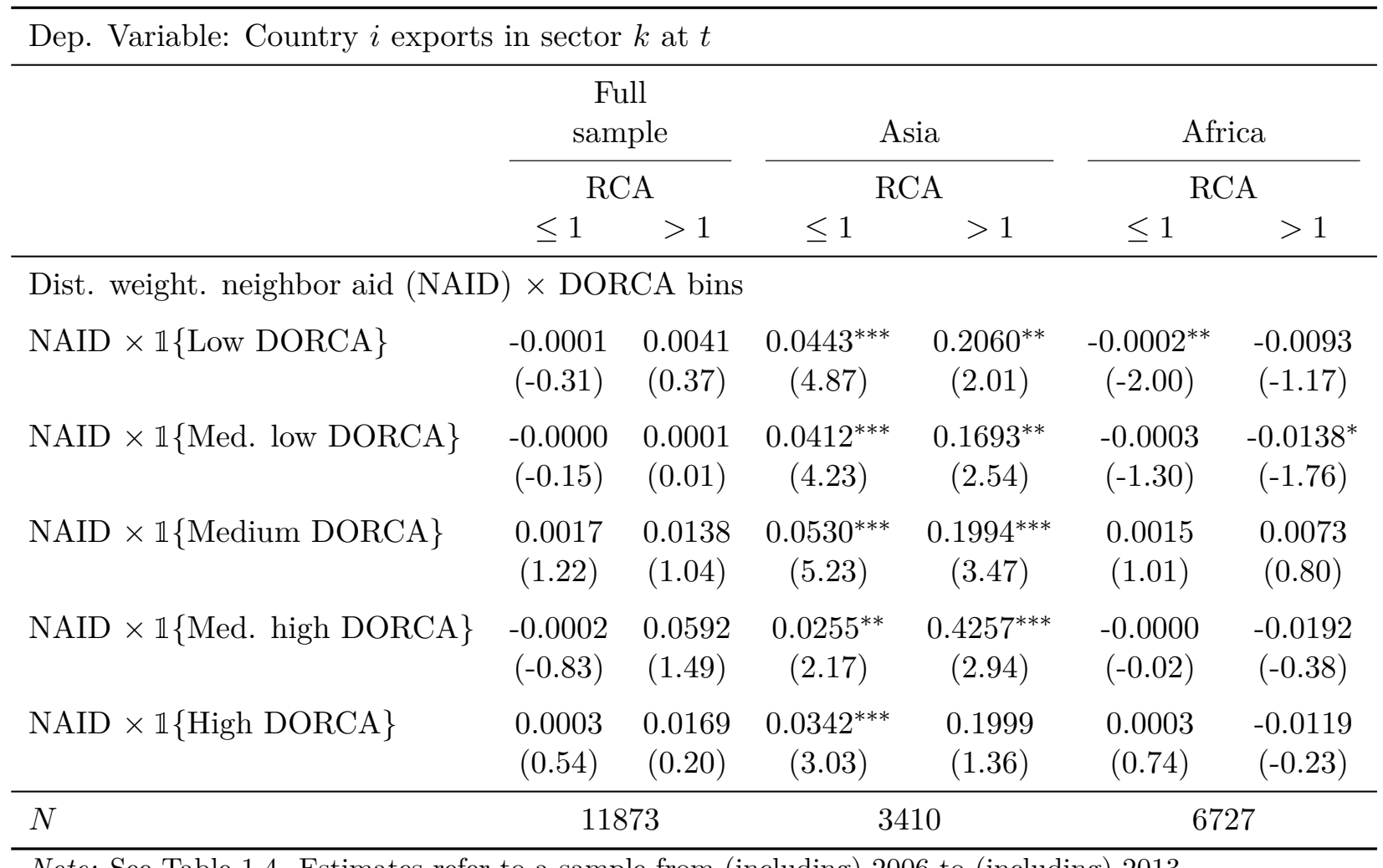

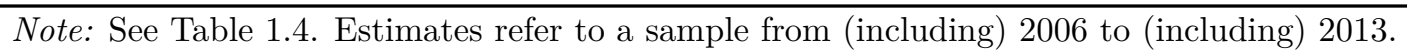


Third-country effects of development aid on sectoral exports

\subsection{Conclusion}

In this paper, we study heterogenous third-country effects of aid on sectoral exports of low and lower middle income countries depending on sectoral product sophistication. Building on the theoretical framework by Trionfetti (2017), we show that aid should lead to a shift in regional exports towards goods in which donors have a comparative advantage if some general assumptions are met. In order to test this, we construct an index called DORCA, which measures to what extent donors enjoy a comparative advantage in a given product. Empirically, the prediction of the model is only borne out for Asian countries, and only if the countries enjoy a comparative advantage in the product in question. The role of the country's own comparative advantage is in line with the model, as countries with an existing comparative advantage will find it easier to meet additional demand. We hypothesize that the reason why the pattern does not materialize in Africa is due to a relatively high level of regional trade costs that is less weakly correlated with distance than in Asia. What is more, applying a sample-split we find that the pattern found in Asia is driven by the post-2005 period. This period was characterized by important changes in the development policy agenda following the Paris Declaration on Aid Effectiveness and other high-level development policy fora meetings. Results hold when applying several robustness checks including a control function approach to address endogeneity.

In our view, these results are relevant for current development policy in a number of ways. First, we demonstrate the potential importance of third-country effects, when assessing the effectiveness of development aid, although, as for now, they only seem to materialize in Asia. The existence of third-country effects also underscores the importance of regional approaches to development policies. This if of particular relevance as the results on the country level are leaning towards insignificant effects of aid on growth for the recipient itself (e.g., Doucouliagos and Paldam, 2008; Dreher and Langlotz, 2017).

However, note that we do not think that the patterns we document are a necessary outcome of a mechanistic relationship. Our regional subsample estimations, which support the predicted pattern for Asia and refute the hypothesis for Africa, are cases in point. It is in accordance with the model, that if regional trade costs are too high compared to trade costs vis-à-vis donors the pattern should not materialize. Thus, several factors including infrastructure, regulation, informal trade barriers, and supply chain governance might dampen or reinforce third-country effects. We leave a further assessment of those channels for future research. 
Third-country effects of development aid on sectoral exports

\section{A Data Sources}

\begin{tabular}{|c|c|c|c|}
\hline Variable Name & Description & $\begin{array}{l}\text { Years Avail- } \\
\text { able }\end{array}$ & Source \\
\hline Gross Exports & $\begin{array}{l}\text { Gross Exports on the sectoral level } \\
\text { (ISIC Rev. 3) reported by exporter. }\end{array}$ & $2000-2013$ & WITS (2018) \\
\hline Neighbor aid & $\begin{array}{l}\text { Own estimation based on distance and } \\
\text { net aid received / given. }\end{array}$ & $2000-2013$ & $\begin{array}{l}\text { Head et al. }(2010) \\
\text { and OECD }(2015)\end{array}$ \\
\hline Market Potential & $\begin{array}{l}\text { Own estimation based on distance and } \\
\text { GDPs of potential partners. }\end{array}$ & 2000-2013 & $\begin{array}{l}\text { World } \\
(2018 \mathrm{~d})\end{array}$ \\
\hline PRODY & $\begin{array}{l}\text { Own estimation based on GDPs and } \\
\text { export data. }\end{array}$ & 2000-2013 & $\begin{array}{lr}\text { World } & \text { Bank } \\
\left(\frac{2018 \mathrm{~d})}{2018)} \text { and }\right. & \text { WITS } \\
\end{array}$ \\
\hline DORCA & $\begin{array}{l}\text { Own estimation based on aid and ex- } \\
\text { port data. }\end{array}$ & $2000-2013$ & \begin{tabular}{|l|l} 
OECD & $(2015)$ and \\
WITS & $(2018)$
\end{tabular} \\
\hline WDORCA & $\begin{array}{l}\text { Own estimation based on aid and ex- } \\
\text { port data using distance weights. }\end{array}$ & 2000-2013 & 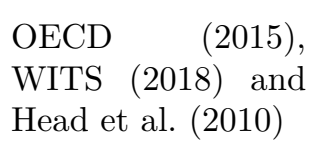 \\
\hline RCA & $\begin{array}{l}\text { Revealed comparative advantage } \\
\text { based on export data. }\end{array}$ & 2000-2013 & WITS (2018) \\
\hline
\end{tabular}

Table A.1 Countries in Sample

A. Low Income Exporters (Recipients)

$\begin{array}{llll}\text { Afghanistan } & \text { Eritrea } & \text { Mali } & \text { Tanzania } \\ \text { Benin } & \text { Ethiopia } & \text { Mozambique } & \text { Togo } \\ \text { Burkina Faso } & \text { Guinea } & \text { Nepal } & \text { Uganda } \\ \text { Burundi } & \text { Guinea-Bissau } & \text { Niger } & \text { Zimbabwe } \\ \text { Cambodia } & \text { Madagascar } & \text { Rwanda } & \\ \text { Central African Republic } & \text { Malawi } & \text { Sierra Leone } & \end{array}$

B. Lower middle Income Importers (Recipients)

\begin{tabular}{llll} 
Armenia & Ghana & Moldova & Sri Lanka \\
Bangladesh & Guatemala & Morocco & Swaziland \\
Bolivia & Honduras & Myanmar & Ukraine \\
Cameroon & India & Nicaragua & Vietnam \\
Congo, Rep. & Indonesia & Nigeria & Yemen \\
Cote d'Ivoire & Kenya & Pakistan & Zambia \\
Egypt, Arab Rep. & Kyrgyz Republic & Papua New Guinea & \\
El Salvador & Lesotho & Philippines & \\
Georgia & Mauritania & Senegal & \\
\hline
\end{tabular}

Note: Income groups according to World Bank definitions 
Third-country effects of development aid on sectoral exports

\section{B Control Function Approach}

Table A.2 Synthetic Aid - First Stage

\begin{tabular}{|c|c|c|c|}
\hline & $\begin{array}{c}\text { Full } \\
\text { sample }\end{array}$ & Asia & Africa \\
\hline \multicolumn{4}{|l|}{ IV First stage: Synthetic Aid } \\
\hline Synthetic NAID $D_{\mathrm{i}, \mathrm{t}}$ & $\begin{array}{c}3.2401^{* * *} \\
(1.1404)\end{array}$ & $\begin{array}{c}1.1469^{* * *} \\
(0.0992)\end{array}$ & $\begin{array}{l}6.4878^{* *} \\
(2.8620)\end{array}$ \\
\hline Kleibergen-Paap under-ID pval & 0.0038 & 0.0003 & 0.0322 \\
\hline Kleibergen-Paap weak ID Fstat & 8.072 & 133.664 & 5.139 \\
\hline$N$ & 673 & 182 & 388 \\
\hline \multicolumn{4}{|c|}{$\begin{array}{l}\text { Note: } t \text { statistics in parentheses. }{ }^{*} p<0.10,{ }^{* *} p<0.05,{ }^{* * *} p<0.01 \text {. The construction of } \\
\text { distance weighted neighbor aid is described in Section } 1.3 \text {. All regressions include exporter and } \\
\text { year fixed effects. All regresions control for the exporters' market potential variable constructed } \\
\text { as distance weighted GDP in export markets as further control variable in year } t \text {. }\end{array}$} \\
\hline
\end{tabular}

Table A.2 depicts the results for the first stage of our instrument. While the FStatistics are below the rule of thumb threshold of 10 in the full and African sample, the instrument is sufficiently strong for the Asian subsample. As the instrument works sufficiently well for the Asian sample, in which we find our main results, we consider the instrument and the corresponding control function approach as sufficiently suitable to address the potential endogeneity concerns in our setting.

\section{C Segment Specific Trends}

Parts of the increase in aid in Figure A.1 are due to changes in the international agenda on development finance. Most notably, throughout our sample period the volume of "Aid for Trade" (AfT) increased steadily (WTO, 2005; Bassnet, 2011; Lammersen and Roberts, 2015). AfT comprises different types of development aid that are intended to facilitating trade. Insofar as the trend is driven by AfT or the reduction of tied aid, we would in accordance with the model expect corresponding trends in exports. Controlling for linear trends will likely capture part of these induced increases in aid and will make it harder to observe the expected pattern. Despite that, the results in Table A.3 indicate that the main findings are robust to this modification. In line with Table 1.4 we find significant positive increases of comparable size across the sectors with $R C A \leq 1$. Estimations for sectors with $R C A>1$ indicate coefficients that are 
again of a larger magnitude in the third, fourth and fifth WDORCA bin ${ }^{15}$

Figure A.1 Trends in Aid and Trade
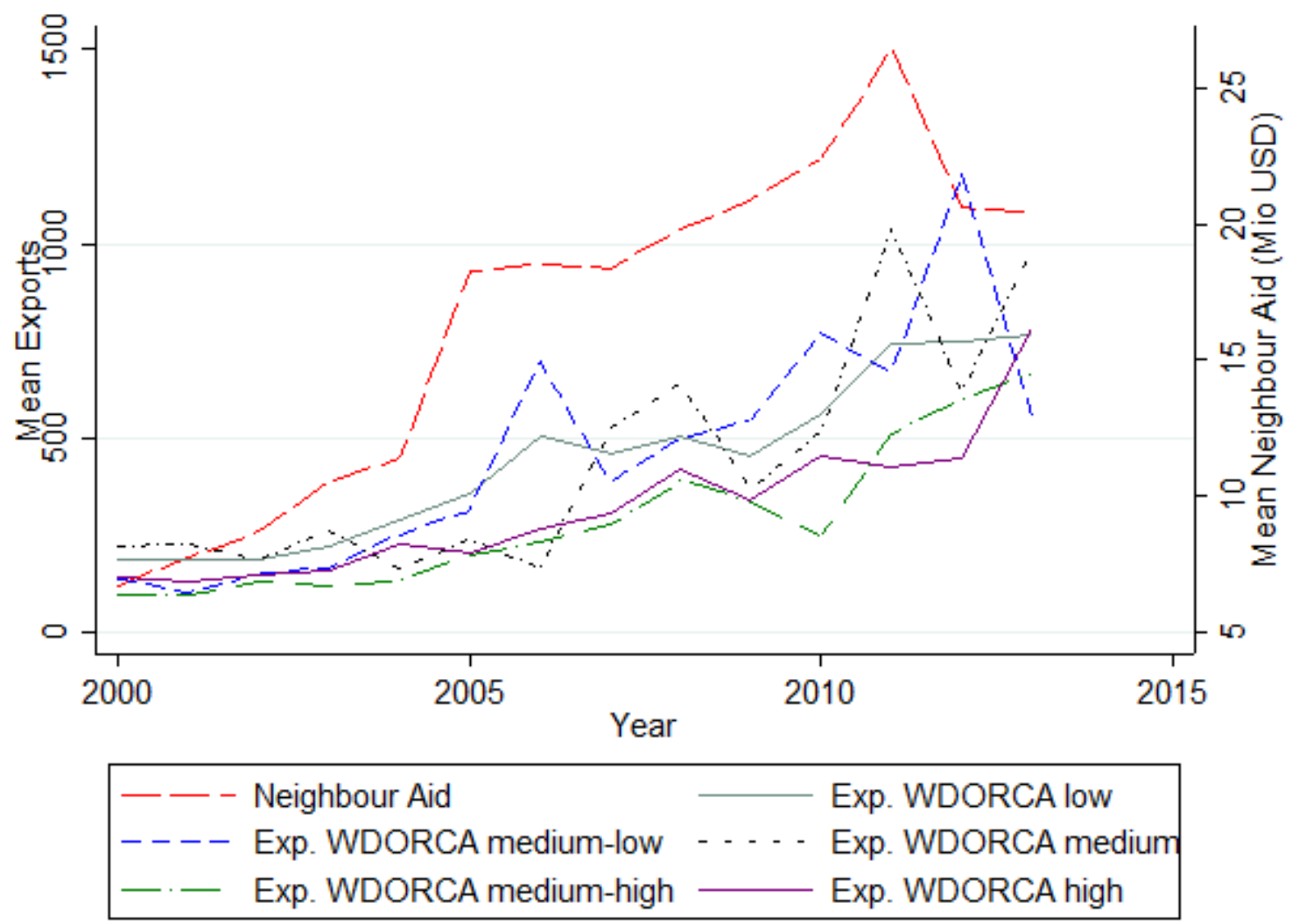

Source: Authors' calculation based on WITS and OECD data.

Note: Averages across quantiles and time.

\footnotetext{
${ }^{15}$ We also estimated results using sector-specific linear time trends and in line with the methodological caution by Christian and Barrett (2017) using segment-specific non-linear trends. Results are largely unchanged and available from the authors upon request.
} 
Third-country effects of development aid on sectoral exports

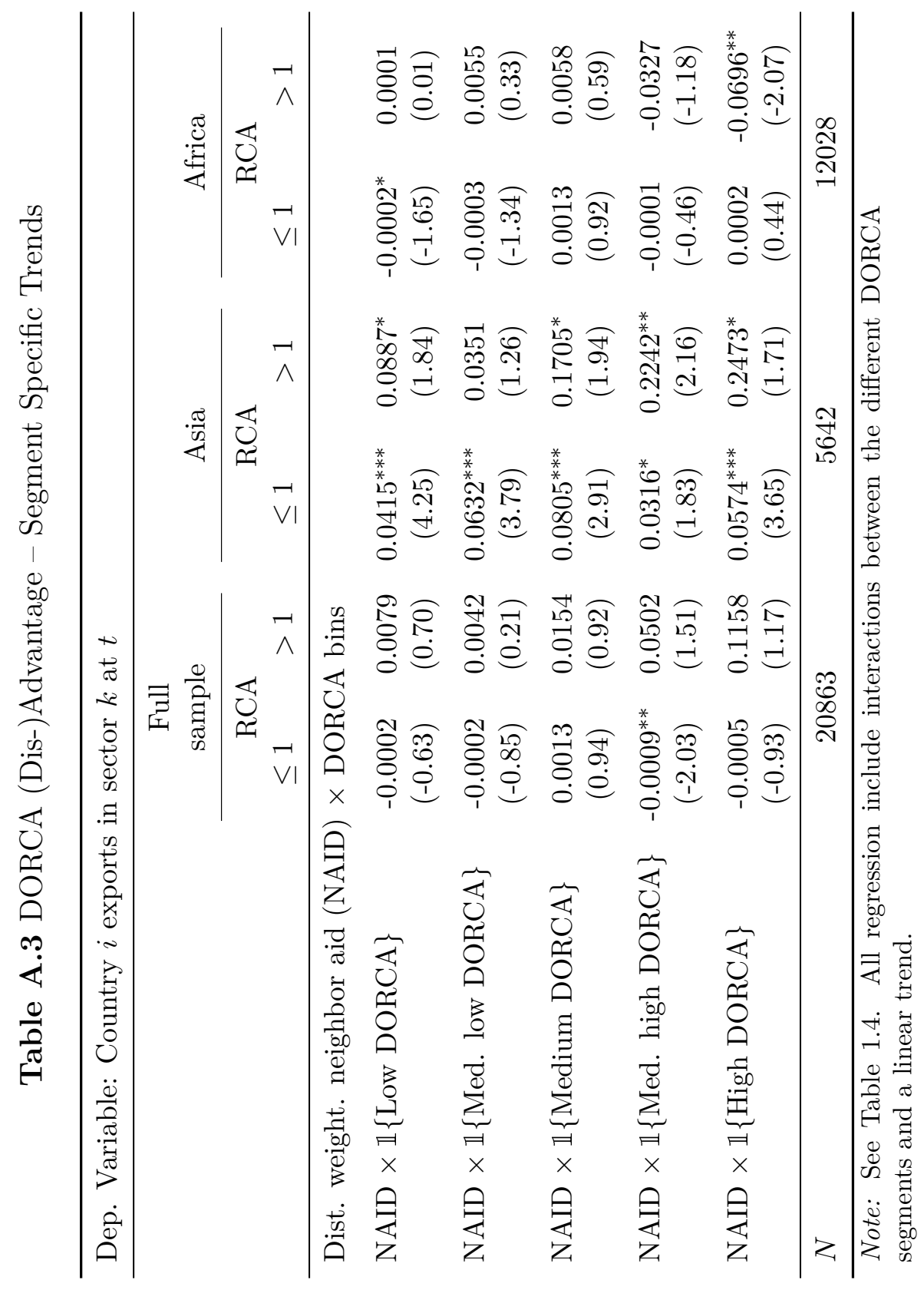


Third-country effects of development aid on sectoral exports

\section{D Tables and Figures}

Figure A.2 Average WDORCA Scores

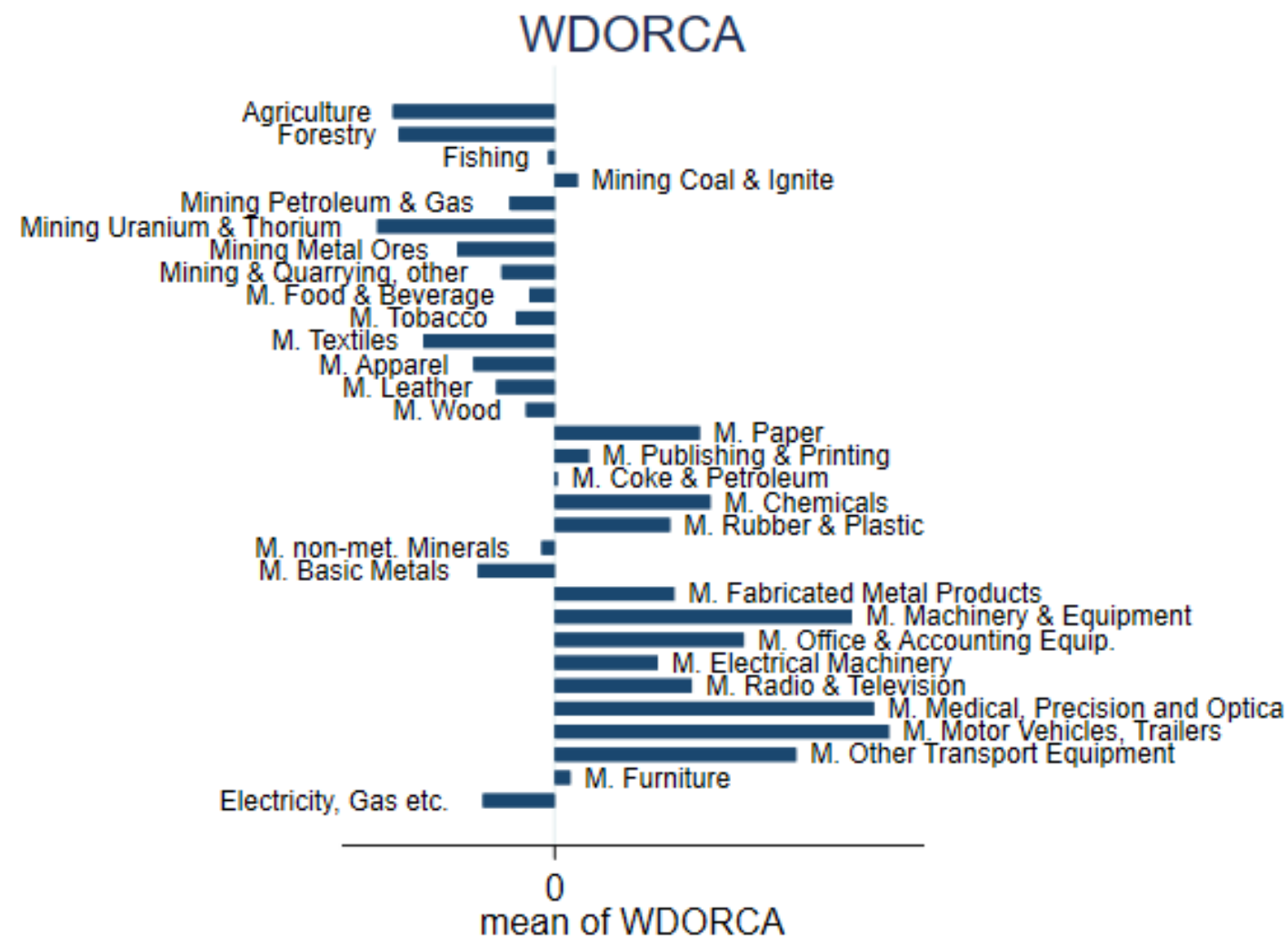

Source: Authors' calculation based on WITS and OECD data.

Note: Averages across countries and time.

The picture from Figure 1.1 changes slightly when we look at the weighted DORCA, which is depicted in Figure A.2. Interestingly, when taking distance into account the scores for the manufacturing of food products and tobacco point to an advantage for recipients. This is due to a smaller difference in RCAs between donor and recipient countries that is overcompensated by bilateral distances. This value indicates that while most recipient countries do not have an RCA in these products globally, they could be competitive in regional markets. 
Third-country effects of development aid on sectoral exports

Table A.4 WDORCA Baseline

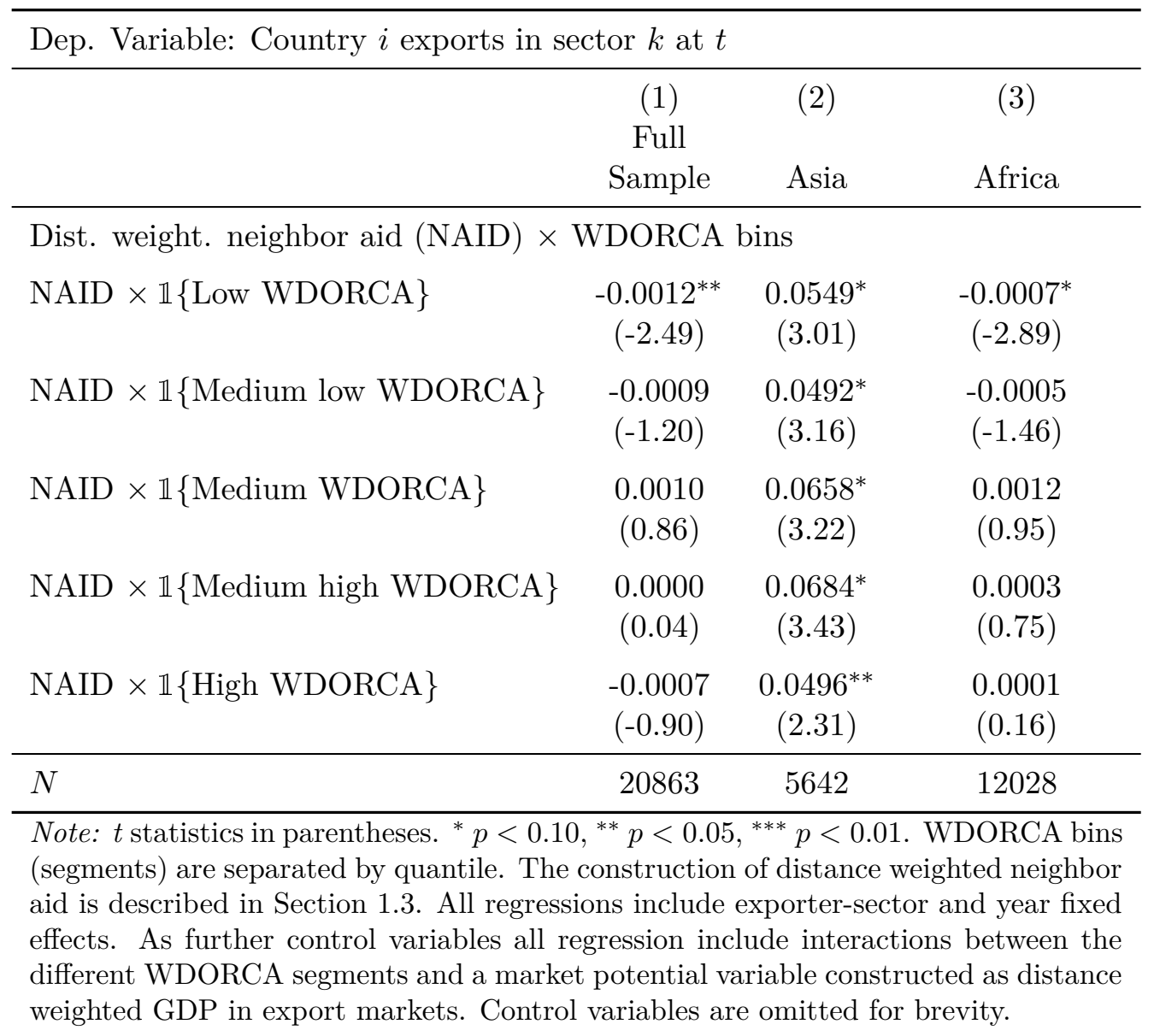


Third-country effects of development aid on sectoral exports

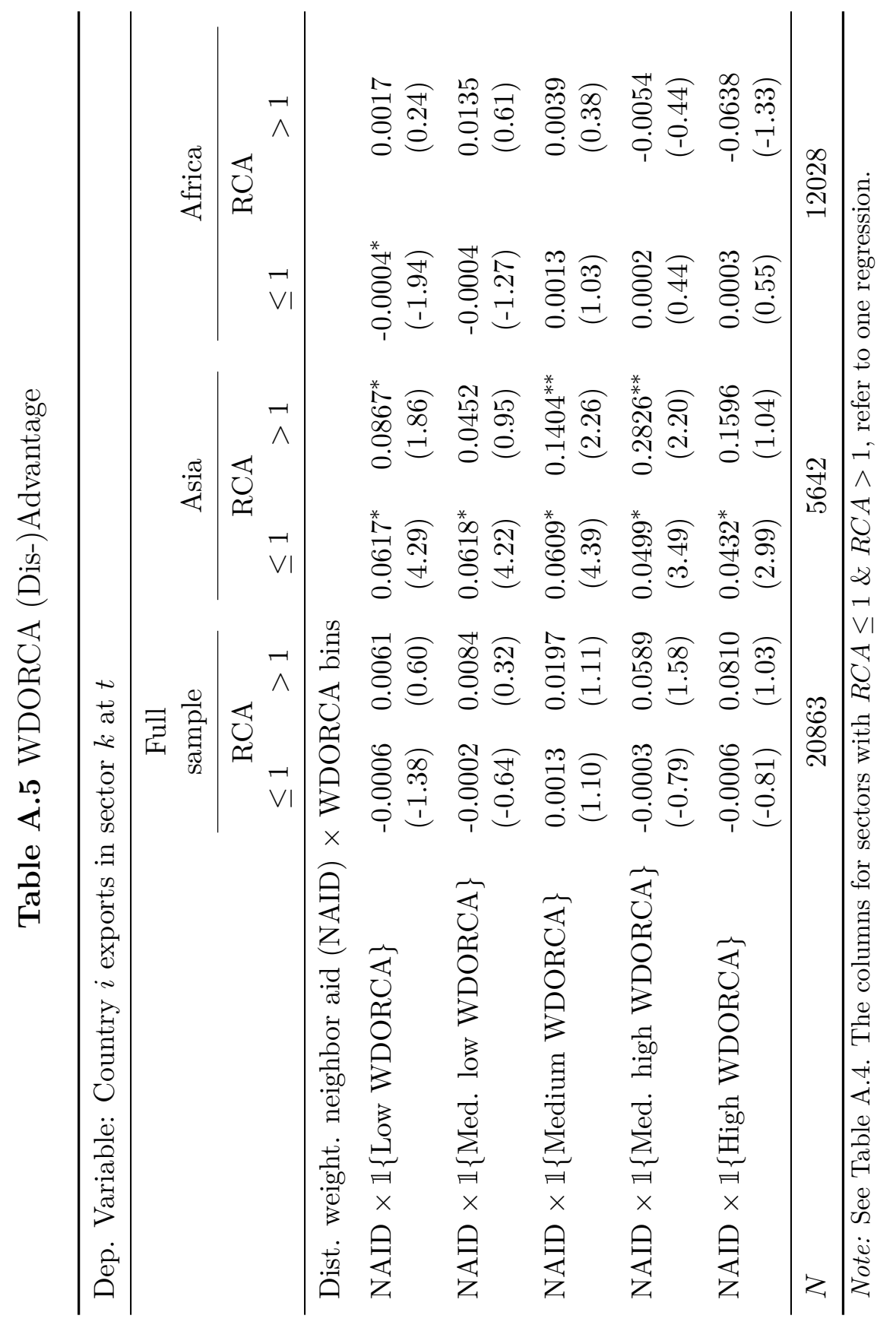


Third-country effects of development aid on sectoral exports

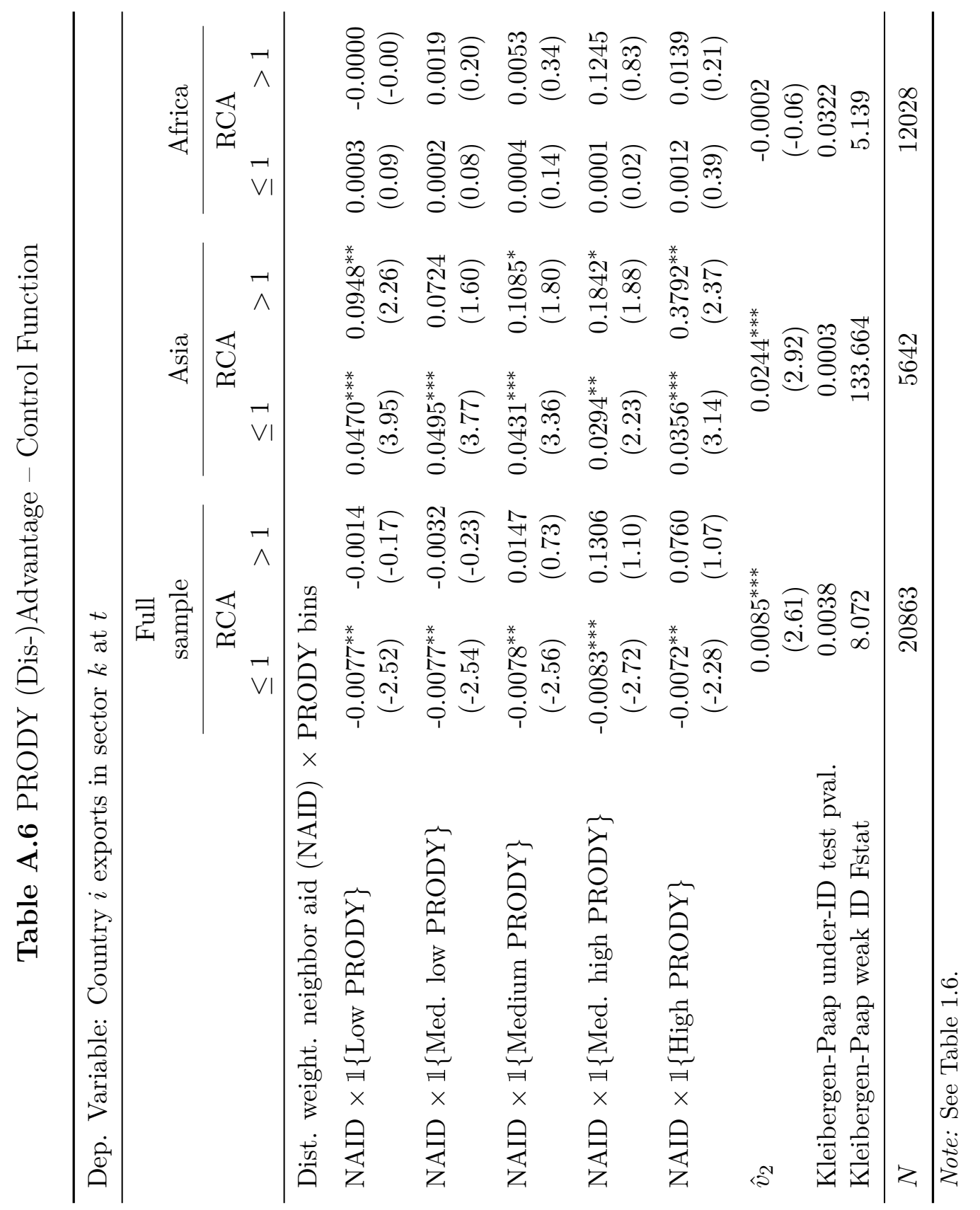


Third-country effects of development aid on sectoral exports

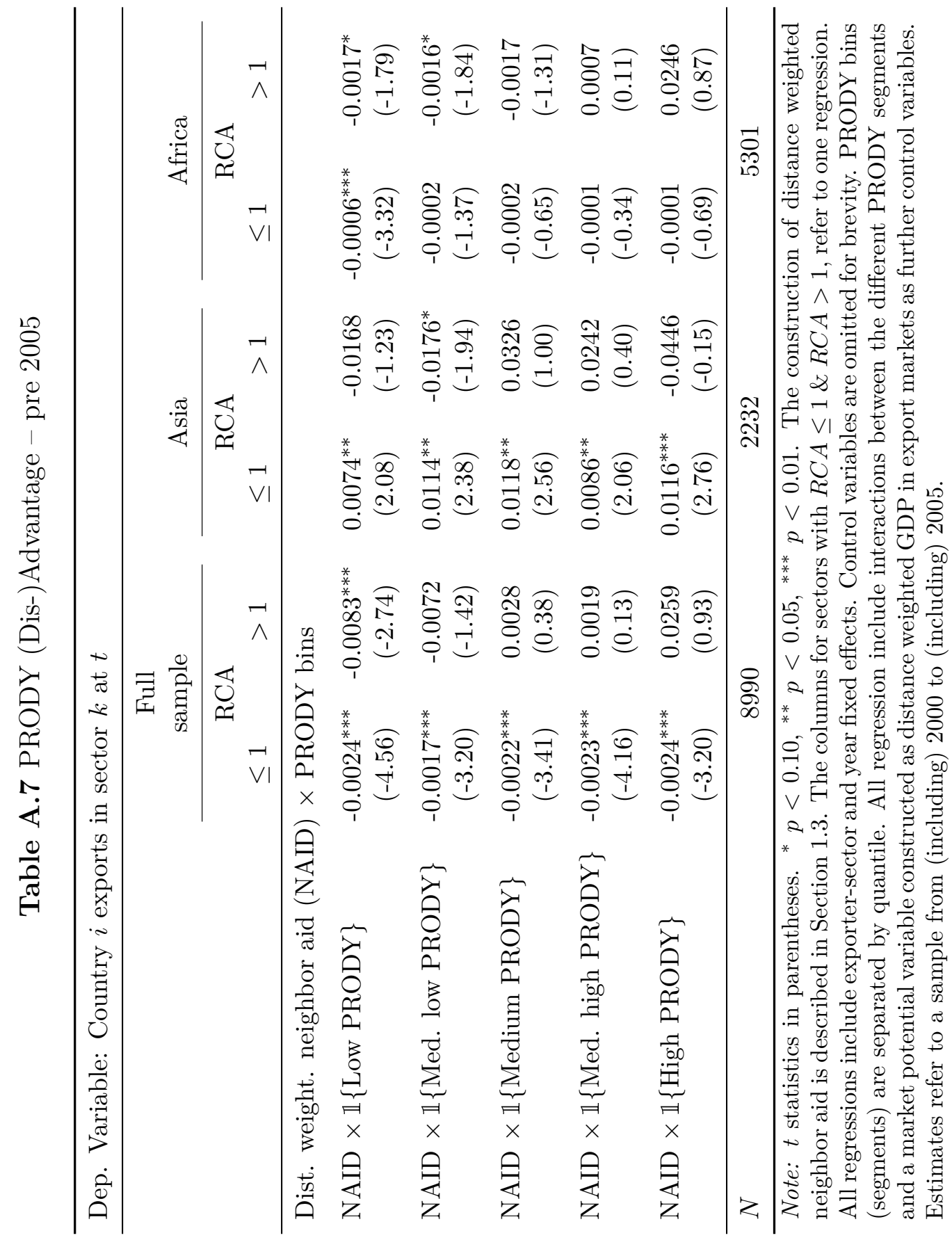


Third-country effects of development aid on sectoral exports

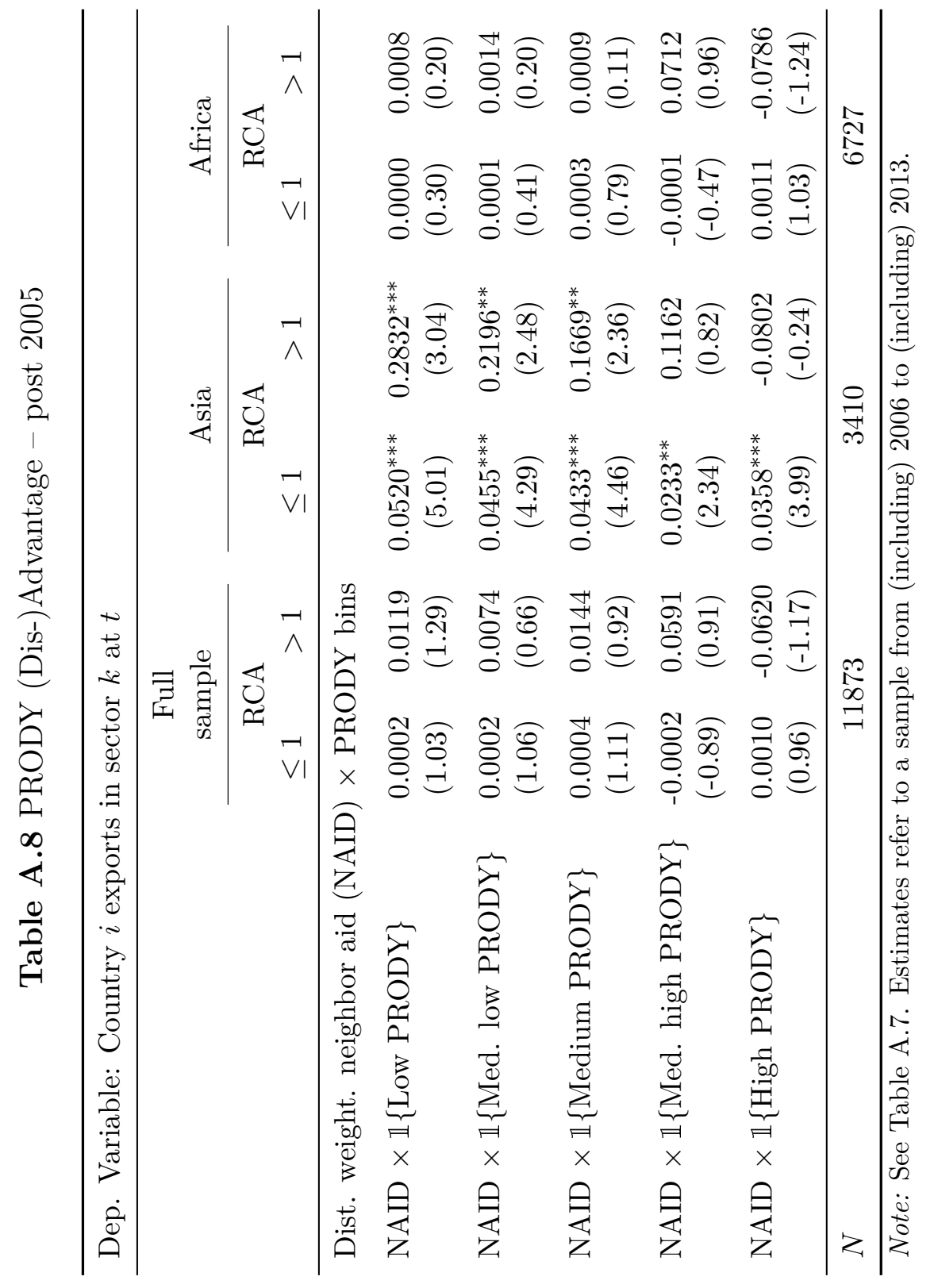




\title{
Chapter 2
}

\section{Unequal Gains from Trade The Role of Political Biases}

\author{
Single Authored
}

\begin{abstract}
Agriculture constitutes the main employment base for several African countries. However, political distortions reduce its potential for inclusive and pro-poor growth. Theory and empirics are ambiguous whether ethnic and regional affiliations with the current national leader have positive or negative effects on gains from agricultural commodity trade. I combine innovative geocoded data to distinguish ethnic and regional political affiliation to resolve these existing ambiguities. Results indicate that ethnic affiliation positively affects gains from trade, while this pattern is further enhanced for coethnics living in the leader's birth region. The findings suggest that leaders target coethnics via subsidies or a preferential tax treatment rather than via the provision of public goods. Democratic institutions reduce but do not offset this pattern.
\end{abstract}



Unequal Gains from Trade

\section{$2.1 \quad$ Introduction}

African countries are often considered in the public perception as victims of their natural resource endowments, causing inequality and distributional conflict. While minerals typically only benefit a narrow elite, the agricultural sector has theoretically a high potential for more inclusive growth as it employs the majority of African workers (ILO, 2013). Still, research indicates low agricultural productivity and limited gains for small holders (Zylberberg, 2013; McMillan et al., 2014). A comprehensive literature suggests various politico-economic constraints, which contribute to disincentives and unsustainable policies (Lipton, 1977; Binswanger and Deininger, 1997; Anderson et al., 2013).

As an example, consider the redistributive policies of Kenya's former president Daniel arap Moi. Once arap Moi came into power in 1978, he redistributed resources from the successful coffee growers, who supported his predecessor Jomo Kenyatta, to benefit grain producers in his home region (Bates, 1989). More recently, the government of Malawi's former president Bingu wa Mutharika implemented a large-scale support program for smallholders, which was appraised as a model for an "African Green Revolution" (Denning et al., 2009). Yet, there are accounts that the president directed higher fertilizer subsidies to coethnic Lomwe people in order to garner political support after 2004's elections (Abman and Carney, 2018). In this vein, Dorward and Chirwa (2011) indicate inefficient targeting during the 2005/2006 period, which reduced the program's potential for poverty reduction.

Both examples point to a more general pattern in political targeting, leading to biases in gains from agricultural commodity trade. Previous research provides some rationale to why bad economics does not necessarily have to be bad politics as targeted transfers can ensure political survival. Both theory and empirics are ambiguous about the direction of those political biases. Bates and Block (2009) state that, in the ethnically diverse countries of Africa, policy makers would generate support by targeting farmers of their home region via favorable redistribution. Contrastingly, Kasara 2007) argues that leaders would counter-intuitively impose higher taxes on coethnic farmers as they would have better monitoring capacities within their home region.

Against this background, this paper discerns the existing ambiguity in the literature by distinguishing regional and ethnic biases in gains from trade, linking high-resolution geospatial data to surveys for 33 African countries. This way, I examine if localized shifts in producer prices heterogeneously contribute to poverty reduction depending on individual residence and ethnicity. More specifically, the analysis considers whether biases are driven by broader (e.g., via public goods) or more specific targeting (e.g., via taxation). One of the challenges is that political biases and local poverty could directly influence local prices. Using an interaction of global commodity prices with local productive capacities allows me to exploit arguably exogenous variation in potential gains from trade. Moreover, a placebo test reduces concerns that regional or ethnic prosperity is laying the foundation for political power and, hence, reversely explains the pattern. I rule out several alternative explanations based on further robustness tests.

The empirical analysis demonstrates that ethnic biases in gains from trade exist and 
are more nuanced in the leader birth region. Coethnics who reside in the birthplace of their leader gain four to five times more than other people from the same ethnicity. For the former group a change in global producer prices by one standard deviation decreases the probability of being poor by $8 \%$ - a sizeable effect. Yet, there are no disproportional gains for people of other ethnicities residing in the leader birth region. This would not be in line with broader targeting via public goods (e.g., infrastructure) and suggests rather an exclusionary targeting via subsidies or taxation in line with the Malawian experience. Based on survey data, I provide some suggestive evidence that the main beneficiaries - coethnics who reside in the leader birth region - have indeed more positive perceptions regarding tax collection than other groups. Previous literature on political favoritism suggests the "value of democracy" (Burgess et al. 2015) for curbing discretionary transfers. The data reveal that democracies can reduce, though not completely resolve, this form of political distortions.

The paper contributes to the open question in the favoritism literature of whether ethnic affiliation of farmers increases or reduces gains from trade. This way, the findings add to the ongoing debate on globalization and inequality. Moreover, they contribute to comparative political economics, stressing the value, but also the limits, of democratic institutions for a more equal distribution of economic gains. The following section describes the different strands of research in order to provide a picture of existing gaps and complementarities in the literature.

\subsection{Literature}

African economies are known for their large wealth of natural resources, which has been identified as more of a curse than a blessing in the literature on resource-driven conflict, corruption and Dutch Disease (Van der Ploeg, 2011) 1 In contrast, agriculture employs on average the majority of African workers, which theoretically increases its potential to affect inclusive and pro-poor growth. The high labor intensity of agriculture ensures that windfall gains are not easily captured by elites, as is usually the case for natural resources or development aid. Although agriculture's share in national GDP is larger than in advanced economies, it is not proportional to the workforce it employs and is, hence, plagued by low productivity. Thus, industrialization could be considered as an alternative growth strategy, especially as recent work indicates the importance of industrial upgrading for economic development (e.g., Hausmann et al., 2007). Despite strong theoretical arguments for structural change (Lewis, 1954; Gollin, 2014), recent studies demonstrate an employment shift to the agricultural sector, increasing rather than decreasing its economic salience (McMillan et al., 2014; Rodrik, 2016).

Against this background, the global integration of agricultural value chains offers ample potential for growth if institutions are in place that promote productivity and an equitable distribution of gains (Zylberberg, 2013; Gereffi and Fernandez-Stark, 2016).

\footnotetext{
${ }^{1}$ Dutch disease refers to resource export induced appreciations of the exchange rate, which lead to reductions of competitiveness in other sectors.
} 
For this reason, the paper is concerned with understanding existing barriers for agricultural commodity trade rather than examining drivers of structural change. In this regard, comprehensive literature suggests various politico-economic constraints which contribute to disincentives and unsustainable policies (Lipton, 1977, Anderson et al. 2013).

As a result, agriculture is highly politicized, making it susceptible to political distortions and favoritism (Binswanger and Deininger, 1997). Although stressing different aspects of the phenomenon, clientelism, patronage, and cronyism can be connected to one strand of the favoritism literature.

Politico-economic theory can rationalize the behavior of policy makers. Bueno De Mesquita (2005) argues that each polity has a group that decides who is the leader of the state - the selectorate. Leaders, who want to stay in power, will have to focus on their selectorate via the provision of benefits. Depending on the effective selectorate in autocracies or democracies, those benefits will be provided via private (small selectorate) or public goods (large selectorate). This form of discretionary redistribution can be summarized as favoritism. Yet, favoritism and vote-buying are by no means exclusive to Africa and there are various accounts from different world regions and political systems (Baskaran et al., 2015; Englmaier and Stowasser, 2017; Curto-Grau et al. 2018). Thus, favoritism can be considered as an "axiom of politics" (De Luca et al. 2018).

It is fair to assume that the role of ethnic cleavages is particularly strong in African states due to its history. Especially, the arbitrary partitioning of states by the colonial powers united people with very diverse identities within unitary nation states (e.g., Alesina et al., 2011; Michalopoulos and Papaioannou, 2016). Thus, after independence, the political landscape was structured strongly along ethnic lines (Van de Walle, 2003). For this reason, strong patronage networks evolved, which have been both highlighted in quasi- and experimental research (e.g., Vicente and Wantchekon, 2009, Keefer and Khemani, 2014).

The literature distinguishes mainly between ethnic and regional favoritism. ${ }^{2}$ With respect to regional favoritism, Hodler and Raschky (2014) show that the birth region of the present chief executive of a country experiences higher night light luminosity, which would proxy local wealth. As a striking example, they describe the rise and fall of Mobutu's ancestral village Gbadolite, which included a marvelous palace during Mobutu's kleptocratic reign ${ }^{3}$

Franck and Rainer (2012) show that this pattern extends to ethnic favoritism. Using data from the Demographic and Health Surveys, they find that ethnic favoritism manifests in worse health and education outcomes for people from ethnicities other than the chief executives'. Regarding the channels of discretionary resource allocation, Hodler and Raschky (2014) document the contribution of oil extraction for regional

\footnotetext{
${ }^{2}$ Regarding agriculture, the well-documented urban-rural bias (Lipton, 1977; Bezemer and Headey, 2008) comes to mind. Although there is partly an overlap between those literatures, heterogeneity analysis indicates that this divide cannot fully explain the biases described subsequently.

${ }^{3}$ The Guardian (2015), last accessed September 21, 2018.
} 
public good provision. Dreher et al. (2016) indicate the discretionary allocation of development finance on a subnational level. This form of favoritism can be considered as particularly salient due to the fungibility of foreign assistance (Pack and Pack, 1993$)$. Bommer et al. (2018) show that biased resource allocation even extends to humanitarian aid. All those studies have in common that they examine how windfall gains are discretionarily reallocated via private and public goods along the lines of the selectorate theory. As argued before, agricultural commodity trade might follow a distinct pattern of favoritism caused by higher labor intensity and geographical dispersion of farmers ${ }^{4}$

First, policy makers could target their selectorate via favorable trade policies. On the one hand, policy makers can protect sectors from import competition via import tariffs. On the other hand, political leaders have some leeway to redistribute gains by imposing export tariffs on goods which are not produced by their support group. However, Anderson et al. (2013) show a recent decline of those trade distortions. The structural adjustment policies of the major international financial institutions - the IMF and the World Bank - as well as the membership of several African states in the WTO have substantially reduced the room for discretion.

Second, policy makers could also target their support group via regional public goods, including infrastructure, electricity provision or irrigation systems. Deficient infrastructure is a major constraint for African export performance (Limao and Venables, 2001; Page, 2012) and inequality (Bluhm et al., 2018). Especially, roads are highly salient for commodity trade, as the quality of the road network determines both travel time and fuel use (Storeygard, 2016). In this context, based on an impressive digitization of Michelin atlases, Burgess et al. (2015) provide evidence that the home regions of Kenyan politicians benefited disproportionally from road construction. However, the spatial dispersion of farmers constrains the potential of targeted public goods allocation due to potential spill-overs to people from other groups and increasing costs (Ejdemyr et al., 2018).

Third, policy makers can influence the gains from trade via domestic redistribution in the form of subsidies and taxes like in the previously named example of fertilizer vouchers in Malawi. In this regard, Bates and Block (2009, 2010) suggest that leaders would reduce the effective tax burden for farmers who grow crops in their home region. A case in point is Félix Houphouët-Boigny, who was the president of Ivory Coast from 1960 to 1993. Working as a planter before his medical and political career, he had sympathy for the agricultural sector, which he supported by imposing lower taxes on cash crops (e.g., cocoa and coffee). His agriculture-based development model for Ivory Coast can be understood against this background.

This is contrasted by empirical work of Kasara (2007). Linking crops with the home regions of political executives, she suggests a counter-intuitive pattern of a higher agricultural tax burden for the ethnic group of the leader. She rationalizes this outcome along the lines of a political-economy model by Padró i Miquel (2007) where, due to the

\footnotetext{
${ }^{4}$ This would be analogous to the heterogeneous effects of agricultural and mineral commodities on conflict dynamics as suggested by Dube and Vargas (2013).
} 
lack of political competition, an extractive coethnic leader is preferred over an extractive leader who favors other groups. This equilibrium is consolidated as farmers have low capacities for collective action due to their geographical dispersion (Anderson et al. 2013). Despite being taxed more heavily, farmers sharing the leader's ethnicity would benefit from other transfers (e.g., education and health benefits) and also draw further "psychic benefits" from knowing that a coethnic is in power. Above that, leaders might have better capacities to monitor their coethnics in the home region.

In sum, while Bates and Block (2009) argue that affiliation with the leader would on average lead to favorable taxation, Kasara (2007) suggests an unfavorable tax treatment. One explanation for those contradicting expectations could be the lack of distinction of regional and ethnic affiliation. For instance, leaders might make use of monitoring capacities to extract higher rents from other ethnicities in their home region, while coethnics remain unaffected 5

Either form of (dis-)favoritism corresponds to a biased political system, and institutional change could reduce these inefficiencies (Bates and Block, 2013). First, when facing autocratic institutions, chief executives are less constrained in decision making North, 1991; Acemoglu et al., 2004). Second, time horizons of politicians are shorter in autocracies because turnover is inherently uncertain (Olson, 1993) ${ }^{6}$

On this basis, I can formulate the following three hypotheses:

Hypothesis 1 (H1) On average, coethnics of the leader will benefit disproportionally more than people from other ethnicities if prices for agricultural goods in their region increase. This will be even more so if they reside in the executive's home region as the feasibility of targeting via public goods or additional transfers (taxes or subsidies) increases.

Hypothesis $2(\mathrm{H} 22)$ People from other ethnicities who reside in the leader's home region will not benefit disproportionally. Spatial proximity facilitates monitoring and, thus, discretionary transfers (taxation or subsidization).

Hypothesis 3 (H[3) Political institutions confine this bias and, hence, heterogeneous effects can be expected across autocratic and democratic systems.

Considering individuals rather than sticking to the unitary group level of regional and ethnic populations, allows me to disentangle those concepts and analyze how they influence the distribution of gains from trade. This assessment only recently became possible due to innovative subnational data, which I present subsequently.

\footnotetext{
${ }^{5}$ Although there are several accounts, which indicate the high geographic concentration of ethnic groups, a substantial portion of people lives outside of their homelands (see, e.g., Bommer et al. 2018).

${ }^{6}$ This would also be the case in a setting where leaders face a high risk of political turnover and try to extract as much rent as possible even if it reduces agricultural export competitiveness. Based on a political economy model, McMillan (2001) suggests that this setting might explain why short-term oriented politicians choose to "kill the golden goose," when facing an unstable political environment. Although autocracies can be surprisingly stable, the history of several African states is marked by various irregular leader exits (Posner and Young, 2007).
} 
Unequal Gains from Trade

\subsection{Data}

Thanks to growing scholarly efforts in environmental, economic and political sciences an increasing body of data is available on the subnational level. Obtaining geolocalized data on individual perceptions and economic well-being is still complicated for low and middle income economies as survey data are usually scarce and often only available on an aggregate level. Fortunately, more fine-grained data recently became available in the framework of the Afrobarometer Survey Program (Afrobarometer, 2018). This study uses data from six rounds of the Afrobarometer, which comprise more than 150,000 survey responses on individual perceptions from 34 countries and 544 subnational regions. Appendix Table B.1 depicts the sampled countries.7 Afrobarometer samples data randomly, but does not provide a panel structure of respondents. Thus, the study relies on repeated cross-sections for the years 1999 to 2015 with gaps. The database provides information on different socio-economic indicators along with perceptions on individual well-being as well as opinions on politics and security. To answer my research question, the data are used to obtain information on individual perceptions, respondents' ethnicity and the main outcome - poverty.

In line with the capabilities approach of Sen (1993) and its empirical application (e.g., Klasen, 2000, Bourguignon and Chakravarty, 2003; Alkire and Santos, 2014), I consider different dimensions of well-being. Following McGuirk and Burke (2017), I construct an index based on the five items in Afrobarometer which refer to poverty. The survey questions read "Over the past year, how often, if ever, have you or your family gone without: food to eat / clean water for home use / medicines or medical treatment / fuel to cook / cash income."8 These items are listed on a 1 ("never") to 5 ("always") scale and are aggregated into an unweighted poverty index. As this multi-dimensional poverty measure is not based on monetary values, it is not necessarily comparable to the World Bank's "1.90 dollar-a-day" poverty line. However, this issue gets mitigated by using country-period fixed effects as they account for national price levels. A further relevant concern arises due to the self-reported nature of the poverty index. Thus, I validated the poverty measure by correlating it with per capita expenditure from the World Bank's Living Standard Measurement Surveys (LSMS) for a limited subsample of countries (Malawi, Niger, Nigeria, Tanzania). Regions with a higher poverty index have a lower per capita expenditure. Results are depicted in Table B.19

This paper makes also use of Afrobarometer's rich data on individual perceptions

\footnotetext{
${ }^{7}$ The sample is highly diverse though, ranging from a $2 \%$ of agricultural employment share in Botswana to a $60 \%$ employment share in Sierra Leone (World Bank, 2017a). Subsequent analysis considers accounts for these differences via country-year fixed effects and heterogeneity analysis. Nonetheless, it is important to keep in mind that there is a distinct heterogeneity across African countries, when interpreting the effects.

${ }^{8}$ While round 1 (exclusively) and round 2 (also) ask for availability of electricity, rounds 3-6 switch to asking for availability of cooking fuel.

${ }^{9}$ Ideally, I would like to validate the main results using LSMS data. However, no data on ethnic affiliation were collected and analysis is confined to leader birth regions. Results qualitatively support subsequent findings on limited regional favoritism and are available upon request.
} 
in order to consider potential channels, specifically, regarding the support for taxes.

For the treatment indicator of interest, I employ data on commodity prices of five main cash crops cocoa, coffee, cotton, tea and tobacco (World Bank, 2018b; IMF, 2018). I chose these particular crops as they are among the most important African export commodities and play a smaller role for domestic consumption (Akiyama and Larson, 1994). In order to maintain statistical power but reduce susceptibility to outliers, monthly prices are averaged over biannual periods. Commodity prices are then combined with local land use indicators from Monfreda et al. (2008). For the latter data, Monfreda et al. use information from international and national censuses as well as satellite data to construct measures of land use. For this purpose, a gridded map of crop-specific and total land use is constructed in order to obtain shares for each crop. If no information was available land use data were imputed.

This localized producer price index (PPI) can be summarized as:

$$
P P I_{c r t}=\sum_{j=1}^{n} P_{j t} \times S_{c j r},
$$

where $P_{j t}$ is the price of good $j$ in period $t$, which is indexed for each product at 100 for the first period (July to December 1999). The global price of each commodity is then interacted with the local production capacity $S_{c j r}$ to grow commodity $j$ in the respective country-region $c r{ }^{10}$ I project the data on the level of first level administrative boundaries based on Hijmans et al. (2012) to match regional price effects to survey responses.

In order to examine the effects of favoritism, I obtain information if administrative regions correspond to the birth region of the recent political leader from Dreher et al. (2016). Using various databases, including Encyclopedia Britannica, CIDOB and Wikipedia, I extended their data for additional years.11 Data on democratic and autocratic polities are from Bjørnskov and Rode (2018), extending information from Cheibub et al. (2010).

Table 2.1 provides descriptive statistics on the main dependent and independent variables. The poverty indicator ranges from 0 to 25 , where 25 indicates the highest possible poverty incidence in all subcategories. Mean (median) poverty equals 10.7 (10). This corresponds to an intermediate poverty level where respondents indicate for every category that they would have gone in the past year "several times" without food, clean

Another potential indicator for regional economic well-being considered in recent scholarly work is night-light output. Although regional light intensity is arguably a viable measure for local economic activity, it is again hard to discern intra-group heterogeneity with this measure. Moreover, while lights might be well-suited to measure industrial productivity, it is questionable if this holds for agricultural output.

${ }^{10}$ Certainly, producer prices are correlated with the consumption side, which can influence individual well-being drastically (Bellemare, 2015, Hendrix and Haggard, 2015). Considering cash crops for the PPI reduces this issue slightly. Nonetheless, Appendix Table B.8 controls for a consumer price index. Subsequent results are qualitatively unchanged.

${ }^{11}$ Information were cross-validated by another coder. What is more, although Wikipedia is less reliable than other commercial services, errors can be considered as random noise. 
Figure 2.1 Poverty and Local Producer Price Indices

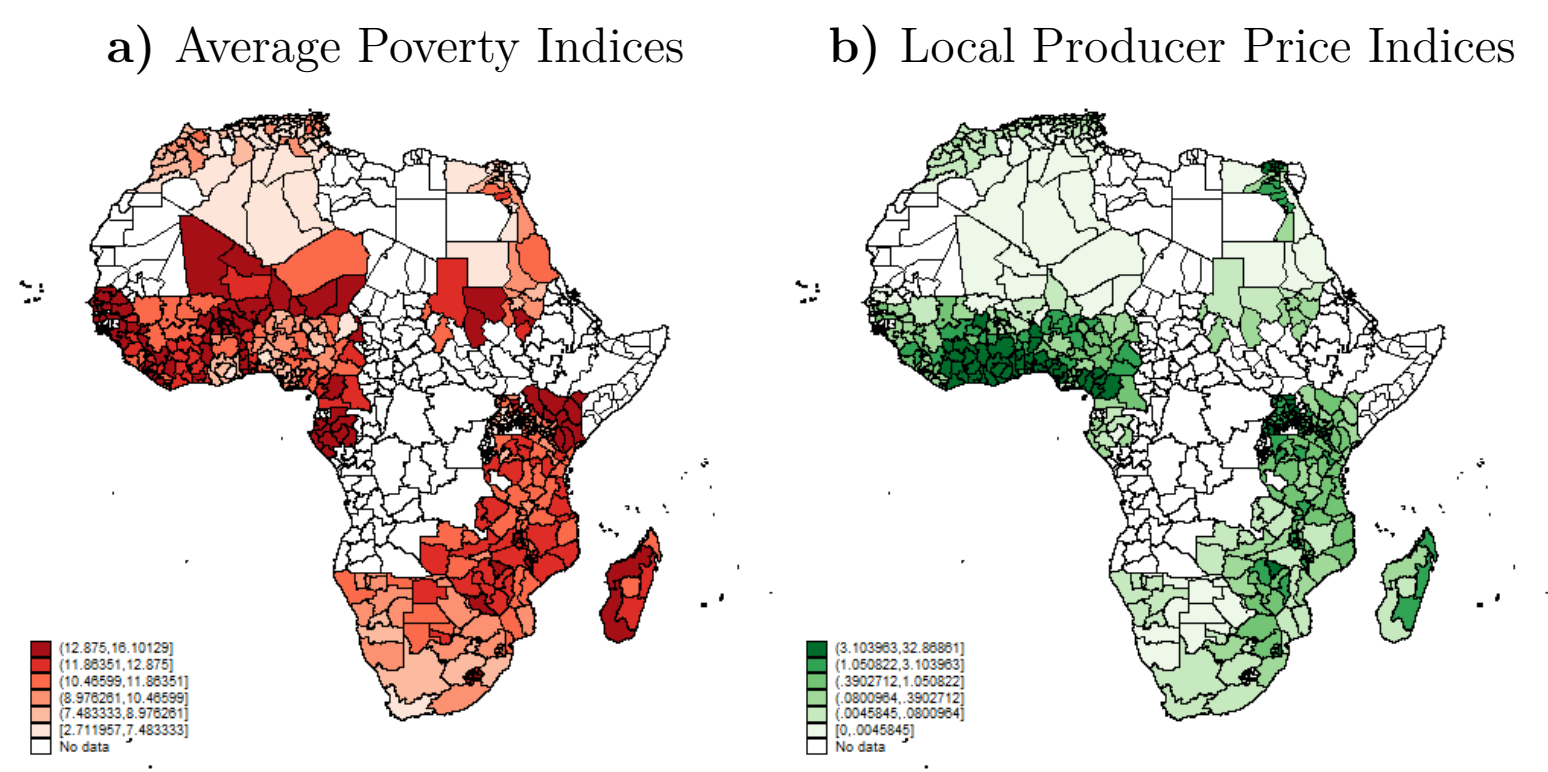

Source: Authors' calculation based on Monfreda et al. (2008), FAO 2018), IMF (2018), World Bank (2018b) and Afrobarometer (2018).

Note: Averages across regions and time.

water, medicine, cooking fuel and cash income. The second outcome measure from Afrobarometer on individual tax support clusters around the mean with a variation of one category ${ }^{12}$ The treatment indicator of producer prices has a high standard deviation (SD), which corresponds to the regional differences indicated in Figure 2.1b. Only the minority of individuals in the considered surveys (approx. 40\%) lives in democratic regimes, which gives rise to expectations that there is substantial room for favoritism.

Figure 2.1a provides an overview of the main outcome variable poverty and indicates strong concentrations of poverty in Kenya, Liberia, Madagascar, Malawi, and Senegal. However, there is a high level of subnational variation, which I will examine in the analysis. Similarly, Figure $2.1 \mathrm{~b}$ indicates that the main treatment indicator of local producer prices varies on a regional level, where particularly high values occur in Western Africa, potentially related to the spike in cocoa prices ${ }^{13}$

Leader birth regions are depicted in Figure 2.2a. In contrast to widespread perceptions that African politics is characterized by long-term autocratic regimes, there is a distinct degree of variation within countries. For instance, three leader changes took place in Mali and Ghana, while there were two in Nigeria - all linked to changes in

\footnotetext{
${ }^{12}$ Tax support was measured via the approval of the statement "The tax department always has the right to make people pay taxes."

${ }^{13}$ I consider the temporal variation of the variable in more detail, when examining potential spurious time trends in Section 2.4 .2
} 
Figure 2.2 Leader Birth Regions and Coethnicity

a) Leader Birth Regions

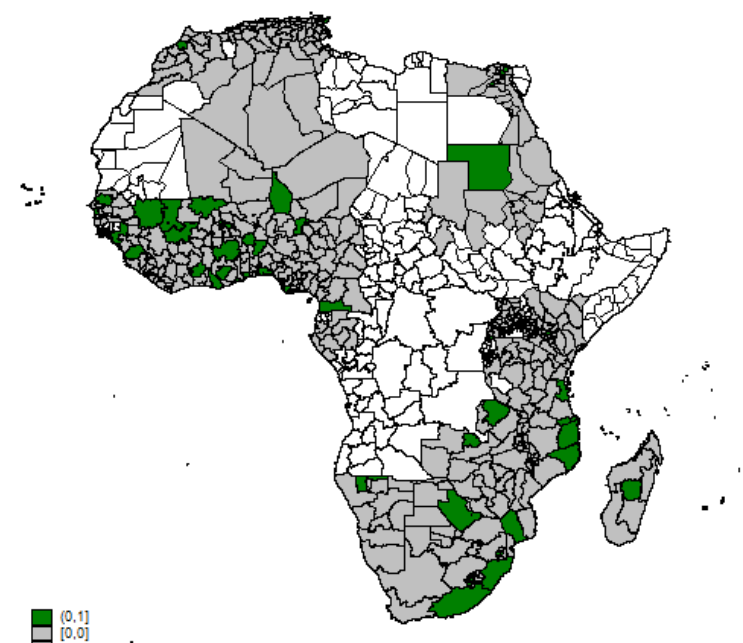

b) Coethnics of Leader

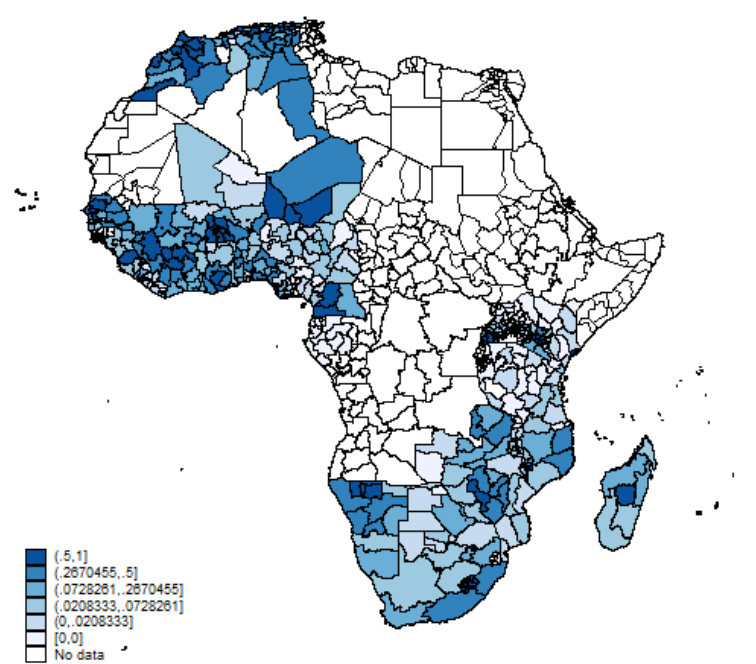

Source: Authors' calculation based on Dreher et al. (2016), Afrobarometer (2018) and own data collection.

Note: Averages across regions and time.

Table 2.1 Descriptives - Main Variables

\begin{tabular}{lccccc}
\hline & $\mathrm{N}$ & Mean & $\mathrm{SD}$ & Max & Min \\
\hline Poverty Index & 175,394 & 10.7 & 4.8 & 25.0 & 0.0 \\
Tax support & 145,141 & 3.7 & 1.2 & 5.0 & 1.0 \\
Producer Price Index & 175,394 & 2.3 & 5.0 & 36.8 & 0.0 \\
Leader Region & 175,394 & 0.1 & 0.3 & 1.0 & 0.0 \\
Leader Ethnicity & 126,317 & 0.2 & 0.4 & 1.0 & 0.0 \\
Democracy & 175,394 & 0.4 & 0.5 & 1.0 & 0.0 \\
Age & 173,325 & 37.0 & 14.6 & 130.0 & 0.0 \\
Education & 174,877 & 2.4 & 1.0 & 4.0 & 1.0 \\
Urban Residence & 174,514 & 0.6 & 0.5 & 1.0 & 0.0 \\
\hline
\end{tabular}

Note: Survey items on tax support and ethnicity were not collected across all rounds.

the corresponding birth region. Several other countries at least observed one leader change linked to distinct birth regions. Beyond local favoritism, the data by Dreher et al. (2016) also consider ethnic affiliations. The underlying groups can be linked to data on individuals' ethnicity from Afrobarometer rounds 3 to 6 . For the ethnic groups also some distinct within-country variation can be observed, which ranges up to three 
different groups in Nigeria (Ijaw, Fulani and Yoruba). For an overview on the leaders and ethnic groups considered please refer to Appendix Tables B.3 and B.4.

Although there is a strong positive correlation between leaders' birth regions and sharing the leaders' ethnicity, Table 2.1 and Appendix Figure B.1 indicate that a considerable fraction of the leaders' coethnics live in other provinces ${ }^{14}$ Similarly, a substantial number of other ethnicities reside in the home region of the leader. First, this makes targeting via public goods less viable due to segregation. Second, it underlines the importance of distinguishing regional and ethnic affiliation more carefully.

Further control variables along with the underlying data sources and a balance test are provided in 2.A.1.

\subsection{Empirical Approach}

\subsubsection{Model}

The outcome of the analysis is the individual poverty indicator, which was presented in the previous section. The main hypothesis is that producer prices have a differential impact on the gains from commodity trade contingent on ethnic or regional political affiliation. I conceptualize this in the following empirical model:

$$
\begin{aligned}
W_{\text {cirt }}= & \alpha+\beta_{1} P P I_{\text {crt }}+\beta_{2} P P I_{\text {crt }} \times \text { leader }_{\text {crt }} \times \text { leadeth }_{\text {cirt }}+\beta_{3} P P I_{\text {crt }} \\
& \times \text { leader }_{\text {crt }}+\beta_{4} P P I_{\text {crt }} \times \text { leadet }_{\text {cirt }}+\beta_{5} \text { leader }_{c r t} \times \text { leadeth }_{\text {cirt }} \\
& +\beta_{6} \text { leader }_{c r t}+\beta_{7} \text { leadeth }_{\text {cirt }}+X_{i} \beta_{9}+\theta_{c t}+\gamma_{s}+\kappa_{c r} \times t+\epsilon_{\text {cirt }}
\end{aligned}
$$

where $W_{\text {cirt }}$ is the welfare indicator of an individual $i$ in country-region $\mathrm{cr}$ in period $t, P P I_{c r t}$ is the corresponding producer price index in country-region $\mathrm{cr}$ and period $t$. The producer prices are interacted with leader $_{c r t}$, which is a binary indicator whether a country-region $\mathrm{cr}$ is the leader birth region in period $t$, and with leadet $h_{\text {cirt }}$, being a dichotomous variable, which is one if the respondent $i$ shares the ethnicity of country $c$ 's leader in period $t$. As the temporal variation comes from global commodity prices, the changes are arguably exogenous with regard to local conditions in subnational localities, especially, when conditioning on country-period fixed effects. However, in order to increase efficiency, all regressions account for individual covariates $X_{i}$ related to poverty, e.g., age, education, gender and rural/urban residence.$^{15}$ Furthermore, all specifications include country-period fixed effects, $\theta_{c t}$, survey round fixed effects, $\gamma_{s}$, and countryregion fixed effects, $\kappa_{c r}{ }^{16}$ The latter control for all time-invariant regional factors

\footnotetext{
${ }^{14}$ In the underlying sample the correlation coefficient of residence in the leader birth region and sharing the leader ethnicity is 0.2214 .

${ }^{15}$ Beyond individual factors, regional time-variant covariates (e.g., climatic shocks) will have a distinct influence on poverty. As those indicators are not available for all region-period observations (which would lead to a loss of more than $25 \%$ of observations), I add those covariates step by step. Results remain qualitatively unchanged.

${ }^{16}$ Due to multiannual survey rounds it is possible to use them along country-period fixed effects.
} 
including the initial production capacity. Although the rich set of control variables and fixed effects reduce endogeneity concerns partly, I consider potential identification issues more carefully in the following section.

\subsubsection{Endogeneity}

A first and apparent concern arises with regard to endogeneity of local producer prices. First, both local prices and poverty could be subject to a third unmeasured variable (e.g., remoteness from markets). Second, poverty itself could influence local production capacities due to reduced investments in inputs, including fertilizers or pesticides. Third, although local price data are becoming increasingly available due to the spread of mobile devices, a broad and unbiased provision of these data across countries is not yet guaranteed. Especially, data from poorer regions could be of worse quality because of the lower provision of mobile technology, inducing correlations in the measurement error between dependent and independent variables.

In order to reduce these concerns, I considered for the local producer price index (PPI), global price changes interacted with local production capacities as suggested by McGuirk and Burke (2017).$^{17}$ The measure resembles a Bartik instrument. Bartik (1991) interacted cross-sectional industry shares with aggregate industry growth to derive an instrument to study exogenous effects on the labor market. A further prominent application is the interaction of Chinese exports volume with cross-sectional industry exposure to imports from China to examine the "China Shock" on US manufacturing (Autor et al. 2013). ${ }^{18}$

Bartik shift-share instruments resemble a Difference-in-Differences (DiD) approach by interacting a global time-series (here prices) with cross-sectional variation (here regional production capacities). Considering the initial production capacities in the year 2000 rather than taking contemporary values, reduces the concern of regional production capacities being endogenous to contemporary regional poverty. This way, the approach comes closer to interacting two exogenous variables as suggested by Christian and Barrett (2017). Analogous to a DiD setting the identification via global prices would be invalidated if systematically different pre-treatment trends in the outcome variable exist among high and low production capacity regions. Due to the interactive nature of the shift-share treatment, no pre-treatment period exists, which precludes a formal test. Instead, I conduct a graphical analysis of trends in the global price treatment and in the outcome across groups with different crop-specific production capacities. Here, a secular non-linear trend in global prices that would be more similar to the changes in poverty among high or low production capacity regions would be problematic, as it could be driven by a third omitted global parameter. Potential factors are global cli-

\footnotetext{
${ }^{17}$ Robustness to excluding crops of potential price makers, defined as $\geq 1 \%$ of world exports, in Appendix Table B.13reduces concerns that subsequent results are driven by endogenously determined global prices.

${ }^{18}$ Further applications of Bartik instruments can be found in Nunn and Qian (2014), Bluhm et al. (2016), Dreher and Langlotz (2017), and Ballard-Rosa et al. (2017).
} 
Figure 2.3 Cash Crop Trends

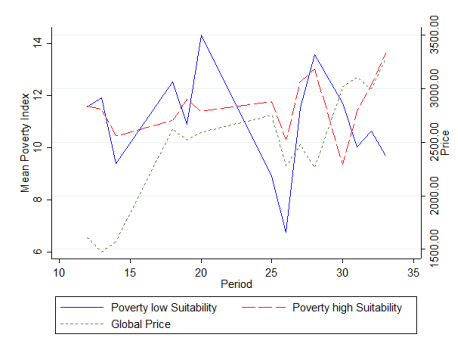

Cocoa

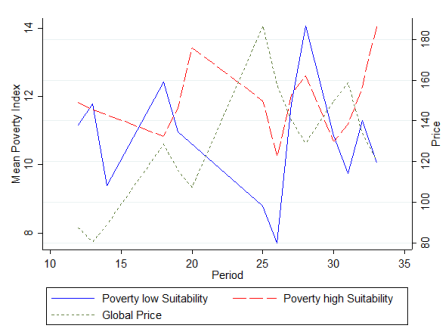

Coffee

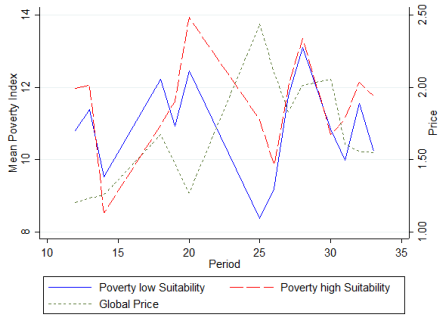

Cotton

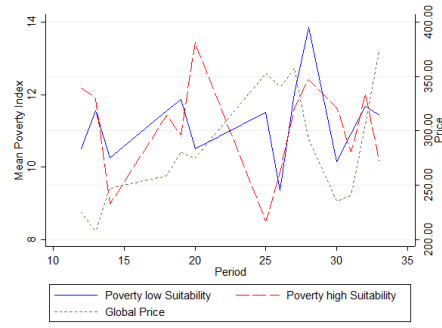

Tea

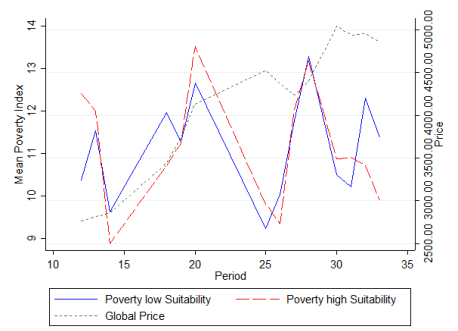

Tobacco

Note: Prices and land use correspond to the specific crop under observation. Biannual periods start in July 1999.

Source: Author's calculation based on Monfreda et al. (2008), IMF (2018), World Bank (2018b) and Afrobarometer (2018).

mate change or the financial crisis 2007/08 and its repercussions, including food price speculation. However, Figure 2.3 shows no evidence for systematically different trends across groups, increasing confidence in the estimation approach.

In this setting, one might be concerned that the power status of regions and ethnic groups might be endogenous. For instance, powerful regions might differ on some other unobserved factor than power status. More specifically, the local population might have better technologies to derive rents from crops. Recent research indicates a strong relationship between historical emergence of ethnic groups as well as agricultural technologies and institutions (Nunn and Wantchekon, 2011; Michalopoulos, 2012; Giuliano and Nunn, 2018). Regional fixed effects would pick up these historical patterns, but do not consider time-variant interactive effects, e.g., regarding access to transport infrastructure. Therefore, I add control variables $Y_{c r t}$ to the regression that could be significantly related to ethnic power status and interact those with the treatment $P P I_{c r t}$ as in Baranov et al. (2017). According to the previous literature this factors include regional prosperity and infrastructure (Burgess et al., 2015; Alesina et al., 2016). What is more, under certain conditions the interaction of an exogenous factor with an endogenous factor can be interpreted as conditionally exogenous, following Nizalova and Murtazashvili (2016): 
Figure 2.4 Trends in Producer Prices and Trends in Poverty across Power Status

\section{a) Birth Regions}

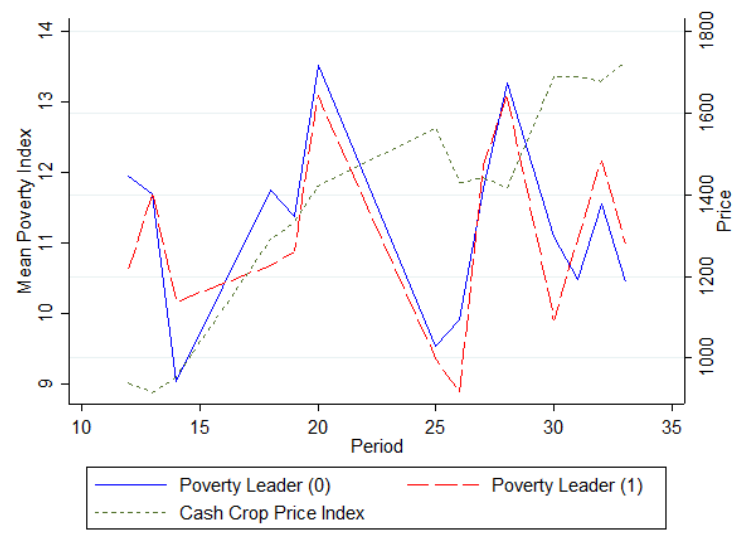

b) Ethnic Groups

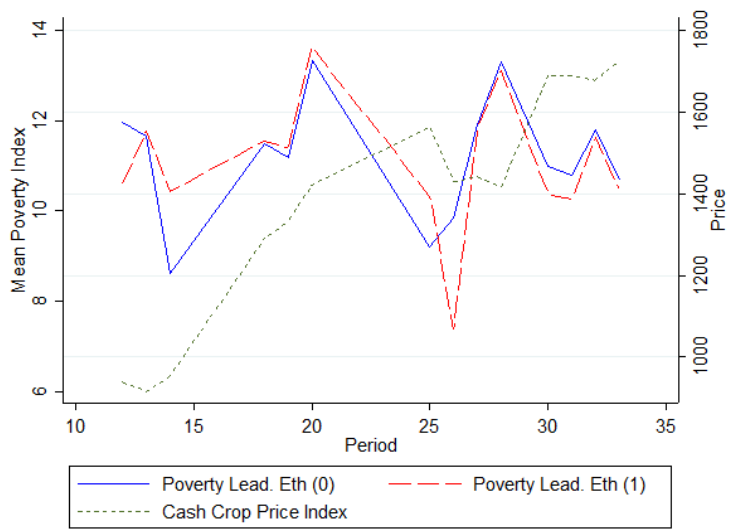

Note: As Afrobarometer only includes data on ethnic affiliation starting from round 3, Figure 2.4 only starts in 2005 (period 10).

Source: Authors' calculation based on Dreher et al. (2016) IMF (2018), World Bank (2018b) and Afrobarometer (2018).

First, the potentially endogenous constituent term needs to be included in the set of explanatory variables. In my setting, this would correspond to the leader birth region and leader ethnicity, which are both parts of Equation 2.2. Second, the potentially endogenous factor (regional and ethnic power status) must be independent from the treatment (producer prices). Especially in autocratic regimes, it is a concern that regions or ethnic groups use economic rents to get into the presidential office. The theory does not provide any clear guidance on the timing of economic rents and its translation into political power. Therefore, I would ideally like to test different lag structures to rule out that power status is determined by crop prices. As Afrobarometer only provides repeated cross sections with periodical gaps between 1999 and 2015, the data preclude such a fine-grained test. Instead, I regress the future power status of a region or of an ethnicity on contemporary producer price changes. Based on this rough test, Appendix Table B.17 provides no evidence for a systematic pattern.

Third, independence must also hold for potentially omitted factors correlated with the power status. Specifically, it would be an issue if non-linear poverty trends in the powerful/-less group would be more similar to the trends of the cash crop price index. In this case the identifying assumptions would be violated, and a spurious trend rather than a causal mechanism might drive the correlation between outcome and treatment. I address this by graphically comparing trends of poverty across ethnicities or regions that were at least one period affiliated to a political leader vis-à-vis groups with no affiliation. Figures $2.4 \mathrm{a}$ and $2.4 \mathrm{~b}$ do not indicate that one of the trends for ethnic and regional groupings would be more similar to the trend in global price changes. Although 
graphical analysis reduces concerns that a spurious non-linear trend of poverty and global prices causes the result further empirical analysis will address this potential issue via a placebo and permutation exercise. While the placebo tests if the statistical relationship holds before and after the leader is in power, the permutation exercise sets the hypothesized mechanism inactive via randomizing the treatments across regions and individuals. In both cases, results would turn insignificant if political biases in gains from trade drive results.

\subsection{Results}

In order to get a first notion about the differential effects regarding favoritism on poverty reduction via agricultural trade, Table 2.2 introduces the concepts of regional and ethnic favoritism in separate regressions as well as via a triple interaction based on Equation 2.2. In column (1) an interaction of the producer price index (PPI) with the leader birth region (local favoritism) is introduced, whereas column (2) accounts for an interaction of PPI with the leader's ethnicity (ethnic favoritism).19 Finally, column (3) considers a combination of both concepts.

Table 2.2 Different Types of Favoritism - Baseline Results

\begin{tabular}{lcccccc}
\hline Dep. Variable: Poverty Index of individual $i$ in region $r$ in country $c$ & & \\
\hline & $(1)$ & $(2)$ & $(3)$ & $(4)$ & $(5)$ & $(6)$ \\
\hline$P P I$ & -0.017 & 0.017 & 0.004 & -0.120 & -0.387 & 1.022 \\
& $(0.045)$ & $(0.072)$ & $(0.074)$ & $(0.109)$ & $(0.320)$ & $(0.960)$ \\
$P P I \times$ Leader $(1)$ & -0.041 & & -0.013 & -0.023 & -0.012 & 0.001 \\
& $(0.037)$ & & $(0.040)$ & $(0.042)$ & $(0.067)$ & $(0.076)$ \\
$P P I \times$ Leadeth $(1)$ & & $-0.040^{* * *}$ & $-0.026^{* *}$ & $-0.025^{* *}$ & $-0.026^{*}$ & $-0.029^{* *}$ \\
& & $(0.013)$ & $(0.012)$ & $(0.012)$ & $(0.015)$ & $(0.014)$ \\
$P P I \times$ Leader $(1) \times$ Leadeth $(1)$ & & & $-0.079^{* *}$ & $-0.086^{* *}$ & $-0.115^{* *}$ & $-0.124^{* *}$ \\
& & & $(0.037)$ & $(0.036)$ & $(0.045)$ & $(0.050)$ \\
$N$ & 171872 & 124320 & 124320 & 114566 & 75873 & 75873 \\
\hline Infrastructure $:$ & No & No & No & Yes & Yes & Yes \\
Lights $_{t-1}:$ & No & No & No & No & Yes & Yes \\
Temperature & No
\end{tabular}

Note: Only the main interactions are displayed for brevity. All regressions include country-period, survey round and regional (province) level fixed effects. All models include individual control variables. Standard errors clustered by region and by country-period in parentheses. ${ }^{*} p<0.10,{ }^{* *} p<0.05$, ${ }^{* * *} p<0.01$.

Although signs are partly negative, Table 2.2 reveals no significant relationship of

\footnotetext{
${ }^{19}$ As information on individuals' ethnicity is only available in survey rounds 3-6, the number of observations is reduced when considering this factor.
} 


\section{Unequal Gains from Trade}

the PPI and individual poverty in the first row. On the one hand, this might be attributable to the aforementioned low productivity in agriculture. On the other hand, political biases might play a role, which I examine in terms of the interactions of the PPI with ethnic and regional affiliations. In this regard, column (1) indicates a negative conditional correlation between higher producer prices and poverty in the leader region, which is insignificant though. The insignificance contrasts previous findings on the preferential treatment of the leader's birth region (Bates and Block, 2010). However, due to the intra-regional ethnic heterogeneity (see Appendix Figure B.1), policy makers might target supporters rather individually along ethnic lines. Column (2) tests this notion empirically by interacting the producer price index with individual ethnic identity. Now the coefficient is both negative and statistically significant, indicating a favorable effect of price shocks for coethnic individuals. This finding indicates the relevance of distinguishing ethnic and regional affiliation, but raises the question of how leaders target their coethnics in order to favorably distribute the gains from trade. Column (3) adds for this reason a further interaction term, which now considers the interplay between regional and ethnic affiliation and reveals additional gains for coethnics that live in the leader region. A one standard deviation (SD) increase in the local producer price treatment would correspond to a decline in the poverty index by 0.11 $\mathrm{SD}$ for a coethnic respondent, residing in the leader birth region.

This might be driven by geographical proximity to policy makers, which increases political clout. What is more, a higher concentration of coethnics facilitates targeting (Ejdemyr et al., 2018). However, as column (3) indicates an insignificant interaction between localized prices and residence in the leader region, this targeting would be exclusionary. This does not correspond to the provision of public goods like wells, roads or ports as there is no evidence for significant spill-overs to people from other ethnicities in leaders' birth regions 20

Column (4) considers this explanation more specifically by adding a further interaction of the localized price indicator with local infrastructure characteristics, including travel time to the nearest urban center, ports, the road network and distance to capital. ${ }^{21}$ However, adding those interacted infrastructure and remoteness measures leaves the pattern unchanged. Due to the time invariant nature of the variables, part of the temporal dynamic is, yet, not considered. For this reason, I add in column (5) the first lag of nightlights as a crude proxy of time-variant economic infrastructure. While

${ }^{20}$ Several articles (including Dube and Vargas (2013), Berman and Couttenier (2015) and McGuirk and Burke (2017)) suggest a causal relationship between commodity prices and armed conflict. A decrease in the PPI causes an increase in conflict also in the underlying sample. Beyond human loss, conflict can have severe consequences for economic poverty by destroying human and physical capital. Differential effects of conflict can be expected as policy makers might deploy security personnel along ethnic and regional lines to protect supporters. I close this channel by including the number of battle related deaths as a further control variable in Appendix Table B.20. While the coefficients for conflict are generally insignificant, the main findings regarding ethnic biases are robust.

${ }^{21}$ Appendix Table B.5 indicates that the latter three are significantly related with either the share of coethnics among respondents or the leader birth region dummy. Thus, controlling for the interactions with the treatment both closes a channel and reduces omitted variable bias. 
the general pattern remains unchanged, controlling for infrastructure characteristics even increases the absolute coefficient size and suggests stronger ethnic biases ${ }^{22}$ Public goods allocation, therefore, does not explain the differential gains from trade.

Another potential explanation for the results could be that powerful groups occupy farmland with better climatic conditions and indeed Appendix Table B.5 indicates that coethnics of the leader rather reside in cooler areas with less rainfall. Adding these climatic controls increases in absolute terms, if anything, the differential effect for coethnic people in the leader birth region as indicated by column (6). A one SD increase in the PPI would imply a $0.16 \mathrm{SD}$ reduction in the poverty index. As commodity prices also determine multi-dimensional poverty in the long term via investments in children's health or education, long term effects could be much larger (Cogneau and Jedwab, 2012). Thus, the estimates arguably constitute a lower bound.

\subsubsection{Channels and Heterogeneities}

If public good provision does not explain the pattern found, the question remains what are the drivers of ethnic biases in agricultural trade? As discussed in Sections 2.1 and 2.2. policy makers might choose to target farmers individually via taxes or subsidies analogous to the Malawian case. ${ }^{23}$ Unfortunately, data on tax collection are very limited in African countries, and no cross-country data on the subnational level are available. Nonetheless, Afrombarometer's survey data allow me to proxy this channel in terms of the support for taxation via the question "For each of the following statements, please tell me whether you disagree or agree: The tax authorities always have the right to make people pay taxes." Although this is a crude proxy and results are only suggestive, it is fair to assume that a favorable treatment would also improve individual perceptions to contribute to public finance ${ }^{24}$

Table 2.3 considers in this respect individual tax support as an outcome and introduces regional and ethnic affiliation measures step by step. Columns (1) and (2) depict no statistically significant coefficients. These null findings might correspond to the ambiguous predictions in the literature on ethnic and regional favoritism in agricultural trade and stress the importance of distinguishing the two concepts more clearly. Thus, I consider in column (3) again the interaction of the two concepts. Coefficients suggest on average a negative effect of producer prices on tax support for respondents that are not coethnic and reside in the leader region, while this effect is neutralized for coethnics in the leader region. This is also in line with further urban-rural heterogeneities. Results in Appendix Table B.9 suggest that the largest gains occur for coethnic rural residents

\footnotetext{
${ }^{22}$ One might be concerned that nightlights would be by definition endogenous as they are frequently also used as a measure of economic prosperity (Henderson et al., 2012). Regression results from Appendix Table B.18 reveal that nightlights are not immediately affected by agricultural producer price shocks. Moreover, using lagged values alleviates the endogeneity concern further.

${ }^{23}$ Taxes and subsidies refer here not only to transfers in the classical sense, but also to indirect taxation/subsidies in terms of guaranteed producer prices.

${ }^{24}$ Tax support provides a notion if individuals feel treated differentially. This is also underlined by the heterogeneous effects on measures of perceived inequality and poverty in Appendix Table B.6.
} 
Table 2.3 Channels - Tax Support

\begin{tabular}{|c|c|c|c|}
\hline & (1) & $(2)$ & (3) \\
\hline$P P I$ & $\begin{array}{c}-0.0264^{*} \\
(0.0157)\end{array}$ & $\begin{array}{c}-0.0222 \\
(0.0160)\end{array}$ & $\begin{array}{l}-0.0234 \\
(0.0166)\end{array}$ \\
\hline$P P I \times$ Leader $(1)$ & $\begin{array}{l}-0.0173 \\
(0.0174)\end{array}$ & & $\begin{array}{c}-0.0405^{* *} \\
(0.0168)\end{array}$ \\
\hline$P P I \times$ Leadeth $(1)$ & & $\begin{array}{l}-0.0020 \\
(0.0020)\end{array}$ & $\begin{array}{l}-0.0037 \\
(0.0023)\end{array}$ \\
\hline$P P I \times$ Leader $(1) \times$ Leadeth $(1)$ & & & $\begin{array}{c}0.0393^{* * *} \\
(0.0125)\end{array}$ \\
\hline$N$ & 142927 & 117619 & 117619 \\
\hline
\end{tabular}

Note: All regressions include country-period, survey round and regional (province) level fixed effects as well as individual control variables analogous to columns (1) to (3) in Table 2.2 Standard errors clustered by region and by country-period in parentheses. ${ }^{*} p<0.10,{ }^{* *} p<0.05,{ }^{* * *} p<0.01$.

in the leader birth region, while I find poverty increasing though insignificant effects for the remaining rural population in the leader birth region. This is not in line with public goods provision, but corresponds to a more exclusive individual targeting. Thus, results on ethnic biases in trade are distinct from previous findings on windfall gain-induced regional public goods provision. While adding a comparable mineral producer price treatment in Appendix Table B.7 leaves main results unchanged, the robustness test confirms regional favoritism due to mineral resources in line with Hodler and Raschky (2014). In contrast, local communities and coethnics are not among the beneficiaries of mineral revenues.

Disentangling the two concepts of ethnic and regional affiliation does partly reconcile the previously found ambiguity between Kasara's (2007) coethnic tax discrimination and Bates and Block's (2010) prediction of favoritism. ${ }^{25}$

One highly relevant question for public policy is, how to reduce these biases. There is a broad consensus in the literature that institutional change introduces checks and balances, which limit the discretionary power of political leaders (North, 1991; Hodler and Raschky, 2014; Burgess et al., 2015). I test this notion empirically by interacting the main terms of interest with a binary indicator, which equals one if the national

\footnotetext{
${ }^{25}$ Beyond Kasara s (2007) focus on regional affiliation (to examine ethnic linkages), her data focus on the pre-2000 period. Agricultural distortions were more prevalent during this period (Anderson et al., 2013). I also tested this notion by regressing nominal rates of protection and agricultural distortions from IFPRI (2013) on the interactions of interest. Results were inconclusive and are available upon request.
} 
regime is democratic and zero if it is autocratic ${ }^{26}$

Table 2.4 Heterogeneous Effects across Regime Types

\begin{tabular}{lccc}
\hline Dep. Variable: Poverty Index of individual $i$ in region $r$ in country $c$ \\
\hline & $(1)$ & $(2)$ & $(3)$ \\
\hline$P P I$ & -0.6989 & 1.1062 & 0.9892 \\
& $(0.9182)$ & $(1.0166)$ & $(0.9426)$ \\
$P P I \times$ Democracy $(1)$ & $-0.1792^{* * *}$ & -0.2093 & $-0.2387^{* * *}$ \\
& $(0.0215)$ & $(0.2445)$ & $(0.0480)$ \\
$P P I \times$ Leader $(1)$ & 0.2002 & & 0.7811 \\
& $(0.5520)$ & & $(0.6120)$ \\
$P P I \times$ Leader $(1) \times$ Democracy $(1)$ & -0.2726 & & -0.7958 \\
& $(0.5496)$ & & $(0.6119)$ \\
$P P I \times$ Leadeth $(1)$ & & $-0.0908^{* * *}$ & $-0.0657^{* * *}$ \\
& & $(0.0243)$ & $(0.0213)$ \\
$P P I \times$ Leadeth $(1) \times$ Democracy $(1)$ & & $0.0713^{* * *}$ & $0.0644^{* *}$ \\
& & $(0.0015)$ & $(0.0309)$ \\
$P P I \times$ Leader $(1) \times$ Leadeth $(1)$ & & & $-0.2400^{* * *}$ \\
PPI $\times$ Leader $(1) \times$ Leadeth $(1) \times$ Democracy $(1)$ & & & $(0.0501)$ \\
& & & $0.1443^{*}$ \\
$N$ & 115662 & 75873 & 75873 \\
\hline
\end{tabular}

Note: All regressions include country-period, survey round and regional (province) level fixed effects as well as control variables from column (6) in Table 2.2. Standard errors clustered by region and by country-period in parentheses. ${ }^{*} p<0.10,{ }^{* *} p<0.05,{ }^{* * *} p<0.01$.

Two main findings can be drawn from Table 2.4. First, while in autocracies respondents that are neither coethnics nor reside in the leader's birth region experience no reduction in poverty if prices for goods in their region rise, columns (1) and (3) indicate that this would be the case in democratic systems. On the one hand, this points to rent extraction and a neglect of politically unimportant regions in autocracies. On the other hand, this could be driven by previous findings that democracies are generally also more open to trade (Aidt and Gassebner, 2010). Second, while the interactions of the PPI and leader ethnicity suggest a bias towards coethnics, especially for those residing in the leader-region, democracy seems to decrease biases as indicated by the positive regime type interactions. Therefore, the results indicate, in line with previous literature, that democracies can reduce biases in gains from trade and provide some further support that the pattern found in this study is driven by political discretion.

\footnotetext{
${ }^{26} \mathrm{I}$ prefer this interaction due to comparability of the sample over a sample split. However, interpretation of triple interactions is non-trivial. Therefore, I also estimated a model using sample splits. Results are robust and estimates are displayed in Table B.16
} 


\subsubsection{Robustness}

Several articles indicate the emergence of ethnicities along agricultural specialization and stress in this regard the unequal distribution of agricultural skills and economic power (Michalopoulos, 2012; Alesina et al., 2016; Giuliano and Nunn, 2018). Although nightlights in column (5) of Table 2.2 partly account for the unequal distribution of economic activity, it is worthwhile to consider more carefully that certain ethnic groups might be both more prosperous and get a hold on political power, e.g., via networks. There is indeed a vast literature that stresses the role of ethnic groups for international trade (e.g., Rauch and Trindade (2002) on Chinese trading networks). Aker et al. (2014) demonstrate that the transport costs induced by the inter-ethnic language border between the Hausa and Zarma groups in Niger would be comparable to the international border between Niger and Nigeria. Iwanowsky (2018) generalizes this notion for intra-African trade, indicating that minorities from the same ethnic group would facilitate cross-border trade. Similarly, business networks might be structured around ethnic lines and allow coethnics better access to market opportunities and inputs like credit (Fafchamps, 2000). If ethnic networks or another omitted factor would be the explanation for the differential gains from trade, the pattern should also persist before and after groups gain access to the presidential post. As suggested by Bommer et al. (2018), I test this via a placebo test in Table 2.5. which considers, instead of recent affiliation, previous and future affiliation with the leader. If previous pattern would not be linked to the power status, coefficients should turn insignificant. The results in columns (2) and (3) indicate no significant relationship between the placebos and disproportional gains from agricultural trade for coethnic respondents. Thus, results provide further evidence that previous pattern is driven by political power structures.

Table 2.5 Robustness - Placebo Test

\begin{tabular}{|c|c|c|c|}
\hline & (1) & $(2)$ & (3) \\
\hline$P P I$ & $\begin{array}{l}-0.6534 \\
(0.9575)\end{array}$ & $\begin{array}{c}0.6839 \\
(0.9749)\end{array}$ & $\begin{array}{c}0.5764 \\
(0.8736)\end{array}$ \\
\hline$P P I \times$ EverLeader $(1)$ & $\begin{array}{c}0.0501 \\
(0.0401)\end{array}$ & & $\begin{array}{c}0.0642 \\
(0.0567)\end{array}$ \\
\hline$P P I \times$ EverLeadeth $(1)$ & & $\begin{array}{l}-0.0062 \\
(0.0196)\end{array}$ & $\begin{array}{l}-0.0176 \\
(0.0205)\end{array}$ \\
\hline$P P I \times$ EverLeader $(1) \times$ EverLeadeth $(1)$ & & & $\begin{array}{c}0.0110 \\
(0.0253)\end{array}$ \\
\hline$N$ & 115662 & 76919 & 76919 \\
\hline
\end{tabular}


Considering the cautionary note by Christian and Barrett (2017), I apply a further robustness test to assess if my results are driven by a spurious relationship. In a permutation test, I randomize the treatment variables PPI and leader ethnicity 500 times, but keep the outcome (poverty) fixed. If differential exposure to local producer prices and ethnic affiliation would indeed affect poverty, I should not expect to find the pattern when the causal mechanisms are set non-operational by randomization. More intuitively, if a cocoa growing region in Nigeria in 2011 is assigned the PPI from a non-cultivatable Sudanese strip of the Sahara, producer prices should not contribute to poverty declines. Similarly, if a respondent from the Yao ethnicity is treated in 2008 as a coethnic of Malawi's president Bingu wa Mutharika, who was in fact from the Lomwe ethnicity, the pattern of coethnic biases should not materialize. Appendix Figure B.2 reveals that the baseline coefficient of PPI $\times$ Leadeth(1) is among the top $1 \%$ of poverty reducing estimates. Thus, I do not find evidence for political biases in gains from trade if the hypothesized mechanism is set inactive. This reduces concerns that the main pattern is driven by a spurious trend.

The pattern of ethnic biases is also robust to the exclusion of price makers (Appendix Table B.13), outliers in terms of countries and years (Table B.15) as well as a "leave-one-out" analysis of the specific commodities of the price index (Appendix Table B.12). Further, Appendix Table B.11 tests for robustness considering an indicator on respondents' perceived honesty as the sensitive nature of political biases could compromise data quality systematically (Adida et al., 2016). The pattern remains qualitatively unchanged. Finally, results remain robust when I modify the treatment variable (e.g., a broader producer price basket in Appendix Table B.8) or when I use a binary outcome variable instead of the continuous index (Appendix Table B.10).

\subsection{Discussion and Conclusion}

Agriculture could theoretically contribute strongly to inclusive growth due to its large employment level and Africa's rich endowment with soils suitable for cash crops. However, research stresses that structural change and productivity growth are still fairly limited (McMillan et al., 2014; Barrett et al., 2017). The domestic political economy in African countries imposes strong distortions on agricultural markets (Lipton, 1977; Anderson et al., 2013). Predictions in the literature of the outcomes are, however, ambiguous. Bates and Block (2009) argue that coethnics are favored if a policy maker from a rural region comes to power. Kasara (2007) suggests a contradicting pattern, where coethnic farmers would be taxed more heavily due to limited political competition and higher monitoring capacities of coethnics. However, those former studies could not sufficiently account for regional and individual ethnic divisions. This just recently became possible due to the availability of high-resolution georeferenced data. Linking geographic information on leader birth regions and local producer price indices with Afrobarometer survey data from 33 African countries, I examine the hypotheses more carefully. 
I find that coethnics disproportionally benefit from higher prices for commodities that can be produced in their region, while other groups in the same region do not benefit significantly. This suggests individual targeting rather than more general public goods provision. Indeed, controlling for infrastructure provision does not alter the findings. A placebo test supports the notion that this is indeed driven by political factors and not by some spurious correlation of more agriculturally skilled groups being also more likely to come to power. I provide some suggestive evidence that discriminatory tax regimes might drive results. In line with previous arguments that institutional change would improve agricultural productivity (Bates and Block, 2013), further econometric analysis suggests that democratic institutions can reduce, though not completely offset, these political biases. The example of discretionary fertilizer voucher distribution under president Bingu wa Mutharika of Malawi stresses that these political biases might persist even in democracies. Persisting clientelism can be attributed to the challenge of making credible commitments in young democracies (Keefer, 2007).

As success stories of African agricultural growth can be found in not fully democratic, hybrid regimes (e.g., the coffee industry in Rwanda), further research could shed some light on the question which specific economic and political institutions are effective in curbing ethnic biases in gains from trade. What is more, an interesting route for research is provided by the linkages of distinct ethnic groups, as Dickens (2018) indicates that patronage networks can include several affiliated ethnicities.

Finally, one main caveat of this study remains. The main outcomes rely on selfreported poverty assessments and perceptions due to the scarcity of data that provide better quantifiable metrics (e.g., expenditures, tax burden) along with information on individual ethnic affiliation. Future research could contribute to a more thorough understanding of the suggested pattern, once more data become available. 
Unequal Gains from Trade

\section{A Appendix}

\section{A.1 Data Appendix}

Table B.1 Afrobarometer - Sampled Countries and Years

\begin{tabular}{|c|c|c|}
\hline $\begin{array}{l}\text { Survey } \\
\text { Round }\end{array}$ & Years & Sampled Countries \\
\hline Round 1: & $1999-2000$ & $\begin{array}{l}\text { Botswana, Ghana, Lesotho, Malawi, Mali, Namibia, Nige- } \\
\text { ria, South Africa, Tanzania, Uganda, Zambia, Zimbabwe }\end{array}$ \\
\hline Round 2: & $2002-2004$ & $\begin{array}{l}\text { Botswana, Ghana, Lesotho, Mali, Mozambique, Namibia, } \\
\text { Nigeria, Senegal, South Africa, Tanzania, Zambia, Zim- } \\
\text { babwe }\end{array}$ \\
\hline Round 3: & $2005-2006$ & $\begin{array}{l}\text { Benin, Botswana, Ghana, Lesotho, Madagascar, Malawi, } \\
\text { Mali, Mozambique, Namibia, Nigeria, Senegal, South } \\
\text { Africa, Tanzania, Uganda, Zambia, Zimbabwe }\end{array}$ \\
\hline Round 4: & $2008-2009$ & $\begin{array}{l}\text { Benin, Botswana, Burkina Faso, Ghana, Kenya, Lesotho, } \\
\text { Liberia, Madagascar, Malawi, Mali, Mozambique, } \\
\text { Namibia, Nigeria, Senegal, South Africa, Tanzania, } \\
\text { Uganda, Zambia, Zimbabwe }\end{array}$ \\
\hline Round 5: & 2011-2013 & $\begin{array}{l}\text { Algeria, Benin, Botswana, Burkina Faso, Cameroon, } \\
\text { Ghana, Guinea, Ivory Coast, Lesotho, Liberia, Madagas- } \\
\text { car, Mali, Mauritius, Morocco, Mozambique, Namibia, } \\
\text { Nigeria, Senegal, Sierra Leone, South Africa, Sudan, Swazi- } \\
\text { land, Tanzania, Togo, Tunisia, Uganda, Zambia, Zimbabwe }\end{array}$ \\
\hline Round 6: & 2014-2015 & $\begin{array}{l}\text { Algeria, Benin, Botswana, Burkina Faso, Cameroon, } \\
\text { Egypt, Gabon, Ghana, Guinea, Ivory Coast, Kenya, } \\
\text { Lesotho, Liberia, Madagascar, Malawi, Mali, Mauritius, } \\
\text { Morocco, Mozambique, Namibia, Niger, Senegal, Sierra } \\
\text { Leone, South Africa, Sudan, Swaziland, Tanzania, Togo, } \\
\text { Tunisia, Uganda, Zambia, Zimbabwe }\end{array}$ \\
\hline
\end{tabular}


Table B.2 Data Sources

Variable Name

Description

Support for tax collection: (1) "Strongly

Disagree." to (5) "Strongly Agree."

Poverty

Leader Ethnicity

Democracy

Leader

Total Road Length

Precipitation

Temperature

Distance to capital Distance to capital in kilometers.

Travel Time

Administrative Boundaries

Aggregate of five individual poverty assessments ranging each from 1 "Never" to 5

"Always."

Information on leader's ethnicity combined with information on individual ethnicity from Afrobarometer Round 3-5: "What is your tribe? You know, your ethnic or cultural group."

Socio-economic indi- Gender, Age, Education, Urban/Rural. cators

Self-constructed index of agricultural producer and consumer prices using prices and land use data.

Binary variable if country has free \& fair elections with peaceful turnovers.

Binary indicator if administrative region was the leader birth region.

Length of all roads in the administrative region measured in kilometers.

Precipitation data based on observational and satellite data.

Means of monthly global land surface temperatures.

Travel time to most proximate urban center.

Boundaries of subnational administrative 1980-2015 divisions.

\section{Years Source \\ Available}

$2002-2015$

1999-2015

Afrobarometer

(2018)

Afrobarometer

(2018)

2005-2013

Dreher et al. (2016)

\& Afrobarometer $(2018)$

1999-2015 Afrobarometer (2018)

1980-2015

IMF (2018), World Bank (2018b),

Monfreda et al. (2008)

1980-2015

Based on Bjørnskov and Rode (2018)

1980-2015

Based on Dreher et al. (2016)

1992-2015

Data in Space (2018)

1980-2013

Adler et al. (2003)

\& Tollefsen et al. (2012)

1980-2013

Fan and Van den

Dool (2008) \&

Tollefsen et al. (2012)

1980-2014

Tollefsen et al. (2012)

Tollefsen et al. (2012)

Hijmans et al. $(2012)$

Control variables on climate, population density, and ethnic exclusion were obtained 
from the PRIO grid (Tollefsen et al., 2012). The regional development indicators dataset provides information on oil fields and local road density (Data in Space, 2018). For a further description of the variables and the respective sample years and sources consult Table B.2. Individual socio-economic control variables are from Afrobarometer (2018) ${ }^{27}$

Producer and Consumer Price Indices are constructed by myself along the lines of McGuirk and Burke (2017). The Producer Price Index is based on price data from the IMF (2018) and the World Bank (2018b). As described in Section 2.3, prices are multiplied with regional weights on the harvested area and potential yield for the corresponding crop based on Monfreda et al. (2008). ${ }^{28}$ For the consumer price index, regional weights are substituted with country-level caloric shares of crops from FAO's "Food Balance" sheets (FAO, 2018). The producer commodities include: cocoa, coffee, tea, tobacco, and cotton. For consumers, I consider prices of cocoa, coconuts, coffee, groundnuts, maize, palm oil, olives, oranges, rice, sorghum, soybeans, sugar, sunflowers, tea, and wheat.

\footnotetext{
${ }^{27}$ Education is measured in four categories, where $1=$ No formal schooling; $2=$ Primary; $3=$ Secondary; $4=$ Post-secondary.

${ }^{28}$ Data from Mofreda, Ramankutty and Foley can be accessed via http://www.earthstat.org/datadownload.
} 
Unequal Gains from Trade

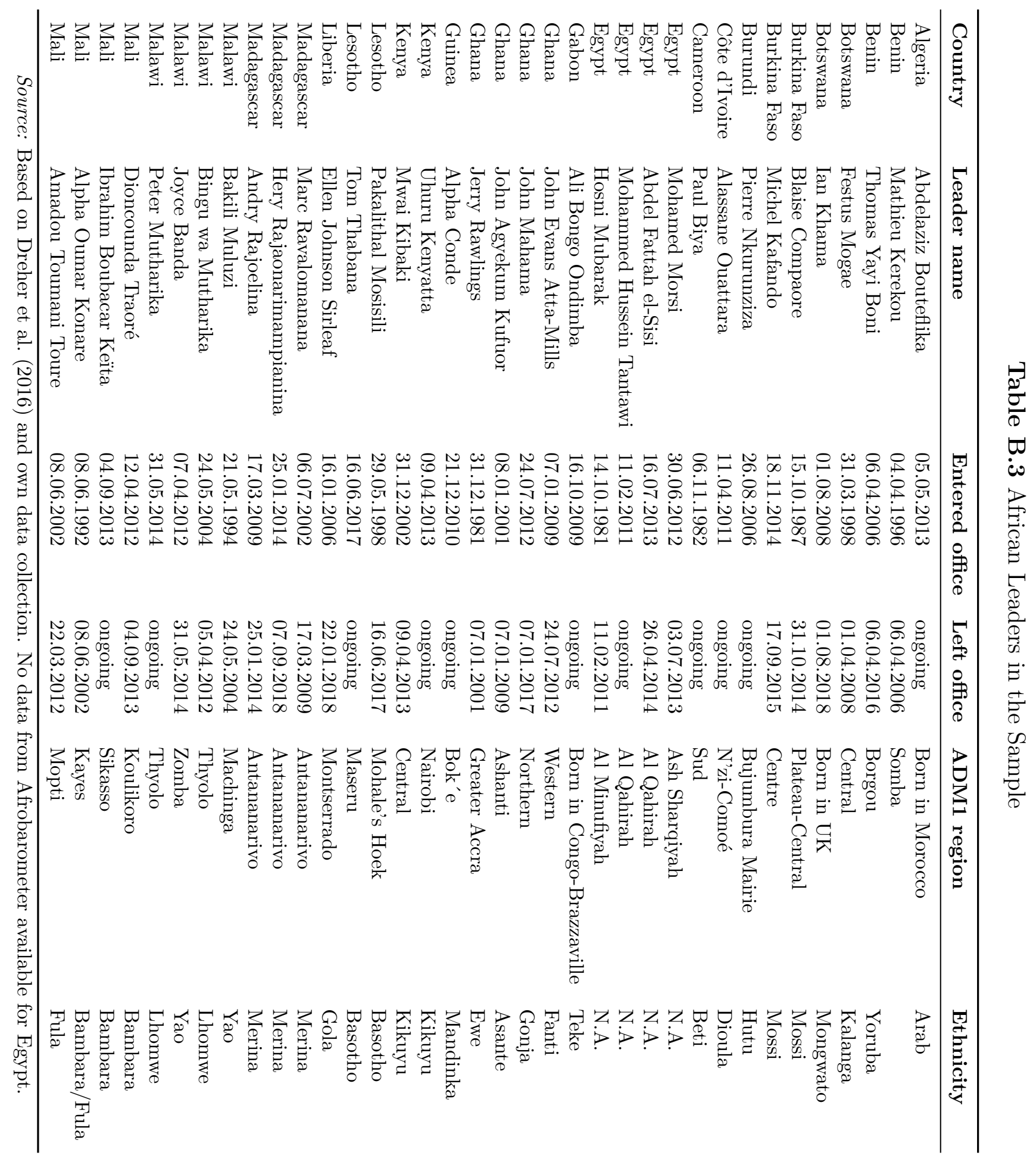


Unequal Gains from Trade

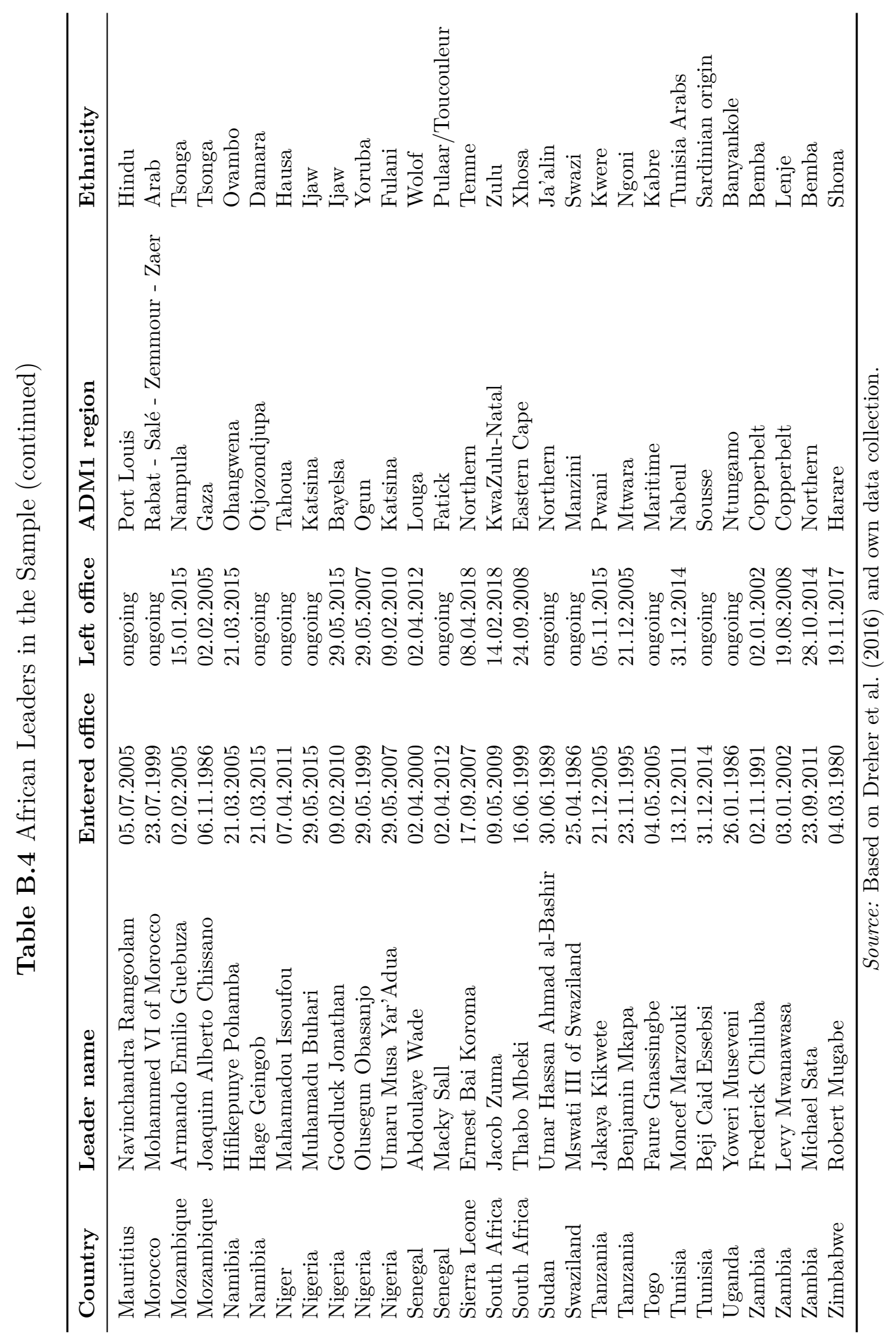




\section{A.2 Analytical Appendix}

Figure B.1 Regional and Ethnic Affiliation of Respondents

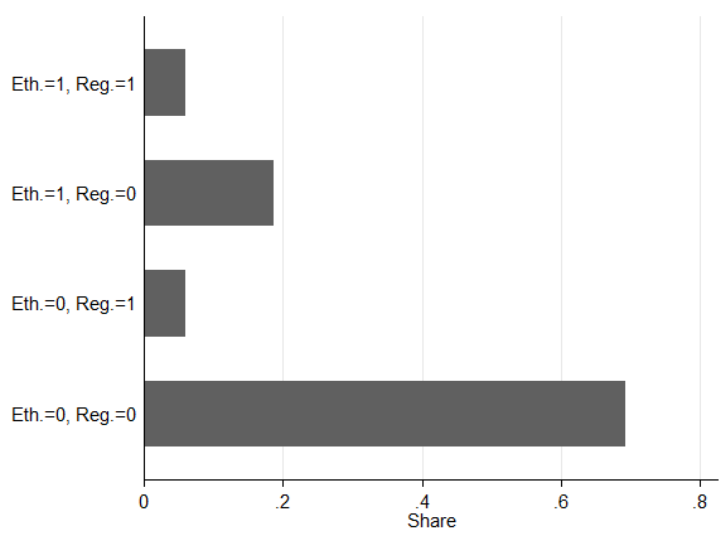

Source: Authors' calculation based on Dreher et al. 2016) and Afrobarometer (2018).

Note: "Eth." and "Reg." refer to ethnic and regional affiliation respectively.

Balance Test Table B.5 presents coefficients from regressions of outcome variables on the dichotomous indicators of leader ethnicity or birth region. The balance test reveals that regional affiliation is indeed correlated with the road and port infrastructure. Regions with a higher share of coethnics are closer to the capital, had in previous periods a higher light output (proxying economic infrastructure) and face different climatic conditions (e.g., temperature and rainfall are lower). These unbalanced covariates are considered in columns (4)-(6) of Table 2.2 .

Table B.5 Balance Test - Leader Birth Region \& Leader Ethnicity

\begin{tabular}{lcccc}
\hline & Leader Birth Region & p-value & Leader Ethnicity & p-value \\
\hline Travel Time & -8.993 & 0.721 & 28.628 & 0.224 \\
Cap. Dist. & 12.621 & 0.597 & -112.836 & 0.000 \\
Road km & $1,933.669$ & 0.001 & 589.642 & 0.305 \\
Ports & 0.177 & 0.077 & -0.067 & 0.538 \\
$\log ($ lights) in 1999 & 0.067 & 0.175 & 0.124 & 0.003 \\
$\log ($ lights) in t-1 & 0.006 & 0.906 & 0.069 & 0.074 \\
Temperature & 0.027 & 0.948 & -4.080 & 0.000 \\
Precipitation & 3.015 & 0.843 & -64.047 & 0.000 \\
\hline
\end{tabular}

Note: Comparison of coefficients for different indicators of leader affiliation. 
Table B.6 Inequality \& Poverty Perceptions

\begin{tabular}{lcc}
\hline Dep. Variable: Perception Measures of individual $i$ in region $r$ in country $c$ \\
\hline & $(1)$ & $(2)$ \\
& Comparative & Problem \#1: \\
& Income & Poverty \\
\hline PPI & $-0.0207^{* *}$ & $0.0079^{* * *}$ \\
& $(0.0089)$ & $(0.0019)$ \\
PPI $\times$ Leader $(1)$ & -0.0054 & $0.0043^{*}$ \\
& $(0.0092)$ & $(0.0022)$ \\
PPI $\times$ Leadeth $(1)$ & $0.0069^{* * *}$ & 0.0005 \\
& $(0.0023)$ & $(0.0005)$ \\
PPI $\times$ Leader $(1) \times$ Leadeth $(1)$ & $0.0156^{* *}$ & $-0.0042^{* *}$ \\
$N$ & $(0.0070)$ & $(0.0020)$ \\
$N$ & 120728 & 124320 \\
\hline
\end{tabular}

Note: All regressions include country-period, survey round and regional (province) level fixed effects as well as individual control variables described in Section 2.4.1. Standard errors clustered by region and by country-period in parentheses. ${ }^{*} p<0.10,{ }^{* *} p<0.05,{ }^{* * *} p<0.01$.

Perceived Inequality / Poverty The results on tax support in Table 2.3 would correspond to a setting where respondents are aware of their differential treatment. In order to test this more specifically Table B.6 provides results for the item "In general, how do you rate: Your living conditions compared to those of other countrymen." Results are generally in line with the main pattern of ethnic biases in poverty reduction and once more underline that individuals also feel relatively deprived. These grievances can undermine societal stability, leading to conflict (see for instance, Cederman et al., 2015). However, further assessment of this hypothesis is left for further research.

Mineral commodities As indicated in Sections 2.1 and 2.2. mineral resources could have a very different effect on individual poverty vis-à-vis agriculture. Theoretically one would expect less inclusive effects as extraction is less intensive in labor. I test this hypothesis empirically estimating a regression analogous to column (6) in Table 2.2 . but adding to the specification a localized mineral commodity price treatment along with the corresponding interaction terms. In line with Berman et al. (2017), I consider platinum, copper, aluminum, gold, iron, lead, silver, tin, zinc, and nickel. The localized mineral commodity price treatment was constructed by interacting global mineral prices (based on data by the IMF (2018) and the World Bank (2018b)) with a binary indicator, whether the specific resource is mined in this region (based on Data in Space (2018)). For easier comparability, I depict the coefficients for the agricultural and mineral price treatment from one regression in columns (1) and (2) of Table B.7. Coefficient size of point estimates in Table B.7 is not directly comparable across agricultural and mineral 
commodities. ${ }^{29}$ Nonetheless, it is informative to compare signs and significance levels across columns. There are three takeaways from Table B.7. First, the pattern of ethnic biases in agricultural commodity trade is robust to the inclusion of localized mineral price treatments. This further reduces concerns that an important omitted variable would drive results as agricultural prices might move in parallel to mineral prices (e.g., petroleum). Second, the regional mineral price treatment induces, surprisingly, an increase in poverty. This is also the case for coethnics. Third, results only indicate poverty reducing effects in the leader birth region. A potential explanation could be that negative externalities occur locally, while leaders transfer rents to their home region. A case in point is the Niger delta region, where oil spills caused severe harvest loss and health hazard (e.g., Idemudia, 2009, Bruederle and Hodler, 2017). In line with theory, mineral commodity price changes are, hence, linked to a very different pattern of political distortions.

Table B.7 Agricultural and Mineral Commodities

\begin{tabular}{lcc}
\hline \multicolumn{2}{l}{ Dep. Variable: Poverty Index of individual $i$ in region $r$ in country $c$} \\
\hline & $(1)$ & $(2)$ \\
& Agriculture & Mining \\
\hline$P P I_{\mathrm{t}}$ & 0.565 & $0.003^{*}$ \\
& $(1.049)$ & $(0.002)$ \\
$P P I_{\mathrm{t}} \times$ Leader $_{\text {it }}(1)$ & 0.034 & $-0.002^{* * *}$ \\
$P P I_{\mathrm{t}} \times$ Leadeth $_{\text {it }}(1)$ & $(0.065)$ & $(0.001)$ \\
& $-0.026^{*}$ & $0.000^{*}$ \\
$P P I_{\mathrm{t}} \times$ Leader $_{\text {it }}(1) \times$ Leadeth $_{\text {it }}(1)$ & $(0.014)$ & $(0.000)$ \\
& $-0.152^{* * *}$ & 0.001 \\
$N$ & $(0.044)$ & $(0.001)$ \\
\hline
\end{tabular}

Note: Columns (1) and (2) are based on one regression. All regressions include country-period, survey round and regional (province) level fixed effects and are structured analogously to column (6) in Table 2.2 Standard errors clustered by region and by country-period in parentheses. ${ }^{*} p<0.10,{ }^{* *} p<0.05,{ }^{* * *} p<0.01$.

Prices The assumptions made for the definition of price indices are not arbitrary. The main part shows results for cash crops. As McGuirk and Burke (2017) also suggest a broader producer price basket, I extend the producer price index to maize, palm oil, rice, sorghum, soybean, sugar, and wheat in Table B.8. The pattern remains qualitatively unchanged, but the coefficient for the interaction with leader ethnicity turns statistically insignificant. Yet, in all cases $P P I \times \operatorname{Leader}(1) \times \operatorname{Leadeth}(1)$ is

\footnotetext{
${ }^{29}$ The former is based on an interaction with a production capacity indicator normalized between zero and one, whereas the latter considers a dichotomous indicator for the interaction.
} 
statistically significant. Thus, the main pattern of ethnic favoritism within the leader's birth region is also retained when considering a broader basket of producer goods.

Table B.8 Other Price Definitons

\begin{tabular}{lcc}
\hline Dep. Variable: Poverty Index of individual $i$ in region $r$ in country $c$ \\
\hline & $(1)$ & $(2)$ \\
& $\begin{array}{c}\text { Broader Producer } \\
\text { Prices }\end{array}$ & $\begin{array}{c}\text { Controlling for } \\
\text { Consumer Prices }\end{array}$ \\
\hline$P P I$ & 0.003 & 0.722 \\
& $(0.074)$ & $(0.958)$ \\
$P P I \times$ Leader $(1)$ & 0.018 & 0.025 \\
& $(0.019)$ & $(0.089)$ \\
$P P I \times$ Leadeth $(1)$ & 0.002 & -0.024 \\
& $(0.006)$ & $(0.017)$ \\
$P P I \times$ Leader $(1) \times$ Leadeth $(1)$ & $-0.025^{* *}$ & $-0.111^{*}$ \\
$N$ & $(0.013)$ & $(0.061)$ \\
Country-Period FE: & 75873 & 75873 \\
Country-Trends: & Yes & No \\
\hline
\end{tabular}

Note: All regressions include country-period, survey round and regional (province) level fixed effects and are structured analogously to Column (6) in Table 2.2 Column (1) applies a broader producer price basket, whereas column (2) includes consumer prices as a further explanatory variable. Standard errors clustered by region and by country-period in parentheses. ${ }^{*} p<0.10,{ }^{* *} p<0.05,{ }^{* * *} p<0.01$.

Due to the scarcity of data, it is not possible to construct a localized measure of consumer price volatility in a consistent way for a broader set of countries. However, as the FAO provides data on national consumption patterns, it is possible to construct a consumer price index $C P I_{i t}$ that varies at the country level. This reads as follows:

$$
C P I_{i t}=\sum_{j=1}^{n} P_{j t} \times * C_{i j},
$$

where $P_{j t}$ is the price of good $j$ in year $t$, which is multiplied with $C_{i j}$, the share of product $j$ in average calorie consumption of country $i$. Column (2) in Table B.8 adds an interaction with those consumer prices to Equation 2.2. As consumer prices only differ on the country level, country-period fixed effects are substituted by linear country-level trends. While the ethnic bias in the leader birth region persists, I do not find significant heterogeneities for consumer prices 30

Urban-Rural Divide The main analysis of the paper is based on all available respondents in Afrobarometer, as I assume that commodity prices have a comprehensive effect

\footnotetext{
${ }^{30}$ Results are available upon request.
} 
on poverty due to agriculture's economic salience. As Kasara/s (2007) argumentation is based on the taxation of farmers, I would ideally like to consider the respondents' occupation. However, Afrobarometer only provides information on occupation in a limited subset of rounds $(1,2,3,5)$, and some respondents did refrain from answering. Therefore, I prefer to work with a slightly broader definition of the urban-rural divide ${ }^{31}$ Information on residence in an urban or rural locality is available for the majority of respondents, and it is fair to assume that in rural regions most of the employment is related to agriculture. Table B.9 is structured analogous to columns (1) to (3) of Table 2.2 , but adds to all terms of interest a further interaction with a binary indicator on rural residence. Results reveal three main findings. First, there seems to be indeed a counter-intuitive poverty increasing effect of higher agricultural commodity prices in rural localities. In line with previous results, poverty among people from other ethnicities would increase if surplus rents are extracted via taxes, while other consumption prices increase (e.g., food and fuel prices). Second, results provide further evidence on gains among coethnics, which are more nuanced in the leader's birth region. Third, those gains for coethnics center in rural regions. The concentration of gains in rural regions provides further confidence that results correspond to agricultural production and not to an unrelated spurious pattern. Overall, I do not find a negative pattern for coethnics concentrated in the leader region as suggested by Kasara (2007). In line with Anderson et al. (2013), this could point to a reduced scope for regional taxation via trade policy measures. As argued before previous results rather suggest an individual targeting via taxes or subsidies. These findings also add to the literature on the urban bias (Lipton, 1977). As in most African countries, the majority of farmers does not share the leader's ethnicity, the poverty increasing effects for other ethnicities in the second row would be in line with an existing urban-rural bias. The favorable effects for coethnic rural populations suggest that individual targeting has the potential to reduce this gap, but is strongly biased towards political support groups. This can explain, why agricultural development has so far not reached its full potential for inclusive pro-poor growth.

\footnotetext{
${ }^{31}$ The occupation data are only available for a minority of individuals. Data could be missing systematically as the hypothesis suggests biases against farmers. Moreover and most importantly, the limited number of observations would leave only small sub-groups for the analysis, which makes the estimates prone to outliers (e.g., only 168 farmers in leader birth regions are also coethnics of the leader).
} 
Table B.9 Urban-Rural Divide

\begin{tabular}{lccc}
\hline Dep. Variable: Poverty Index of individual $i$ in region $r$ in country $c$ & \\
\hline & $(1)$ & $(2)$ & $(3)$ \\
\hline$P P I$ & -0.0334 & -0.0111 & -0.0218 \\
$P P I \times$ Rural $(1)$ & $(0.0456)$ & $(0.0727)$ & $(0.0742)$ \\
& $0.0270^{* * *}$ & $0.0423^{* * *}$ & $0.0387^{* * *}$ \\
$P P I \times$ Leader $(1)$ & $(0.0091)$ & $(0.0083)$ & $(0.0092)$ \\
& -0.0380 & & -0.0413 \\
$P P I \times$ Leader $(1) \times$ Rural $(1)$ & $(0.0343)$ & & $(0.0453)$ \\
& 0.0044 & & 0.0631 \\
$P P I \times$ Leadeth $(1)$ & $(0.0242)$ & & $(0.0452)$ \\
& & -0.0197 & -0.0077 \\
$P P I \times$ Leadeth $(1) \times$ Rural $(1)$ & & $(0.0156)$ & $(0.0148)$ \\
& & $-0.0427^{* *}$ & $-0.0381^{*}$ \\
$P P I \times$ Leader $(1) \times$ Leadeth $(1)$ & & $(0.0179)$ & $(0.0222)$ \\
& & & -0.0324 \\
$P P I \times$ Leader $(1) \times$ Leadeth $(1) \times$ Rural $(1)$ & & & $(0.0428)$ \\
& & & $-0.0896^{*}$ \\
$N$ & 171872 & 124320 & $(0.0537)$ \\
\end{tabular}

Note: "Rural" is a binary indicator, which equals one for rural and zero for non-rural residence. All regressions include country-period, survey round and regional (province) level fixed effects as well as individual controls analogously to Table 2.2 columns (1) to (3). Standard errors clustered by region and by country-period in parentheses. ${ }^{*} p<0.10,{ }^{* *} p<0.05,{ }^{* * *} p<0.01$.

Table B.10 Poverty - Binary Outcome Measure

Dep. Variable: Binary poverty indicator of individual $i$ in region $r$ in country $c$

\begin{tabular}{lcccccc}
\hline & $(1)$ & $(2)$ & $(3)$ & $(4)$ & $(5)$ & $(6)$ \\
\hline$P P I$ & -0.004 & -0.000 & -0.001 & -0.009 & -0.048 & 0.094 \\
& $(0.004)$ & $(0.007)$ & $(0.007)$ & $(0.013)$ & $(0.032)$ & $(0.095)$ \\
$P P I \times$ Leader $(1)$ & -0.003 & & 0.001 & 0.001 & -0.000 & 0.001 \\
\multirow{2}{*}{$P P I \times$ Leadeth $(1)$} & $(0.004)$ & & $(0.004)$ & $(0.004)$ & $(0.008)$ & $(0.008)$ \\
& & $-0.004^{* * *}$ & $-0.002^{* *}$ & $-0.002^{* *}$ & $-0.003^{* *}$ & $-0.003^{* *}$ \\
$P P I \times$ Leader $(1) \times$ Leadeth $(1)$ & & $(0.001)$ & $(0.001)$ & $(0.001)$ & $(0.001)$ & $(0.001)$ \\
\multirow{2}{*}{$N$} & & & $-0.009^{* * *}$ & $-0.010^{* * *}$ & $-0.012^{* *}$ & $-0.013^{* *}$ \\
& 171872 & 124320 & 124320 & 114566 & 75873 & 75873 \\
\hline
\end{tabular}

Note: All regressions include country-period, survey round and regional (province) level fixed effects and are structured analogously to Table 2.2 The dependent variable is a dichotomous measure, if the individual is above or below the median of the poverty index. Standard errors clustered by region and by country-period in parentheses. ${ }^{*} p<0.10,{ }^{* *} p<0.05,{ }^{* * *} p<0.01$. 
Binary Outcome Variable The specifications in Table B.10 include a binary outcome variable in the same setting as Equation 2.2. The dependent variable is a dichotomous measure if the individual is above or below the median of the poverty index. The pattern remains unchanged. Column (6) implies for coethnics residing in the leader birth region that a one standard deviation increase in producer prices would induce a $8 \%$ lower probability to be poor.

Honesty Afrobarometer also includes an item, which indicates whether the interviewer had the impression that the respondent is answering honestly. This might play a role in the African context, where other studies indicate that coethnicity can influence response under certain conditions (Adida et al., 2016). As this item is self-reported and, hence, might also suffer from bias, it is only included for a robustness test. Here, I either constrain the sample to respondents, who were considered as honest or interact the producer price change with the honesty indicator. For the "honest sample" in column (1) the interaction of $P P I \times$ Leadeth(1) is negative though insignificant, but the significance for the coefficient of ethnic favoritism in the leader birth region is retained. When considering the interaction of the PPI with the categorical honesty variable of interest in column (2), both coefficients for ethnic biases are robustly negative and significant.

Table B.11 Robustness - Perceived Honesty

\begin{tabular}{lcc}
\hline Dep. Variable: Poverty Index of individual $i$ in region $r$ in country $c$ \\
\hline & $(1)$ & $(2)$ \\
\hline$P P I$ & 0.959 & 0.981 \\
& $(0.981)$ & $(0.957)$ \\
$P P I \times$ Leader $(1)$ & 0.000 & 0.002 \\
& $(0.089)$ & $(0.076)$ \\
$P P I \times$ Leadeth $(1)$ & -0.018 & $-0.029^{* *}$ \\
& $(0.017)$ & $(0.014)$ \\
$P P I \times$ Leader $(1) \times$ Leadeth $(1)$ & $-0.144^{* *}$ & $-0.123^{* *}$ \\
& $(0.062)$ & $(0.052)$ \\
$N$ & 60609 & 75792 \\
"Honest" Subsample: & Yes & No \\
Interaction with honesty: & No & Yes \\
\hline
\end{tabular}

Note: All regressions include country-period, survey round and regional (province) level fixed effects as well as control variables from column (6) in Table 2.2 Afrobarometer interviewers report if they perceived the respondent as answering honestly. This measure is either used to constrain the sample or used for interactions. Standard errors clustered by region and by country-period in parentheses.

${ }^{*} p<0.10,{ }^{* *} p<0.05,{ }^{* * *} p<0.01$. 
Randomization Inference (RI) based Permutation Test The main concern with the underlying identification strategy is that the variation in the global treatment (e.g., price changes) might follow a similar secular trend as the outcome variable - the poverty index. The graphical inspection based on Figures 2.3 and 2.4 provides no indication that one of the treated groups would follow a differential non-linear trend.

Figure B.2 Randomization Inference - Producer Prices and Coethnicity

a) Producer Price Index

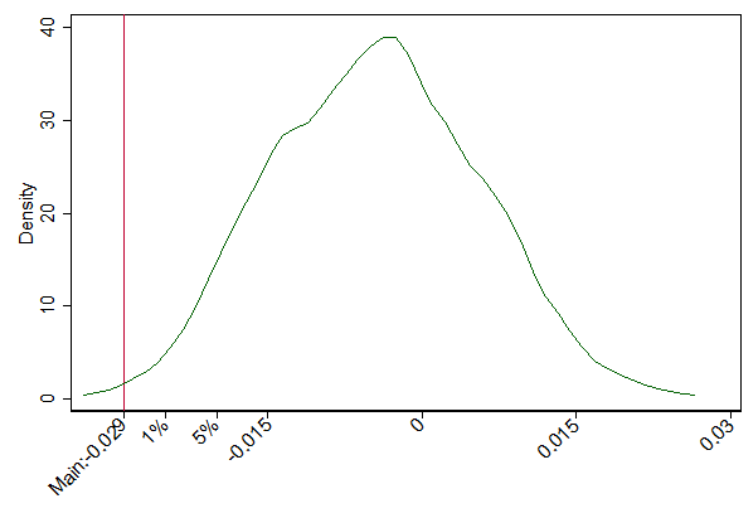

Point Estimate for Leadeth $x$ PPI b) Leader Coethnicity

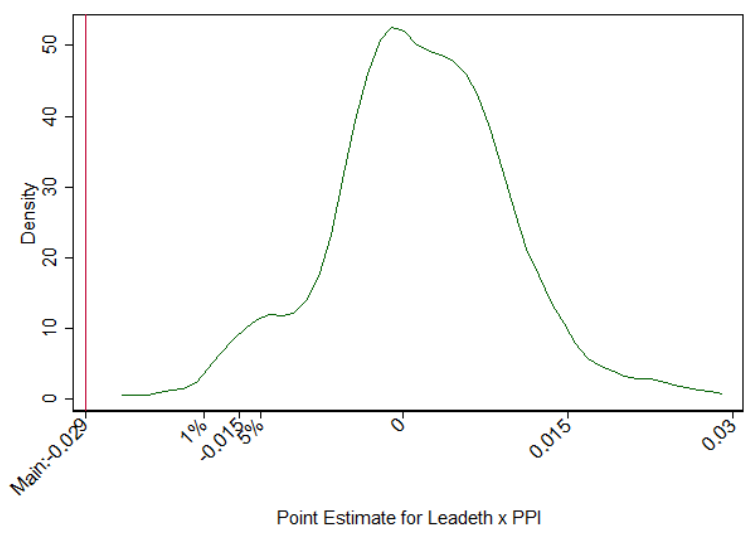

Note: Density plot of point estimates from 500 permutation tests analogous to Table 2.2 column (1).

I apply a further robustness test, where the basic idea is to assume uncertainty about the actual treatment allocation and running a permutation test analogous to R.A. Fisher's approach of statistical inference (Young, 2017). The randomization would set the hypothesized causation de facto inactive. Figure B.2 shows a density distribution of coefficients for $P P I_{\mathrm{t}} \times$ Leadeth $_{\mathrm{it}}(1)$ based on 500 permutation tests, which either randomly allocate the PPI or leader ethnicity. Randomly allocating producer prices, Figure B.2b indicates that the coefficient from column (6) of Table 2.2 would be among the top $1 \%$ of most negative coefficients. In the case of randomly allocated leader coethnicity, the picture is even clearer, where none of the 500 estimated coefficients would be as small as the original estimate from column (6). Hence, I do not find the previous pattern of differential effects for coethnic respondents if the hypothesized mechanism is not active.

Leave-one-(commodity)-out Analysis The literature has indicated strong heterogeneities across crops - e.g., some ethnicities might specialize in farming specific commodities corresponding to different degrees of labor intensity or vulnerability towards climatic shocks (see, e.g., Murdock, 1959; Sokoloff and Engerman, 2000). In order to reduce susceptibility to one of these relationships, I address this potential caveat via a "leave-one-out" analysis in Table B.12, where I exclude in each column one of the respective commodities from the cash crop index. 
The exclusion of cocoa and coffee, which are main cash crops in Cameroon, Ethiopia, Ghana, Kenya, Ivory Coast, Nigeria, Tanzania, and Uganda, has some effect on results. Notably, the coefficient for $P P I_{\mathrm{t}} \times$ Leader $_{\text {it }}(1)$ becomes statistically significant and positive, when cocoa is excluded. Moreover, the interaction for $P P I_{\mathrm{t}} \times \operatorname{Leader}_{\mathrm{it}}(1) \times$ Leadeth $_{\text {it }}(1)$ and $P P I_{\mathrm{t}} \times$ Leadeth $_{\text {it }}(1)$ become insignificant in columns (1) and (2) respectively. Yet, the main pattern of disproportionally stronger gains for coethnic respondents is robust. Coefficients point in the expected direction and either the coefficient for general ethnic biases or for ethnic biases in the leader birth region is statistically significant.

Table B.12 Robustness - Leave One Commodity Out

\begin{tabular}{lccccc}
\hline Dep. Variable: Poverty Index of individual $i$ in region $r$ in country $c$ & & \\
\hline & $(1)$ & $(2)$ & $(3)$ & $(4)$ & $(5)$ \\
& Cocoa & Coffee & Cotton & Tea & Tobacco \\
\hline PPI & 3.851 & 0.830 & 0.681 & 1.019 & 1.080 \\
& $(2.724)$ & $(1.102)$ & $(1.199)$ & $(0.966)$ & $(0.973)$ \\
PPI $\times$ Leader $(1)$ & $0.521^{* * *}$ & -0.001 & $-0.102^{* * *}$ & 0.001 & -0.001 \\
& $(0.124)$ & $(0.076)$ & $(0.038)$ & $(0.076)$ & $(0.075)$ \\
PPI $\times$ Leadeth $(1)$ & $-0.111^{* * *}$ & -0.024 & $-0.028^{*}$ & $-0.029^{* *}$ & $-0.029^{* *}$ \\
& $(0.039)$ & $(0.017)$ & $(0.014)$ & $(0.014)$ & $(0.014)$ \\
$P P I \times$ Leader $(1) \times$ Leadeth $(1)$ & -0.163 & $-0.125^{* *}$ & $-0.052^{* *}$ & $-0.124^{* *}$ & $-0.121^{* *}$ \\
& $(0.173)$ & $(0.052)$ & $(0.026)$ & $(0.050)$ & $(0.049)$ \\
$N$ & 75873 & 75873 & 75873 & 75873 & 75873 \\
& & & & & \\
\hline
\end{tabular}

Note: All regressions include country-period, survey round and regional (province) level fixed effects as well as control variables from column (6) in Table 2.2. The commodity in the column head was left out for the estimation of the producer price treatment. Standard errors clustered by region and by country-period in parentheses. ${ }^{*} p<0.10,{ }^{* *} p<0.05,{ }^{* * *} p<0.01$.

Price Makers Readers might be concerned that global commodity prices cannot be treated as exogenous for the main producers of certain crops. For instance, if farmers in Ivory Coast - the main exporter of cocoa - are affected by an unrelated poverty shock, they will be less able to invest in their cocoa plantations. This lowers the harvest in the subsequent year, which will then again contribute to poverty. Table B.13 addresses this concern by excluding crops for the construction of the PPI if the country exports $\geq 1 \%$ of the global trade volume. Given that African countries are among the main exporters for several cash crops, this is a fairly conservative robustness check. While the main effect of ethnic biases in gains from trade is retained in columns (2) and (3), the interaction with the leader birth region becomes statistically insignificant, but keeps the expected sign. Thus, the pattern is not driven by the fact that African countries are potentially price makers at international markets. 
Table B.13 Robustness - Without Price Makers

\begin{tabular}{lccc}
\hline \multicolumn{3}{l}{ Dep. Variable: Poverty Index of individual $i$ in region $r$ in country $c$} \\
\hline \multicolumn{2}{c}{$(1)$} & $(2)$ & $(3)$ \\
\hline PPI & 0.292 & 0.447 & 0.479 \\
& $(0.263)$ & $(0.274)$ & $(0.296)$ \\
PPI $\times$ Leader $(1)$ & -0.095 & & -0.020 \\
PPI $\times$ Leadeth $(1)$ & $(0.183)$ & & $(0.172)$ \\
& & $-0.183^{* * *}$ & $-0.170^{* * *}$ \\
$P P I \times$ Leader $(1) \times$ Leadeth $(1)$ & & $(0.036)$ & $(0.040)$ \\
& & & -0.137 \\
$N$ & 171872 & 124320 & $(0.126)$ \\
\end{tabular}

Note: All regressions include country-period, survey round and regional (province) level fixed effects and are structured analogously to Table 2.2 columns (1) to (3). Standard errors clustered by region and by countryperiod in parentheses. ${ }^{*} p<0.10,{ }^{* *} p<0.05,{ }^{* * *} p<0.01$.

Susceptibility to outliers Although the pattern is not driven by one specific commodity, the possibility remains that one period, country or even region is driving the results. As there is no formal statistical test to pick outliers, I address this concern by a graphical analysis in Figure B.3, which plots the PPI against the regional mean of the outcome variable. Moreover, I consider the statistical leverage in Table B.14 ${ }^{32}$

Figure B.3 Partial Regression Plots

\section{a) Countries}

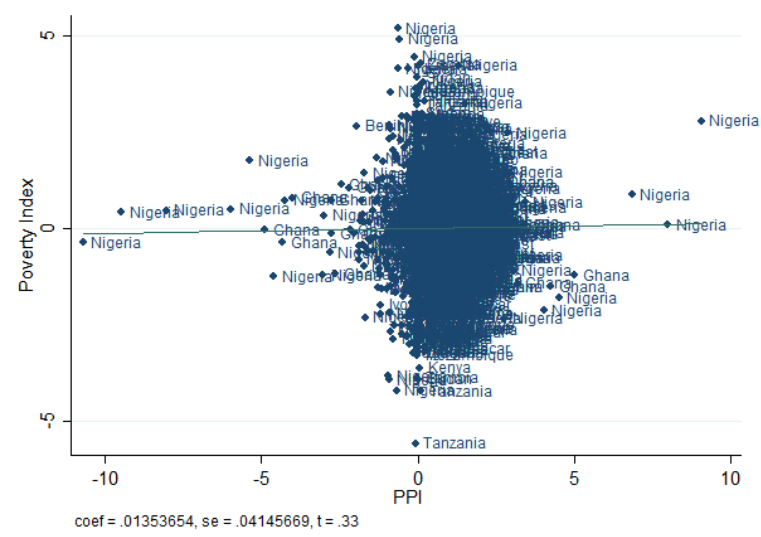

b) Years

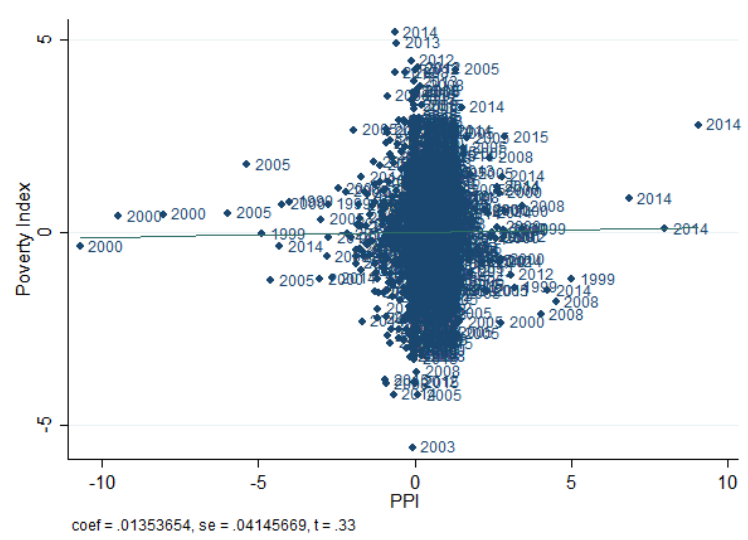

Source: Authors' calculation based on Monfreda et al. (2008), World Bank (2018b) and IMF (2018).

\footnotetext{
${ }^{32}$ For this purpose I regress regional means of the poverty index on the PPI and the set of fixed effects included in all regressions. Subsequently, I obtain the statistical leverage.
} 
Figure B.3a indicates that Nigerian regions are subject to outliers of PPI and poverty at both ends of the distribution. What is more, Figure B.3b reveals that there could be potential outliers in the years 2000, 2005 and 2014. This is potentially problematic as these observations are at the beginning and end of the time series and could, thus, induce a correlation with a time trend. Although Nigeria does not feature that frequently in the top 30 leverage observations, Table B.14 indicates that the observations at the end of the panel (2014 and 2015) have a high leverage. Those are the sampling years of the sixth Afrobarometer round and it might be problematic if one survey round would drive results (though survey round fixed effects partly account for this issue). For this reason, Table B.15 tests robustness excluding Nigerian respondents in column (1) and the years 2000, 2005, 2014 and 2015 in column (2). Although the triple interaction in the fourth row loses statistical significance in column (1), the pattern remains qualitatively unchanged and the main interaction points to significantly higher poverty reducing effects for leaders' coethnics. The robustness test in column (2) corresponds to the main pattern and indicates that high leverage years do not drive the main results.

Table B.14 Leverage - Top 20 Observations

\begin{tabular}{lccc}
\hline & $(1)$ & $(2)$ & $(3)$ \\
& Country & ADM1 & Year \\
\hline 1 & Uganda & Kampala & 2015 \\
2 & Gabon & Wouleu-Ntem & 2015 \\
3 & Nigeria & Lagos & 2003 \\
4 & Uganda & Bundibugyo & 2008 \\
5 & Algeria & Relizane & 2015 \\
6 & Gabon & Moyen-Ogooué & 2015 \\
7 & Kenya & Isiolo & 2014 \\
8 & Kenya & Samburu & 2014 \\
9 & Gabon & Ogooué & 2015 \\
10 & Niger & Diffa & 2013 \\
11 & Algeria & Tipaza & 2015 \\
12 & Egypt & Bur Sa‘id & 2015 \\
13 & Tanzania & Njombe & 2014 \\
14 & Kenya & Mandera & 2014 \\
15 & Gabon & Nyanga & 2015 \\
16 & Algeria & Mila & 2015 \\
17 & Uganda & Yumbe & 2005 \\
18 & Egypt & Aswan & 2015 \\
19 & Gabon & Haut-Ogooué & 2015 \\
20 & Kenya & Nyamira & 2014 \\
\hline
\end{tabular}

Note: Statistical leverage is based on a regression of regional mean poverty on the regional PPI as well as regional, country-period and survey round fixed effects. 
Table B.15 Robustness - Excluding High Leverage Observations

\begin{tabular}{lcc}
\hline Dep. Variable: Poverty Index of individual $i$ in region $r$ in country $c$ \\
\hline & $(1)$ & $(2)$ \\
\hline$P P I$ & 1.689 & 1.309 \\
& $(1.118)$ & $(1.052)$ \\
$P P I \times$ Leader $(1)$ & -0.060 & -0.002 \\
& $(0.052)$ & $(0.066)$ \\
PPI $\times$ Leadeth $(1)$ & $-0.046^{* * *}$ & $-0.042^{* * *}$ \\
& $(0.012)$ & $(0.012)$ \\
PPI $\times$ Leader $(1) \times$ Leadeth $(1)$ & -0.071 & -0.086 \\
& $(0.049)$ & $(0.068)$ \\
$N$ & 68847 & 59418 \\
\hline
\end{tabular}

Note: All regressions include country-period, survey round and regional (province) level fixed effects as well as control variables from column (6) in Table 2.2 Column (1) excludes Nigerian respondents, column (2) excludes the years 2000, 2005, 2014 and 2015. Standard errors clustered by region and by country-period in parentheses. ${ }^{*} p<0.10,{ }^{* *} p<0.05,{ }^{* * *} p<0.01$.

\section{Miscellaneous}

Table B.16 Heterogeneous Effects across Regime Types - Sample Split

\begin{tabular}{lcc}
\hline \multicolumn{2}{l}{ Dep. Variable: Poverty Index of individual $i$ in region $r$ in country $c$} \\
\hline & $(1)$ & $(2)$ \\
\hline$P P I$ & $12.779^{* *}$ & 1.324 \\
& $(4.665)$ & $(1.282)$ \\
$P P I \times$ Leader $(1) \times$ Leadeth $(1)$ & $-0.227^{* * *}$ & -0.121 \\
& $(0.046)$ & $(0.073)$ \\
$P P I \times$ Leader $(1)$ & 1.399 & -0.064 \\
& $(1.345)$ & $(0.084)$ \\
$P P I \times$ Leadeth $(1)$ & $-0.062^{* * *}$ & 0.003 \\
& $(0.021)$ & $(0.028)$ \\
$N$ & 40402 & 35471 \\
\hline
\end{tabular}

Note: Sample split analogous to column (6) of Table 2.2 Standard errors clustered by region and by country-period in parentheses.

${ }^{*} p<0.10,{ }^{* *} p<0.05,{ }^{* * *} p<0.01$. 


\section{Unequal Gains from Trade}

Table B.17 Pre Trends of Power Status and Producer Prices

Dep. Variable: Binary power status of individual $i$ in region $r$ in country $c$

\begin{tabular}{|c|c|c|}
\hline & $\begin{array}{c}\quad(1) \\
\text { Leader } \\
\text { Region }\end{array}$ & $\begin{array}{c}(2) \\
\text { Leader } \\
\text { Ethnicity }\end{array}$ \\
\hline$P P I$ & $\begin{array}{l}-0.1626 \\
(0.1989)\end{array}$ & $\begin{array}{c}0.0714 \\
(0.0620)\end{array}$ \\
\hline$N$ & 115662 & 76919 \\
\hline \multicolumn{3}{|c|}{$\begin{array}{l}\text { Note: All regressions include country-period, } \\
\text { survey round and regional (province) level } \\
\text { fixed effects and are structured analogously } \\
\text { to column }(6) \text { in Table } 2.2 \text {. Standard errors } \\
\text { clustered by region and by country-period in } \\
\text { parentheses. } \\
{ }^{*} p<0.10,{ }^{* *} p<0.05,{ }^{* * *} p<0.01 \text {. }\end{array}$} \\
\hline
\end{tabular}

Table B.18 Correlation - Lights \& Producer Prices

Log of night light emission in country-region $\mathrm{cr}$ in period $t$

\begin{tabular}{lcc}
\hline PPI & -0.0065 & \\
& $(0.0042)$ & \\
PovertyIndex & & -0.0018 \\
& & $(0.0016)$ \\
$N$ & 1088 & 1088 \\
\hline
\end{tabular}

Note: All regressions include period and regional (province) level fixed effects. Standard errors clustered by region and by country-period in parentheses. ${ }^{*} p<0.10,{ }^{* *} p<0.05,{ }^{* * *} p<0.01$. 
Table B.19 Correlation of Poverty Index and Expenditure

\begin{tabular}{lcc}
\hline \multicolumn{3}{l}{ Dep. Variable: Regional average of Poverty Index (0-25) } \\
\hline \multicolumn{3}{l}{$(1)$} \\
\hline Expenditure p.c.c,r,t & $-0.0021^{* * *}$ & $-0.0017^{* *}$ \\
$N$ & $(0.0000)$ & $(0.0001)$ \\
$N$ & 75 & 75 \\
Country FE: & No & Yes \\
Year FE: & No & Yes \\
\hline
\end{tabular}

Note: Expenditure data are based on Living Standard Measurement Surveys. Standard errors clustered by country in parentheses. ${ }^{*} p<0.10,{ }^{* *} p<0.05,{ }^{* * *} p<0.01$.

Table B.20 Robustness - Controlling for Conflict

\begin{tabular}{|c|c|c|c|}
\hline & (1) & $(2)$ & $(3)$ \\
\hline$B R D \times$ Leadeth $(1)$ & $\begin{array}{l}-0.002 \\
(0.002)\end{array}$ & $\begin{array}{l}-0.002 \\
(0.003)\end{array}$ & $\begin{array}{c}0.001 \\
(0.002)\end{array}$ \\
\hline$B R D \times$ Leader $(1) \times$ Leadeth $(1)$ & $\begin{array}{c}0.055 \\
(0.049)\end{array}$ & $\begin{array}{c}0.048 \\
(0.048)\end{array}$ & $\begin{array}{c}-0.033 \\
(0.040)\end{array}$ \\
\hline$B R D \times$ Leader $(1)$ & $\begin{array}{l}-0.047 \\
(0.049)\end{array}$ & $\begin{array}{l}-0.053 \\
(0.034)\end{array}$ & $\begin{array}{c}-0.011 \\
(0.053)\end{array}$ \\
\hline$B R D$ & $\begin{array}{c}-0.001 \\
(0.001)\end{array}$ & $\begin{array}{c}-0.001 \\
(0.001)\end{array}$ & $\begin{array}{c}-0.001 \\
(0.001)\end{array}$ \\
\hline$P P I$ & $\begin{array}{c}0.966 \\
(0.968)\end{array}$ & $\begin{array}{c}1.117 \\
(1.022)\end{array}$ & $\begin{array}{c}1.060 \\
(0.952)\end{array}$ \\
\hline$P P I \times$ Leader $(1)$ & $\begin{array}{l}-0.079 \\
(0.053)\end{array}$ & & $\begin{array}{l}-0.001 \\
(0.077)\end{array}$ \\
\hline$P P I \times$ Leadeth $(1)$ & & $\begin{array}{c}-0.050^{* * *} \\
(0.015)\end{array}$ & $\begin{array}{c}-0.028^{* *} \\
(0.014)\end{array}$ \\
\hline$P P I \times$ Leader $(1) \times$ Leadeth $(1)$ & & & $\begin{array}{c}-0.126^{* *} \\
(0.050)\end{array}$ \\
\hline$N$ & 75873 & 75873 & 75873 \\
\hline
\end{tabular}

Note: All regressions include country-period, survey round and regional (province) level fixed effects as well as control variables from column (6) in Table 2.2 The battle related death count variable is based on Croicu and Sundberg (2015). Standard errors clustered by region and by country-period in parentheses. ${ }^{*} p<0.10,{ }^{* *} p<0.05,{ }^{* * *} p<0.01$. 


\title{
Chapter 3
}

\section{Aid and conflict at the subnational level \\ - Evidence from World Bank and Chinese development projects in Africa}

Joint work with Kai S. Gehring and Melvin H. L. Wong.

\begin{abstract}
Using georeferenced data on development projects by the World Bank and China, we provide a comprehensive analysis of the effect of aid on conflict using fixed effects and instrumental variables strategies. The results show that aid projects on average seem to reduce rather than fuel conflict. Our analysis suggests that this is driven by projects in the transport and financial sectors, and by less lethal violence by governments against civilians. There are no clear differences based on ethnic fractionalization and government affiliation of a region, but some indications of spill-overs to other regions. We also find no increased likelihood of demonstrations, strikes or riots associated, but a higher likelihood of non-lethal government repression in areas where China is active.
\end{abstract}



Aid and conflict at the subnational level

\subsection{Introduction}

Development aid has been criticized on several grounds, e.g., for being politicized (Dreher et al., 2018) or lacking effectiveness (Doucouliagos and Paldam, 2009). However, one of the most alarming concerns is the suggestion that aid fuels conflict in the receiving countries. Nunn and Qian (2014), for instance, show that US food aid leads to more conflict, by using US wheat production to explain variation in the supply of food aid. In contrast, Berman et al. (2011) use localized data to document that specific types of development projects succeed in reducing conflict in Iraq. Generally, the existing literature on the relationship between aid and conflict is focusing rather on the macro level (Nielsen et al., 2011; Nunn and Qian, 2014; Bluhm et al., 2016), specific types of aid (Berman et al., 2011; Crost et al., 2014; Child, 2018), or on a limited subset of countries (van Weezel, 2015; Crost et al., 2016; Sexton, 2016).

Our paper aims to combine the strength of the existing approaches. We consider a large set of countries in Africa to draw broader implications, but use subnational data to link aid projects and conflict events more precisely. This enables us to rule out concerns about omitted variables and better understand the underlying mechanisms. A deeper understanding of the impact of development projects is currently of particular relevance, because fragile, conflict-prone states are described as the "new frontier of development. ${ }^{1}$ In this regard important donors, like the World Bank and the UK, plan to increase their activities in those countries.

Our study makes three major contributions. First, we cover aid projects in a broad set of developing countries in all of Africa and are able to assign projects locations to specific subnational administrative units (Strandow et al., 2011; Strange et al., 2017). This degree of precision in our dataset allows us to flexibly control for a wide range of potentially distorting factors through fixed effects, time trends and observable regionspecific factors. To further reduce endogeneity concerns, we also propose an instrumental variable strategy that combines spatial variation in the region's pre-determined likelihood to receive projects with temporal variation that is exogenous to conflict in particular regions.

Second, we consider two donors that represent contrasting types of projects and approaches to development. The World Bank (WB) is a multilateral donor that emphasizes scientific expertise and expert knowledge, frequently imposes human-right and sustainability conditions, and aims not only at growth but also at social and political improvements in destination countries. China, in contrast, is not a member of the OECD's Development Assistance Committee (DAC) and often portrayed as a "rogue" donor (Naím, 2007). China conducts a policy of "non-interference" in the internal affairs of recipient countries and emphasizes economic "mutual benefits." In addition, Chinese economic goals such as securing resource supply are observed as well and might be incompatible with interests of local communities. It seems plausible to expect that WB projects are less likely to cause conflict, whereas Chinese engagement is often seen more

\footnotetext{
${ }^{1}$ See The Economist (2017), last accessed June 14, 2018.
} 
Aid and conflict at the subnational level

critically and accused of fueling conflict and repression (Raleigh et al., 2010). Comparing two extreme ends of the spectrum provides a good impression of the underlying relationship.

Third, we can consider aid projects in various sectors, and distinguish between conflict actors and types. In addition, we can exactly identify the regions within countries where development projects are implemented, and where conflicts take place. We use data on the spatial distribution of ethnic homelands, which we intersect with the administrative regions, and combine with data about the group's status as belonging to the governing coalition or not. This allows us, for instance, to measure whether more aid to regions controlled by the government increases the likelihood of government violence in non-governing coalition regions. By combining spatial data on development projects and conflict actors we are, thus, able to also test specific mechanisms.

Using subnational data is, hence, not just a matter of more detail and precision, but opens the opportunity to better understand and distinguish between different theories. There are, generally, two main mechanisms emphasized in the literature linking aid to conflict. On the one hand, the opportunity cost hypothesis claims that higher resources and the associated revenues, as well as higher incomes, make it less likely that people join rebel groups or fight (Collier and Hoeffler, 2004, McGuirk and Burke, 2017). On the other hand, resources may be regarded as a price of winning control, and the contest (or rapacity) theory suggests that a higher price sets an incentive to engage into combat (e.g., Grossman, 1992). Still, there are several other possible channels besides these prominent main theories that we describe in more detail below.

To test for a potential effect of aid projects on conflict, we make use of georeferenced project level data for the WB and China, available due to the efforts of various scholars (see Strandow et al., 2011; Dreher et al., 2016, Strange et al., 2017) associated with AidData. With US\$ 13.4 bn disbursed in 2014 (World Bank, 2017b), the WB's foreign aid arm "the International Development Association (IDA)" is arguably the most important multilateral donor organization in the World. At the same time, China is continually expanding its development and investment activities. Recently, the One Belt, One Road initiative was prominently and controversially discussed, but China's engagement in Africa has started to expand considerably already in the late 1990s.

In order to further establish causality, we use an identification strategy combining pre-determined cross-sectional variation interacted with a conditionally exogenous time series (as in Dreher et al., 2017, Bluhm et al., 2018, Gehring and Lang, 2018 and Lang, 2016). Following Nunn and Qian (2014) and Bluhm et al. (2018), we create cross-sectional variation by computing the probability that a region receives aid from a donor. Based on Dreher et al. (2017), we use official information on the World Bank's funding position and Chinese excess steel production (World Steel Association, 2014) as temporal variation that is arguably exogenous to conflict in individual regionyears when conditioning on regional and country-year fixed effects. Our results provide several important insights. Most importantly, the OLS and IV specifications provide no indication that aid fuels conflict on average. For the World Bank, a 10\% increase in aid even seems to reduce the likelihood of a conflict by up to two percentage points. This 
Aid and conflict at the subnational level

result becomes insignificant when using an IV specification, however. More surprisingly, there is also no conflict fueling relationship for Chinese aid on average. The point estimates are mostly negative, but close to zero and in almost all cases statistically insignificant.

Starting from these results, we then investigate heterogeneous effects and examine some hypotheses in more detail. Regarding projects in different sectors, we find a significant negative relationship between projects in the finance sector (WB only), as well as in the transportation sector (WB and China). Aid in no sector is related to significantly more conflict. When considering conflict actors, we find that both WB and Chinese engagements seem to lead to a reduction in lethal violence by governments against civilians in the respective regions and years. We also find no evidence of a conflict-fueling effect when considering different levels of aggregation, setting a higher threshold of battle-related deaths for our conflict indicator, or when using the continuous number of deaths instead. Additional specifications related to, among others, spill-overs, the clustering of standard errors, and taking account of ethnic groups expand upon these main results and are explained in detail in the respective sections.

Subsequently, we examine types of conflicts that might remain overlooked with our main outcome variable, which is based on the number of battle-related deaths. Specifically, we consider lower level types of conflict like demonstrations, riots and strikes, as well as repression used by governments against the population. For both donors, we find no positive effect on any of the first three measures. We do, however, find that an increased Chinese engagement leads to an increase in non-lethal government repression.

The paper proceeds as follows. Section 2 summarizes the existing literature and outlines proposed theories linking development finance to conflict. Section 3 explains the data and the corresponding sources, and provides descriptive statistics. Section 4 presents the specification and empirical strategy. Section 5 shows and discusses the results, and Section 6 concludes.

\subsection{Existing Literature and theoretical considera- tions}

\subsubsection{Literature and theories}

Many papers have linked development aid to conflict in different ways. The underlying theories, if spelled out explicitly, however, often make diverse and contradictory predictions. Generally, aid can be considered as a type of windfall income shock, linking this literature to the larger research field on (resource-related) income shocks and conflict (e.g., Berman and Couttenier, 2015; Caselli et al., 2015; Morelli and Rohner, 2015: Berman et al., 2017). The literature then proposes two main mechanisms on how aid affects conflict. The opportunity costs mechanism (e.g., Grossman 1991; McGuirk and Burke 2017) and the contest model (e.g., Hirshleifer 1989, 1995). The first the- 
ory hypothesizes that with a rise in income the opportunity costs of fighting increase (McGuirk and Burke, 2017), leading to less conflict on average. Similarly, if aid commitments are withdrawn, e.g., negative aid shocks occur, recipient governments' ability to make credible commitments is weakened and citizens' opportunity costs of engaging into conflict are reduced (Nielsen et al., 2011; Strange et al., 2017). The contest model, or rapacity effect, in contrast, predicts that with higher income the potential gains from fighting increase. This makes fighting more attractive, both for groups as the payoff to "winning" control increases and for individuals who are offered higher wages for fighting in expectation of higher gains (Collier and Hoeffler, 2004). Considering aid projects and conflict in the same unit of observation can reflect both those channels. This is the main approach of our analysis, resembling Figure 3.1 a.).

Figure 3.1 Scenarios Linking Aid to Conflict

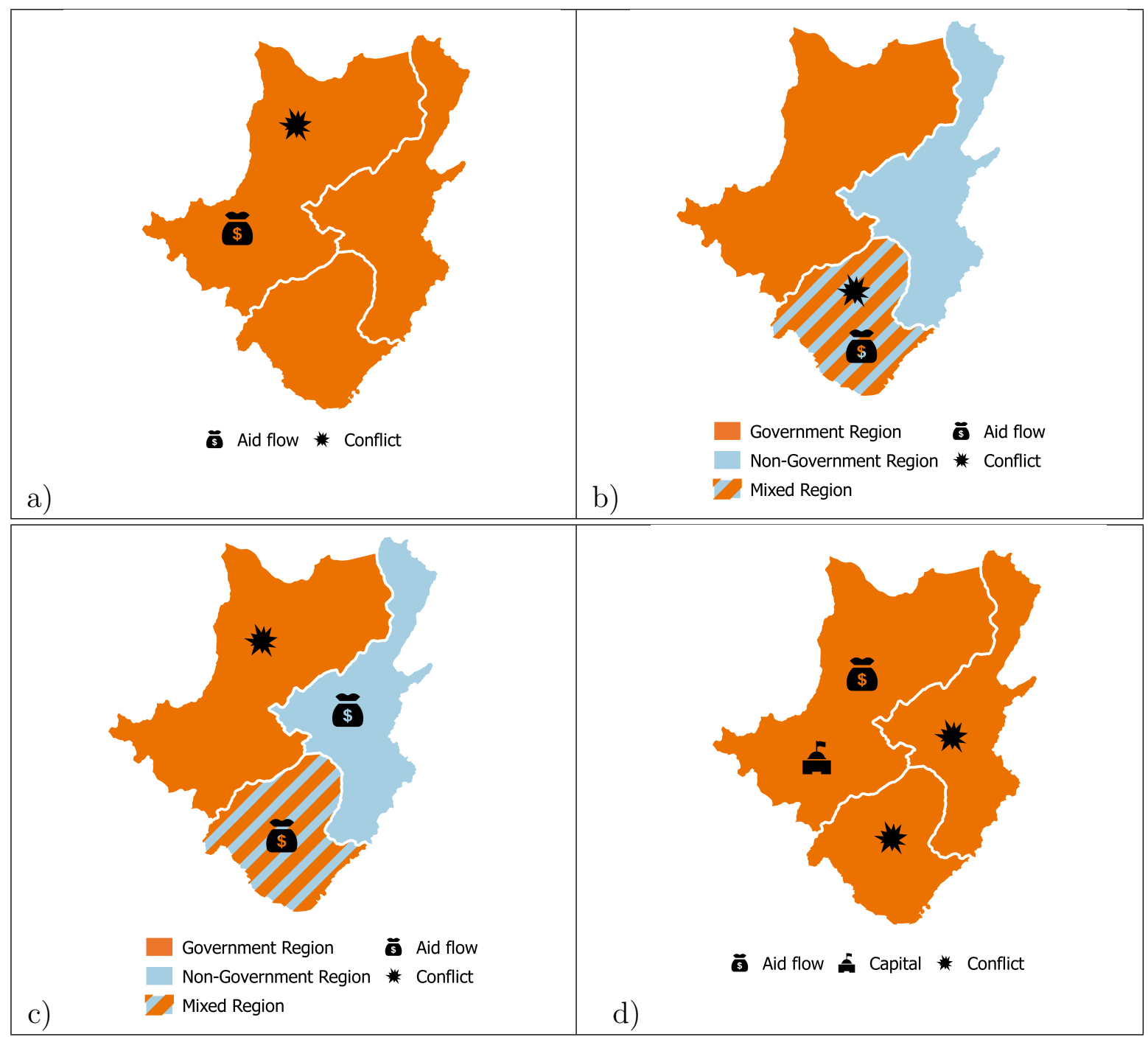

Source: Authors' own depiction. 
Aid and conflict at the subnational level

As suggested above, the distributional dimension is important as conflict in many African countries is often best characterized as conflict between opposing groups and coalitions, less often between individuals (Cederman et al., 2009). In many cases, existing tensions between ethnic groups can be amplified or dampened by foreign aid projects. Still, the incentives can be very different in regions controlled by the government or by ethnic groups that are part of the governing coalition, than in other regions. To examine a potential contest effect, where groups "fight" for the prize of holding the government, more accurately, we distinguish between different groups of regions. More specifically, we distinguish between (i) regions controlled by the government, (ii) those being composed of ethnic groups that are not part of the ruling coalition, and (iii) mixed regions.

Aid is usually controlled by the government and can help to undermine the political power of opposing groups and increase support for the government (Beath et al., 2012). Crost et al. (2014) suggest that rebel groups sabotaged a large community-driven development program in the Philippines anticipating that it might be successful and weaken support for the rebels. Sexton (2016) shows that aid is associated with increases in insurgent violence in contested districts. Figure 3.1 b.) shows an example of a specification focusing on regions, which are home to ethnic groups with differing power status and, hence, more likely to be contested. Similarly, we can also restrict the analysis to government-controlled regions, as Berman et al. (2013) postulate that communities profit from aid projects only in areas controlled by the government.

Another large strand of the literature revolves around equity questions of local revenues from resources (Morelli and Rohner, 2015). In this regard, the importance of inter-group grievances is stressed, which would particularly play a role in the ethnically diverse sub-Saharan African region (Østby, 2008, Cederman et al., 2011, Michalopoulos and Papaioannou, 2016). To explore this, we test whether the relationship between development projects and conflict differs between highly fractionalized and more homogeneous regions.

Moreover, intra-country spill-over effects are typically not considered. Aid payments in one region might not fuel conflict in the region itself, but increase it in other regions. Again, existing theories provide hypotheses about such a relationship that we can put to an empirical test. For instance, other research emphasized that aid payments are largely fungible. This means that governments that receive health aid might cut their own health expenditures, and use the free funds to bolster military spending. Kishi and Raleigh (2015) suggest that if a country receives Chinese aid, its military increases its violence against civilians (including bombing them). Moreover, the government might use developmental funds to increase its control over minorities' homelands, which could induce backlash effects by the "sons of the soil" (Fearon and Laitin, 2011). The same holds for aid to regions controlled by rebel groups. A higher military capacity by one conflict party can be used to attack regions controlled by rival groups or mixed regions that feature both government-related and other groups. At the same time, a more capable military might make it less likely that the respective other parties dare to attack. The direction of the net effect is again theoretically unclear. Figure 3.1 c.) 
Aid and conflict at the subnational level

depicts this case for the example of aid flowing mainly to non-coalition regions (and potential rebel groups) as well as measuring conflict in regions that are part of the governing coalition. Figure 3.1 d.) depicts this case for the example of aid flowing mainly to the capital and measuring conflict in regions outside the capital. ${ }^{2}$

Nonetheless, our data also allow us to distinguish more nuanced theories and test them empirically. For instance, when considering development aid as a potential price for opposing groups, this would not apply equally to all types of aid. We can distinguish between different aid types, some of them with output that is hard to loot (e.g., a street or bridge) and others making looting more likely (e.g., expensive health equipment in hospitals). The prior literature has also pointed towards an interesting incentive aid can set for recipient governments. In order not to lose aid, they might be more reluctant to engage in conflict actions that appear unnecessary or overly violent to reduce the risk of being shamed at the international stage (Lebovic and Voeten, 2009). We test both hypotheses by considering aid flows, specifically, to the capital region or regions associated with the governing coalition, and relating those to higher or lower conflict in other regions of the same country (e.g., Figure 3.1 d.).

Returning to the main theories, whether aid succeeds in raising average incomes and, thus, increases opportunity costs is fiercely discussed in the aid effectiveness literature. The results converge towards a null on average (Doucouliagos and Paldam, 2009) or only small positive effects (Galiani et al., 2017). This effect is, however, depending on whether aid was politically motivated or had a clearer development focus (Dreher et al. (2018). Thus, the motivation of donors can be important. Accordingly, whether and to what extent aid projects raise income at the regional level depends on the circumstances. The effect is most likely quite heterogeneous, comprising both negative and positive impacts.

When comparing the impact of aid projects to the gains from resource-related income shocks (Berman et al., 2017; Gehring et al., 2018), it becomes clear that in both cases the distribution of gains is also important. Dube and Vargas (2013) document that in the case of Colombia, higher resource prices lowered conflict if the resource was more labor-intensive. In contrast, if it was more capital intensive and the gains most likely accrued only to a small elite, price spikes fueled conflict. Similarly, there will be groups or people that profit from aid (the money must always go somewhere), but whether these gains are used for short-term consumption, invested in fostering development or ending up in the foreign bank accounts of government officials is unclear.

One aspect where aid differs from other shocks, prominently featured in the literature, is that donors can to some extent impose which conditions and procedures need to be respected during the implementation. Minasyan et al. (2017), for example, demonstrate the importance of donor quality for aid effectiveness and Berman et al. (2013) hypothesize that projects are more successful in reducing violence if they require the integration of development experts. Aid can also be earmarked for certain

${ }^{2}$ Further work also stresses the context specificity of aid (e.g., resource endowments or institutions) as well as its role for conflict dynamics (De Ree and Nillesen, 2009, Bluhm et al., 2016, Strange et al., 2017 ) - two aspects, which we leave for further research on the local level . 
Aid and conflict at the subnational level

projects or sectors, for instance generally for infrastructure or specifically for building a particular school or hospital, which is a second conceptual difference compared to other windfall income gains. Berman et al.'s (2011) analysis of development projects in Iraq, for instance, suggests that only a small share and specific types of projects have a conflict-reducing effect.

Considering donors that reflect the different ends of the distribution along those dimensions, can crucially contribute to evaluating the effect of aid on conflict more systematically than the existing literature. The next section explains shortly why the WB and China differ consistently with regard to (i.) the use of conditionality, (ii.) the use of development expert knowledge, and (iii.) the focus of their projects.

\subsubsection{Two Types of Donors: China versus the World Bank}

The WB mostly reflects a model of conditional aid integrating expert knowledge with a clear focus on development, whereas China specifically highlights non-interference, mutual economic benefits and room to maneuver for the recipient governments. This is visible along three dimensions. First, conditionality is very common and used intensively by the WB. Projects often have a large variety of conditions attached ranging from human rights and democratic procedures to gender equality. Second, the WB employs a large team of academics and country experts with the aim to ensure that aid is spent effectively. Third, WB projects have a rather clear focus on development and supporting particular democratic institutions as well as civil organizations. Although there is also some political influence on WB decisions (Dreher et al., 2018), its projects are less politically motivated than other types of aid (e.g., Dreher et al., 2009).

The World Bank's aid arm provided 16.8\% of funding of traditional Western donors between 1995 and 2012. This makes IDA the second largest donor after the EU institutions (18.7\%) and before UN agencies (6.4\%) (OECD, 2017). As mentioned above, there are concrete plans to intensify and scale-up its involvement in conflict-prone regions. For instance, the World Bank has spent up to 500 million in the Central African Republic, approximately a third of the country's GDP, to prevent the fragile state from sliding back into civil war. The Kecamatan Development program, which was directed by the World Bank Group in cooperation with the Indonesian government, was designed to reduce conflict probability via a transparent and participatory approach Gibson and Woolcock, 2005; Barron et al., 2011). Nevertheless, WB projects have also been linked to increases in civil unrest and conflict. The construction of the Pak Mun hydroelectric dam in the rural north-east of Thailand, for instance, sparked widespread protests due to complaints that it displaced families, destroyed local fish stocks and wrecked irrigation systems. ${ }^{3}$

China, in contrast, is the most prominent example of an emerging "rogue" donor (Naím, 2007), that is not a member of the OECD's traditional Development Assistance Committee (DAC). It is constantly expanding its activities in Africa, and during the

\footnotetext{
${ }^{3}$ See The Economist, "Rural unrest," last accessed June 14, 2018.
} 
Aid and conflict at the subnational level

2000-2012 period, its official development aid (ODA) commitments equaled $17.8 \%$ of US aid commitments (based on OECD, 2017; Strange et al., 2017). When considering ODA and other official finance (OOF) activities USAID and Chinese aid are en par. 4 The country is often characterized as ignoring conditions on human rights and good governance practices, in particular by the Western world and media. One example is Ethiopia, where large energy projects allegedly ignored the needs and demands of the local population. As another case in point, China's president has visited and himself welcomed Zimbabwe's former president Mugabe, contrasting efforts of Western donors to sanction the country for electoral fraud and human right abuses. $5^{5}$ At another instance, Uganda turned to China to increase its engagement, after Western donors protested against strict "anti-gay" laws in the country. ${ }^{6}$ Regarding conditions and focus, the Chinese perspective is to run a policy of "non-interference" in the internal affairs of recipients, where projects are more often directly offered to state leaders and regimes focusing on economic "mutual benefit.' 7 In this regard, Dreher et al. (2016) find that Chinese projects in Africa are more likely to benefit the birth regions of the respective leader, i.e., seem to be allocated less on a need-base. The implementation is in most cases left to a larger degree to the respective partner governments, although there are some cases where projects have been mostly implemented by China and Chinese workers.

In contrast, Western development projects have also been criticized for a lack of "ownership" and missing use of local knowledge in recipient countries. Hence, the Chinese approach can have an upside, which several African countries have also welcomed along with the larger focus on developing common business interests. 8

Empirically, Dreher et al. (2018) and Fuchs and Vadlamannati (2013) suggest that the degree to which the Chinese government considers demand-side humanitarian and socioeconomic needs is comparable to Western donors. Even though China puts less emphasis on strict human rights conditions, China's increasing focus on humanitarian issues becomes evident in its growing role in UN peacekeeping missions over time and its official aim to "play a constructive role of settling conflicts and hot issues and

${ }^{4}$ Strange et al. (2017) as cited in Reuters, "New database focuses on China's secretive aid to Africa,"last accessed October 8, 2018. The authors refer to the OECD definition where OOF comprises "[t]ransactions by the official sector with [developing] countries [...] which do not meet the conditions for eligibility as Official Development Assistance, either because they are not primarily aimed at development, or because they have a grant element of less than 25 per cent."

${ }^{5}$ Washington Post, "When China gives aid to African governments, they become more violent", last accessed July 26, 2018.

${ }^{6}$ See The Diplomat, "Uganda Looks to China," last accessed July 26, 2018.

${ }^{7}$ David Shinn on Chinausfocus, "Africa Test's China's Non-interference Policy," last accessed July 26, 2018.

${ }^{8}$ Anthony Germain on CBC, "China in Africa: No strings attached," last accessed September 12, 2018. 
Aid and conflict at the subnational level

maintaining peace and security in Africa.? 9 What is more, with its expanding activities and larger presence of Chinese employees in Africa, it also has a rising interest in avoiding conflicts that threaten the value of its investments or the life of its citizens.

To sum up, when considering the mechanisms highlighted above, it becomes apparent that almost all of them work at the subnational level, whereas most of the literature operates with national level data. When aggregating both aid and conflict data at the national level most of the postulated conflict theories are indistinguishable from each other. To analyze channels in more detail with the help of subnational data, we differentiate between (i.) different types of aid, (ii.) different actors, (iii.) regional attributes (e.g., fractionalization and power status), (iv.) different spatial aggregations and (v.) spatial spill-overs. We will compare two donors. The WB with its strong use of conditionality and expert knowledge, as well as its clear development focus should theoretically have a low likelihood of leading to conflict. China, in contrast, is a donor that most observers would deem much more likely to fuel conflicts due to the lack of human rights conditions, more leeway for local politicians and a stronger focus on business interests.

\subsection{Data}

\subsubsection{Aid Data}

Our unit of observation is the country-region-year, and the unit of analysis is the first level of subnational administrative regions, henceforth ADM1 or regions (data from Hijmans et al., 2012). The names of ADM1 regions vary by country but are commonly known as "provinces" or "states." We choose those ADM1 regions as the main unit over lower level administrative regions (ADM2), ethnic groups, or grid-cells. Figure 3.2 shows that georeferenced projects alone, those that contain latitude and longitude coordinates, comprise only less than $50 \%$ of overall projects. Taking projects assigned to ADM2 and ADM1 regions also into account ensures that a reasonable share of total aid is covered. ${ }^{10}$ The right hand side shows that for both China and the World Bank this allows us to exploit variation covering over $90 \%$ of the overall spending by the two donors in Africa. Note that we capture a lower fraction of projects for China, but these are mostly smaller projects. The first order administrative level is also highly relevant

\footnotetext{
${ }^{9}$ See saferworld.org.uk, "China's growing role in African peace and security" and The Guardian, "New report discusses China's role in Africa's conflicts," last accessed July 26, 2018. Moreover, The Guardian, for instance, postulates that "Chinese aid to Africa is going to come with all sorts of strings attached, despite the "no-conditionality rhetoric." The Guardian: "The west has no right to criticise the China-Africa relationship,", last accessed August 30, 2018.

i"The World Bank officially releases information on its disbursements. In contrast, the only opportunity to compile information on Chinese projects is the open source data collection on commitments. In line with Dreher et al. (2017), who show that "project duration amounts to 664 days" on average, we take this into account by assuming a two year lag until which Chinese aid projects would become effective.
} 
for aid allocation, as many projects are assigned to specific regions, and the regional government can decide how or where to spend the money, which is relevant for conflict outcomes.

Figure 3.2 Distribution of Georeferencing Precision

a) Project Locations

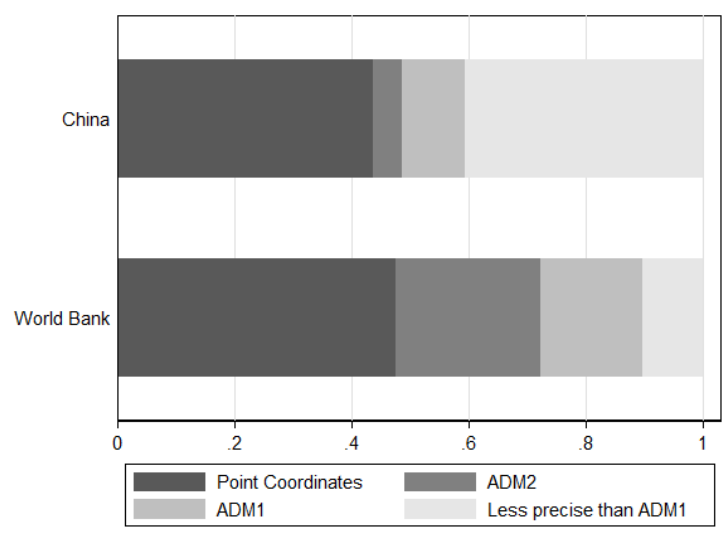

b) Disbursement / Commitment Amounts

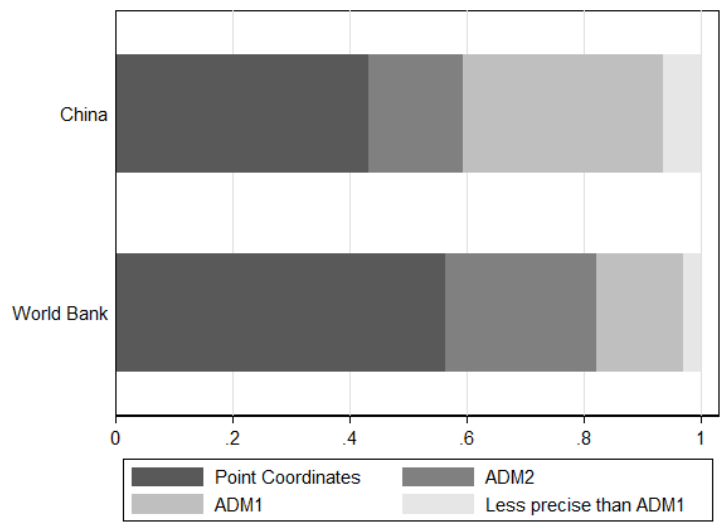

Source: Authors' calculation based on Strandow et al. (2011), Dreher et al. (2016) and Strange et al. (2017).

Precisely georeferenced projects and projects where we possess information about the ADM2 regions are assigned to the respective ADM1 region. In most cases, projects also have several locations. When processing the project level data, we assume that aid is distributed equally across locations and allocate aid proportionally to the locations per region, which is in line with previous research (Dreher and Lohmann, 2015). For instance, for a project with 10 locations, where four locations are in region $\mathrm{A}$ and six locations are in region $\mathrm{B}, 40 \%$ of project volume would be accounted in region $\mathrm{A}$ and $60 \%$ in region $\mathrm{B} .11$

The data appendix provides more details. The remainder with less precise locations is mostly non-geocoded aid accruing directly to the government, which we assign to the capital region in a robustness test when considering potential spill-overs. We show results using the ADM2 regions as a robustness test in the appendix, and incorporate ethnic group homelands by intersecting those with the regions.

Table 3.1 shows a comparison of the two donors in some important dimensions. While information for aid disbursements by World Bank's IDA is available from 1995 to 2012, information on Chinese aid commitments in Africa is constrained to the years

\footnotetext{
${ }^{11}$ Hence, our aid attribution formula is: $A i d_{p i j t}=\frac{\text { Aid }_{p i t}}{\int \text { Locations }_{p i}} * \int$ Locations $_{p j}$, where $\mathrm{p}$ is the project, $\mathrm{i}$ is the country, $\mathrm{j}$ is the region and $\mathrm{t}$ is the period for which we estimate the allocation shares.
} 
Aid and conflict at the subnational level

2000 to 2012 ${ }^{12}$ Over the sample period, the World Bank still outspends China with USD 29.4 bn compared to USD 13.2 billion 13

Table 3.1 Donor Comparison - WB versus China

\begin{tabular}{lcc}
\hline & World Bank Aid & Chinese Aid \\
\hline Total Disbursements / Commitments (USD): & $29.4 \mathrm{bn}$ & $13.2 \mathrm{bn}$ \\
Active in number of Countries: & 35 & 41 \\
Number of projects: & 1,472 & 333 \\
Number of locations: & 25,041 & 1,308 \\
Mean number of locations per project: & 17 & 4 \\
Mean per project (USD): & $19.97 \mathrm{~m}$ & $39.63 \mathrm{~m}$ \\
Mean per location (USD): & $1.17 \mathrm{~m}$ & $10.09 \mathrm{~m}$ \\
Years covered: & $1995-2012$ & $2000-2012$ \\
\hline \hline
\end{tabular}

Notes: Aid is measured in constant 2011 USD.

Both are active in most African countries, 35 for the World Bank and 41 for China. They are, thus, mostly active in the same set of countries (Humphrey and Michaelowa 2018), which adds to the comparability of donors. One interesting difference is that the World Bank finances a larger number of projects which then also have more locations across countries on average. China finances fewer but larger projects. Accordingly, China spends nearly twice as much per project and nearly ten times as much per project location.

We focus our analysis on the African continent and on countries with more than 1 million inhabitants and include all countries, which were on the OECD's DAC recipient list in the initial year of 1995. The remaining sample comprises 728 ADM1 regions in 45 countries. Table 3.2 provides summary statistics of our most important analytical variables at the country-region-year level. With regard to the main treatment variables World Bank and Chinese Aid, it becomes visible that the World Bank provides higher levels of aid on average (e.g., USD 2.2 million versus USD 1.4 million per region-year).

\footnotetext{
${ }^{12}$ This analysis focuses on Official Development Aid (ODA) flows in contrast to other official finance (OOF). OOF also plays a large role in China's finance portfolio, but has a less development oriented focus. The WB also augments its ODA with the International Bank for Reconstruction and Development (IBRD), which provides development finance in the form of loans with interest rates closer to market rates. However, we expect a clearer relationship between aid and conflict than with less concessionary development finance. One reason is that the domestic government's role in distributing concessionary development aid might increase the risk of distributive conflicts. Moreover, as development finance is acquired on a loan basis, the respective government has to pay it back and, hence, has larger incentives to invest it in a sustainable way.

${ }^{13}$ This also holds for the shorter 2000 to 2012 period (USD $27.9 \mathrm{bn}$ ).
} 
Aid and conflict at the subnational level

However, the large standard deviation indicates that Chinese aid has a higher degree of variation, with the maximum Chinese spending per region-year being USD 900 million - nearly twice as large as the highest value for the WB. The high project values indicate China's large involvement in mega-projects to fund infrastructure including dams and power plants.

Table 3.2 Descriptive statistics - ADM1 Region

\begin{tabular}{lcccc}
\hline & Mean & SD & Min & Max \\
\hline World Bank Aid & $2,240,340$ & $8,991,909$ & 0 & $488,643,178$ \\
$\ln ($ WB Aid) & 6 & 9 & -5 & 20 \\
Chinese Aid & $1,391,272$ & $22,843,120$ & 0 & $900,000,000$ \\
$\ln ($ Chinese Aid) & -4 & 4 & -5 & 21 \\
Battle-Related Deaths & 21 & 342 & 0 & 33,417 \\
Conflict Incidence in Percent & 12 & 32 & 0 & 100 \\
\hline
\end{tabular}

Notes: Descriptive statistics for our main variables. $\ln$ (Aid) is based on aid +0.01 USD. The sample period is 1995-2012 for IDA and 2000-2012 for Chinese Aid. For Chinese Aid 41 and for the World Bank Aid 35 recipients are considered respectively.

\section{World Bank Aid}

The dataset from AidData (Strandow et al., 2011) about World Bank aid disbursements is comprehensive both regarding time, ranging from 1995 to 2012, and regarding project scope. Geocoded disbursements sum up to US\$29.4 bn distributed over 1,472 projects in 25,041 locations in Africa. Additionally, AidData provides information on the sectoral allocation of disbursements, enabling us to distinguish potentially differential effects of different aid types on conflict probability and intensity. We focus on disbursements by "the International Development Association (IDA)," the World Bank's arm for development aid.

\section{Chinese Aid}

Although China is perceived as a major political and economic actor, it was also a recipient of sizeable amounts of development aid until recently. For instance, China only graduated from IDA in 1999 (Galiani et al. 2017). Since the 2000s, China has become a major donor itself and extended its activities especially in Africa. However, China does not provide official disaggregated information on aid flows according to the DAC standards. One reason is that large disbursements could lead to Chinese citizens' discontent since they might prefer regional development programs in China. We build 
Aid and conflict at the subnational level

on the impressive data collection and geolocalization efforts by Strange et al. (2017) and Dreher et al. (2016), associated with AidData. Those authors compile data on Chinese ODA-like commitments for the years 2000-2012 based on a variety of sources, mostly media reports. In total, the ODA flows amount to USD 13.2 bn from 333 projects in 1308 locations.

\subsubsection{Conflict Measures}

For our main specification, we rely on the number of battle-related deaths at the regional level based on the Uppsala Conflict Data Program's (UCDP) georeferenced event dataset (GED) (Sundberg and Melander, 2013, Croicu and Sundberg, 2015). Derived from media and NGO reports, as well as secondary sources (e.g., field reports or books), GED provides the most reliable and comprehensive data on incidences of violence including the involved parties, casualties and location 14 Table 3.2 shows that the range of battle-related deaths per region-year varies between 0 and 33,417. The thresholds commonly used in the cross-country literature to identify conflict are not applicable at the smaller regional level. A threshold of 1000 casualties is too high, but a minimum threshold of just one casualty would be too low and create too much measurement error. Acknowledging the apparent trade-off, we chose 5 (low intensity) as the threshold for our main specifications. We use 25 (medium intensity) as well as the log of battle-related deaths for robustness tests. We use a similar measure from the Social Conflict Analysis Database (SCAD) to evaluate smaller-scale conflict events like demonstrations, strikes or riots and non-lethal government repression (Salehyan et al., 2012).

We depict the geographical distribution of development aid locations for the WB and for China in Figure 3.3a, as well as the number of experienced conflict years in Figure 3.3b. Until 2012, China was active in a large range of African countries, but still on a smaller scale than the World Bank.

Visually examining the overlap between average aid disbursements / commitments and conflict years in these maps is not very informative, as they do not display the temporal order of events. Moreover, we cannot distinguish selection into conflict prone regions from an effect of aid, as well as account for particular regions being different in unobservable factors that cause them to be large aid recipients and conflict prone at the same time. Countries that had endured conflict in the past are also more in need of post-conflict aid. IDA, for instance, disbursed $19 \%$ of its funds to regions recently suffering from conflict, and China commits about $10 \%$ of its project volume to such regions. Generally, conflict is widespread and often overlaps with the presence of the two donors. $52 \%$ of the World Bank's IDA resources and $31 \%$ of Chinese ODA-like

\footnotetext{
${ }^{14}$ An alternative would be the ACLED and PRIO Gridded datasets, which rely on similar primary data as UCDP. One issue with PRIO Gridded data is that neighboring cells in a $50 \mathrm{~km}$ radius are also coded as conflict-affected, which might lead to erroneous conflict coding of neighboring regions (Tollefsen et al. 2012). Moreover, PRIO only provides dichotomous information on conflict occurrence, but not on intensity. ACLED is broader in coverage than UCDP data, but is criticized for its ambiguous inclusion criteria and vague geocoding (Eck, 2012).
} 
Figure 3.3 Maps: Conflict and Aid in Africa

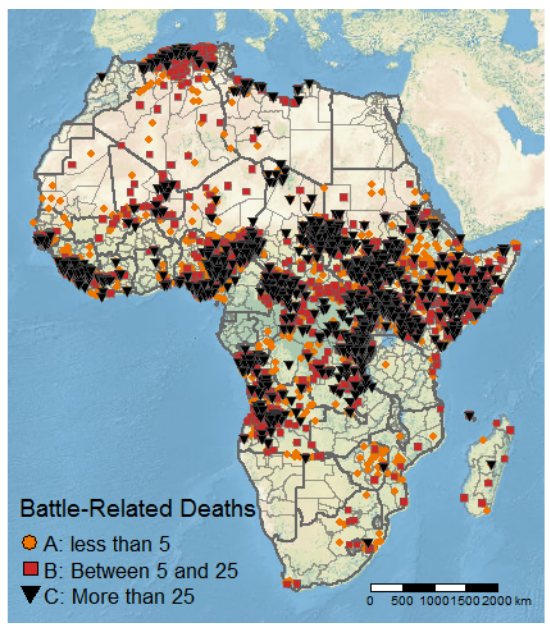

a) Conflict

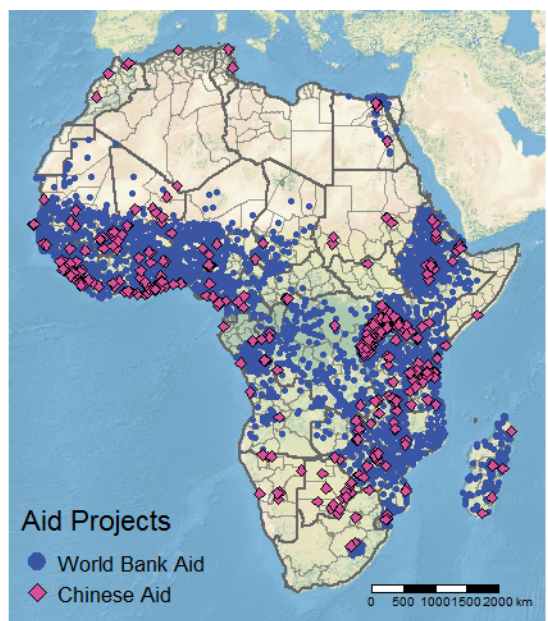

b) Development Aid

Source: Authors' depiction based on Croicu and Sundberg (2015), Dreher et al. (2016) and AidData (2017).

Note: Conflict refers to more or equal to five casualties per region-year 2000-2012. Chinese aid refers to the years 2000-2012 and World Bank aid to 1995-2012. The depicted borders refer to countries (thick line) and first administrative divisions (thin line).

finance are spent in regions that also experience conflict at some point during the observation period.

Overall, there is a lot of variation in aid from both donors, as well as in conflict across and within countries. This variation is crucial for our analysis, which distinguishes between two main types of equations. In the first set, we condition on observables and unobservables through various fixed effects and time trends. For instance, regionfixed effects eliminate within-country differences related to the likelihood of receiving aid and experiencing conflict, which gets lost when aggregating at the national level. For example, Angola appears to receive relatively more aid projects in specific regions, which at the same time experience more conflict. However, this relationship may be driven by a third omitted factor. The second set goes one step further and uses country times year (from now on country-year) fixed effects to rule out an effect of any spurious events at the country-year level affecting conflict and by chance coinciding with changes in aid allocation (e.g., a change in political regime).

\subsubsection{Control Variables}

Besides our main variables of interest, we consider several other variables, which are suggested in the literature as either determinants of aid allocation or drivers of conflict. Regarding the targeting of development aid, it is interesting to account for the initial 
Aid and conflict at the subnational level

regional development. GDP is proxied using nighttime light, as subnational income estimates are scarce and of poor quality in low and lower-middle income states (Henderson et al., 2012). Although lights already capture parts of population density, as indicated by Henderson et al. (2017), we account for regional population taken from the Center for International Earth Science Information Network's gridded population of the world dataset (CIESIN, 2016). Population is both a relevant variable in terms of aid allocation as well as in terms of a scale effect for conflict potential (Hegre and Sambanis, 2006).

As a large literature stresses the potentially conflict-inducing effects of windfall gains related to certain resources (e.g., Berman et al., 2017), we control for several natural resource indicators including oil, gold, gem-stones and narcotics. For this purpose, we use information from the PRIO Gridded data (Tollefsen et al., 2012) and project them on the administrative boundaries. This dataset also includes measures on temperature and precipitation, providing us with proxy variables for local income shocks causing conflict (Miguel et al., 2004). To match the gridded data to the respective regional units of observation, we intersect the PRIO-Grid with the countries' regional dimension and calculate area-weighted averages for each region. Finally, we use data from Cederman et al. (2014) and Wucherpfennig et al. (2011) to control for the spatial distribution of ethnic groups, which are often linked to conflict (Esteban et al., 2012; Michalopoulos and Papaioannou, 2016).

\subsection{Empirical Strategy}

Aid projects are not randomly allocated. This potential endogeneity of aid project allocation is the concern when studying the relationship between development finance and conflict. Time-varying omitted variables, like economic or political shocks at the regional level can affect both aid inflows and conflict. Additionally, donors might tend to reduce or increase aid targeting to conflict-affected regions depending on their allocation targets, raising issues of reverse causality. We pursue two different empirical strategies. First, we use OLS regressions with varying sets of fixed effects, time trends and control variables, which allow a transparent examination of the underlying relationship when exploiting different variation in the data. Our detailed subnational dataset exhibits enough variation to allow the use of very restrictive sets of fixed effects and time trends that rule out many concerns raised in the existing literature. Second, we will pursue instrumental variable strategies for each of the two donors.

\subsubsection{Linear Models - Fixed Effects, Time Trends and Control Variables}

Our baseline empirical specification is:

$$
C_{i, c, t}=\beta_{1} A_{i, c, t-1}+\beta_{2} X_{i, c, t-2}+\delta_{i}+\lambda_{c}+\gamma_{t}+\kappa_{c, t}+\epsilon_{i, c, t},
$$


Aid and conflict at the subnational level

where $C_{i, c, t}$ is our conflict indicator of interest in region $i$, in country $c$ and year t. $A_{i, c, t-1}$ are the log of per capita aid disbursements / commitments. With regard to the timing, we consider the WB disbursements from the previous year and follow the literature (Dreher et al., 2016, 2017), while we use a two year lag for Chinese commitment data 15

$X_{i, c, t-2}$ is a vector of lagged control variables, where we distinguish three types of controls. First, controls such as climatic shocks are exogenous and not affected by our treatment variable. Second, we account flexibly for the effect of time-invariant controls like elevation or ruggedness by interacting them with year dummies. Third, we lag potential "bad controls" like nighttime light (as a proxy for economic activity) or population, which can be affected directly by aid projects, by two periods. This does remedy but not solve the problem, which is why we show the third category only as a robustness test.

Furthermore, our baseline specification contains $\gamma_{t}, \lambda_{c}$, and $\kappa_{c, t}$ which are time, country, and country-year fixed effects, respectively. We also add country-specific linear and quadratic time trends, as well as regional linear time trends. The error term is denoted as $\epsilon_{i r, t}$. Country-year fixed effects need to be considered carefully, especially, due to the national dynamics of conflict. They eliminate many potentially critical omitted variable problems, but also a lot of variation in the data. In essence, including them asks a subtly different question: conditional on the whole country being in conflict or not in a particular year, how have previous aid payments affected the likelihood of a particular region to be in conflict. For that reason, we will always consider specifications with and without country-year fixed effects.

We cluster standard errors at the country-year and regional level (Cameron et al. 2011). This allows for arbitrary correlation within a country and year, which is important as conflicts often have a strong spatial component and tend to spill over. Also allowing for correlation within a region over time is important as conflict also tends to exhibit strong persistence over time. Other potential clustering options are shown in the Appendix (Tables C.38 and C.39).

\subsubsection{Instrumental Variable Approach}

Our instrumental variable strategy exploits the heterogenous impact of a plausibly exogenous time-series interacted with a (pre-determined or fixed) cross-sectional difference ${ }^{16}$ The identifying assumption is that in absence of a change in the time series

\footnotetext{
${ }^{15}$ In line with personal correspondence with staff from aid agencies, China would disburse commitments quickly with a lag of one to three years. We assume a two-year lag structure as reasonable.

${ }^{16}$ This builds on Nunn and Qian (2014), who exploit temporal variation in US wheat production, which they then interact with the aid recipient's probability to receive US food aid. In essence, this strategy is similar to Bartik instruments used in the labor economics literature (e.g., Autor et al., 2013) or the shift-share instruments common in the migration literature (Altonji and Card, 1991). In contrast to most Bartik and shift-share instruments, where cross-sectional units differ in many dimensions, e.g., different industry shares or immigrant enclave sizes, the units in this approach differ only along one dimension.
} 
Aid and conflict at the subnational level

there would be common trends in aid allocation in low and high aid probability recipient regions. As in any Difference-in-Difference (DiD) setup, the first and second stage control for the main constituting terms forming the interaction and only the interaction term is used as the conditionally exogenous instrument.

For both the WB and China, we use a cumulative (initial or pre-determined) probability as opposed to a constant probability over the whole sample period. This is computed by dividing the number of years a region $i$ has received aid in the past by the number of years passed until period $t{ }^{17}$ Beyond the donor-specific probability, the World Bank and China differ only in the time-varying factor $T_{t}$ used to induce variation in project allocations over time.

\section{Instrumenting World Bank Aid}

For the World Bank, we use exogenous yearly variation in the availability of free IDA resources. This funding position is defined as "the extent to which IDA can commit to new financing of loans, grants and guarantees given its financial position at any point in time" (World Bank, 2015a). ${ }^{18}$ Starting in 2008, we use the measure publicly disclosed in the annual financial reports. From 1995 to 2008 we rely on the reconstructed time series by Dreher et al. (2017). Thus, the first stage equation has the following form:

$$
\operatorname{Aid}_{i, c, t-1}=\alpha_{1} \operatorname{prob}_{i, c, t-2}+\alpha_{2} I D A_{t-1}+\alpha_{3} p_{i, c, t-2} I D A_{t-1}+X_{i, c, t-2}+\epsilon_{i, c, t-1}
$$

where $X_{i, c, t-2}$ is again a vector of lagged control variables. Figure 3.5 shows the fluctuations in the indicator. The variation can be caused by internal adjustments, the timing of payments by the shareholders, as well as repayments by large borrowers like India or Nigeria. Conflict in any individual African region cannot plausibly affect the measure to a significant degree. Overall, there is a downward trend, partly caused by some major shareholders failing to deliver on payments promised before. However, despite the general decline, the indicator also fluctuates strongly between the years. For instance, it initially increases between 1996 and 1997, before it falls sharply in the following years.

We then interact this time-varying variable with $\operatorname{prob}_{i, c, t}$, the probability of a region receiving aid. Based on anecdotal evidence, for instance from personal correspondence

\footnotetext{
${ }^{17}$ If our sample begins in 1995, and a region received aid in three out of five years, the value of the probability in 1999 would be 0.6 . If aid receipts stop in 1999, the probability would decline to 0.5 in 2000 as the country would have received aid in three out of six years. The constant probability used in Nunn and Qian (2014) or Bluhm et al. (2018) relies on all observed treatment values per unit, i.e., the term for region $i$ in year $t$ also depends on the values in $t+1, t+2, \ldots$. These future values can themselves be a function of conflict. Nizalova and Murtazashvili (2016) show that under certain assumptions the interaction of an exogenous variable with an endogenous variable can be interpreted as exogenous when controlling for the endogenous factor (in this case the constant probability). Nonetheless, using initial or pre-determined values gets us closer to a setting of interacting two exogenous variables.

${ }^{18}$ The idea is based on Lang (2016) and Gehring and Lang (2018), who employ such a supply-push identification approach using variation in the IMF's liquidity.
} 
Aid and conflict at the subnational level

with recipient country personnel administering WB projects, regions with a higher likelihood to receive aid in the past seem to profit more if there are additional funds available. Thus, we expect a positive interaction term in the first stage.19

\section{Instrumenting Chinese Aid}

Due to data limitations, there is no exact equivalent to the IDA's funding position. Instead, $T_{i, c, t}$ is a time series on production in the country's over-sized steel sector (World Steel Association, 2009, 2014). The production level was shown to affect the overall amount of Chinese aid as China would commit to more aid projects to clear markets and protect domestic companies from potential losses (Dreher et al., 2016). These projects are often large-scale infrastructure projects (Bräutigam, 2011), but Bluhm et al. (2018) show that steel production also induces variation in other sectors (social, education or health) beyond roads and railways.20 China is also generally known as engaging in "mega-deals" (Strange et al., 2017), which are generally larger than WB projects. Thus, the local average treatment effect we want to estimate with the IV is not atypical for its activities. The time series is again plausibly exogenous to any individual region in Africa, and we then interact it with the cross-sectional specific cumulative probability to receive Chinese aid. Theoretically, one would expect that overcapacities in steel benefit regions with a low probability of previous aid receipts more as China expands its activities to new regions. However, the existing literature indicates that an increase in steel overproduction benefits regions with an initially high probability the most (Dreher et al., 2016, Bluhm et al., 2018). The first stage equation for Chinese aid has the following form:

$$
\operatorname{Aid}_{i, c, t-2}=\alpha_{1} \operatorname{prob}_{i, c, t-3}+\alpha_{2} \text { Steel }_{t-3}+\alpha_{3} p_{i, c, t-3} \text { Steel }_{t-3}+X_{i, c, t-2}+\epsilon_{i, c, t-2}
$$

One potential issue is a long-term upward trend in Chinese steel (over-)production and the fact that there is less year-on-year variation than in the WB funding position. This linear trend increases the risk of picking up trends in other variables that differ between high and low probability regions and overlap with the conflict trends, one of the concerns raised by Christian and Barrett (2017). For that reason, we de-trend steel production for our main specification, so that we exploit only deviations from the long-term production trends. ${ }^{21}$

\footnotetext{
${ }^{19}$ Because the World Bank's fiscal year ends in June, the reported position in the fiscal years $t$ and $\mathrm{t}-1$ can both affect disbursements in $\mathrm{t}-1$. Using only the position in $\mathrm{t}-1$ is a viable alternative and also works well in first stage estimations, which is demonstrated in Appendix Table C.10. Using both fiscal years $t$ and $t-1$ to compute the funding position appears more coherent and is applied subsequently.

${ }^{20}$ Although to a lesser extent, other sectors than hard infrastructure use steel as an input. E.g., the social sectors education and health rely on steel to construct schools and hospitals.

${ }^{21}$ Detrending the global time series is not exactly analogue to the use of regional linear time trends or country-year fixed effects as the interaction of the global trend with cumulative probabilities induces yearly rescaling on a regional level.
} 
Aid and conflict at the subnational level

\section{Examining the first stages}

In order to provide readers with a transparent depiction of trends in the outcome and instrumental variable as suggested by Christian and Barrett (2017), Figure 3.4 shows the de-trended time series that we use, along with the variation in conflict in low and high probability regions. On the left panel, we show the raw variation in conflict, on the right panel we show the residual variation net of fixed effects and time trends that we exploit in our estimations. There is no clear overlap between trends in the time series variable and outcomes in either low or high probability regions, in particular when considering the residual variation used in our subsequent analysis. The same holds true for the WB (Figure 3.5) ${ }^{22}$

Figure 3.4 Deviations from Chinese Steel Production Trend \& Battle-Related Deaths

a) Mean Battle-Related Deaths (raw)

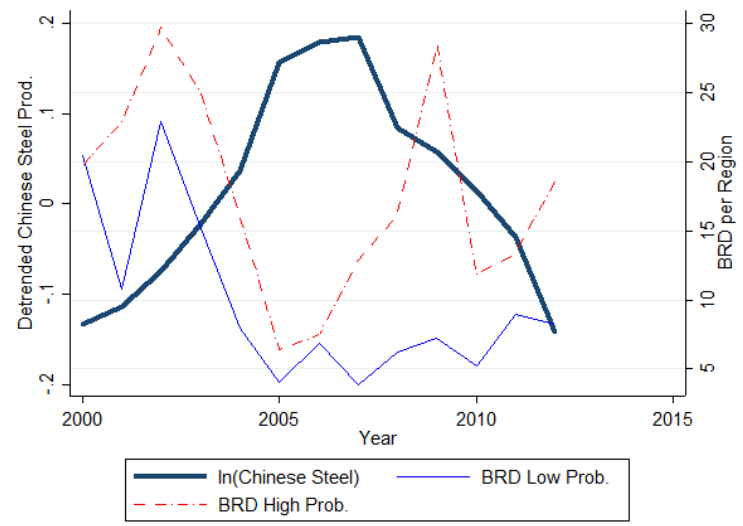

b) Mean Battle-Related Deaths (residual)

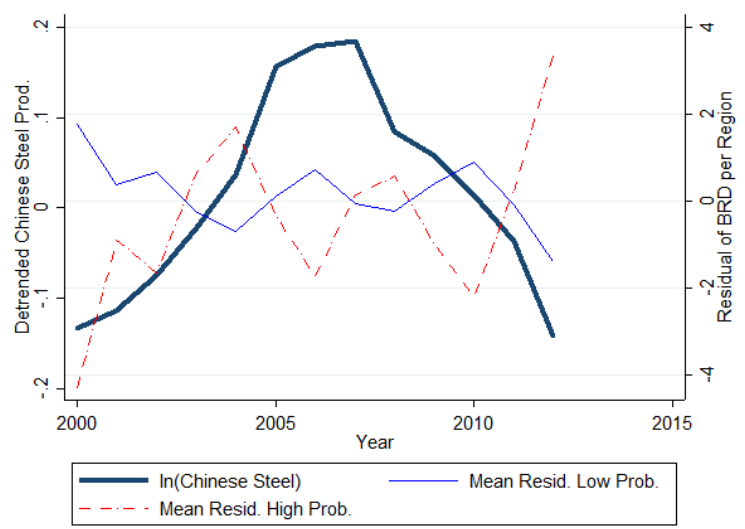

Source: Authors' calculation.

Note: Figure 3.4a displays the log of the detrended Chinese Steel Production (thick line), the mean Battle-Related Deaths per low probability recipient regions (thin line) and the mean Battle-Related Deaths per high probability recipient regions (dashed line). Figure 3.4b displays the log of Chinese Steel Production (thick line), the mean residual of the Battle-Related Deaths per low probability recipient regions (thin line) and the mean residual of the Battle-Related Deaths per high probability recipient regions (dashed line). The residuals refer to the underlying variation used in our preferred specification from column (4) in Table 3.3 and are net of FE and time trends.

Goldsmith-Pinkham et al. (2018) describe the potential risks and caveats of similar IV strategies and highlight the importance of considering differences in the crosssectional units and emphasize the need to consider whether the first stage is driven by only a few observations or outliers. Christian and Barrett (2017) emphasize potential problems with trends that differ between high and low probability countries (regions)

\footnotetext{
${ }^{22}$ To allow the reader to assess the trends in the treatment variable, Appendix Figure C.4 depicts the time series for the means of logged WB and Chinese aid per high and low exposure regions.
} 
both in the treatment and in the outcome variable. We carefully examine potential problems with the IV approach in different robustness tests, but also highlight that we regard the instrumental variable (IV) approach as complementary to the OLS specifications, which are also important and informative.

Figure 3.5 World Bank IDA funding Position \& Battle-Related Deaths

a) Mean Battle-Related Deaths (raw)

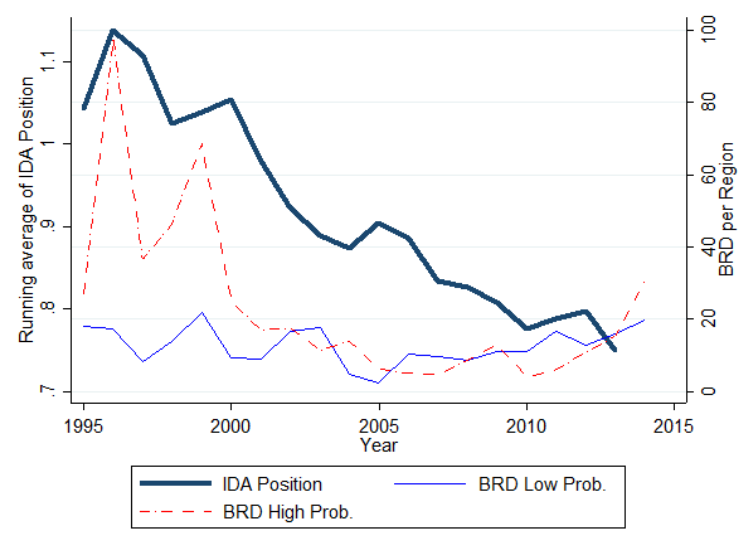

b) Mean Battle-Related Deaths (residual)

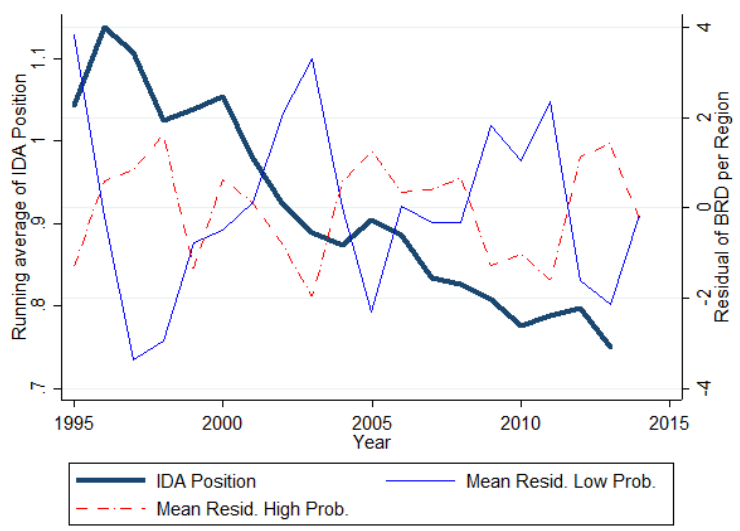

Source: Authors' calculation.

Note: Figure 3.5a displays the IDA Funding Position (thick line), the mean Battle-Related Deaths per low probability recipient regions (thin line) and the mean Battle-Related Deaths per high probability recipient regions (dashed line). Figure 3.5b displays the IDA Funding Position (thick line), the mean residual of the Battle-Related Deaths per low probability recipient regions (thin line) and the mean residual of the Battle-Related Deaths per high probability recipient regions (dashed line). The residuals refer to the underlying variation used in our preferred specification from column (4) in Table 3.3 and are net of FE and time trends.

\subsection{Results}

\subsubsection{OLS, Fixed Effects and Time Trends}

We estimate different specifications to transparently show the implicit trade-offs between them. Our dataset allows us to rule out many potential sources of omitted variables bias in cross-country studies, but this elimination of potentially biasing information comes at the cost of losing useful variation. Under most circumstances, we try to minimize false discoveries. A plausible prior with regard to our research question, however, is to assume that aid might fuel conflict (e.g., based on studies like Nunn and Qian, 2014 and Crost et al., 2014). Thus, focusing on conservative specifications which eliminate much variation creates the risk of over-looking such an effect. 
Aid and conflict at the subnational level

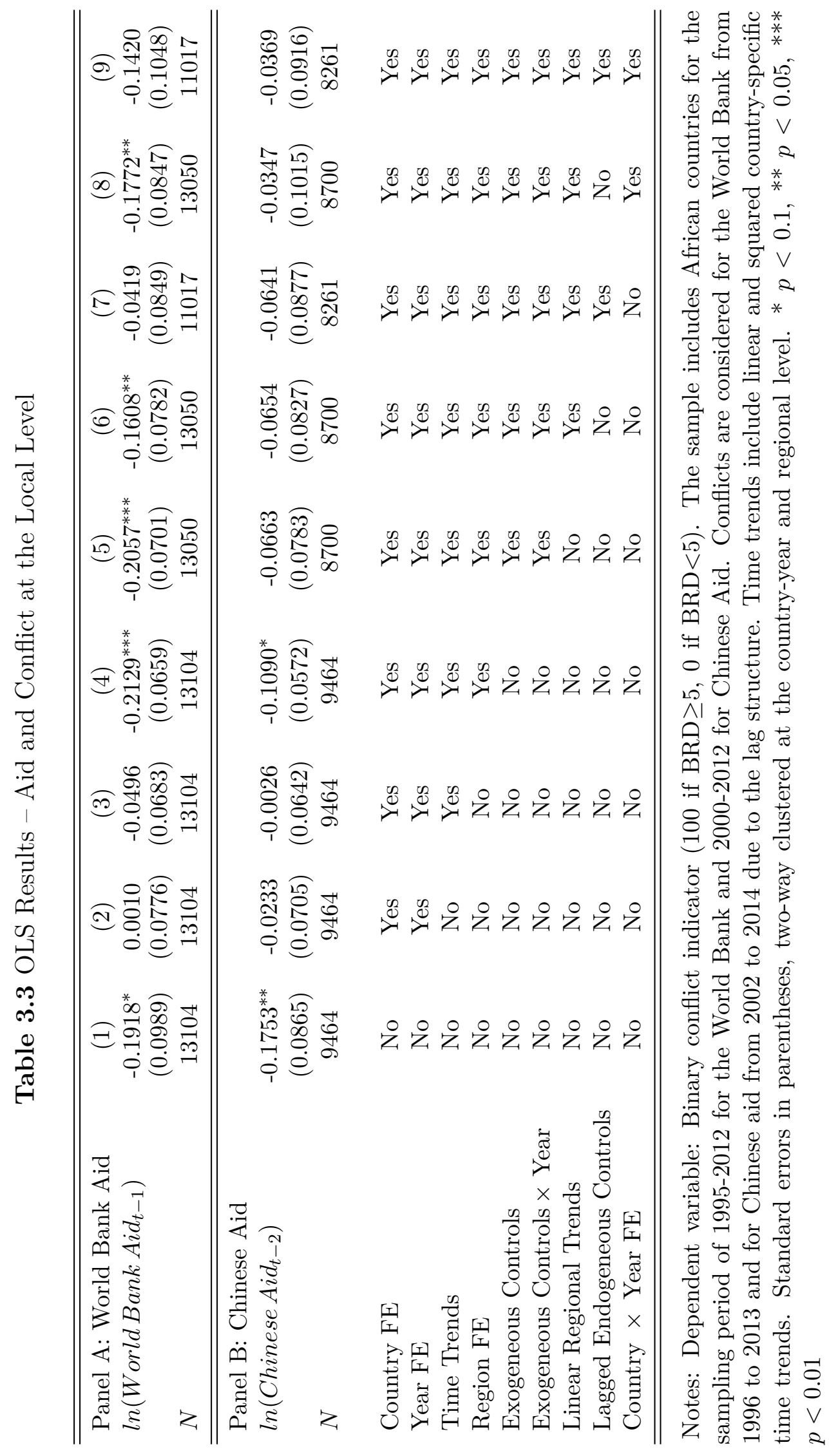


Aid and conflict at the subnational level

We begin by showing simple correlations and then step-by-step add fixed effects, time trends and different categories of control variables ${ }^{23}$

Beginning with World Bank aid in Table 3.3, we find that the raw correlation with conflict incidence is negative. The coefficient of -0.19 suggests that $10 \%$ more $\mathrm{WB}$ aid is correlated with a conflict likelihood that is about 1.9 percentage points lower. Adding country and year fixed effects shifts the coefficient upward (column 2), adding countryspecific linear and quadratic trends to capture country-specific conflict dynamics moves it again slightly downward to -0.05 (column 3). When adding region fixed effects, which capture region-specific time-invariant attributes that can explain heterogeneity within countries, the point estimates nearly quadruple in size $(-0.21)$ and become statistically significant at the $1 \%$-level (column 4).

Adding exogenous controls and time-invariant region characteristics, interacted with year dummies to capture their potentially time-varying influence (column 5), as well as adding region-specific linear time trends changes the coefficient only slightly (column 6). Column 8 goes one step further by controlling for country-year fixed effects. The remaining variation is then only due to differences in aid across regions within countryyears, conditional on the country as a whole being in conflict or not. Despite the strict specification, the robust negative relationship between WB aid and conflict does not disappear and remains significant at the 5\%-level. It becomes insignificant when controlling for lagged values of factors that are potentially endogenous controls (columns 7 and 9), but remains negative. Although these are only conditional correlations, the fact that 8 out of 9 coefficients are negative suggests that there is no conflict-fueling effect of WB aid on average.

Turning to China, our prior is that a positive relationship with conflict is more likely. Chinese aid is by some observers deemed as "rogue aid," which promotes authoritarian and violent elites and leaders. Against this background, it comes at first glance as a surprise that the raw correlation with conflict is also negative. The coefficient drops drastically in size when adding country and time fixed effects, as well as country-specific quadratic time trends (columns 2 and 3), but loses significance. Overall, the coefficients are much smaller and closer to zero than for the WB. Remarkably, however, there is not a single positive coefficient, also suggesting no signs of a conflict-inducing effect of Chinese aid. Our preferred specifications in columns 6 and 8 indicate that $10 \%$ more Chinese aid corresponds to a 0.65 and 0.35 percentage points decrease in conflict incidence.

These results need to be put into perspective. Table 3.3 reveals that researchers have many degrees of freedom, especially at the subnational level. What we find reassuring is that throughout all these different specifications there is no sign of a conflict-inducing

\footnotetext{
${ }^{23} \mathrm{~A}$ second trade-off concerns showing both donors over the same period. The advantage is that it would increase comparability. The disadvantage is that we would lose five years for the WB (1996 to 2001 due to the lag structure). Moreover, when doing this for IV specifications the F-statistics for the WB are much smaller, giving rise to potential weak instrument concerns. Hence, we exploit the full range of available data for the main specification, and show the results for both donors combined in Appendix Table C.42 with OLS and Table C.43 with IV.
} 
Aid and conflict at the subnational level

effect for either World Bank or Chinese development finance projects. Relating to the ideas in Altonji et al. (2005) and Oster (2017), we also see that the effect of adding additional fixed effects, trends, and covariates neither suggests a clear upward nor a downward bias. Certainly, a zero as well as negative effects could be a part of the true confidence interval. Still, it seems unlikely that unobserved factors would push the average effect towards a positive and significant coefficient.

We continue examining a potentially remaining selection bias with our IV estimations, focusing on the specifications in columns 6 and 8 .

\subsubsection{Instrumental Variable Results}

Table 3.4 shows the instrumental variable results for our preferred specifications. The first stages for both donors work well. The interaction term between the prior probability to receive aid and the IDA position (Chinese steel, respectively) is highly significant in both specifications, with and without country-year fixed effects. On average, the first stage works better for the World Bank $(\mathrm{F}=99 / 86)$ than for China $(\mathrm{F}=22 / 16)$, but all F-statistics are well above the critical value of 10 .

In addition to being relevant, the signs of the coefficients are also plausible. Regions with a higher initial probability profit more from a higher WB liquidity. Appendix Table C.5 and C.6 illustrate that the mechanism seems to work through both the extensive and intensive margin. High probability regions receive more projects, but the size of projects also increases. As expected, China shows a reverse pattern. In years where excess steel production is higher, China expands its activities with new projects in regions with an initially lower likelihood of receiving a project.

The second stage results largely confirm the OLS results. Both specifications yield a negative coefficient for the WB and China. The coefficients for the WB are somehow smaller (larger) in the specification without (with) country-year fixed effects, and become statistically insignificant. The coefficients for China become much more negative, but remain insignificant. There is again no evidence for a conflict-fueling effect of aid projects. This is noteworthy, as despite estimating a rich set of specifications, we could not find for any of the two extremely different donors an average effect, which would link aid to conflict.

Examining those results with more scrutiny raises the question to what degree they represent a local average treatment effect (LATE) that might be different from the average effect. By definition, the IV estimate is identified using a particular kind of variation in the variable of interest. Nonetheless, comparing the IV point estimates with OLS shows some differences in size but no difference with regard to the direction of the effects. 
Aid and conflict at the subnational level

Table 3.4 IV Results - Aid and Conflict at the Local Level

\begin{tabular}{|c|c|c|}
\hline Panel A: World Bank Aid & (1) & $(2)$ \\
\hline \multicolumn{3}{|l|}{ IV Second stage: IDA Position } \\
\hline $\ln \left(\right.$ World Bank Aid $\left.\mathrm{t}_{\mathrm{t}-1}\right)$ & $\begin{array}{l}-0.1014 \\
(0.3752)\end{array}$ & $\begin{array}{l}-0.2252 \\
(0.4192)\end{array}$ \\
\hline Kleibergen-Paap underidentification test p-value & 0.000 & 0.000 \\
\hline Kleibergen-Paap weak identification F-statistic & 99.639 & 86.724 \\
\hline \multicolumn{3}{|l|}{ IV First stage: IDA Position } \\
\hline ID A Position $_{\mathrm{t}-1} \times$ Cum. Prob Pr-2 $_{\mathrm{t}}$ & $\begin{array}{c}70.9363^{* * *} \\
(7.1065)\end{array}$ & $\begin{array}{c}80.8832^{* * *} \\
(8.6854)\end{array}$ \\
\hline$N$ & 12325 & 12325 \\
\hline Panel B: Chinese Aid & (1) & $(2)$ \\
\hline \multicolumn{3}{|l|}{ IV Second Stage: Chinese Steel } \\
\hline $\ln \left(\right.$ China $\left.A i d_{t-2}\right)$ & $\begin{array}{l}-0.4509 \\
(0.6168)\end{array}$ & $\begin{array}{l}-0.4276 \\
(0.8068)\end{array}$ \\
\hline Kleibergen-Paap underidentification test p-value & 0.000 & 0.000 \\
\hline Kleibergen-Paap weak identification F-statistic & 22.468 & 16.456 \\
\hline \multicolumn{3}{|l|}{ IV First stage: Chinese Steel } \\
\hline Steel Prod detrend $\mathrm{t}_{\mathrm{t}-3} \times$ Cum. $_{\text {Prob }} \mathrm{t}-3$ & $\begin{array}{c}-70.8763^{* * *} \\
(14.9526)\end{array}$ & $\begin{array}{c}-60.6567^{* * *} \\
(14.9524)\end{array}$ \\
\hline$N$ & 7975 & 7975 \\
\hline Country-Year FE & No & Yes \\
\hline
\end{tabular}

Notes: Dependent variable: Binary conflict indicator (100 if $\mathrm{BRD} \geq 5,0$ if $\mathrm{BRD}<5)$. The sample includes African countries for the sampling period of 1995-2012 for the World Bank and 2000-2012 for Chinese Aid. Both regressions include exogenous (time-varying) controls. Year and region fixed effects as well as time trends are included in all regressions. Time trends include linear and squared country-specific time trends and a linear regional trend. The constituent term of the probability is depicted in Appendix Table C.7. Standard errors in parentheses, two-way clustered at the country-year and regional level. ${ }^{*} p<0.1,{ }^{* *} p<0.05,{ }^{* * *} p<0.01$

We can check whether the direction of the changes when moving from OLS to IV estimations is plausible by running OLS specifications using leads and lags of our variable of interest (Appendix Table C.4). More specifically, we include three lags, the contemporaneous value and a lead term. For the World Bank, there are no clear indications of a pre-trend that would signal selection bias. For China, however, the lead terms are positive in both cases. This indicates that China selects regions that are more likely to have experienced a conflict in the previous years. Maybe this is due to China being less worried about violent regimes, or attempts to fill up the space left by other 
Aid and conflict at the subnational level

donors who are more hesitant to enter that type of region. ${ }^{24}$ This suggests an upward bias in the OLS coefficients, which is in line with the IV coefficients for China being more negative. For the World Bank, without apparent pre-trends, IV and OLS results are very similar. Despite signaling a null or slightly negative effect on average, the rather large standard errors suggest that this average effect hides considerable heterogeneity. Thus, we continue by examining different types of aid, the actors involved in conflict, and potential heterogeneity related to ethnic fractionalization and governing coalition membership.

\subsubsection{Channels - Aid Subtypes}

Theoretically, different types of aid should be more or less likely to fuel or calm down a conflict. Investments in education and communication infrastructure are often highlighted as those with particularly high long-term benefits, but most likely also require more time to have an effect. To the extent that projects in particular areas stimulate economic development in the short run, we would expect that they increase the opportunity costs of fighting and could, thus, lead to less conflict. At the same time, some development projects like hospitals, and to a lesser extent schools, provide more potential for looting due to, for instance, expensive machines that can be sold on the black market. Other areas, like infrastructure projects are notoriously known for being prone to corruption. We assign aid projects to eight subcategories, and consider them as a treatment in our two favorite specifications with and without country-year fixed effects. For the WB, the IV strategy works well, using sector-specific probabilities. For China, the IV does not work sufficiently well, because there are only few observations in some sectors. Thus, we show those results using OLS. Interesting differences emerge, suggesting that different types of aid indeed can have a different relationship to subsequent conflict. Note that in almost all cases, the country-year fixed effects only affect the coefficient sizes, not their signs.

In some categories, there is a positive coefficient of World Bank (Chinese) aid, but it never becomes statistically significant. Based on significance, the negative coefficient we found for the WB seems to be driven by projects in the area "finance" and "transportation" on average. Those coefficients remain significant both in the less and more restrictive specification with country-year fixed effects. In the latter specification, a $10 \%$ increase in World Bank spending on transportation (finance) is related to a 6.7 (16) percentage points reduction in the likelihood of conflict. Transportation comprises both a large scope of projects and funds, compared to financial development which is rather small in terms of dollars spent. The negative effect for transportation, often infrastructure projects, is particularly interesting when considering the potential for corruption and cronyism in this sector.

\footnotetext{
${ }^{24}$ In this regard, Strange et al. $(2017)$ demonstrate that after withdrawal of Western aid Chinese aid does fill gaps and, hence, can reduce conflict risk.
} 
Aid and conflict at the subnational level

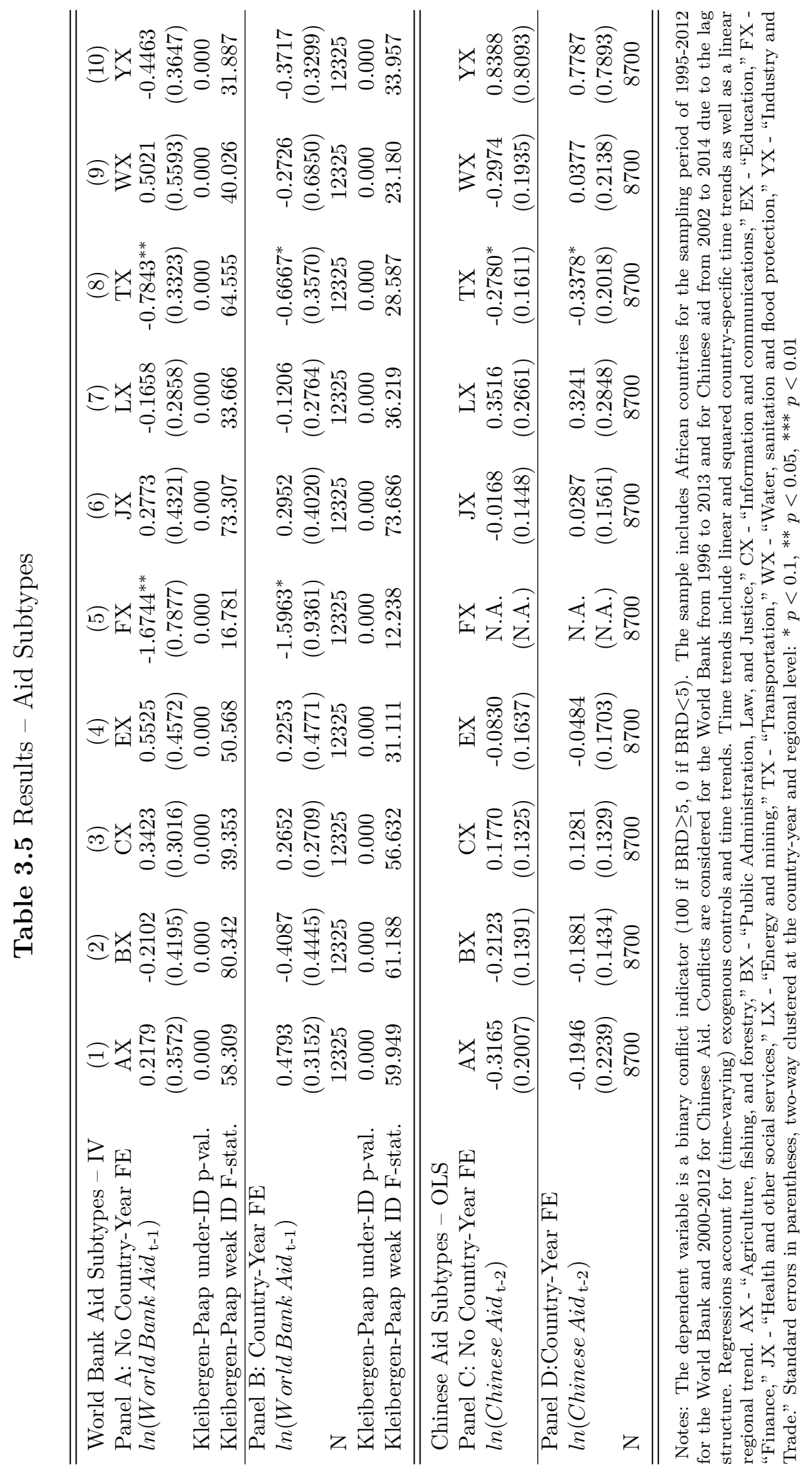


Aid and conflict at the subnational level

It suggests that existing constraints on movement or high transportation costs were a significant obstacle for development before.25 Moreover, transportation is the only sector where we consistently find negative and significant effects on conflict likelihood for both the WB and China.

Putting these sector-specific results into perspective, Table 3.5 suggests heterogeneities across aid categories which help to explain the large confidence interval when estimating the mostly negative coefficient on overall aid. It is important to note that we find no significant conflict-fueling effect for any type of aid and any of the two donors. It is reassuring that the negative relationship is not masking strong conflict-fueling effects for some sectors 26

\subsubsection{Actors}

Many claims about a conflict-fueling or alleviating effect make implicit assumptions about involved actors. It is a crucial difference whether the government is fighting with rebel groups, rebel groups are fighting each other, or uninvolved third parties (i.e., civilians) are attacked. Depending on political alignment, war actions against rebel groups might be accepted or even supported by donors. ${ }^{27}$ In contrast, attacks on civilians are often condemned by donors, even if happening during an existing conflict, and might be a reason to withhold aid or reduce future payments. The UCDP data allow us to distinguish between state and rebel violence, and actions by those two groups against civilians not directly involved in the conflict 28

Table 3.6 shows the results for both the World Bank and China with and without country-year fixed effects. State-based violence decreases with additional World Bank aid, but increases with additional Chinese aid. The coefficients are not statistically significant, but of an economically meaningful magnitude. Both for the World Bank and China, we find positive coefficients on violence by actors like rebel groups, which are larger for China but never statistically significant. The picture looks very different when considering violence against civilians. In a region that receives either more World Bank or Chinese aid, there are fewer attacks and assaults that kill civilians. This holds for both violence by non-state and state actors, but the effect is more nuanced for state violence.

\footnotetext{
${ }^{25}$ The high conflict reducing effect of aid in the "Transportation" sector also corresponds to other related studies, which indicate the salience of transport costs for economic growth across African countries (Berman and Couttenier, 2015, Storeygard, 2016).

${ }^{26}$ Appendix Table C.32 presents the regressions for the WB with OLS and China with IV. The OLS results differ in some cases, but again there is no significant positive coefficient for any sector.

${ }^{27}$ Analogously donors might also accept or encourage rebels to fight an opposed regime as in the case of covert aid to Angolan UNITA under president Reagan (Lagon, 1992). But as the data cover mostly projects implemented in accordance with the government the latter will play less of a role.

${ }^{28}$ The UCDP Codebook describes one-sided violence as "the use of armed force by the government of a state or by a formally organized group against civilians [...]. Extrajudicial killings in custody are excluded" (Eck and Hultman, 2007).
} 
Aid and conflict at the subnational level

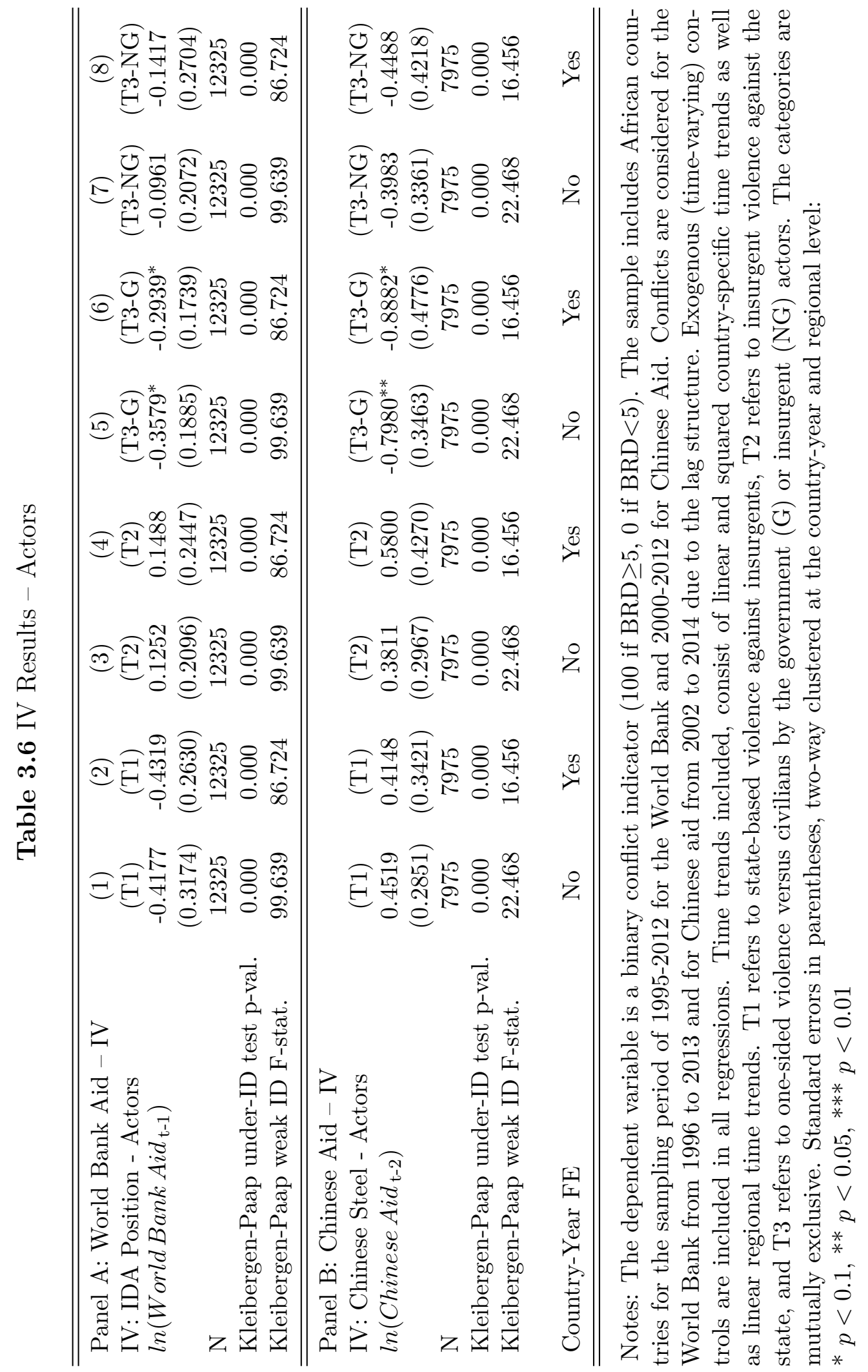


Aid and conflict at the subnational level

10\% more World Bank aid leads to a between 3.6 and 2.9 percentage points lower likelihood of lethal violence against civilians (columns 5 and 6), and $10 \%$ more Chinese aid even to a between 7.9 and 8.9 percentage points reduction (columns 5 and 6). Both coefficients are remarkably stable to the addition of country-year fixed effects, suggesting that this effect is not driven by unobservable time-varying factors at the country level. Even within a country that is already in conflict, administrative regions with aid projects are less likely to experience violence against civilians.

A plausible, and so far maybe underappreciated channel is the threat of losing out on future payments and projects (Lebovic and Voeten, 2009). Even for recipient politicians who are not solely concerned with public goods, the withdrawal of aid can be a viable threat, especially for important projects to the region or the government. It is interesting to observe that this conflict-reducing effect is even stronger for Chinese projects. Even without officially imposing conditions about human-right violations, governments in Africa abstain at least from lethal actions against civilians when China supports a project in a particular region. Besides business interests, the presence of Chinese workers might be another reason to prevent recipient governments from engaging in actions that could give rise to larger conflicts.

\subsubsection{Types of Violence}

In their article in the Washington Post, Kishi and Raleigh emphasize "dire consequences" of Chinese aid and that "political violence rates involving state forces also increase" (based on Raleigh et al. 2010). Should we conclude that these fears are unwarranted? Not necessarily. Our analysis so far has focused on violent conflict that involves battle-related deaths, but Kishi and Raleigh highlight that states "use this aid to finance their hold on power by repressing political competitors." It seems plausible that China has every interest to avoid outright battles, but it might be more likely to turn a blind eye on government repression as long as it ensures stability. Chinese aid might even be used to build up recipient countries' surveillance capacities to effectively repress elements of civil society ${ }^{29}$

To evaluate this hypothesis, we rely on the Social Conflict Analysis Database (SCAD) (Salehyan et al., 2012). The particular strength of this database is that it covers types of social and political disorder that are usually overlooked in other conflict datasets, with georeferenced data available from 1990-2016. We are in particular interested in two types of variables. We code binary variables that take on the value one if there was at least one riot, strike, or demonstration in a district to measure potential civil unrest or protests against projects related to China. Second, we code whether there was at least one event recorded as repression by the government, focusing on non-lethal repression to distinguish these regressions from our prior results.

\footnotetext{
${ }^{29}$ Washington Post, "When China gives aid to African governments, they become more violent," last accessed July 26, 2018.
} 
Aid and conflict at the subnational level

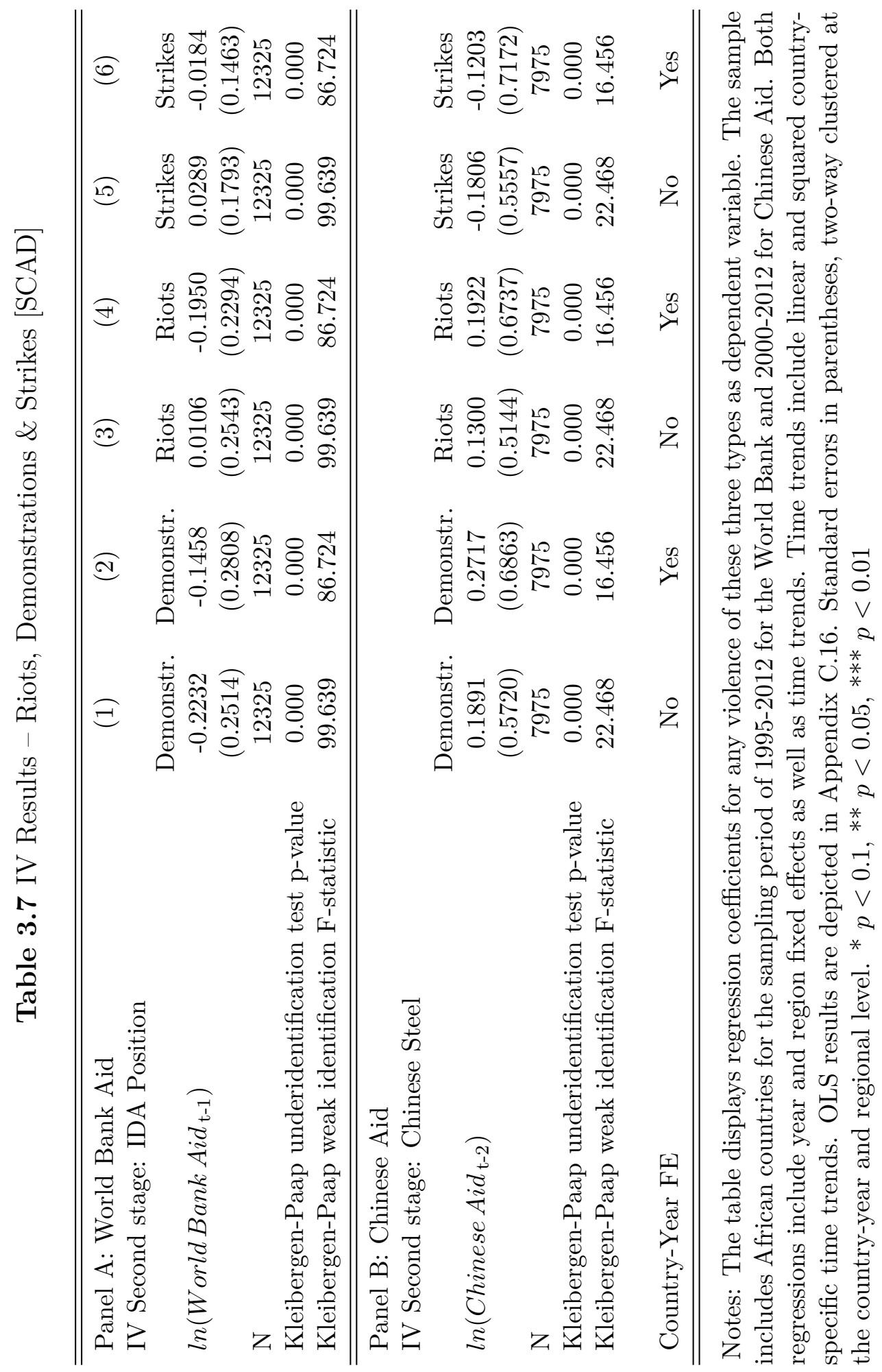


Aid and conflict at the subnational level

Table 3.8 IV Results - Non-lethal pro-government Violence [SCAD]

\begin{tabular}{lcc}
\hline \hline Panel A: World Bank Aid & $(1)$ & $(2)$ \\
IV Second stage: IDA Position & & \\
$l n\left(\right.$ World Bank Aid $\left.\mathrm{t}_{\mathrm{t}}\right)$ & 0.1543 & 0.0885 \\
& $(0.1042)$ & $(0.1177)$ \\
$\mathrm{N}$ & 12325 & 12325 \\
Kleibergen-Paap underidentification test p-value & 0.000 & 0.000 \\
Kleibergen-Paap weak identification F-statistic & 99.639 & 86.724 \\
\hline \hline Panel B: Chinese Aid & & \\
IV Second Stage: Chinese Steel & & \\
ln(Chinese Aid $\left.\mathrm{t}_{-2}\right)$ & $0.9798^{* * *}$ & $1.3059^{* * *}$ \\
& $(0.3663)$ & $(0.5025)$ \\
$\mathrm{N}$ & 7975 & 7975 \\
Kleibergen-Paap underidentification test p-value & 0.000 & 0.000 \\
Kleibergen-Paap weak identification F-statistic & 22.468 & 16.456 \\
& & \\
Country-Year FE & No & Yes \\
\hline \hline
\end{tabular}

Notes: The table displays regression coefficients for a binary indicator of non-lethal pro-government violence as dependent variable. The sample includes African countries for the sampling period of 1995-2012 for the World Bank and 2000-2012 for Chinese Aid. Both regressions include year and region fixed effects as well as time trends. Time trends include linear and squared country-specific time trends. Standard errors in parentheses, twoway clustered at the country-year and regional level. ${ }^{*} p<0.1,{ }^{* *} p<0.05$, $* * * \quad p<0.01$.

Table 3.7 begins with regressions running our two main specifications, but now replacing the outcome variable with an indicator measuring whether at least one demonstration, riot, or strike took place ${ }^{30}$ For the World Bank, all specifications yield a negative or very small positive coefficient, but remain statistically insignificant. Regarding China, we observe positive coefficients for demonstrations and riots, but although they are rather large (10\% more aid increases the likelihood of riots by $5.3 \%$ ) they remain statistically insignificant. Accordingly, despite reports about widespread protests against Chinese development projects, we find no clear evidence of this. Recipient governments might achieve this absence of protests and outright conflict by intensifying non-lethal repression.

Table 3.8 tests whether there were more reports of non-lethal government repression related to aid. The results indicate neither a positive nor significantly negative relationship for the World Bank. The results for China are in contrast to our prior

\footnotetext{
${ }^{30}$ Tables $\mathrm{C} .15$ depicts the corresponding OLS results. Moreover, Tables C.17 C.18 and C.19 show OLS regressions separately for demonstrations, riots and strikes. Figure C.5 presents the spatial distribution of demonstrations, riots and strikes.
} 
Aid and conflict at the subnational level

findings and confirm that repression intensifies in regions where China is present. In line with Bluhm et al. (2016), a 10\% increase in Chinese aid increases the likelihood of experiencing repression by about $13 \%$. 13

\subsubsection{Spatial Spill-overs}

Moving beyond studying aid and conflict in the same region we account for potential spatial spill-over effects. This is important for two reasons. First, some existing theories can only be tested by considering the effect of aid in location $i$ on conflict in a particular location $j$. The "price" theory postulating government as a price for rebels would predict that more aid to capital regions or the capital itself leads to a higher likelihood of conflict in that location. Other theories, however, predict that aid payments to one region affect the likelihood of conflict in another region. Kishi and Raleigh (2015) suggest that as aid is fungible, governments can shift expenditures towards strengthening their military. Improved military forces could then be used to strike down on rebel groups and other areas of the country.

In line with our prior results, aid projects to outsider regions might strengthen those regions and reduce conflict there, but also enable rebel groups to contest the government and attack regions that belong to the governing coalition. To test this, we code binary variables indicating (i) whether a region is the capital region or not, and (ii) whether a region features only groups that are part of the governing coalition, is mixed or has no coalition groups. Second, even if actors are similarly concerned about losing aid revenues, we would expect that fighting continues in other regions if underlying tensions are not resolved.

For these tests, we proceed in the following way. Within each country and year, we aggregate all aid projects and conflicts at the categorical level of these variables. For instance, we aggregate the overall amount of aid spent in regions that belong to the governing coalition in a country $(\mathrm{A})$, and the overall amount spent in all other regions (B). We apply the same procedure to get an aggregate of the conflict incidence variable. In the following, we then test whether aid receipts in area A lead to a higher likelihood of conflict in A but also in area B. Table 3.9 presents the results using OLS regressions and clustering standard errors at the country level.

In line with previous results, aid disbursements in coalition regions as well as to non-coalition regions strongly and significantly reduce conflict in the respective same regions. In mixed districts, there is no significant relationship. For China, there are no signs of any spill-overs on lethal conflict incidence. For the WB, spill-overs are more nuanced. More aid to coalition regions increases the likelihood of violent conflict in non-coalition regions, in line with the increase in state capacity as suggested by Kishi and Raleigh (2015). This effect is only marginally significant, but considerably large in

\footnotetext{
${ }^{31}$ Table C.21 reports results for a count variable of non-lethal pro-government violence events, which are robust to this change in the outcome variable. Table C.20 verifies that this is driven by events recorded in SCAD that are distinct from the UCDP events, by coding only those region-years as a one that did not experience lethal government violence against civilians according to UCDP.
} 
Aid and conflict at the subnational level

size. $10 \%$ more WB aid to the governing regions increases the likelihood of conflict with at least five casualties by 10 percentage points. Moreover, more aid to mixed regions also correlates with more conflict in coalition regions ${ }^{32}$

Table 3.9 OLS Results - Spill-Overs from Coalition to Non-Coalition Regions

\begin{tabular}{|c|c|c|c|}
\hline \multicolumn{4}{|l|}{ Panel A: World Bank } \\
\hline Conflict in region belonging to... & Non-Coalition & Coalition & Mixed \\
\hline \multirow{2}{*}{$\ln \left(W B\right.$ Aid noncoalition $\left.{ }_{\mathrm{t}-1}\right)$} & $-1.7092^{* * *}$ & $0.4046^{* *}$ & -0.0432 \\
\hline & $(0.5116)$ & $(0.1942)$ & $(0.4648)$ \\
\hline \multirow[t]{2}{*}{$\ln \left(W B\right.$ Aid coalition $\left._{\mathrm{t}-1}\right)$} & $1.3437^{* *}$ & $-1.4479^{* * *}$ & -0.0482 \\
\hline & $(0.5493)$ & $(0.3317)$ & $(0.6200)$ \\
\hline \multirow[t]{2}{*}{$\ln \left(W B\right.$ Aid mixed $\left._{\mathrm{t}-1}\right)$} & -0.6811 & $0.6578^{* *}$ & 0.1513 \\
\hline & $(0.4946)$ & $(0.2806)$ & $(0.6715)$ \\
\hline$N$ & 703 & 703 & 703 \\
\hline \multicolumn{4}{|l|}{ Panel B: China } \\
\hline \multirow{3}{*}{$\begin{array}{l}\text { Conflict in region belonging to... } \\
\ln \left(\text { Chinese Aid noncoalition }{ }_{\mathrm{t}-2}\right)\end{array}$} & Non-Coalition & Coalition & Mixed \\
\hline & -0.2931 & -0.2897 & $-0.8032^{* * *}$ \\
\hline & $(0.4996)$ & $(0.3274)$ & $(0.2367)$ \\
\hline \multirow[t]{2}{*}{$\ln \left(\right.$ Chinese Aid coalition $\left._{\mathrm{t}-2}\right)$} & -0.1080 & -0.1373 & -0.1501 \\
\hline & $(0.1816)$ & $(0.1482)$ & $(0.1673)$ \\
\hline \multirow[t]{2}{*}{$\ln \left(\right.$ Chinese Aid mixed $\left._{\mathrm{t}-2}\right)$} & 0.2577 & -0.0313 & 0.1550 \\
\hline & $(0.3071)$ & $(0.1773)$ & $(0.2523)$ \\
\hline$N$ & 666 & 666 & 666 \\
\hline Country FE & Yes & Yes & Yes \\
\hline Year FE & Yes & Yes & Yes \\
\hline
\end{tabular}

Notes: Dependent variable: Binary conflict indicator $(100$ if $\mathrm{BRD} \geq 25,0$ if $\mathrm{BRD}<5)$. The sample includes African countries for the sampling period of 1995-2012 for the World Bank and 2000-2012 for Chinese Aid. Conflicts are considered for the World Bank from 1996 to 2013 and for Chinese aid from 2002 to 2014 due to the lag structure. Both regressions include year and country fixed effects as well as time trends. Time trends include a linear country-specific time trend. Columns (1) \& (2) refer to all regions without members of the governing coalition, whereas columns (3) \& (4) to mixed regions with some groups in and out of the coalition, and columns (5) \& (6) to regions that contain groups exclusively from the coalition. Standard errors in parentheses are clustered at the country level. ${ }^{*} p<0.1,{ }^{* *} p<0.05,{ }^{* * *} p<0.01$

Finally, we aggregate the aid and conflict data at the country level. This allows us to see whether our prior analyses of spill-overs hide important patterns that we might see in the aggregation, but also makes the results comparable to studies at the country level. We show results with the WB and China in the same regression, with and without

\footnotetext{
${ }^{32}$ Appendix Table C.37 runs a similar analysis, but instead of regions that according to EPR are part of the governing coalition, it focuses on the capital versus other regions in the country.
} 
Aid and conflict at the subnational level

Table 3.10 OLS Results - Aggregate Cross-Country Analysis

\begin{tabular}{lcc}
\hline \hline & Excl. Budget Aid & Incl. Budget Aid \\
$\ln \left(W B\right.$ Aid $\left._{\mathrm{t}-1}\right)$ & -0.2035 & 0.1578 \\
& $(0.2492)$ & $(0.4179)$ \\
$\ln \left(\right.$ Chinese Aid $\left._{\mathrm{t}-2}\right)$ & $-0.2061^{*}$ & 0.0775 \\
& $(0.1043)$ & $(0.1437)$ \\
$R^{2}$ & 0.317 & 0.315 \\
$N$ & 792 & 792 \\
& & \\
\hline \hline
\end{tabular}

Notes: Dependent variable: Binary conflict indicator (100 if $\mathrm{BRD} \geq 25,0$ if $\mathrm{BRD}<25)$. Estimates refer to the country level, where aid and battle-related deaths were aggregated at the country level. The sample includes African countries for the sampling period of 1995-2012 for the World Bank and 20002012 for Chinese Aid. Conflicts are considered for the World Bank from 1996 to 2013 and for Chinese aid from 2002 to 2014 due to the lag structure. All regressions include year and country fixed effects as well as time trends. Regressions include country and year fixed effects as well as a linear county-trend. Standard errors in parentheses are clustered at the country level. ${ }^{*} p<0.1,{ }^{* *} p<0.05, * * * p<0.01$

adding non-geocoded aid to the model. ${ }^{33}$ When considering only geocoded aid, we find a negative and for China even statistically significant effect. This changes, when adding non-geocoded flows. Coefficients turn positive, but remain statistically insignificant. In contrast to the non-geocoded projects, the geocoded aid could be earmarked for more specific purposes and, hence, be less fungible. In this regard, project specificity might be linked to different conflict outcomes analogous to the growth effect heterogeneity observed for project and budget aid (Dreher et al., 2017).

\subsubsection{Sensitivity}

We conduct a large range of sensitivity tests, which we describe in short here grouped by issue.

Aggregation level: Appendix Table C.34 C.33) depicts the corresponding OLS (IV) results at the ADM2 level. The OLS results for the WB and China are both similar to the ones at the ADM1 level, with the majority of coefficients being negative. The patterns of statistical significance are also similar with OLS. Five out of nine coefficients

\footnotetext{
${ }^{33}$ Non-geocoded refers here to the projects, which could not be precisely allocated to an administrative region.
} 
Aid and conflict at the subnational level

are significantly negative for the WB, and none for China. The IV point estimates differ somehow, but in no case become statistically significant.

Computation of standard errors: Table C.38 (Table C.39) presents corresponding OLS (IV) results using errors clustered only at the regional level. For the WB, seven out of nine OLS coefficients are now significantly negative. For China, only one negative coefficient becomes significant at the five percent level. The average IV results remain negative and insignificant in both cases.

Choice of conflict indicator: As we discuss in the data section, there is no "correct" coding of the dependent variable, just more and less plausible choices. Table C.25(C.26) presents alternative regression results with a higher conflict threshold of at least $25 \mathrm{BRD}$ per region year using the OLS (IV) specifications. Appendix Table C.23 (Table C.24) considers the $\log$ of battle-related deaths $(+0.01)$ as a continuous measure of conflict intensity instead of looking at a binary indicator of conflict incidence using OLS (IV). We find largely negative OLS coefficients for the WB and slightly positive ones for China, but with IV both coefficients turn negative in line with prior results.

Instrumental variable: We conduct the majority of robustness tests regarding our instrumental variable strategy. As outlined above, we detrended the Chinese steel production time series because it is dominated by a long-term trend, but not the WB liquidity where there is enough year-to-year variation. ${ }^{34}$ Table C.13 shows that our first stages also work when using the detrended IDA position or the unadjusted Chinese steel excess production. This suggests that the long-term trends in steel production do not overlap with a problematic trend in conflict that differs between low and high probability regions.

The second component of the instrumental variable, the probability term, can also be computed in different ways. We test various plausible options. Using the cumulative probability is advantageous as it only uses pre-determined values, but could create problems if the probability in the first year(s) is not as informative. Appendix Table C.12 drops the first year of the respective panel (start at 1998 for the World Bank's IDA and 2003 for Chinese Steel), so that the first probability observation is already based on at least two observations. Table C.14 uses a constant probability from the third year of the respective sample onwards, i.e., 1998 for the World Bank's IDA, and 2003 for Chinese Steel, analogous to Nunn and Qian (2014). Appendix Table C.11 drops the 10 highest leverage region-year observations. The instrumental variable is robust to all these choices and specifications.

Moreover, Appendix Table C.8 reports reduced form estimates. Table C.9 uses a lead of aid as a placebo treatment in the first stage, which always shows up statisti-

\footnotetext{
${ }^{34}$ Although we control in later specifications for linear trends on the country and regional level, we would not capture the variation incorporated in the interaction of a linear trend with the time-varying exposure term.
} 
Aid and conflict at the subnational level

cally insignificantly. Table C.7 reports the first stage including the coefficient for the probability.

Non-linear estimators: In line with Berman et al. (2017), we also run a Poisson Pseudo-Maximum Likelihood estimation in Table C.41, which is suitable for binary outcomes with a large fraction of zeros. The results are generally in line with the main findings in terms of coefficient signs. However, one needs to note that we could only include year fixed effects as the inclusion of further fixed effects caused convergence issues.

Temporal dependence: As conflict might be highly persistent over time, we include a lagged dependent variable in Table C.40. The results are very similar, with mostly negative and partly significant coefficients for the WB and China.

Overlapping panels: Our main table uses the years 1995-2012 for the WB, and the years 2000-2012 for China. As there could be coordination or competition between the two donors (e.g., Gehring et al., 2017, Humphrey and Michaelowa, 2018), we also want to estimate both jointly in one regression. Appendix Tables C.44 and C.45 show that the coefficients change slightly, with the WB estimates becoming less negative on average. This change seems to be nearly entirely explained by periodical differences in the effect of WB aid. When re-estimating the WB results for the years 2000-2012 in Appendix Tables C.42 and C.43, the point estimates are nearly the same without conditioning on Chinese Aid. Hence, not controlling directly for the other donor does not seem to create a large bias, it seems rather that the effects differ between different observation periods. As limiting the WB period creates a weak IV problem with country-year fixed effects (see Appendix Table C.43), we choose our two main specifications with differing sample periods in order to exploit the maximum available information for each donor.

\subsection{Conclusion}

Our paper aims to provide a comprehensive analysis of the relationship between development aid and conflict at the subnational level. Therefore, we augment an important literature that has so far either focused on the macro level (Nielsen et al., 2011; Nunn and Qian, 2014, Bluhm et al., 2016), very specific types of aid (Berman et al., 2011; Crost et al., 2014), or on a limited subset of countries (Berman et al., 2011, van Weezel, 2015: Crost et al., 2016), and has not converged towards a consensus.

To achieve that aim, we examine two donors that represent two contrasting approaches to development, the World Bank and China. One is a multilateral donor that emphasizes human right conditions and expert knowledge, the other an emerging South-South donor that emphasizes "mutual benefits" without many official strings attached (Asmus et al., 2017). 
Our results on aid and conflict in the same region show no signs of a conflict-fueling effect on average. Rather aid seems to be able to somehow reduce the likelihood of conflict in particular for WB projects. When distinguishing between different sectors, we find the strongest and most significant conflict-reducing effects for projects in the transport sector (both donors). Distinguishing different conflict types suggests that the reduction in conflict is driven by less lethal violence by governments against civilians.

We examine claims that in particular Chinese projects lead to civilian unrest in Africa by ignoring local traditions and circumstances, or replacing people. For none of the two donors, we find evidence that demonstrations, strikes, or riots increase significantly. When focusing on non-lethal repression by recipient governments, however, we find consistent evidence that regions in which China is engaged show an increased likelihood of repressive measures. The precise reasons for this should be explored in future research. It seems in line with a rationale where China is eager to avoid violent conflict that endangers its workers and investment, but less opposed to repression than the Western donors.

We try to rule out whether, even if aid does not fuel conflict on average, it does so in regions that are not part of the governing coalition. In this regard, we consider whether there are spill-overs of aid-driven conflict between the governing coalition and other regions, or between the capital and other regions. There is no evidence of conflict spillovers for China, but some suggestive positive correlations for the World Bank. Overall, we conclude, based on OLS and IV results using geocoded data, that with regard to outright conflict with at least five battle-related deaths, WB and Chinese projects both seem to damping instead of fueling such conflicts.

Finally, country level aid to the government seems to be the factor in reconciling the discrepancy in the literature. The conclusion that WB and Chinese aid projects seem rather to dampen conflicts also holds when aggregating this project aid to the country level. In contrast, including non-geocoded aid, which is directly allocated to the government, the country level analysis reveals positive relationships of aid and conflict for both donors, though statistically insignificant. Thus, aid fungibility remains a critical issue that should be further investigated. 
Aid and conflict at the subnational level

\section{A Data Appendix}

\section{A.1 Sources}

Tables C.1 and C.2 lists descriptions and sources of our independent, dependent and control variables.

Table C.1 Data Sources

\begin{tabular}{|c|c|c|c|}
\hline Variable Name & Variable Description & Time Period & Variable Source \\
\hline World Bank Aid & $\begin{array}{l}\text { log of World Bank Aid disburse- } \\
\text { ments in a given region-year }\end{array}$ & 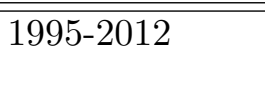 & Strandow et al. $(2011)$ \\
\hline Chinese Aid & $\begin{array}{l}\text { log of Chinese Aid commitments } \\
\text { in a given region-year }\end{array}$ & $2000-2012$ & Dreher et al. (2017) \\
\hline $\begin{array}{l}\text { Strikes, Riots, } \\
\text { Demonstrations }\end{array}$ & $\begin{array}{l}\text { Binary indicator }(100 ; 0) \text { if any vi- } \\
\text { olent event of this type in a given } \\
\text { region-year took place }\end{array}$ & $1995-2012$ & Salehyan et al. $(2012)$ \\
\hline Intensity $1 / 2$ & $\begin{array}{l}\text { Binary indicator }(100 ; 0) \text { if } \\
\geq 5 / \geq 25 \text { persons were killed in a } \\
\text { given region-year }\end{array}$ & $1995-2014$ & \begin{tabular}{|lll} 
Croicu and & Sundberg \\
$(2016)$ & &
\end{tabular} \\
\hline Population & $\begin{array}{l}\text { Continuous indicator of regional } \\
\text { population }\end{array}$ & $1995-2014$ & CIESIN $(2016)$ \\
\hline $\begin{array}{l}\text { Drought (end of } \\
\text { rainseason) }\end{array}$ & $\begin{array}{l}\text { SPI value of drought severity of } \\
\text { the region's entire rainy season }\end{array}$ & $1995-2014$ & \begin{tabular}{|l} 
Guttman $(1999)$ and \\
Tollefsen et al. $(2012)$ \\
\end{tabular} \\
\hline $\begin{array}{l}\text { Drought (start of } \\
\text { rainseason) }\end{array}$ & $\begin{array}{l}\text { SPI value of drought severity dur- } \\
\text { ing the first month of the region's } \\
\text { rainy season }\end{array}$ & $1995-2014$ & $\begin{array}{l}\text { Guttman }(1999) \text { and } \\
\text { Tollefsen et al. }(2012)\end{array}$ \\
\hline Temperature & $\begin{array}{l}\text { Mean temperature (in degrees } \\
\text { Celsius) per region-year }\end{array}$ & $1995-2014$ & $\begin{array}{l}\text { Fan and Van den Dool } \\
(2008) \text { and Tollefsen } \\
\text { et al. }(2012)\end{array}$ \\
\hline Precipitation & $\begin{array}{l}\text { Total amount of precipitation (in } \\
\text { millimeter) per region-year }\end{array}$ & $1995-2014$ & $\begin{array}{l}\text { Tollefsen et al. }(2012) \\
\text { and Schneider et al. } \\
(2015)\end{array}$ \\
\hline Chinese Steel & $\begin{array}{l}\text { Production of Chinese Steel in } \\
\text { tonnes }\end{array}$ & $1999-2013$ & $\begin{array}{l}\text { World Steel Association } \\
(2009,2014)\end{array}$ \\
\hline Elevation & $\begin{array}{l}\text { Standard deviation of regional el- } \\
\text { evation as an indicator of rugged- } \\
\text { ness of terrain }\end{array}$ & Constant & Riley et al. $(1999)$ \\
\hline Borders & $\begin{array}{l}\text { Binary indicator if a given ADM1 } \\
\text { region borders another country }\end{array}$ & Constant & Hijmans et al. (2012) \\
\hline $\begin{array}{l}\text { Ocean, Rivers, } \\
\text { Lakes }\end{array}$ & $\begin{array}{l}\text { Binary indicator of presence of } \\
\text { rivers, lakes or ocean in a given } \\
\text { ADM1 region }\end{array}$ & Constant & Natural Earth (2018) \\
\hline
\end{tabular}


Aid and conflict at the subnational level

Table C.2 Data Sources (continued)

\begin{tabular}{|c|c|c|c|}
\hline Variable Name & Variable Description & Time Period & Variable Source \\
\hline $\begin{array}{l}\text { IDA Funding Po- } \\
\text { sition }\end{array}$ & $\begin{array}{l}\text { "Bank's net investment port- } \\
\text { folio and its non-negotiable, } \\
\text { non-interest-bearing demand obli- } \\
\text { gations (on account of members' } \\
\text { subscriptions and contributions)" } \\
\text { divided "by the sum of the } \\
\text { Bank's undisbursed commit- } \\
\text { ments of development credits and } \\
\text { grants."(Dreher et al., 2017) }\end{array}$ & (1995-2012 & Dreher et al. $(2017)$ \\
\hline Landarea & Area of a given region & Constant & Hijmans et al. $(2012)$ \\
\hline $\begin{array}{l}\text { Travel } \\
\text { (Mean) }\end{array}$ & $\begin{array}{l}\text { Gives the mean regional estimate } \\
\text { of the travel time to the nearest } \\
\text { major city }\end{array}$ & Constant & $\begin{array}{l}\text { Uchida and Nelson } \\
(2009) \text { and Tollefsen } \\
\text { et al. }(2012)\end{array}$ \\
\hline
\end{tabular}

\section{A.2 Independent Variables (Development Aid)}

World Bank's IDA \& IBRD disbursements For our analysis we draw on the "World Bank IBRD-IDA, Level 1, Version 1.4.1" provided by the AidData consortium, which covers approved loans under the IBRD-IDA lending line between 1995 and 2014 35 These data correspond to project aid disbursed from 5,684 projects in 61,243 locations. The data build on information provided by the World Bank, including the disbursement dates, project sectors and disbursement amounts. These values were deflated to 2011 values. In an effort to allow for more fine-grained analysis of aid projects, AidData's coders filtered the location names from aid project documentation and assigned these to specific locations. While for some projects exact locations including latitude and longitude were assigned, other projects, which had a more policy or regulation oriented purpose, could only be assigned to an administrative level (e.g., the first level of subnational regions (provinces) or the second level (districts)). In order to include as many disbursements as possible, but to be also able to grasp the advantages of georeferenced data, we focus our analysis on these administrative levels. For our administrative boundaries, we build on the GADM dataset constructed by Hijmans et al. (2012). One difficulty with these data is that for some countries, including more populous nations like Armenia, more fine grained administrative distinctions are missing. As the size of administrative regions is not fixed by size across countries, we assume in this cases that our ADM1 regions would be ADM2 regions.

Figure 3.2 displays the development finance locations coded by donor, distinguishing all projects (precision 1-8), projects coded at least at the first administrative level

\footnotetext{
${ }^{35}$ As the number of documented projects declines steeply after 2012, we focus on the 1995-2012 period.
} 
Aid and conflict at the subnational level

(precision 1-4), projects coded at least at the second administrative level (precision 1-3) and projects coded more precise (precision 1-2).

One challenge arises in projects with a multitude of locations, where it is not possible to derive a distinct value of disbursements. In this regard, we suggest two solutions.

First, we allocate disbursements by the number of locations. In line with previous research by Dreher and Lohmann (2015), we assume that aid is distributed equally across locations and allocate aid proportionally to the locations per region. For instance, for a project with 10 locations, where four locations are in region A and six locations are in region B, $40 \%$ of project disbursements would be accounted in region $\mathrm{A}$ and $60 \%$ in region $\mathrm{B}$.

Second, we calculate population weighted disbursements. Here, we assume that aid is allocated based on the regional population shares. For instance, if a project would have project locations in two regions of a country, where two million inhabitants would reside in region $\mathrm{A}$ and three million would reside in region $\mathrm{B}, 40 \%$ of project disbursements would be accounted in region $\mathrm{A}$ and $60 \%$ in region $\mathrm{B}$. Here, the aid attribution formula would write as follows: $A i d_{p i j t}=\frac{\text { Aid }_{p i t}}{\int \text { Population }_{p i}} *$ Population $_{p j}$, where $\mathrm{p}$ is the project, $\mathrm{i}$ is the country, $\mathrm{j}$ is the region and $\mathrm{t}$ is the period for which we estimate the allocation shares.

Finally, our dataset comprises development finance from IBRD and IDA. However, only IDA disbursements can be classified as Official Development Assistance. For this purpose, projects and corresponding finance were disentangled into IDA (development aid) and IBRD (development finance) disbursements.

Chinese Aid (ODA-like and OOF flows) In order to create our data on the ADM2 and ADM1 level, we make use of the feature that aid can be defined on the ADM2 level and then aggregated to the ADM1 level. One challenge with the data is, however, that we lack information on the ADM2 regions for some countries (as there are no ADM2 regions in small countries). Therefore, we create two spatial joins of ADM1 and ADM2 regions from the GADM dataset with Chinese aid point features. This yields matches of the specific project locations with the administrative regions as depicted in Figure C.1.

In order to create our data, we first load our ADM2 data into Stata and drop the ADM0 and ADM1 identifiers in order to be later able to rely on the identifiers from the ADM1-Aid spatial join. The next step involves merging the ADM2-Aid spatial join with the ADM1-Aid spatial join by the target-fid, which uniquely identifies the points from the Dataset "aiddata_china_1_1_1.xlsx" by Dreher et al. (2016) and Strange et al. (2017). Based on this data, we create unique identifiers for all ADM1 and ADM2 regions, whereby we treat ADM1 regions as ADM2 regions in cases that ADM2 regions are missing (e.g., in Cape Verde). This assumption can be made as size of administrative regions are rather arbitrary and several ADM2 regions are larger than other countries' ADM1 regions. After getting the regional identifiers right, we can merge (a) the spatial joins of ADM regions and Chinese aid locations with (b) data on flows of Chinese aid. 
Aid and conflict at the subnational level

Figure C.1 Chinese Aid ADM1 Spatial Join

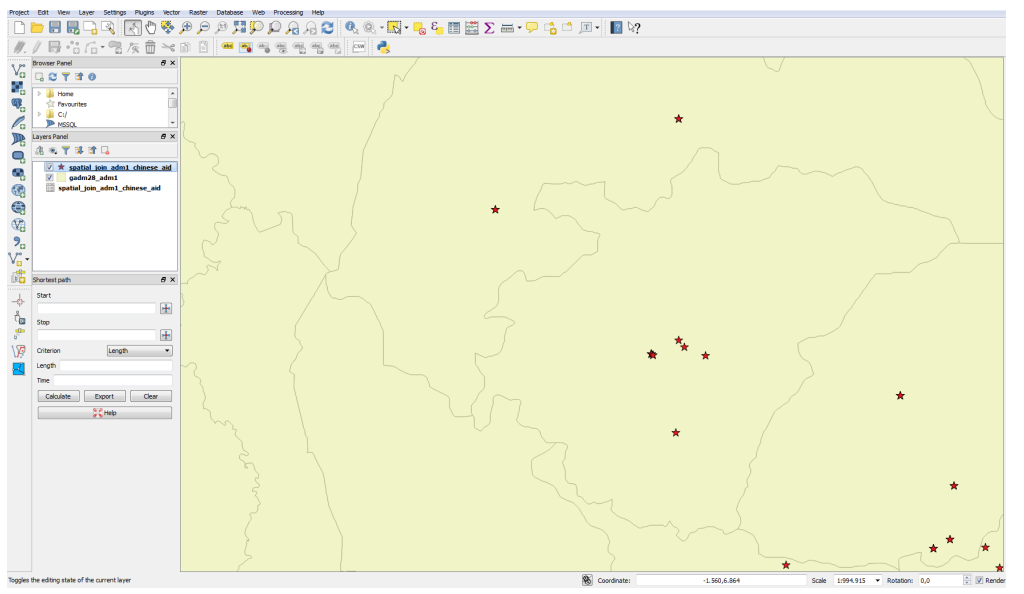

Notes: Graphical depiction based on Quantum GIS.

In a first step, we clean these data from entries that only relate to pledges of Chinese aid (information is from the variable status254). Although the data on Chinese finance to Africa also contain information on official investment, the focus of this paper is on development aid. Thus, we focus on flows, which correspond to "ODA-like" funds as those would correspond closest to development aid (following individual correspondence with the authors of Strange et al. (2017)). The data are then merged with population data from the gridded population of the world data (CIESIN, 2016) in order to be able to allocate financial flows with population weights in case one project had commitment locations in different administrative regions. Yet, one further challenge has to be resolved before allocating the commitments to regions, as the Chinese aid commitments are coded like World Bank disbursements with different precision (e.g., some are coded only for geographic features, which involve several administrative regions or are flows which go to central ministries or the government). For our commitment allocation, we only consider those projects, which are at least coded at the ADM1 level. This means that we proportionally exclude commitments, which provide information only on the central level. We furthermore distinguish between projects, which are coded only at the ADM1 level and ones that provide information on the ADM2 level (or more precise). The former are proportionally split over the underlying ADM2 regions. Although the latter can be precisely traced back to the ADM2 region, it might happen that projects have commitments in several ADM2 regions. In this case, we also split the commitments proportionally by locations or population as indicated earlier.

To exploit sectoral variation in development finance both for the World Bank and China, we make use of the information provided by Strange et al. (2017) on Chinese aid's sectoral allocation using the OECD's Creditor Reporting System (CRS) codes. To achieve comparability with the broad sectors indicated for the World Bank, we assign sectors as follows: "Agriculture, Fishing and Forestry" (CRS-310: "Agriculture, Forestry and Fishing"), "Public Administration, Law and Justice" (CRS-150: "Govern- 
ment and Civil Society"), "Information and communication" (CRS-220: "Communications"), "Education" (CRS-110: "Education"), "Finance" (CRS-240: "Banking and Financial Services"), "Health and other social services" (CRS-120: "Health," CRS160: "Other Social infrastructure and services"), "Energy and mining" (CRS-230: "Energy Generation and Supply"), "Transportation" (CRS-210: "Transport and Storage"), "Water, sanitation and flood protection" (CRS-140: "Water Supply and Sanitation"), "Industry and Trade" (CRS-330: "Trade and Tourism," CRS-320: "Industry, Mining, Construction").

Sectoral distribution of aid disbursements We use additional information on the financier for each disbursement for each project. Based on these information, we can construct sectoral distributions of aid flows. While both donors are investing heavily in transportation across Africa, further priorities differ. The World Bank supports Health and Social Services strongly, whereas China commits a large share of its funds to Industry \& Trade.

Figure C.2 Sectoral Distribution of Aid

a) World Bank's IDA

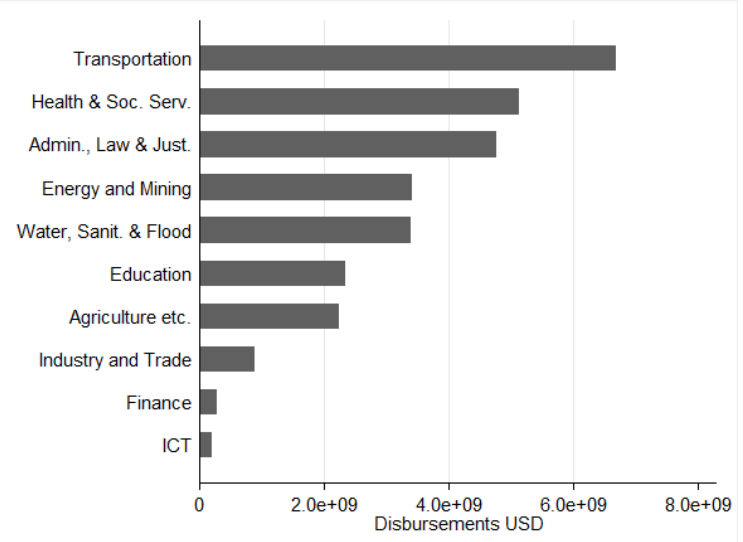

b) China

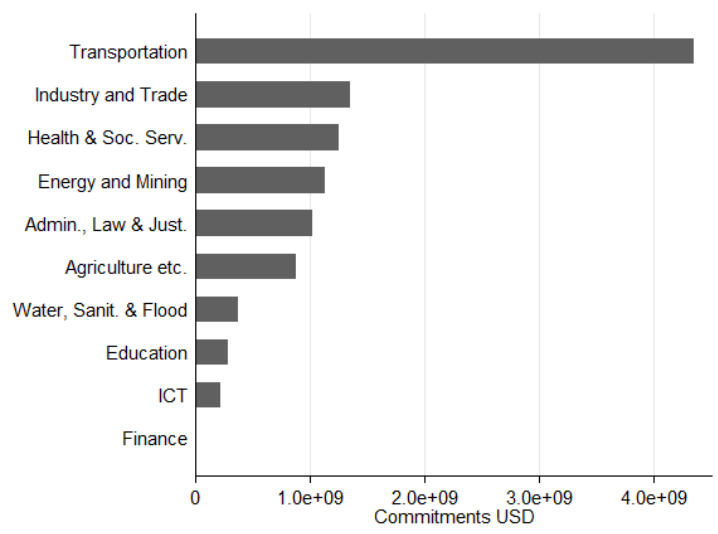

Source: Authors' calculation. 
Aid and conflict at the subnational level

\section{Allocation scheme (more detailed)}

Location weighting The World Bank geocoded data release comes in the format of projects and several corresponding locations. For instance, a typical project report would mention the transaction amounts, the project purpose as well as different project locations. The latter can be classified in different degrees of precision (e.g., precision codes smaller than 4 correspond to locations that refer to an ADM2 region or even more precise, while precision code 4 corresponds to locations at the ADM1 level). When allocating the development aid across locations on the ADM1 and ADM2 level, we make following assumptions based on a three step procedure. ${ }^{36}$ First, we subtract the share of development aid, which corresponds to locations, which are coded less precise than ADM1 (e.g., large geographic regions or aid at the country level). E.g., if three out of 10 locations in a project are coded less precise than ADM1, the further analysis focuses on the remaining $70 \%$ of development aid. Second, we then allocate all aid with precision codes 1-3 to the corresponding ADM2 regions. This is done by taking the location share (either by equal or population weights) of the transaction amount per location. As certain ADM2 regions might have several locations per project or even several projects, we collapse our data by ADM2 region. Third, we then allocate all aid with precision code 4 to the corresponding ADM1 regions. This is done by taking the location share (either by equal or population weights) of the transaction amount per location. As certain ADM1 regions might have several locations per project or even several projects, we collapse our data by ADM1 region. In order to allow for inference on the ADM2 level, we make the assumption that transactions coded with precision 4 are attributable equally to all corresponding ADM2 regions. In practice, this is done by merging the ADM1 regions with all corresponding ADM2 regions and then splitting the aid with location or population weights. Finally, data with precision codes 1-3 and precision code 4 can be simply added up on the ADM2 level yielding our treatment variable of interest. For inference on the ADM1 level, totals of ADM2 level development assistance are created on the geounit-year level.

\footnotetext{
${ }^{36}$ Throughout the paper we allocate the aid either assuming equal weights per location or weighting each location by population.
} 
Aid and conflict at the subnational level

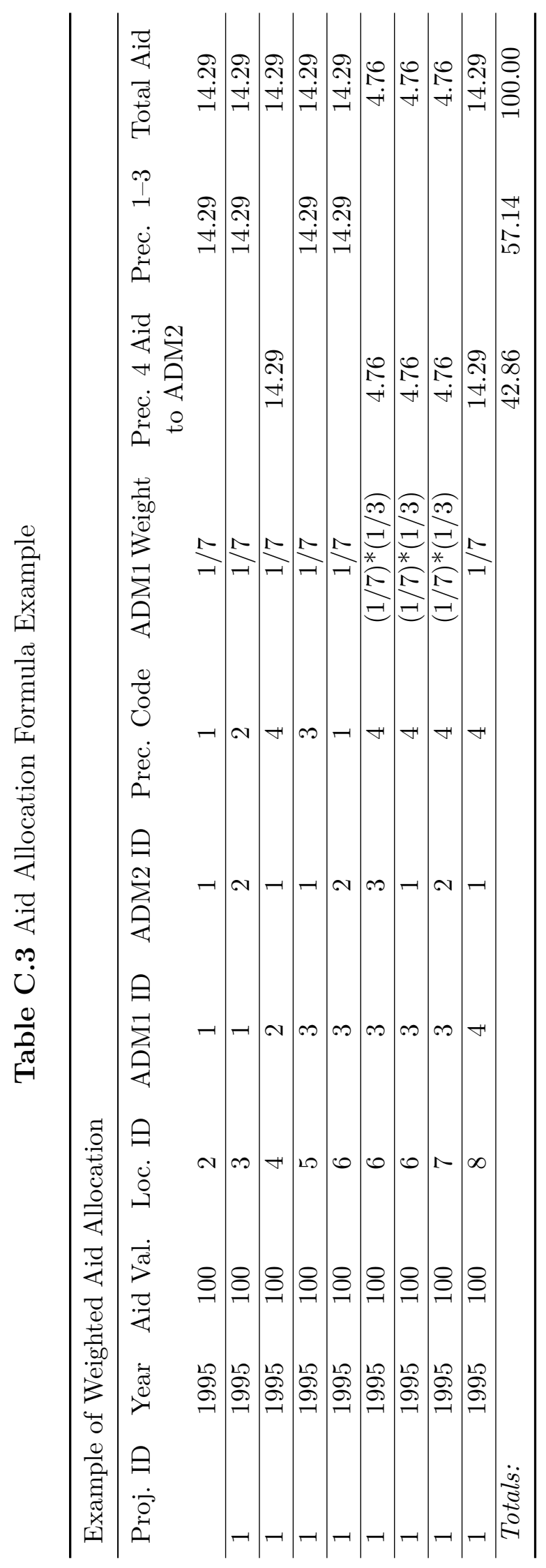


Aid and conflict at the subnational level

Population weighting Analogous to the location weighted aid, we also distribute aid with population weights. Our population data are from the Center for International Earth Science Information Network (CIESIN, 2016). However, some projects only consist of locations without population estimates (e.g., deserts). In this case, we assume a population of 1 citizen per location in order to be able to distribute those aid disbursements. We then consequently attribute population of ADM1 regions to project locations, which are coded at the ADM1 level (precision 4), and ADM2 populations to project locations, which are coded at least as precise as the ADM2 level (precision 1-3).

Similar to the location-weighing, we construct the total population of each projectyear pop project. For the projects coded with precision 4, we then attribute disbursements via the regional share in population $\operatorname{pop}_{A D M 1}$. This is then divided by pop project and multiplied with the project disbursements TransactionValue proj in each year: $A D M 1$ Precision $_{4}=\frac{\text { pop }_{A D M 1}}{\text { pop proj }_{\text {proj }}} *$ TransactionValue $_{\text {proj }}$. As there might be several active projects per ADM1 region, we aggregate the disbursements on the ADM1 level. In order to break those numbers down to the ADM2 level, we merge all corresponding ADM2 regions to the ADM1 regions. We then divide the population in each ADM2 region by the population in each ADM1 region and multiply this share with the yearly disbursements per region, $A D M 2$ Precision $_{4}=\frac{p_{\text {op }} \text { pDM }_{A D M 1}}{\text { op }_{A D}} * A D M 1$ Precision $_{4}$. For the precision codes 1-3 (at least coded as precise as the ADM2 level), we then attribute disbursements via the regional share in population divided by pop project. This is then multiplied with the project disbursements in each year: ADM2Precision A $_{123}=$

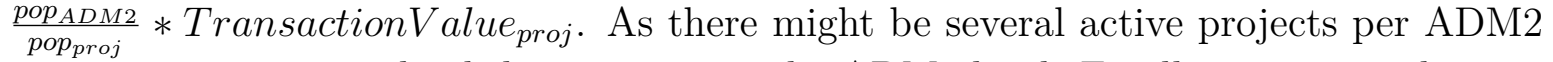
region, we aggregate the disbursements on the ADM2 level. Finally, we merge the precision code 1-3 and 4 data on the ADM2 level to obtain our variables of interest. Those can then be aggregated on the ADM1 level.

\section{A.3 Dependent Variables (Conflict data)}

As AidData and UCDP use the same coding framework, we can make use of similar coding rules and use likewise only observations, which are coded at least at the ADM1 level (precision codes 1-4).

Again for the more precise data (precision codes 1 and 2), we use a point to polygon analysis on the ADM level. As one conflict event is always coded in one discernible location (Croicu and Sundberg, 2016), we do not need to make additional distributional assumptions by location number or population size for conflict data, because we do not face issues of multiple project locations, which we had in the aid data. Yet, for conflict observations on the ADM1 level (precision code 4), we do not distribute battle-related deaths by population weights across ADM2 regions.

One further useful feature of the UCDP data is that it is possible to discern three different types of violence. Those are namely the government against organized groups (type 1), organized non-governmental groups versus the government (or against another non-governmental group) (type 2), and one-sided violence by the government against civilians (type 3 governmental) and by non-governmental groups against civilians (type 
Aid and conflict at the subnational level

3 non-governmental) ${ }^{37}$ UCDP data can be considered as comprehensive for our 1995 to 2012 sample, despite for Syria for which no battle-related deaths information are providend. Hence, all missing values are treated as zeros except for the Syrian case, which is not part of our analyisis.

SCAD data UCDP data focus on organized violence with lethal outcomes. However, along with the different theories it could be hypothesized that discontent and aid appropriation do not necessarily need to be linked to full-fledged conflict. What is more, recent empirical work by Bluhm et al. (2016) underscores the role of aid in conflict dynamics. Thus, we also consider social conflict as a further outcome, in terms of demonstrations and repressions, based on the Social Conflict Analysis Database (Salehyan et al., 2012). SCAD involves demonstrations, riots, strikes, coups, pro-, antiand extra-government violence, which can, but do not necessarily have to involve casualties. In this way SCAD complements the UCDP data. 38 SCAD mainly builds on data compiled by the Lexis-Nexis services from searches of Agence France Presse and Associated Press (Lexis Nexis, 2018). Based on the available information, data are georeferenced by web searches of the locations mentioned in the event reports. Analogous to UCDP data, precision codes are provided, which are used to allocate events in a similar manner.

Matching EPR to GREG To measure ethnic homelands, we use the Georeferencing of Ethnic Groups (GREG) dataset (Weidmann et al., 2010), which is a georeferenced version of the initial locations of ethnic homelands based on the Soviet Atlas Narodov Mira. The information about the power status comes from the time-variant Ethnic Power Relations (EPR) dataset (Vogt et al., 2015). Wherever possible, we match the group power status from EPR in a particular year to one of the time-invarying GREG group homelands. The original dataset assigns eight different power statuses to groups. The differences are sometimes marginal and hard to interpret, which is why to minimize measurement error we only use the more precises information on whether a group was part of the governing coalition or not. We then intersect the ethnic group polygons with the administrative regions to classify regions as one of the three categories.

\footnotetext{
${ }^{37}$ For a more detailed decription of the different types of violence, please consult Croicu and Sundberg (2015).

${ }^{38}$ Prior to 2014 armed conflict was not included in SCAD data and is now also distinguished from "social disturbances" (Salehyan and Hendrix, 2017).
} 
Aid and conflict at the subnational level

\section{B Analytical Appendix}

\section{B.1 Instrumental Variable}

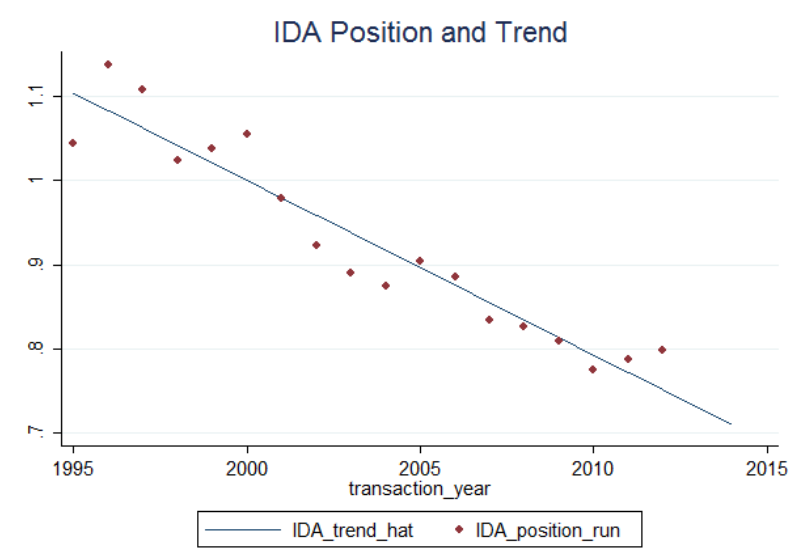

Notes: Yearly IDA-Position based on Dreher et al. (2017).

Figure C.3 IDA Funding Position - Time Series

Figure C.4 Donor Funding Positions and Aid

a) World Bank IDA Funding

Position and $\ln$ (World Bank Aid)

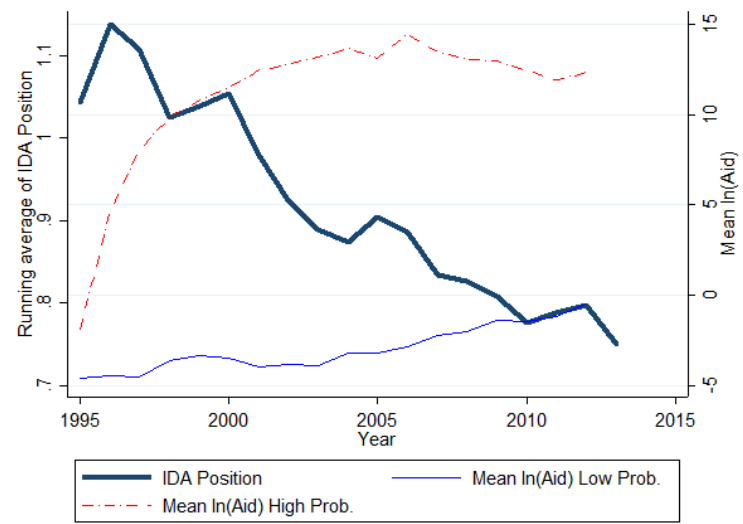

b) Deviations from Trend in Steel Production and $\ln ($ Chinese Aid)

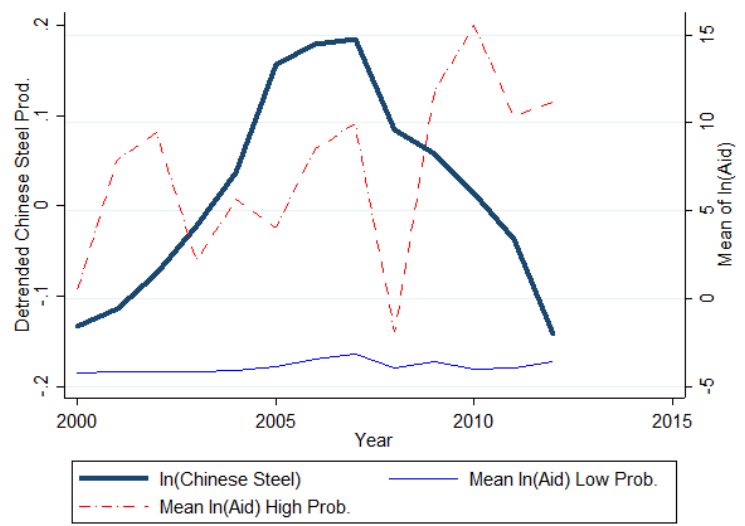

Note: Figure C.4a displays the IDA Funding Position (thick line), the mean of logged World Bank Aid disbursements per low probability recipient regions (thin line) and the mean of logged World Bank Aid disbursements per high probability recipient regions (dashed line). Figure C.4b displays the log of the detrended Chinese Steel Production (thick), the mean of logged Chinese Aid per low probability recipient regions (thin line) and the mean of logged Chinese Aid per high probability recipient regions (dashed line). 
Aid and conflict at the subnational level

Table C.4 Leads and Further Lags

\begin{tabular}{lcc}
\hline \hline & $(1)$ & $(2)$ \\
\hline Panel A: World Bank Aid & & \\
Two Leads and Lags: World Bank & & \\
$\ln \left(\right.$ World Bank Aid $\left._{\mathrm{t}+1}\right)$ & -0.0059 & 0.1559 \\
& $(0.1298)$ & $(0.1199)$ \\
$\ln \left(\right.$ World Bank Aid $\left._{\mathrm{t}}\right)$ & -0.1089 & $-0.2128^{*}$ \\
& $(0.1152)$ & $(0.1157)$ \\
$\ln \left(\right.$ World Bank Aid $\left._{\mathrm{t}-1}\right)$ & 0.0214 & -0.0933 \\
& $(0.0973)$ & $(0.0956)$ \\
$\ln \left(\right.$ World Bank Aid $\left._{\mathrm{t}-2}\right)$ & 0.0516 & 0.1424 \\
& $(0.0939)$ & $(0.1212)$ \\
$\ln \left(\right.$ World Bank Aid $\left._{\mathrm{t}-3}\right)$ & -0.0811 & -0.0535 \\
& $(0.0877)$ & $(0.1076)$ \\
$N$ & 10150 & 10150 \\
\hline \hline Panel B: Chinese Aid & & \\
Lead and Lag: China & & \\
$\ln \left(\right.$ Chinese Aid $\left._{\mathrm{t}+1}\right)$ & 0.1681 & $0.2083^{*}$ \\
& $(0.1244)$ & $(0.1258)$ \\
$\ln \left(\right.$ Chinese Aid $\left._{\mathrm{t}}\right)$ & -0.0127 & 0.0231 \\
$\ln \left(\right.$ Chinese Aid $\left._{\mathrm{t}-1}\right)$ & $(0.1268)$ & $(0.1358)$ \\
& -0.0086 & -0.0481 \\
$\ln \left(\right.$ Chinese Aid $\left._{\mathrm{t}-2}\right)$ & $(0.1514)$ & $(0.1600)$ \\
$\ln \left(\right.$ Chinese Aid $\left._{\mathrm{t}-3}\right)$ & 0.0121 & -0.0506 \\
& $(0.1165)$ & $(0.1313)$ \\
$N$ & 0.0572 & -0.0308 \\
Exogeneous Controls & $(0.0986)$ & $(0.1102)$ \\
Exogeneous Controls $\times$ Year & Yes & Yes \\
Linear Regional Trends & Yes \\
Country- $\times$ Year & Yes \\
\hline \hline
\end{tabular}

Notes: Dependent variable: Binary conflict indicator (100 if $\mathrm{BRD} \geq 5,0$ if $\mathrm{BRD}<5$ ). The sample includes African countries for the sampling period of 1995-2012 for the World Bank and 20002012 for Chinese Aid. Conflicts are considered for the World Bank from 1996 to 2013 and for Chinese aid from 2002 to 2014 due to the lag structure. Both regressions include year and region fixed effects as well as time trends. Time trends include linear and squared country-specific time trends. Standard errors in parentheses, two-way clustered at the country-year and regional level. ${ }^{*} p<0.1,{ }^{* *} p<0.05,{ }^{* * *} p<0.01$ 
Aid and conflict at the subnational level

Table C.5 IV Results - First Stage: Extensive Margin

\begin{tabular}{lcc}
\hline \hline & $(1)$ & $(2)$ \\
\hline Panel A: World Bank Aid & & \\
IV FS Extensive Margin: IDA Position & & \\
ID A Position $\mathrm{t}-1 \times$ Cum. Prob $\mathrm{t}-2$ & $4.0782^{* * *}$ & $4.8249^{* * *}$ \\
& $(0.4140)$ & $(0.5238)$ \\
Cum. Prob ${ }_{\mathrm{t}-2}$ & $-4.3155^{* * *}$ & $-5.0339^{* * *}$ \\
& $(0.4512)$ & $(0.5506)$ \\
$N$ & 12325 & 12325 \\
\hline \hline Panel B: Chinese Aid & & \\
IV FS Extensive Margin: Chinese Steel & & \\
Steel Prod detrend $\mathrm{t}-3 \times$ Cum. Prob $\mathrm{t}-3$ & $-3.7025^{* * *}$ & $-3.1905^{* * *}$ \\
& $(0.7694)$ & $(0.7572)$ \\
Cum. Prob ${ }_{\mathrm{t}-3}$ & $-1.7443^{* * *}$ & $-1.5365^{* * *}$ \\
& $(0.2117)$ & $(0.1989)$ \\
$N$ & 7975 & 7975 \\
& & \\
Exogeneous Controls & Yes & Yes \\
Exogeneous Controls $\times$ Year & Yes & Yes \\
Linear Regional Trends & Yes & Yes \\
Country-Year FE & No & Yes \\
\hline \hline
\end{tabular}

Notes: The table displays regression coefficients the first stage of the instrumental variable regression, when instead of the aid amount a binary indicator of aid receipts is used. The sample includes African countries for the sampling period of 1995-2012 for the World Bank and 2000-2012 for Chinese Aid. Both regressions include year and region fixed effects as well as time trends. Time trends include linear and squared country-specific time trends. The constituent term of the probability is depicted in Appendix Table C.7. Standard errors in parentheses, two-way clustered at the country-year and regional level. ${ }^{*} p<0.1,{ }^{* *} p<0.05,{ }^{* * *} p<0.01$ 
Aid and conflict at the subnational level

Table C.6 IV Results - First Stage: Intensive Margin

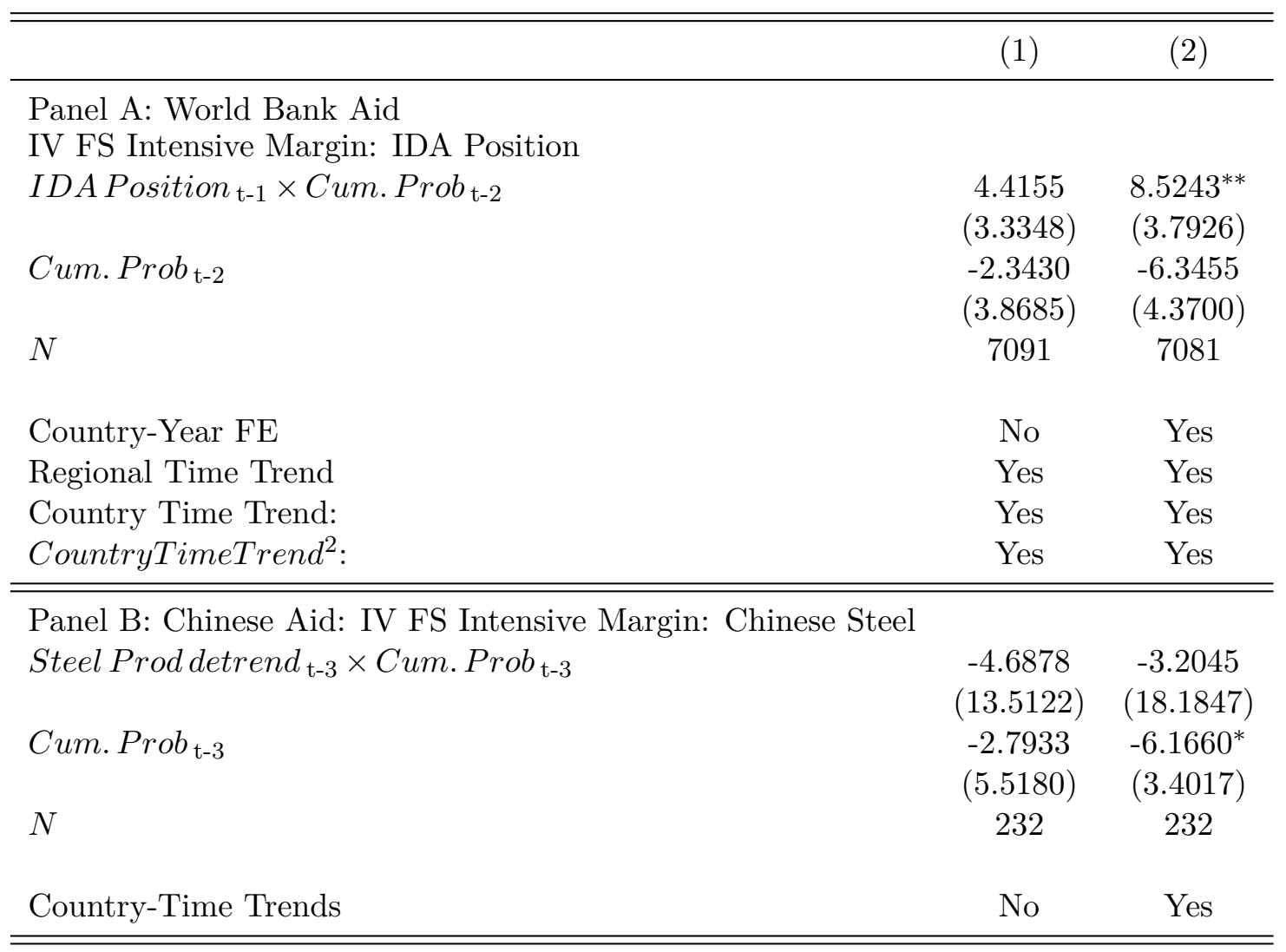

Notes: The table displays regression coefficients the first stage of the instrumental variable regression, when constraining the sample only on recipient regions. The sample includes African countries for the sampling period of 1995-2012 for the World Bank and 2000-2012 for Chinese Aid. All regressions include exogenous controls, region fixed effects and year fixed effects. Country-Year fixed effects and more rigid time trends are not included for Chinese Aid due to the more limited variation. The constituent term of the probability is depicted in Appendix Table C.7. Standard errors in parentheses, two-way clustered at the country-year and regional level. ${ }^{*} p<0.1,{ }^{* *} p<0.05$, ${ }^{* * *} p<0.01$ 
Aid and conflict at the subnational level

Table C.7 IV Results - First Stage with Probability Constituent Term

\begin{tabular}{|c|c|c|}
\hline Panel A: World Bank Aid & (1) & $(2)$ \\
\hline \multicolumn{3}{|l|}{ IV First stage: IDA Position } \\
\hline IDA Position $_{\mathrm{t}-1} \times$ Cum. Prob $_{\mathrm{t}-2}$ & $\begin{array}{c}70.9363^{* * *} \\
(7.1065)\end{array}$ & $\begin{array}{c}80.8832^{* * *} \\
(8.6854)\end{array}$ \\
\hline Cum. Prob ${ }_{\mathrm{t}-2}$ & $\begin{array}{c}-72.7723^{* * *} \\
(7.7291)\end{array}$ & $\begin{array}{c}-82.0994^{* * *} \\
(9.2698)\end{array}$ \\
\hline$N$ & 12325 & 12325 \\
\hline \multicolumn{3}{|l|}{ Panel B: Chinese Aid } \\
\hline Steel Prod detrend $\mathrm{t}_{\mathrm{t}-3} \times$ Cum. Prob $_{\mathrm{t}-3}$ & $\begin{array}{c}-70.8763^{* * *} \\
(14.9526)\end{array}$ & $\begin{array}{c}-60.6567^{* * *} \\
(14.9524)\end{array}$ \\
\hline Cum. Prob ${ }_{\mathrm{t}-3}$ & $\begin{array}{c}-33.3092^{* * *} \\
(3.9348)\end{array}$ & $\begin{array}{c}-29.6850^{* * *} \\
(3.7560)\end{array}$ \\
\hline$N$ & 7975 & 7975 \\
\hline Exogeneous Controls & Yes & Yes \\
\hline Exogeneous Controls $\times$ Year & Yes & Yes \\
\hline Linear Regional Trends & Yes & Yes \\
\hline Country-Year FE & No & Yes \\
\hline
\end{tabular}

Notes: The table displays regression coefficients the first stage of the instrumental variable regression, displaying additionally the constituent term of the probability, which was also used in Table 3.4 The sample includes African countries for the sampling period of 19952012 for the World Bank and 2000-2012 for Chinese Aid. Both regressions include year and region fixed effects as well as time trends. Time trends include linear and squared country-specific time trends. The constituent term of the probability is depicted in Appendix Table C.7. Standard errors in parentheses, two-way clustered at the country-year and regional level. ${ }^{*} p<0.1,{ }^{* *} p<0.05,{ }^{* * *} p<0.01$ 
Aid and conflict at the subnational level

Table C.8 IV Results - Reduced Form

\begin{tabular}{|c|c|c|}
\hline & (1) & $(2)$ \\
\hline \multicolumn{3}{|l|}{ Panel A: World Bank Aid } \\
\hline Cum. Prob ${ }_{\mathrm{t}-2}$ & $\begin{array}{c}10.8281 \\
(27.3795)\end{array}$ & $\begin{array}{c}19.2994 \\
(33.4583)\end{array}$ \\
\hline IDA $_{\text {Position }} \mathrm{t}-1 \times C u m$. Prob $_{\mathrm{t}-2}$ & $\begin{array}{c}-7.1921 \\
(26.5498)\end{array}$ & $\begin{array}{c}-18.2132 \\
(33.5818)\end{array}$ \\
\hline$N$ & 12325 & 12325 \\
\hline \multicolumn{3}{|l|}{ Panel B: Chinese Aid } \\
\hline Cum. Prob $\mathrm{t}-3$ & $\begin{array}{c}-12.0548 \\
(9.1057)\end{array}$ & $\begin{array}{c}-17.4914^{*} \\
(9.5552)\end{array}$ \\
\hline Steel Prod detrend $\mathrm{t}_{\mathrm{t}-3} \times$ Cum. Prob $_{\mathrm{t}-3}$ & $\begin{array}{c}47.2461 \\
(47.4192)\end{array}$ & $\begin{array}{c}39.7102 \\
(51.6767)\end{array}$ \\
\hline$N$ & 7250 & 7250 \\
\hline Exogeneous Controls & Yes & Yes \\
\hline Exogeneous Controls $\times$ Year & Yes & Yes \\
\hline Linear Regional Trends & Yes & Yes \\
\hline Country $\times$ Year FE & No & Yes \\
\hline
\end{tabular}

Notes: Dependent variable: Binary conflict indicator (100 if $\mathrm{BRD} \geq 5,0$ if $\mathrm{BRD}<5)$. The sample includes African countries for the sampling period of 1995-2012 for the World Bank and 2000-2012 for Chinese Aid. Both regressions include year and region fixed effects as well as time trends. Time trends include linear and squared country-specific time trends. Standard errors in parentheses, two-way clustered at the country-year and regional level. ${ }^{*} p<0.1$, ** $p<0.05$, *** $p<0.01$ 
Aid and conflict at the subnational level

Table C.9 Placebo - Instrumented Lead of Aid

\begin{tabular}{lcc}
\hline \hline & $(1)$ & $(2)$ \\
\hline Panel A: World Bank Aid & & \\
Placebo (Lead): World Bank & & \\
$l n\left(\right.$ World Bank Aid $\left.{ }_{\mathrm{t}+1}\right)$ & 0.2299 & 0.2332 \\
$\mathrm{~N}$ & $(0.3586)$ & $(0.3704)$ \\
Kleibergen-Paap underidentification test p-value & 12325 & 12325 \\
Kleibergen-Paap weak identification F-statistic & 0.000 & 0.000 \\
\hline \hline Panel B: Chinese Aid & 99.481 & 86.444 \\
Placebo (Lead): China & & \\
ln Chinese Aid $\mathrm{t}+1)$ & -0.1709 & -0.8099 \\
& $(0.4393)$ & $(0.5778)$ \\
N & 8700 & 8700 \\
Kleibergen-Paap underidentification test p-value & 0.000 & 0.000 \\
Kleibergen-Paap weak identification F-statistic & 17.628 & 12.910 \\
& & \\
Exogeneous Controls & Yes & Yes \\
Exogeneous Controls $\times$ Year & Yes & Yes \\
Linear Regional Trends & Yes & Yes \\
Country $\times$ Year FE & No & Yes \\
\hline \hline
\end{tabular}

Notes: Dependent variable: Binary conflict indicator (100 if $\mathrm{BRD} \geq 5,0$ if $\mathrm{BRD}<5)$. The sample includes African countries for the sampling period of 1995-2012 for the World Bank and 2000-2012 for Chinese Aid. Both regressions include year and region fixed effects as well as time trends. Time trends include linear and squared country-specific time trends. Standard errors in parentheses, two-way clustered at the country-year and regional level. $* p<0.1, * * p<0.05, * * * p<0.01$ 
Aid and conflict at the subnational level

Table C.10 IV Results - IDA-Position ${ }_{t-1}$

\begin{tabular}{|c|c|c|}
\hline & (1) & $(2)$ \\
\hline \multicolumn{3}{|l|}{$\begin{array}{l}\text { Panel A: World Bank Aid } \\
\text { IV Second Stage: IDA Position (t-1) }\end{array}$} \\
\hline $\ln \left(\right.$ World Bank Aid $\left.{ }_{\mathrm{t}-1}\right)$ & $\begin{array}{l}-0.1294 \\
(0.3976)\end{array}$ & $\begin{array}{l}-0.0251 \\
(0.3868)\end{array}$ \\
\hline \multicolumn{3}{|l|}{ IV FS: IDA Position (t-1) } \\
\hline IDA Position $_{\mathrm{t}-1} \times$ Cum. Prob Pr-2 & $\begin{array}{c}51.3655^{* * *} \\
(5.6627)\end{array}$ & $\begin{array}{c}65.1984^{* * *} \\
(6.9103)\end{array}$ \\
\hline Cum. Prob ${ }_{\mathrm{t}-2}$ & $\begin{array}{l}-52.8484^{* * *} \\
(6.2620)\end{array}$ & $\begin{array}{c}-67.1407^{* * *} \\
(7.5204)\end{array}$ \\
\hline$N$ & 12325 & 12325 \\
\hline Exogeneous Controls & Yes & Yes \\
\hline Exogeneous Controls $\times$ Year & Yes & Yes \\
\hline Linear Regional Trends & Yes & Yes \\
\hline Country-Year FE & No & Yes \\
\hline
\end{tabular}

Notes: Dependent variable: Binary conflict indicator (100 if $\mathrm{BRD} \geq 5,0$ if $\mathrm{BRD}<5)$. The sample includes African countries for the sampling period of 1995-2012 for the World Bank and 20002012 for Chinese Aid. Both regressions include year and region fixed effects as well as time trends. Time trends include linear and squared country-specific time trends. Instead of a running sum of IDA funding position in " $t$ " and "t-1" only the variation in "t-1" is used. Standard errors in parentheses, two-way clustered at the country-year and regional level. ${ }^{*} p<0.1,{ }^{* *} p<0.05,{ }^{* * *} p<0.01$ 
Aid and conflict at the subnational level

Table C.11 IV Results - Without high Leverage Regions

\begin{tabular}{|c|c|c|}
\hline & $(1)$ & $(2)$ \\
\hline \multicolumn{3}{|l|}{ Panel A: World Bank Aid } \\
\hline $\ln \left(\right.$ World Bank Aid $\left.\mathrm{t}_{\mathrm{t}-1}\right)$ & $\begin{array}{l}-0.0990 \\
(0.3761)\end{array}$ & $\begin{array}{l}-0.2268 \\
(0.4197)\end{array}$ \\
\hline Kleibergen-Paap underidentification test p-value & 0.000 & 0.000 \\
\hline Kleibergen-Paap weak identification F-statistic & 99.363 & 86.752 \\
\hline \multicolumn{3}{|l|}{ IV First stage: IDA Position } \\
\hline ID A Position $_{\mathrm{t}-1} \times$ Cum. Prob Pr-2 $_{\mathrm{t}}$ & $\begin{array}{c}70.8414^{* * *} \\
(7.1068)\end{array}$ & $\begin{array}{c}80.8936^{* * *} \\
(8.6851)\end{array}$ \\
\hline$N$ & 12317 & 12291 \\
\hline \multicolumn{3}{|l|}{ Panel B: Chinese Aid } \\
\hline $\ln \left(\right.$ Chinese Aid $\left.{ }_{\mathrm{t}-2}\right)$ & $\begin{array}{l}-0.4529 \\
(0.6166)\end{array}$ & $\begin{array}{l}-0.4367 \\
(0.8058)\end{array}$ \\
\hline Kleibergen-Paap underidentification test p-value & 0.000 & 0.000 \\
\hline Kleibergen-Paap weak identification F-statistic & 22.462 & 16.449 \\
\hline \multicolumn{3}{|l|}{ IV First stage: Chinese Steel } \\
\hline Steel Prod detrend $\mathrm{t}_{\mathrm{t}-3} \times$ Cum. Prob $_{\mathrm{t}-3}$ & $\begin{array}{c}-70.8804^{* * *} \\
(14.9554)\end{array}$ & $\begin{array}{c}-60.6611^{* * *} \\
(14.9568)\end{array}$ \\
\hline$N$ & 7974 & 7974 \\
\hline Exogeneous Controls & Yes & Yes \\
\hline Exogeneous Controls $\times$ Year & Yes & Yes \\
\hline Linear Regional Trends & Yes & Yes \\
\hline Country-Year FE & No & Yes \\
\hline
\end{tabular}

Notes: Dependent variable: Binary conflict indicator (100 if $\mathrm{BRD} \geq 5,0$ if $\mathrm{BRD}<5)$. The sample includes African countries for the sampling period of 1995-2012 for the World Bank and 2000-2012 for Chinese Aid. Both regressions include year and region fixed effects as well as time trends. Time trends include linear and squared country-specific time trends. Standard errors in parentheses, two-way clustered at the country-year and regional level.

${ }^{*} p<0.1,{ }^{* *} p<0.05,{ }^{* * *} p<0.01$ 
Aid and conflict at the subnational level

Table C.12 IV Results - Excluding First Year

\begin{tabular}{|c|c|c|}
\hline & (1) & $(2)$ \\
\hline \multicolumn{3}{|l|}{ Panel A: World Bank Aid } \\
\hline IV Second stage: IDA Position $\ln \left(\right.$ World Bank Aid $\left.{ }_{\mathrm{t}-1}\right)$ & $\begin{array}{c}-0.2904 \\
(0.4172)\end{array}$ & $\begin{array}{l}-0.2681 \\
(0.3975)\end{array}$ \\
\hline Kleibergen-Paap underidentification test $\mathrm{p}$-value & 0.000 & 0.000 \\
\hline Kleibergen-Paap weak identification F-statistic & 80.438 & 78.004 \\
\hline IV First stage: IDA Position ID A Position t $-1 \times C u m$. Prob $_{\mathrm{t}-2}$ & $\begin{array}{c}68.5810^{* * *} \\
(7.6467)\end{array}$ & $\begin{array}{c}88.1297^{* * *} \\
(9.9784)\end{array}$ \\
\hline$N$ & 11600 & 11600 \\
\hline \multicolumn{3}{|l|}{ Panel B: Chinese Aid } \\
\hline $\ln \left(\right.$ Chinese Aid $\left.\mathrm{t}_{\mathrm{t}-2}\right)$ & $\begin{array}{c}-0.9072 \\
(0.9329)\end{array}$ & $\begin{array}{c}-0.9387 \\
(1.2510)\end{array}$ \\
\hline Kleibergen-Paap underidentification test p-value & 0.002 & 0.012 \\
\hline Kleibergen-Paap weak identification F-statistic & 9.548 & 6.144 \\
\hline \multicolumn{3}{|l|}{ IV First stage: Chinese Steel } \\
\hline Steel Prod detrend $\mathrm{t}-3 \times$ Cum. Prob t -3 & $\begin{array}{c}-52.0807^{* * *} \\
(16.8548)\end{array}$ & $\begin{array}{c}-42.3054^{* *} \\
(17.0681)\end{array}$ \\
\hline$N$ & 7250 & 7250 \\
\hline Exogeneous Controls & Yes & Yes \\
\hline Exogeneous Controls $\times$ Year & Yes & Yes \\
\hline Linear Regional Trends & Yes & Yes \\
\hline Country-Year FE & No & Yes \\
\hline
\end{tabular}

Notes: Dependent variable: Binary conflict indicator (100 if $\mathrm{BRD} \geq 5,0$ if $\mathrm{BRD}<5$ ). The sample includes African countries for the sampling period of 1995-2012 for the World Bank and 2000-2012 for Chinese Aid. Both regressions include year and region fixed effects as well as time trends. Time trends include linear and squared country-specific time trends. The constituent term of the probability is depicted in Appendix Table C.7. Standard errors in parentheses, two-way clustered at the country-year and regional level.

${ }^{*} p<0.1,{ }^{* *} p<0.05,{ }^{* * *} p<0.01$. 
Aid and conflict at the subnational level

Table C.13 IV Results - WB Aid detrended \& Chinese Aid not detrended

\begin{tabular}{|c|c|c|}
\hline & (1) & $(2)$ \\
\hline \multicolumn{3}{|l|}{ Panel A: World Bank Aid } \\
\hline $\ln \left(\right.$ World Bank Aid $\left.\mathrm{t}_{\mathrm{t}-1}\right)$ & $\begin{array}{c}0.3239 \\
(0.7185)\end{array}$ & $\begin{array}{c}0.0770 \\
(0.7595)\end{array}$ \\
\hline Kleibergen-Paap underidentification test p-value & 0.000 & 0.001 \\
\hline Kleibergen-Paap weak identification F-statistic & 30.474 & 15.646 \\
\hline \multicolumn{3}{|l|}{ IV First stage: IDA Position } \\
\hline IDA Position detrend t $-1 \times$ Cum. Prob t -2 & $\begin{array}{c}49.1363^{* * *} \\
(8.9010)\end{array}$ & $\begin{array}{c}59.7776^{* * *} \\
(15.1125)\end{array}$ \\
\hline Cum. Prob ${ }_{\mathrm{t}-2}$ & $\begin{array}{c}1.0001 \\
(1.5130)\end{array}$ & $\begin{array}{c}0.3355 \\
(1.8596)\end{array}$ \\
\hline$N$ & 12325 & 12325 \\
\hline \multicolumn{3}{|l|}{ Panel B: Chinese Aid } \\
\hline & $\begin{array}{l}-0.0980 \\
(0.2384)\end{array}$ & $\begin{array}{c}0.0374 \\
(0.2766)\end{array}$ \\
\hline Kleibergen-Paap underidentification test p-value & 0.000 & 0.000 \\
\hline Kleibergen-Paap weak identification F-statistic & 66.567 & 58.408 \\
\hline \multicolumn{3}{|l|}{ IV First stage: Chinese Steel } \\
\hline Steel Prod $_{\mathrm{t}-3} \times$ Cum. Prob ${ }_{\mathrm{t}-3}$ & $\begin{array}{c}-54.7934^{* * *} \\
(6.7158)\end{array}$ & $\begin{array}{c}-50.5179^{* * *} \\
(6.6102)\end{array}$ \\
\hline Cum. Prob $\mathrm{t}_{\mathrm{t} 3}$ & $\begin{array}{c}634.3188^{* * *} \\
(80.2897)\end{array}$ & $\begin{array}{c}585.1439^{* * *} \\
(79.2510)\end{array}$ \\
\hline$N$ & 7975 & 7975 \\
\hline Exogeneous Controls & Yes & Yes \\
\hline Exogeneous Controls $\times$ Year & Yes & Yes \\
\hline Linear Regional Trends & Yes & Yes \\
\hline Country-Year FE & No & Yes \\
\hline
\end{tabular}

Notes: Dependent variable: Binary conflict indicator (100 if $\mathrm{BRD} \geq 5,0$ if $\mathrm{BRD}<5)$. The sample includes African countries for the sampling period of 1995-2012 for the World Bank and 2000-2012 for Chinese Aid. Both regressions include year and region fixed effects as well as time trends. Time trends include linear and squared country-specific time trends. The constituent term of the probability is depicted in Appendix Table C.7. Standard errors in parentheses, two-way clustered at the country-year and regional level.

${ }^{*} p<0.1,{ }^{* *} p<0.05,{ }^{* * *} p<0.01$ 
Aid and conflict at the subnational level

Table C.14 IV Results - Initial Probability

\begin{tabular}{|c|c|c|}
\hline & $(1)$ & $(2)$ \\
\hline \multicolumn{3}{|l|}{$\begin{array}{l}\text { Panel A: World Bank Aid } \\
\text { IV Second stage: IDA Position }\end{array}$} \\
\hline $\ln \left(\right.$ World Bank Aid $\left.\mathrm{t}_{\mathrm{t}-1}\right)$ & $\begin{array}{c}0.2253 \\
(0.7469)\end{array}$ & $\begin{array}{l}-0.3389 \\
(0.6205)\end{array}$ \\
\hline Kleibergen-Paap underidentification test p-value & 0.000 & 0.000 \\
\hline Kleibergen-Paap weak identification F-statistic & 27.151 & 26.086 \\
\hline \multicolumn{3}{|l|}{ IV First stage: IDA Position } \\
\hline 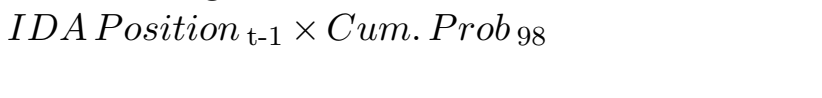 & $\begin{array}{c}43.4309^{* * *} \\
(8.3349)\end{array}$ & $\begin{array}{r}61.1537^{* * *} \\
(11.9734)\end{array}$ \\
\hline$N$ & 11600 & 11600 \\
\hline \multicolumn{3}{|l|}{ Panel B: Chinese Aid } \\
\hline $\ln \left(\right.$ Chinese Aid $\left.\mathrm{t}_{\mathrm{t}-2}\right)$ & $\begin{array}{l}-1.6319 \\
(1.3706)\end{array}$ & $\begin{array}{l}-1.4597 \\
(1.4889)\end{array}$ \\
\hline Kleibergen-Paap underidentification test $\mathrm{p}$-value & 0.001 & 0.004 \\
\hline Kleibergen-Paap weak identification F-statistic & 10.461 & 7.880 \\
\hline \multicolumn{3}{|l|}{ IV First stage: Chinese Steel } \\
\hline Steel Prod detrend $\mathrm{t}_{\mathrm{t}-3} \times$ Cum. $_{\text {Prob }} 03$ & $\begin{array}{c}-36.7317^{* * *} \\
(11.3566)\end{array}$ & $\begin{array}{c}-35.9689^{* * *} \\
(12.8131)\end{array}$ \\
\hline$N$ & 7250 & 7250 \\
\hline Exogeneous Controls & Yes & Yes \\
\hline Exogeneous Controls $\times$ Year & Yes & Yes \\
\hline Linear Regional Trends & Yes & Yes \\
\hline Country-Year FE & No & Yes \\
\hline
\end{tabular}

Notes: Dependent variable: Binary conflict indicator $(100$ if $\mathrm{BRD} \geq 5,0$ if $\mathrm{BRD}<5)$. The sample includes African countries for the sampling period of 1995-2012 for the World Bank and 2000-2012 for Chinese Aid. Both regressions include year and region fixed effects as well as time trends. Time trends include linear and squared country-specific time trends. The probability is based on the third year in the corresponding sample (1998 for the World Bank's IDA; 2003 for Chinese Steel) and held thereafter constant. Standard errors in parentheses, two-way clustered at the country-year and regional level.

${ }^{*} p<0.1,{ }^{* *} p<0.05,{ }^{* * *} p<0.01$ 


\section{B.2 Alternative Outcome Variables}

Figure C.5 SCAD Data for Precision Codes 1-4
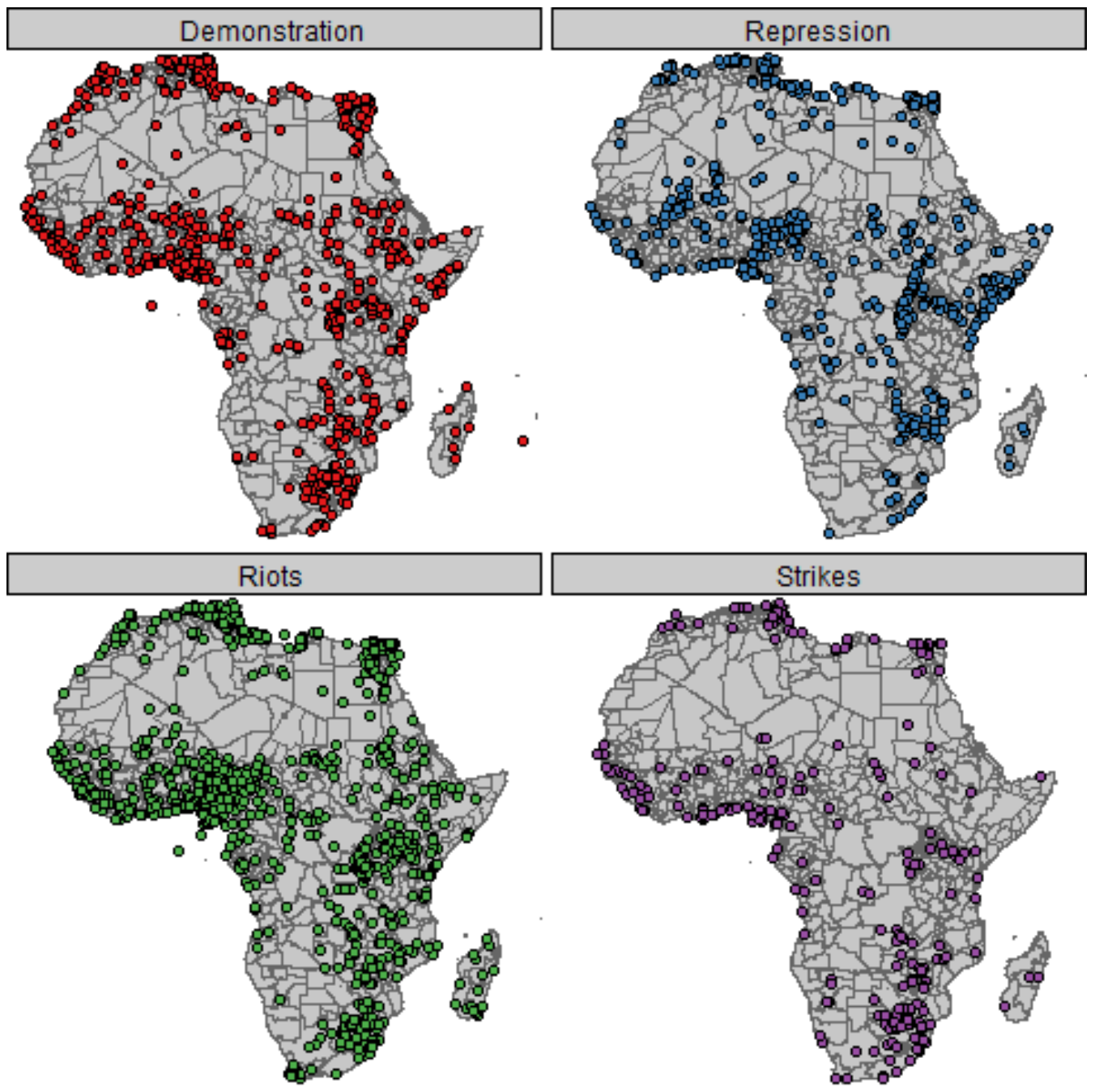

Source: Own depiction bases on Salehyan et al. (2012). 
Aid and conflict at the subnational level

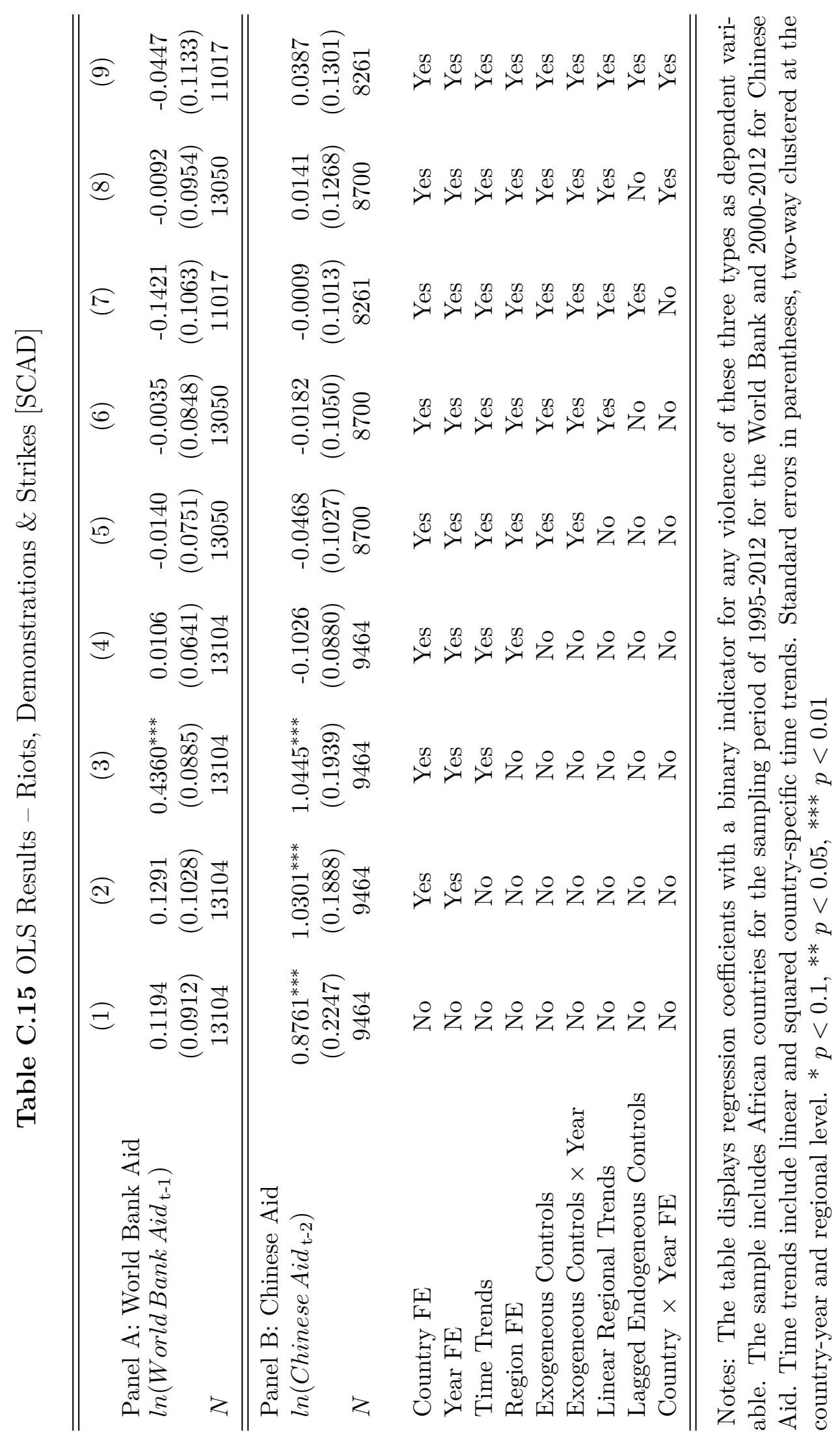


Aid and conflict at the subnational level

Table C.16 IV Results - Riots, Demonstrations \& Strikes [SCAD]

\begin{tabular}{|c|c|c|}
\hline & $(1)$ & $(2)$ \\
\hline \multicolumn{3}{|l|}{$\begin{array}{l}\text { Panel A: World Bank Aid } \\
\text { IV Second stage: IDA Position }\end{array}$} \\
\hline $\ln \left(\right.$ World Bank Aid $\left.{ }_{\mathrm{t}-1}\right)$ & $\begin{array}{l}-0.3854 \\
(0.3092)\end{array}$ & $\begin{array}{l}-0.2032 \\
(0.3362)\end{array}$ \\
\hline Kleibergen-Paap underidentification test p-value & 0.000 & 0.000 \\
\hline $\begin{array}{l}\text { Kleibergen-Paap weak identification F-statistic } \\
\text { IV First stage: IDA Position }\end{array}$ & 99.639 & 86.724 \\
\hline ID A Position $_{\mathrm{t}-1} \times$ Cum. Prob Pr-2 $_{\mathrm{t}}$ & $\begin{array}{c}70.9363^{* * *} \\
(7.1065)\end{array}$ & $\begin{array}{c}80.8832^{* * *} \\
(8.6854)\end{array}$ \\
\hline$N$ & 12325 & 12325 \\
\hline \multicolumn{3}{|l|}{ Panel B: Chinese Aid } \\
\hline \multicolumn{3}{|l|}{ IV Second Stage: Chinese Steel } \\
\hline $\ln \left(\right.$ Chinese Aid $\left.{ }_{\mathrm{t}-2}\right)$ & $\begin{array}{c}0.1578 \\
(0.6087)\end{array}$ & $\begin{array}{c}0.2686 \\
(0.7312)\end{array}$ \\
\hline Kleibergen-Paap underidentification test p-value & 0.000 & 0.000 \\
\hline $\begin{array}{l}\text { Kleibergen-Paap weak identification F-statistic } \\
\text { IV First stage: Chinese Steel }\end{array}$ & 22.468 & 16.456 \\
\hline Steel Prod detrend ${ }_{\mathrm{t}-3} \times C u m$. Prob $_{\mathrm{t}-3}$ & $\begin{array}{c}-70.8763^{* * *} \\
(14.9526)\end{array}$ & $\begin{array}{c}-60.6567^{* * *} \\
(14.9524)\end{array}$ \\
\hline$N$ & 7975 & 7975 \\
\hline Exogeneous Controls & Yes & Yes \\
\hline Exogeneous Controls $\times$ Year & Yes & Yes \\
\hline Linear Regional Trends & Yes & Yes \\
\hline Country-Year FE & No & Yes \\
\hline
\end{tabular}

Notes: The table displays regression coefficients for any violence of these three types as dependent variable. The sample includes African countries for the sampling period of 1995-2012 for the World Bank and 2000-2012 for Chinese Aid. Both regressions include year and region fixed effects as well as time trends. Time trends include linear and squared country-specific time trends. The constituent term of the probability is depicted in Appendix Table C.7. Standard errors in parentheses, two-way clustered at the country-year and regional level. ${ }^{*} p<0.1,{ }^{* *} p<0.05,{ }^{* * *} p<0.01$ 
Aid and conflict at the subnational level

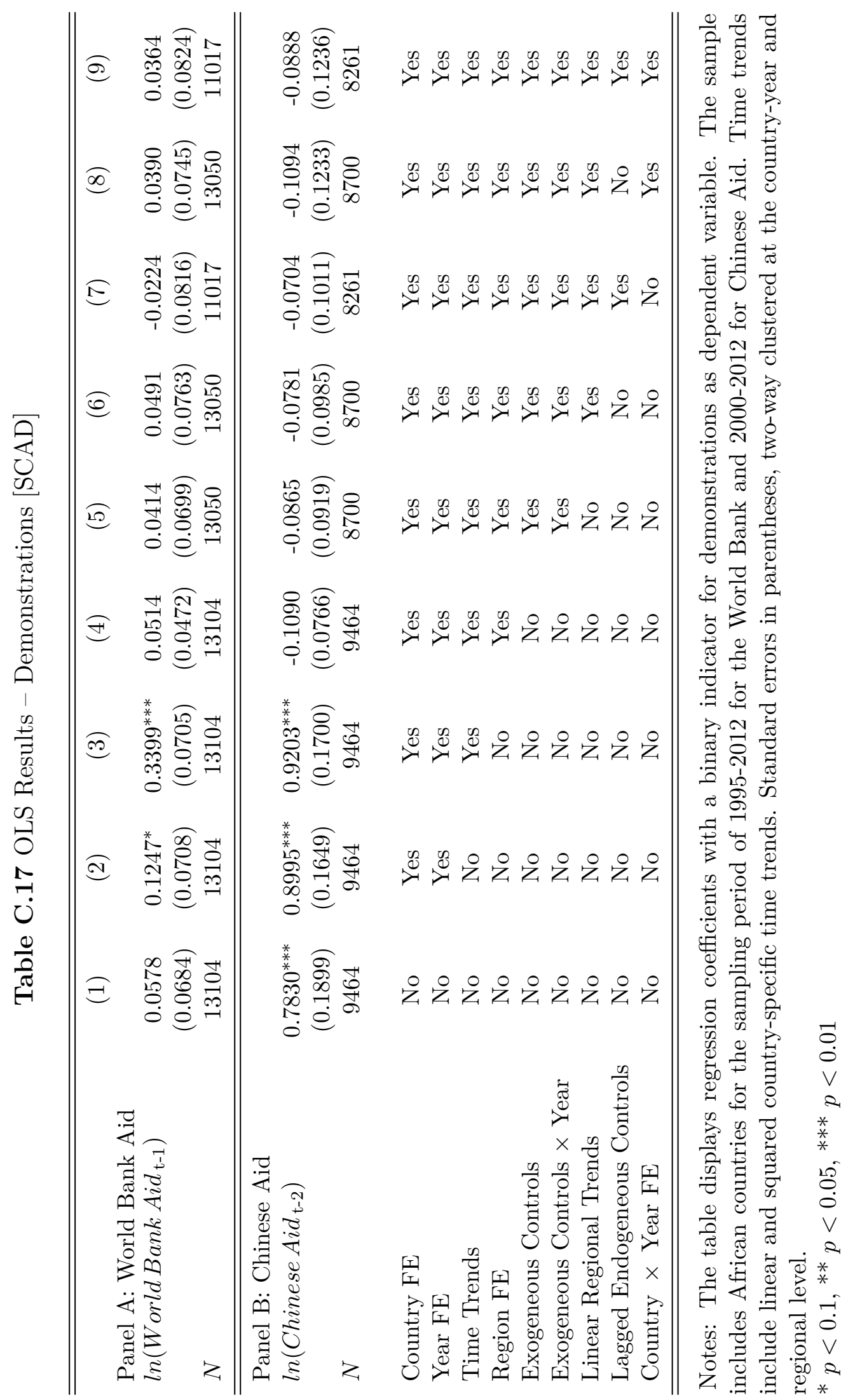


Aid and conflict at the subnational level

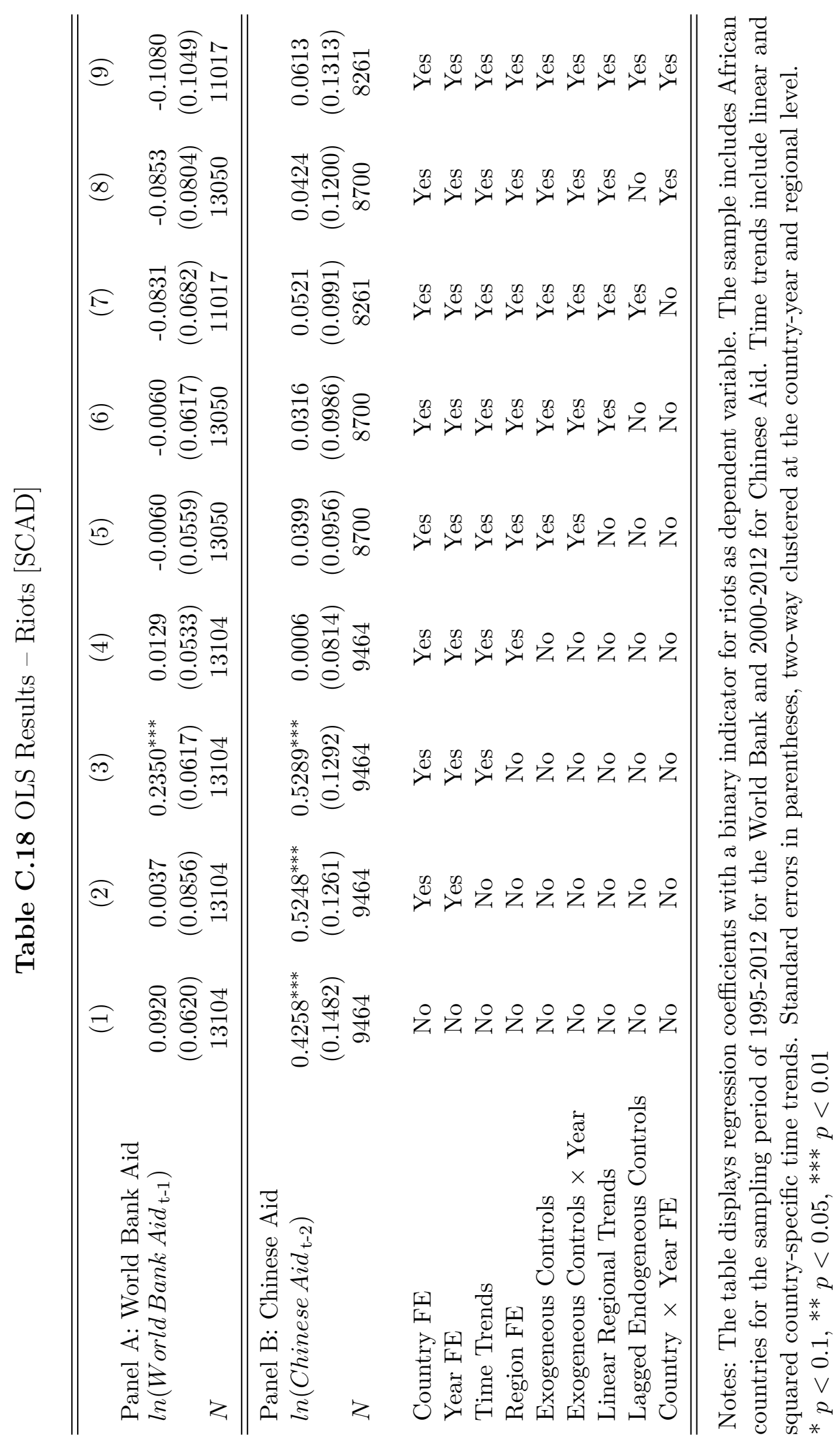


Aid and conflict at the subnational level

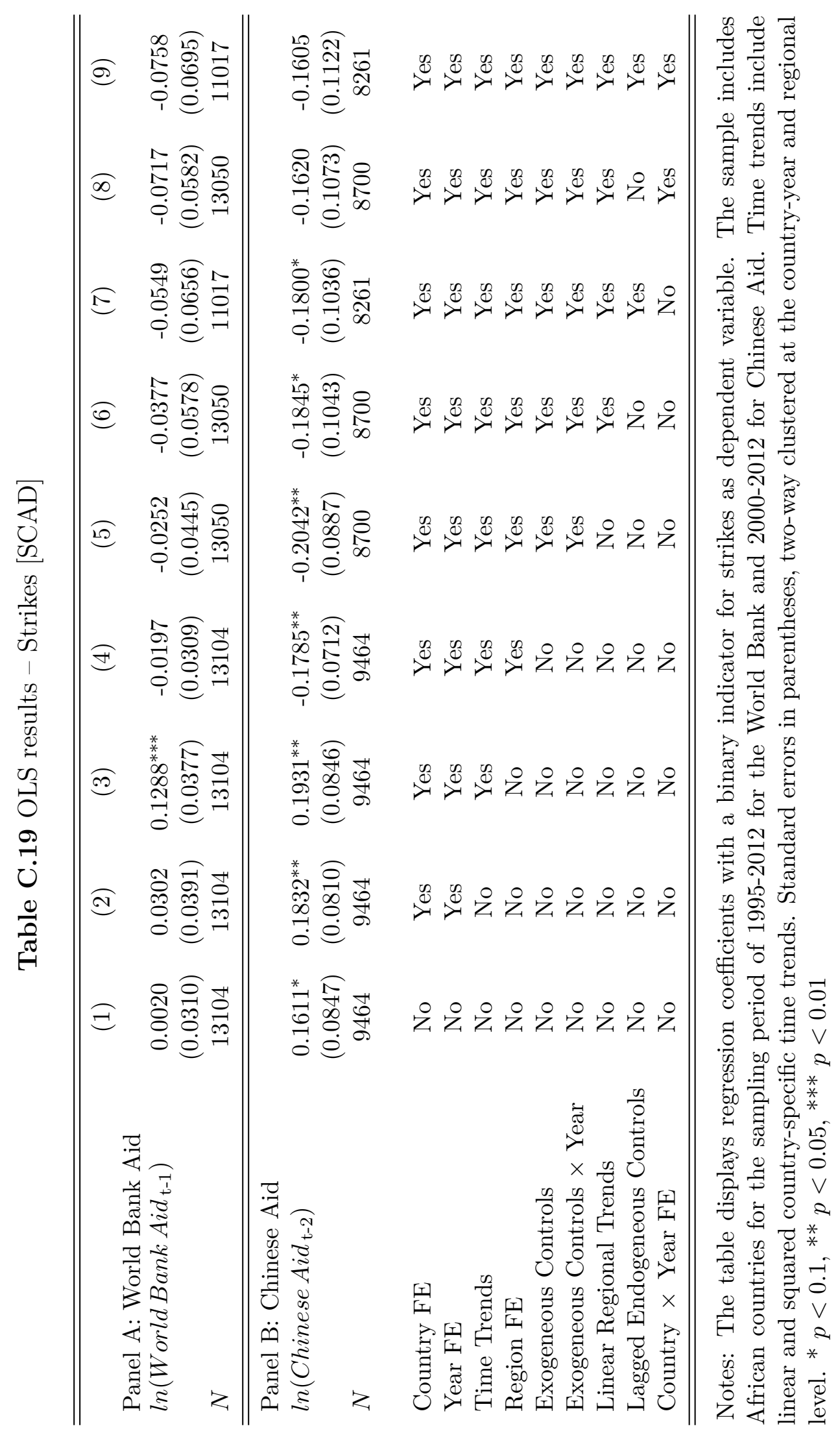


Aid and conflict at the subnational level

Table C.20 IV Results - Repression (non-lethal) without UCDP Violence

\begin{tabular}{lcc}
\hline \hline & $(1)$ & $(2)$ \\
Panel A: World Bank Aid & & \\
IV: IDA Position - Actors & 0.1543 & 0.0885 \\
$l n\left(\right.$ W orld Bank Aid $\left.\mathrm{t}_{\mathrm{l}}\right)$ & $(0.1042)$ & $(0.1177)$ \\
$\mathrm{N}$ & 12325 & 12325 \\
Kleibergen-Paap underidentification test p-value & 0.000 & 0.000 \\
Kleibergen-Paap weak identification F-statistic & 99.639 & 86.724 \\
\hline \hline Panel B: Chinese Aid & & \\
IV: Chinese Steel - Actors & & \\
$l n($ Chinese Aid t-2 $)$ & $0.9798^{* * *}$ & $1.3059^{* * *}$ \\
& $(0.3663)$ & $(0.5025)$ \\
N & 7975 & 7975 \\
Kleibergen-Paap underidentification test p-value & 0.000 & 0.000 \\
Kleibergen-Paap weak identification F-statistic & 22.468 & 16.456 \\
& & \\
Exogeneous Controls & Yes & Yes \\
Exogeneous Controls $\times$ Year & Yes & Yes \\
Linear Regional Trends & Yes & Yes \\
Country-Year FE & No & Yes \\
\hline \hline
\end{tabular}

Notes: The table displays regression coefficients for a binary progovernmental violence indicator as dependent variable. Outcomes in regions with UCDP governmental violence against civilians are coded as zero. The sample includes African countries for the sampling period of 1995-2012 for the World Bank and 2000-2012 for Chinese Aid. Both regressions include year and region fixed effects as well as time trends. Time trends include linear and squared country-specific time trends. The constituent term of the probability is depicted in Appendix Table C.7. Standard errors in parentheses, two-way clustered at the country-year and regional level.

${ }^{*} p<0.1,{ }^{* *} p<0.05,{ }^{* * *} p<0.01$ 
Aid and conflict at the subnational level

Table C.21 IV Results - Count of non-lethal pro-government Violence [SCAD]

\begin{tabular}{lcc}
\hline \hline Panel A: World Bank Aid & $(1)$ & $(2)$ \\
IV Second stage: IDA Position & & \\
ln World Bank Aid $\left._{\mathrm{t}-1}\right)$ & 0.0011 & 0.0012 \\
& $(0.0014)$ & $(0.0013)$ \\
$\mathrm{N}$ & 12325 & 12325 \\
Kleibergen-Paap underidentification test p-value & 0.000 & 0.000 \\
Kleibergen-Paap weak identification F-statistic & 99.639 & 86.724 \\
\hline \hline Panel B: Chinese Aid & & \\
IV Second Stage: Chinese Steel & & \\
ln(Chinese Aid t-2 $)$ & $0.0146^{* * *}$ & $0.0197^{* *}$ \\
& $(0.0056)$ & $(0.0092)$ \\
N & 7975 & 7975 \\
Kleibergen-Paap underidentification test p-value & 0.000 & 0.000 \\
Kleibergen-Paap weak identification F-statistic & 22.468 & 16.456 \\
& & \\
Country-Year FE & No & Yes \\
\hline \hline
\end{tabular}

Notes: The table displays regression coefficients for a continuous measure of non-lethal pro-government violence as dependent variable. The sample includes African countries for the sampling period of 1995-2012 for the World Bank and 2000-2012 for Chinese Aid. Both regressions include year and region fixed effects as well as time trends. Time trends include linear and squared country-specific time trends. Standard errors in parentheses, two-way clustered at the country-year and regional level.

${ }^{*} p<0.1,{ }^{* *} p<0.05,{ }^{* * *} p<0.01$. 
Aid and conflict at the subnational level

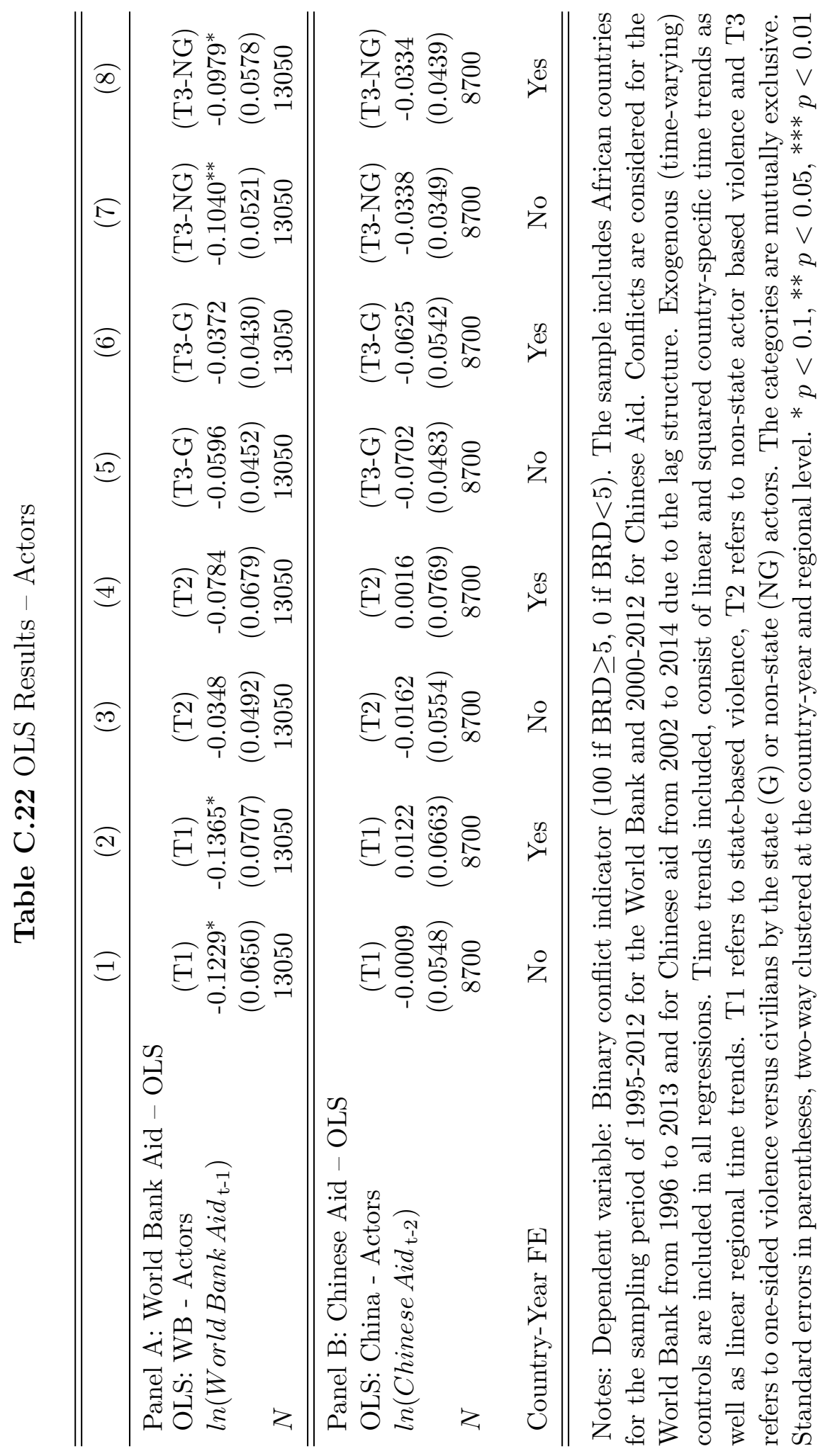


Aid and conflict at the subnational level

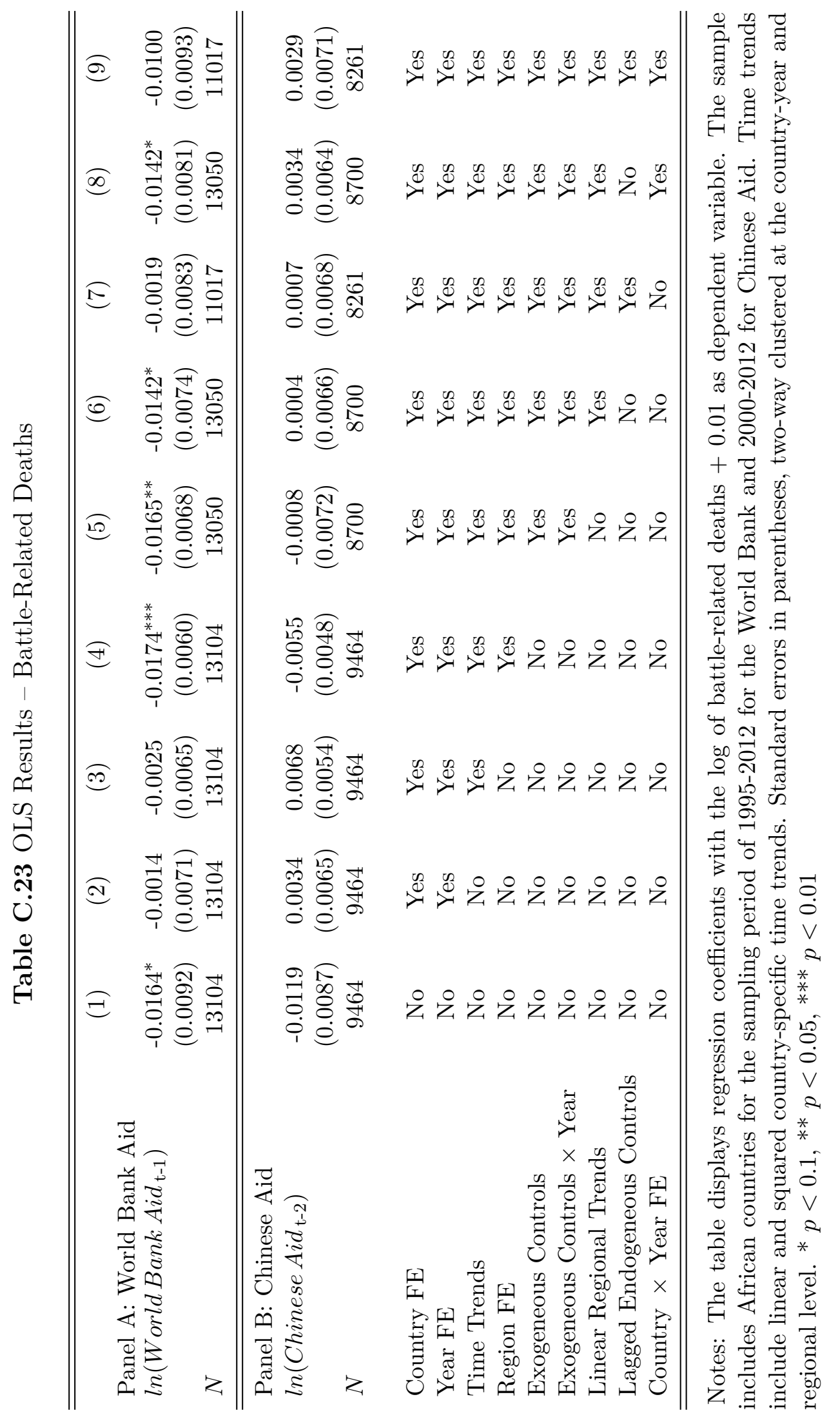


Aid and conflict at the subnational level

Table C.24 IV Results - Battle-Related Deaths

\begin{tabular}{|c|c|c|}
\hline & $(1)$ & $(2)$ \\
\hline \multicolumn{3}{|l|}{$\begin{array}{l}\text { Panel A: World Bank Aid } \\
\text { IV Second stage: IDA Position }\end{array}$} \\
\hline $\ln \left(\right.$ World Bank Aid $\left.{ }_{\mathrm{t}-1}\right)$ & $\begin{array}{l}-0.0179 \\
(0.0340)\end{array}$ & $\begin{array}{l}-0.0340 \\
(0.0358)\end{array}$ \\
\hline Kleibergen-Paap underidentification test p-value & 0.000 & 0.000 \\
\hline Kleibergen-Paap weak identification F-statistic & 99.639 & 86.724 \\
\hline \multicolumn{3}{|l|}{ IV First stage: IDA Position } \\
\hline IDA Position $_{\mathrm{t}-1} \times$ Cum. Prob $\mathrm{t}-2$ & $\begin{array}{c}70.9363^{* * *} \\
(7.1065)\end{array}$ & $\begin{array}{c}80.8832^{* * *} \\
(8.6854)\end{array}$ \\
\hline$N$ & 12325 & 12325 \\
\hline \multicolumn{3}{|l|}{ Panel B: Chinese Aid } \\
\hline $\ln \left(\right.$ Chinese Aid $\left.\mathrm{t}_{\mathrm{t}-2}\right)$ & $\begin{array}{l}-0.0413 \\
(0.0470)\end{array}$ & $\begin{array}{l}-0.0270 \\
(0.0635)\end{array}$ \\
\hline Kleibergen-Paap underidentification test p-value & 0.000 & 0.000 \\
\hline Kleibergen-Paap weak identification F-statistic & 22.468 & 16.456 \\
\hline \multicolumn{3}{|l|}{ IV First stage: Chinese Steel } \\
\hline Steel Prod detrend $\mathrm{t}_{\mathrm{t}-3} \times$ Cum. Prob $\mathrm{t}_{\mathrm{t}-3}$ & $\begin{array}{c}-70.8763^{* * *} \\
(14.9526)\end{array}$ & $\begin{array}{c}-60.6567^{* * *} \\
(14.9524)\end{array}$ \\
\hline$N$ & 7975 & 7975 \\
\hline Exogeneous Controls & Yes & Yes \\
\hline Exogeneous Controls $\times$ Year & Yes & Yes \\
\hline Linear Regional Trends & Yes & Yes \\
\hline Country-Year FE & No & Yes \\
\hline
\end{tabular}

Notes: The table displays regression coefficients for the log of battle-related deaths +0.01 as dependent variable. The sample includes African countries for the sampling period of 1995-2012 for the World Bank and 2000-2012 for Chinese Aid. Both regressions include year and region fixed effects as well as time trends. Time trends include linear and squared country-specific time trends. The constituent term of the probability is depicted in Appendix Table C.7. Standard errors in parentheses, two-way clustered at the country-year and regional level. ${ }^{*} p<0.1,{ }^{* *} p<0.05,{ }^{* * *} p<0.01$ 
Aid and conflict at the subnational level

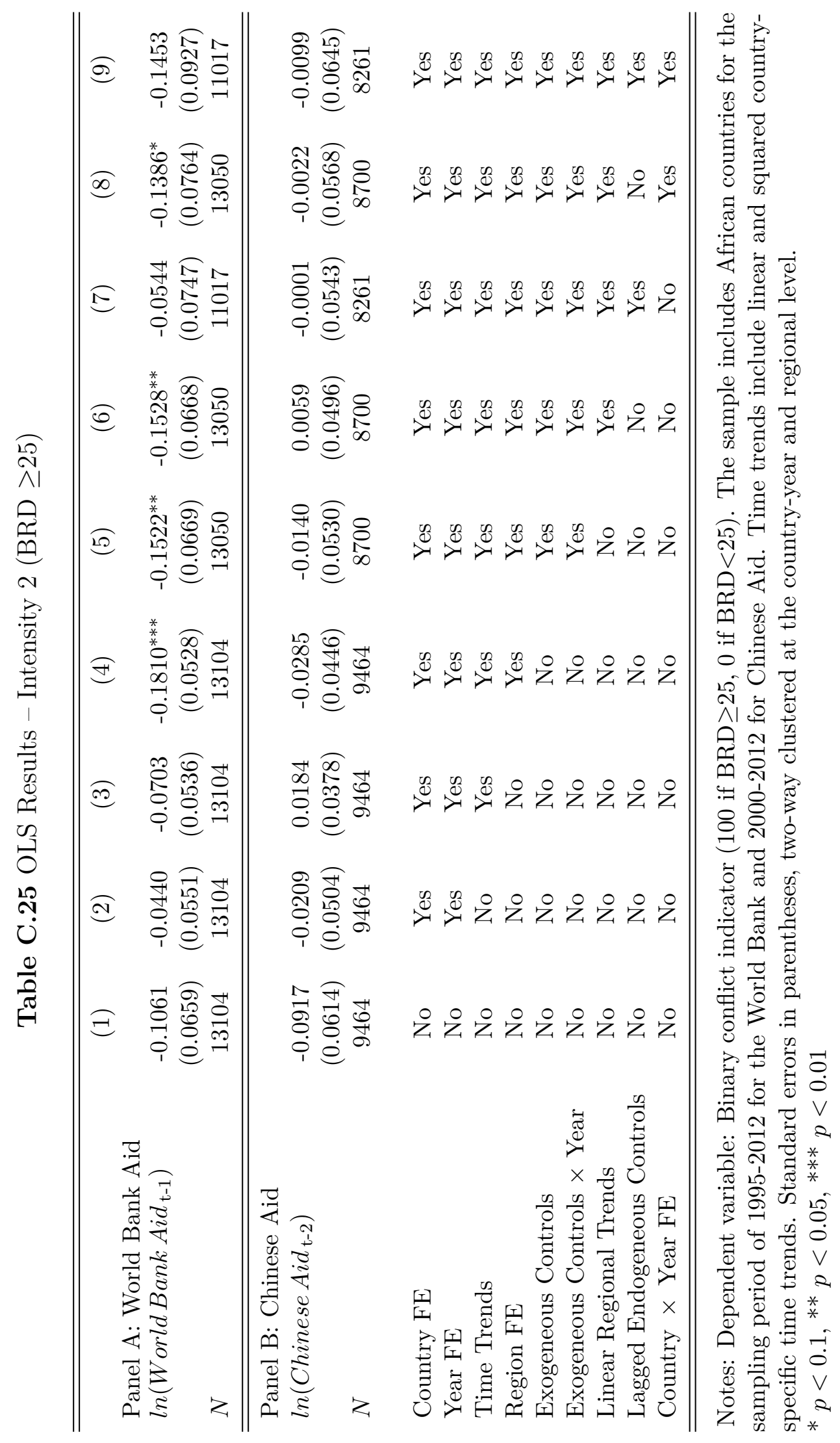


Aid and conflict at the subnational level

Table C.26 IV Results - Intensity $2(\mathrm{BRD} \geq 25)$

\begin{tabular}{|c|c|c|}
\hline $\begin{array}{l}\text { Panel A: World Bank Aid } \\
\text { IV Second Stage: IDA Position } \\
\ln (\text { World Bank Aid } \text { t }-1)\end{array}$ & $\begin{array}{l}-0.1437 \\
(0.3075)\end{array}$ & $\begin{array}{l}-0.4581 \\
(0.3301)\end{array}$ \\
\hline $\begin{array}{l}\text { IV First stage: IDA Position } \\
\text { ID A } \text { Position }_{\mathrm{t}-1} \times \text { Cum }_{\text {. Prob }} \mathrm{t}-2 \\
N\end{array}$ & $\begin{array}{c}70.9363^{* * *} \\
(7.1065) \\
12325\end{array}$ & $\begin{array}{c}80.8832^{* * *} \\
(8.6854) \\
12325\end{array}$ \\
\hline $\begin{array}{l}\text { Panel B: Chinese Aid } \\
\text { IV Second Stage: Chinese Steel } \\
\ln \left(\text { Chinese Aid } d_{\mathrm{t}-2}\right)\end{array}$ & $\begin{array}{c}0.1980 \\
(0.3729)\end{array}$ & $\begin{array}{c}0.2563 \\
(0.4669)\end{array}$ \\
\hline $\begin{array}{l}\text { IV First stage: Chinese Steel } \\
\text { Steel Prod detrend }{ }_{\mathrm{t}-3} \times \text { Cum. Prob }{ }_{\mathrm{t}-3} \\
N\end{array}$ & $\begin{array}{c}-70.8763^{* * *} \\
(14.9526) \\
7975\end{array}$ & $\begin{array}{c}-60.6567^{* * *} \\
(14.9524) \\
7975\end{array}$ \\
\hline $\begin{array}{l}\text { Exogeneous Controls } \\
\text { Exogeneous Controls } \times \text { Year } \\
\text { Linear Regional Trends } \\
\text { Country-Year FE }\end{array}$ & $\begin{array}{l}\text { Yes } \\
\text { Yes } \\
\text { Yes } \\
\text { No }\end{array}$ & $\begin{array}{l}\text { Yes } \\
\text { Yes } \\
\text { Yes } \\
\text { Yes }\end{array}$ \\
\hline
\end{tabular}

Notes: Dependent variable: Binary conflict indicator (100 if $\mathrm{BRD} \geq 25,0$ if $\mathrm{BRD}<25$ ). The sample includes African countries for the sampling period of 1995-2012 for the World Bank and 2000-2012 for Chinese Aid. Both regressions include year and region fixed effects as well as time trends. Time trends include linear and squared country-specific time trends. The constituent term of the probability is depicted in Appendix Table C.7. Standard errors in parentheses, two-way clustered at the country-year and regional level.

${ }^{*} p<0.1,{ }^{* *} p<0.05,{ }^{* * *} p<0.01$ 
Aid and conflict at the subnational level

\section{B.3 Channels - Ethnic Groups, Governing Coalition and Aid Types}

Conflicts are not only driven by economic considerations, but often strongly influenced by existing cleavages between groups. Ethnic identities are the most salient traits and ethnic groups the most important reference group in most African countries. To measure ethnic homelands, we use the GREG dataset (Weidmann et al., 2010), which is a georeferenced version of the initial locations of ethnic homelands based on the Soviet Atlas Narodov Mira. These locations were determined before our sample, and, even though immigration becomes more important over time, prior studies suggest that a large share of Africans still live in their ethnic home region (Nunn and Wantchekon. 2011). This makes those group polygons a noisy, but still informative measure.

A first important question is whether the effect of aid projects differs between more and less ethnically fractionalized regions. Theoretically, one might expect more potential for dissatisfaction about an unequal allocation of projects or the distribution of the associated benefits in ethnically fractionalized regions. We compute standard fractionalization measures in line with the literature (Fearon and Laitin, 2003, Alesina and Ferrara, 2005), and split the sample between countries in regions with fractionalization above or below the mean or median. Appendix Tables C.27 and C.28 show no large differences. When including country-year $\mathrm{FE}$, the negative relationship between aid and conflict becomes even a bit stronger, but the difference is small. Even in the more fractionalized regions, it does not turn positive ${ }^{39}$

More important than considering ethnic cleavages in general is to define which ethnic groups are allies and form a joint coalition and which groups are outside that coalition. To classify administrative regions, our unit of analysis, we distinguish whether all groups (Coalition), at least one group (Mixed), or no group (N-Coalition) in a region is part of the governing coalition in a particular year. The information about the power status comes from the time-variant Ethnic Power Relations (EPR) dataset (Vogt et al., 2015). Wherever possible, we match the group power status from EPR in a particular year to one of the time-invariant GREG group homelands. The original dataset assigns eight different power statuses to groups. The difference are sometimes marginal and hard to interpret, which is why we only use the more precise information on whether a group was part of the governing coalition or not. We then intersect the ethnic group polygons with the administrative regions to classify regions as one of the three categories.

This distinction aims at testing the plausibility of the existing results, and at uncovering heterogeneous effects that might be hidden in the averages. For instance, it might be that there is no conflict-inducing effect on average. However, assuming that aid project benefit governing groups more often, existing tensions and conflict might be fueled especially in mixed districts where other groups observe these distributional

\footnotetext{
${ }^{39}$ Note that like for individual aid types, the IV does not perform sufficiently well for China when splitting the samples. Hence, we show the OLS specifications for all the sample splits for China. We intend to conduct a more in-depth analysis of aid inequality and ethnic groups in an accompanying paper.
} 
Aid and conflict at the subnational level

differences. In contrast, rapacity theory would predict that governing coalition regions with large aid inflows become more attractive for rebels to capture.

We find several interesting differences in Table C.29, The results for the WB always change signs depending on the inclusion of country-year fixed effects. Nonetheless, there is again never a significant conflict-inducing effect. For China, all coefficients are negative, even though again statistically insignificant. Even when considering governing coalition structures, on average Chinese aid does not increase conflicts with at least five battle-related deaths. 40

Table C.27 Sample split - Mean of Fractionalization

\begin{tabular}{lcccc}
\hline \hline Panel A: World Bank Aid - IV: & & & & \\
$\ln ($ World Bank Aid $\mathrm{t}-1)$ & 0.0492 & -0.5546 & -0.0498 & -0.0256 \\
& $(0.4419)$ & $(0.4796)$ & $(0.6270)$ & $(0.8597)$ \\
$\mathrm{N}$ & 6715 & 6698 & 3757 & 3740 \\
Kleibergen-Paap underidentification test p-value & 0.000 & 0.000 & 0.000 & 0.000 \\
Kleibergen-Paap weak identification F-statistic & 79.593 & 56.722 & 63.955 & 45.934 \\
\hline \hline Panel B: Chinese Aid - OLS: & & & & \\
$\ln ($ Chinese Aid $\mathrm{t}-2)$ & -0.0069 & -0.0044 & -0.0990 & 0.0527 \\
& $(0.1222)$ & $(0.1434)$ & $(0.1845)$ & $(0.1641)$ \\
$\mathrm{N}$ & 4740 & 4728 & 2652 & 2640 \\
& & & & \\
Country $\times$ Year FE & No & Yes & No & Yes \\
\hline \hline
\end{tabular}

Notes: Dependent variable: Binary conflict indicator (100 if $\mathrm{BRD} \geq 5,0$ if $\mathrm{BRD}<5$ ). The sample is split in regions, which are below the country level mean of ethnic fractionalization (0) [columns (1) \& (2)] or above the mean (1) [columns (3) \& (4)]. Ethnic fractionalization is based on $1-\sum s^{2}$, where $\mathrm{s}$ is the ethnic groups area share in the administrative region. The sample includes African countries for the sampling period of 1995-2012 for the World Bank and 2000-2012 for Chinese Aid. Conflicts are considered for the World Bank from 1996 to 2013 and for Chinese aid from 2002 to 2014 due to the lag structure. Both regressions include (time-varying) exogenous controls, year and region fixed effects as well as time trends. Time trends include linear and squared country-specific time trends as well as linear regional time trends. Standard errors in parentheses, two-way clustered at the country-year and regional level. ${ }^{*} p<0.1,{ }^{* *} p<0.05,{ }^{* * *} p<0.01$

\footnotetext{
${ }^{40}$ This finding is robust to defining the coalition only as the more powerful senior, dominant or monopoly groups and excluding junior partners. Results are available upon request from the authors. Appendix Table C.31 presents the coalition sample split without controlling for fractionalization. Appendix Table C.30 shows the results in Table C.29 for the WB using OLS and for China using IV. There are overall no large differences that substantially alter our conclusions.
} 
Aid and conflict at the subnational level

Table C.28 Sample-split - Median Fractionalization

\begin{tabular}{lcccc}
\hline \hline Panel A: World Bank Aid - IV: & & & & \\
ln W orld Bank Aid $\left.{ }_{\mathrm{t}-1}\right)$ & -0.2585 & -0.6189 & 0.1471 & -0.0455 \\
& $(0.4163)$ & $(0.4904)$ & $(0.5688)$ & $(0.7054)$ \\
$\mathrm{N}$ & 5474 & 5474 & 4998 & 4998 \\
Kleibergen-Paap underidentification test p-value & 0.000 & 0.000 & 0.000 & 0.000 \\
Kleibergen-Paap weak identification F-statistic & 71.721 & 49.454 & 75.067 & 65.391 \\
\hline \hline Panel B: Chinese Aid - IV: & & & & \\
ln Chinese Aid $\left.d_{\mathrm{t}-2}\right)$ & -0.7075 & -0.8209 & 0.0282 & 1.3653 \\
& $(0.8256)$ & $(1.0744)$ & $(0.8463)$ & $(1.1783)$ \\
N & 3542 & 3542 & 3234 & 3234 \\
Kleibergen-Paap underidentification test p-value & 0.000 & 0.000 & 0.001 & 0.007 \\
Kleibergen-Paap weak identification F-statistic & 30.983 & 21.080 & 15.370 & 9.900 \\
& & & & \\
Country $\times$ Year FE & No & Yes & No & Yes \\
\hline \hline
\end{tabular}

Notes: Dependent variable: Binary conflict indicator (100 if $\mathrm{BRD} \geq 5,0$ if $\mathrm{BRD}<5$ ). The sample is split in regions, which are below the country level median / mean of ethnic fractionalization (0) [columns (1) \& (2)] or above the median / mean (1) [columns (3) \& (4)]. Ethnic fractionalization is based on $1-\sum s^{2}$, where $\mathrm{s}$ is the ethnic groups area share in the administrative region. The sample includes African countries for the sampling period of 1995-2012 for the World Bank and 2000-2012 for Chinese Aid. Conflicts are considered for the World Bank from 1996 to 2013 and for Chinese aid from 2002 to 2014 due to the lag structure. Both regressions include (time-varying) exogenous controls, year and region fixed effects as well as time trends. Time trends include linear and squared country-specific time trends as well as linear regional time trends. Standard errors in parentheses, two-way clustered at the country-year and regional level. ${ }^{*} p<0.1,{ }^{*} * p<0.05,{ }^{* * *} p<0.01$ 
Aid and conflict at the subnational level

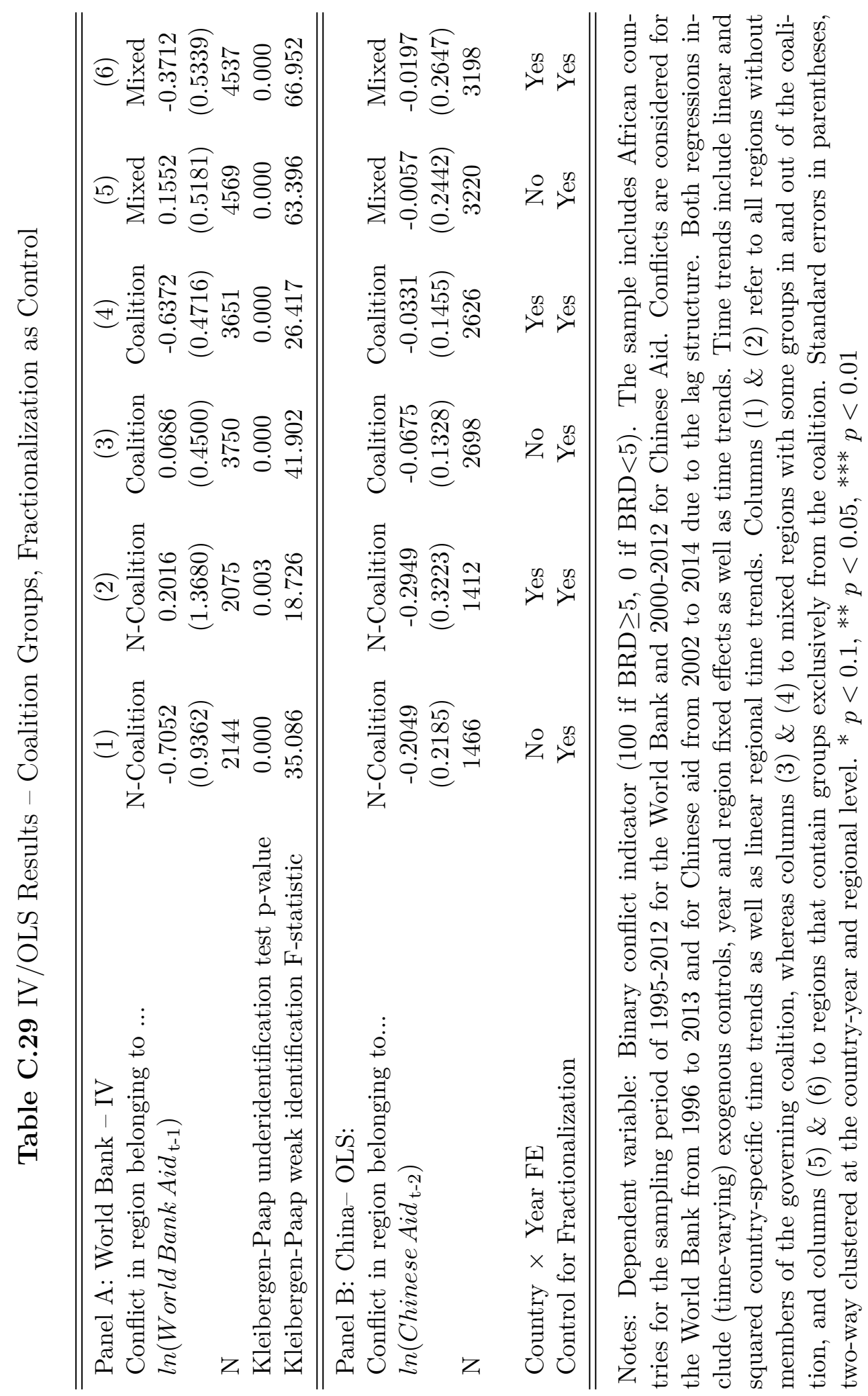


Aid and conflict at the subnational level

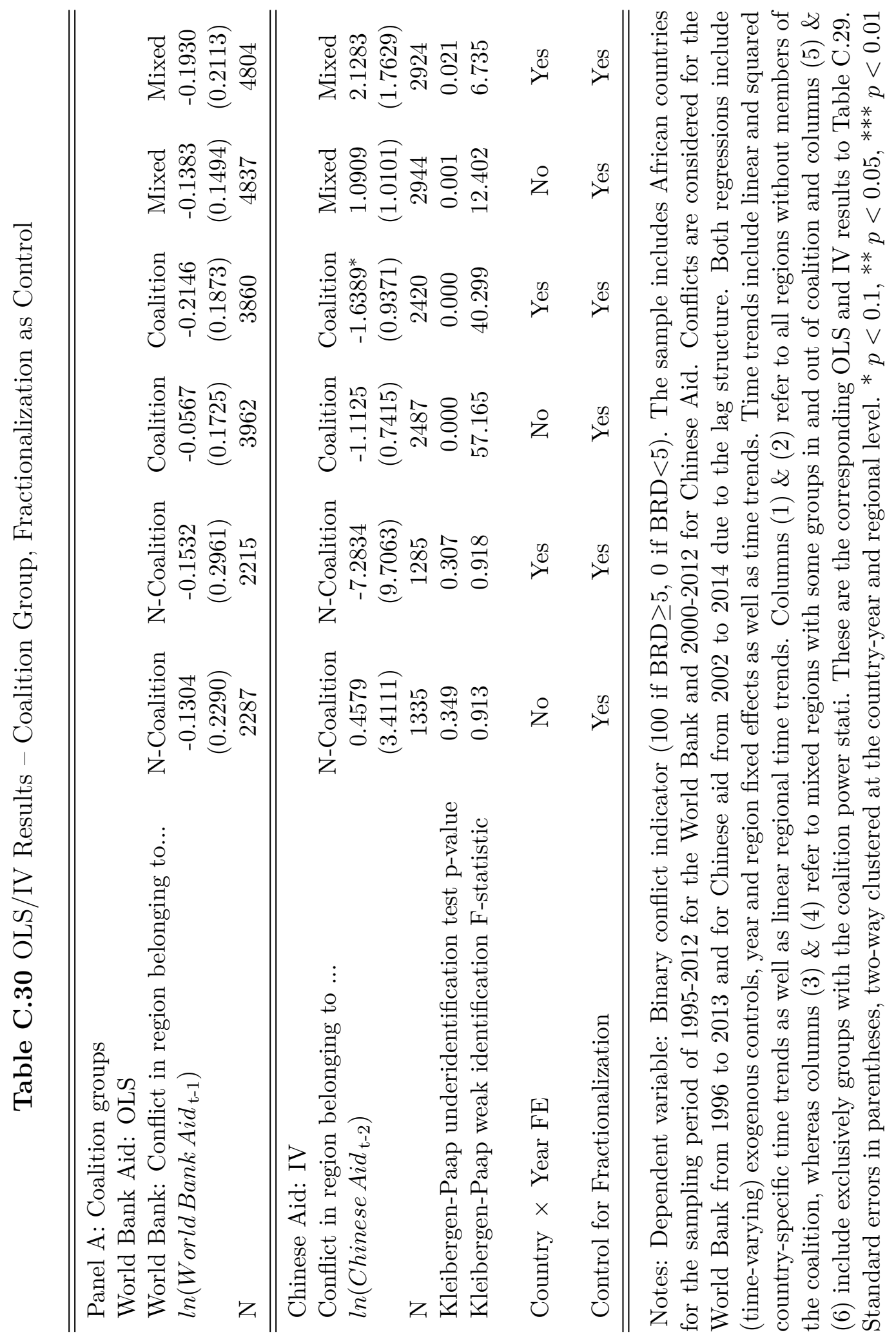


Aid and conflict at the subnational level

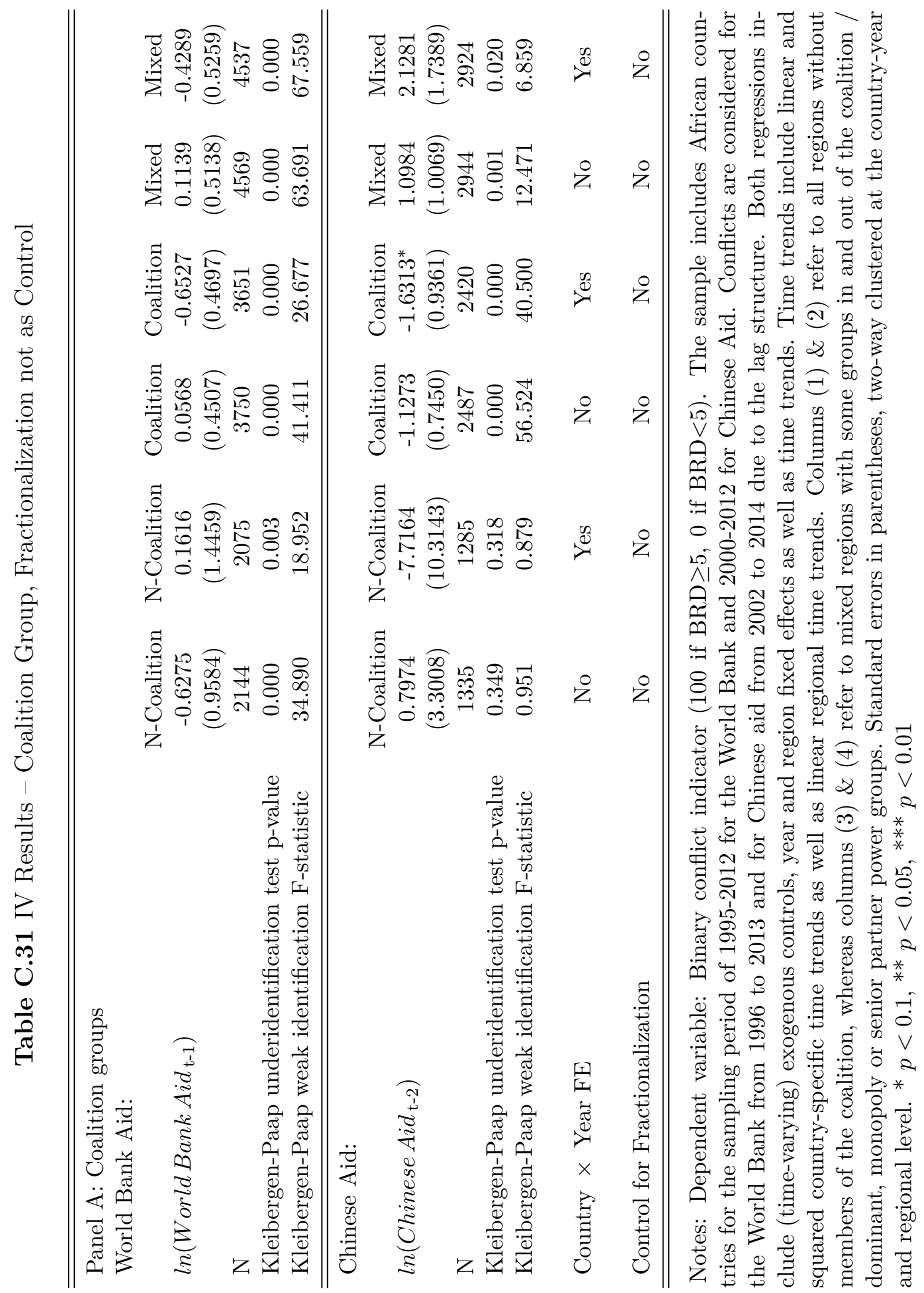


Aid and conflict at the subnational level

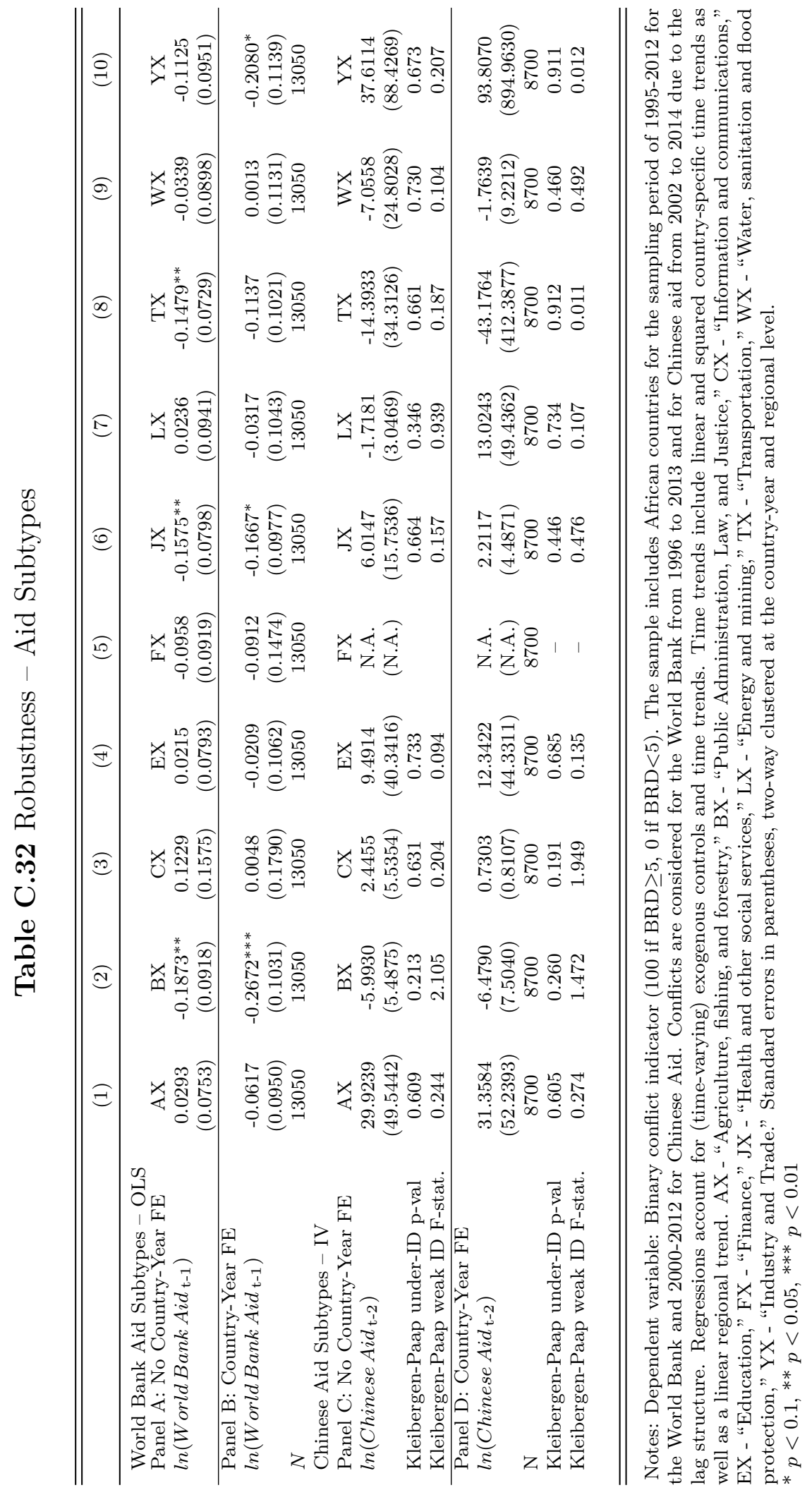


Aid and conflict at the subnational level

\section{B.4 Estimations - Miscellaneous}

Table C.33 IV Results - ADM2 Regions

\begin{tabular}{lcc}
\hline \hline & $(1)$ & $(2)$ \\
Panel A: World Bank Aid & & \\
IV Second stage: IDA Position & & \\
$\ln ($ World Bank Aid $\mathrm{t}-1)$ & 0.2599 & 0.1522 \\
$N$ & $(0.1644)$ & $(0.1171)$ \\
& 99367 & 99367 \\
\hline \hline Panel B: Chinese Aid & & \\
IV Second Stage: Chinese Steel & & \\
$\ln \left(\right.$ Chinese Aid $\left.\mathrm{t}_{\mathrm{t} 2}\right)$ & -0.0151 & -0.0289 \\
& $(0.1116)$ & $(0.1459)$ \\
$N$ & 64285 & 64285 \\
\hline & & \\
Exogeneous Controls & Yes & Yes \\
Exogeneous Controls $\times$ Year & Yes & Yes \\
Linear Regional Trends & Yes & Yes \\
Country-Year FE & No & Yes \\
\hline \hline
\end{tabular}

Notes: Dependent variable: Binary conflict indicator $(100$ if $\mathrm{BRD} \geq 5,0$ if $\mathrm{BRD}<5)$. The sample includes African countries for the sampling period of 1995-2012 for the World Bank and 2000-2012 for Chinese Aid. Both regressions include year and region fixed effects as well as time trends. Time trends include linear and squared country-specific time trends. The constituent term of the probability is depicted in Appendix Table C.7. Standard errors in parentheses, two-way clustered at the country-year and regional level.

${ }^{*} p<0.1,{ }^{* *} p<0.05,{ }^{* * *} p<0.01$ 
Aid and conflict at the subnational level

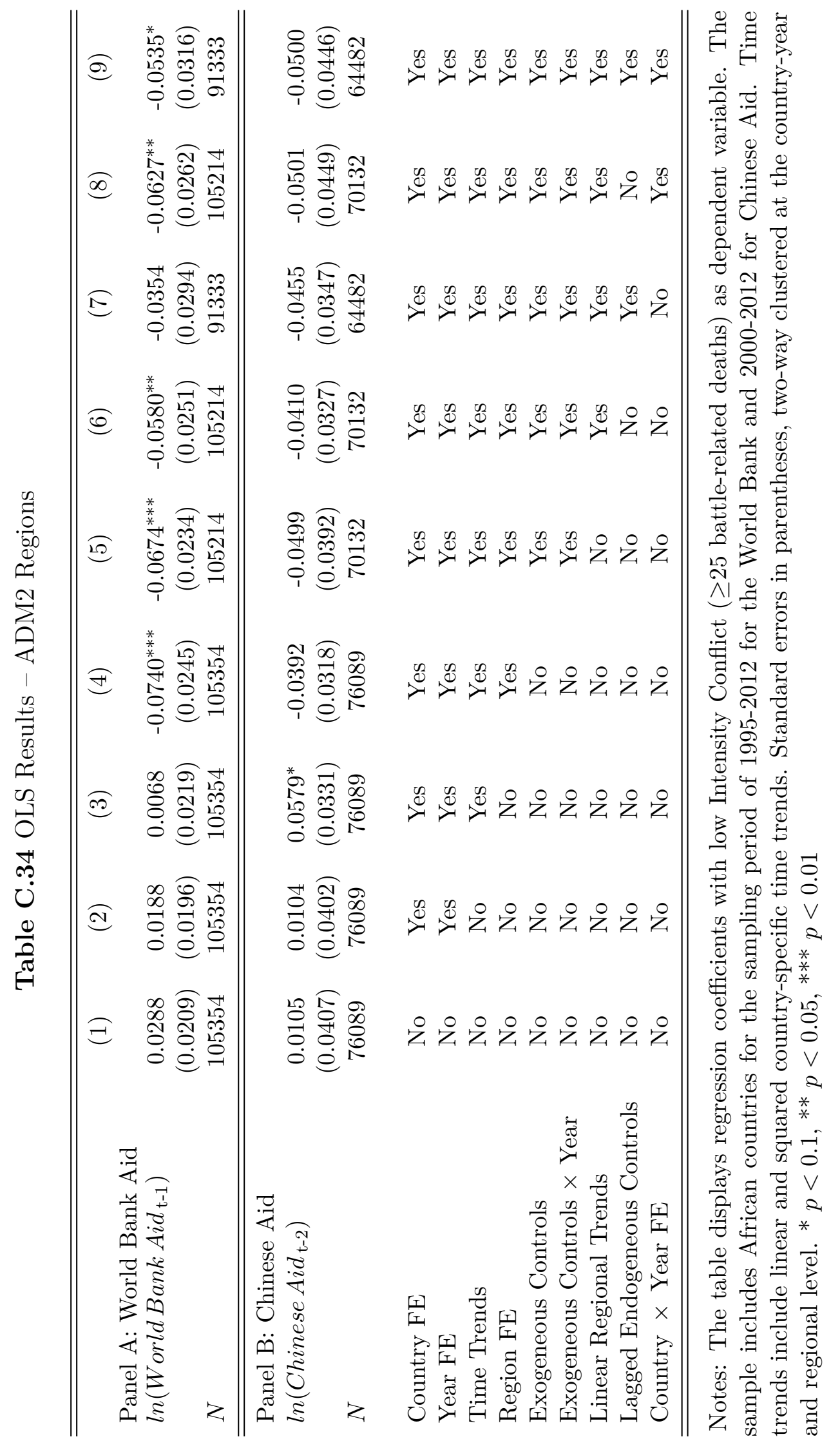


Aid and conflict at the subnational level

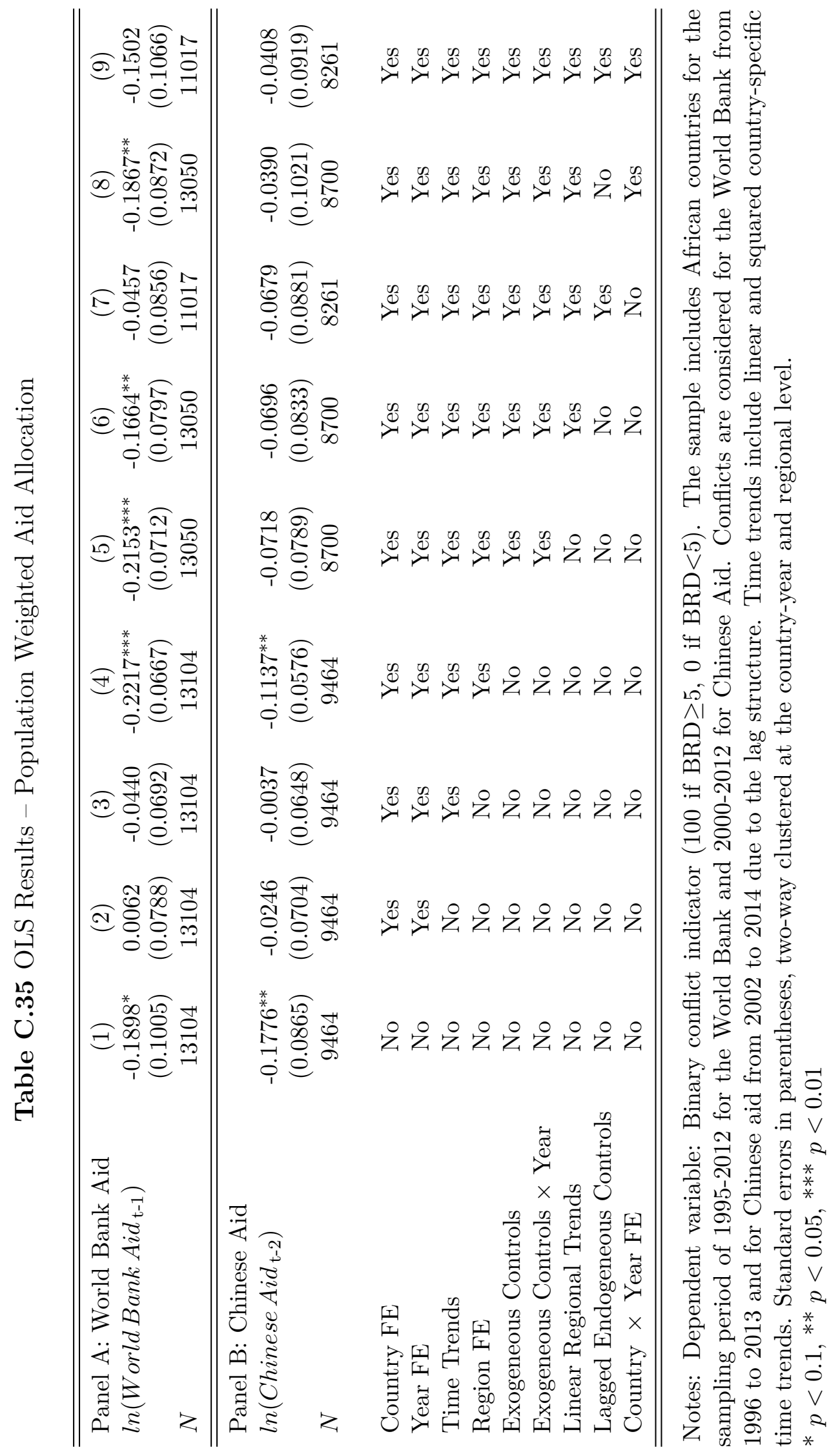


Aid and conflict at the subnational level

Table C.36 IV Results - Population Weighted Aid Allocation

\begin{tabular}{lcc}
\hline \hline Panel A: World Bank Aid & $(1)$ & $(2)$ \\
IV Second stage: IDA Position & & \\
$\ln \left(\right.$ World Bank Aid $\left._{\mathrm{t}-1}\right)$ & -0.1026 & -0.2286 \\
& $(0.3798)$ & $(0.4256)$ \\
$\mathrm{N}$ & 12325 & 12325 \\
Kleibergen-Paap underidentification test p-value & 0.000 & 0.000 \\
Kleibergen-Paap weak identification F-statistic & 100.841 & 88.424 \\
\hline \hline Panel B: Chinese Aid & $(1)$ & $(2)$ \\
IV Second Stage: Chinese Steel & & \\
ln(Chinese Aid t-2 $)$ & -0.4569 & -0.4323 \\
& $(0.6251)$ & $(0.8160)$ \\
N & 7975 & 7975 \\
Kleibergen-Paap underidentification test p-value & 0.000 & 0.000 \\
Kleibergen-Paap weak identification F-statistic & 22.601 & 16.535 \\
Country-Year FE & No & Yes \\
\hline \hline
\end{tabular}

Notes: Dependent variable: Binary conflict indicator $(100$ if $B R D \geq 5,0$ if $\mathrm{BRD}<5)$. The sample includes African countries for the sampling period of 1995-2012 for the World Bank and 2000-2012 for Chinese Aid. Both regressions include exogenous (time-varying) controls. Year and region fixed effects as well as time trends are included in all regressions. Time trends include linear and squared country-specific time trends and a linear regional trend. The constituent term of the probability is depicted in Appendix Table C.7. Standard errors in parentheses, two-way clustered at the country-year and regional level.

${ }^{*} p<0.1,{ }^{* *} p<0.05,{ }^{* * *} p<0.01$ 
Aid and conflict at the subnational level

Spatial spill-overs Analyzing spill-overs between capital and non-capital regions has the advantage of not relying on the EPR data and the ethnic homelands, and the disadvantage that it plots one region against all others. We run two sets of regressions. In some we use only the aid payments we included so far, in the second set we assign all aid that could not be allocated to an ADM1 region to the capital region. These specifications indicate no significant spill-overs between capital and other regions. 
Aid and conflict at the subnational level

Table C.37 OLS Results - Spill-Overs from Capital to Non-Capital

\begin{tabular}{|c|c|c|}
\hline & (1) & $(2)$ \\
\hline \multicolumn{3}{|l|}{ Panel A: } \\
\hline \multicolumn{3}{|l|}{ Including Non-GeoCoded Aid } \\
\hline Conflict in other Region - World Bank & Capital & Non-Capital \\
\hline \multirow{2}{*}{$\ln \left(W B\right.$ Aid non-Capital $\left._{\mathrm{t}-1}\right)$} & -0.3243 & -0.7626 \\
\hline & $(0.4335)$ & $(0.4634)$ \\
\hline \multirow[t]{2}{*}{$\ln \left(W B\right.$ Aid Capital $\left._{\mathrm{t}-1}\right)$} & 0.3851 & 0.5004 \\
\hline & $(0.4071)$ & $(0.4782)$ \\
\hline$N$ & 836 & 836 \\
\hline Conflict in other Region - China & Capital & Non-Capital \\
\hline \multirow[t]{2}{*}{$\ln ($ Chinese Aid non-Capital t-2) } & -0.1629 & -0.0306 \\
\hline & $(0.1542)$ & $(0.1637)$ \\
\hline \multirow[t]{2}{*}{$\ln \left(\right.$ Chinese Aid Capital $\left._{\mathrm{t}-2}\right)$} & -0.0173 & 0.1896 \\
\hline & $(0.1308)$ & $(0.2087)$ \\
\hline$N$ & 792 & 792 \\
\hline \multicolumn{3}{|l|}{ Panel B: } \\
\hline \multicolumn{3}{|l|}{ Excluding Non-GeoCoded Aid } \\
\hline \multirow{3}{*}{$\begin{array}{l}\text { Conflict in other Region - World Bank } \\
\ln \left(W B \text { Aid non-Capital }{ }_{\mathrm{t}-1}\right)\end{array}$} & Capital & Non-Capital \\
\hline & -0.3725 & -0.3694 \\
\hline & $(0.2928)$ & $(0.4252)$ \\
\hline \multirow[t]{2}{*}{$\ln \left(W B\right.$ Aid Capital $\left._{\mathrm{t}-1}\right)$} & 0.3953 & -0.0802 \\
\hline & $(0.2417)$ & $(0.4529)$ \\
\hline$N$ & 836 & 836 \\
\hline Conflict in other Region - China & Capital & Non-Capital \\
\hline \multirow[t]{2}{*}{$\ln \left(\right.$ Chinese Aid non-Capital $\left.{ }_{\mathrm{t}-2}\right)$} & -0.1047 & 0.0585 \\
\hline & $(0.1647)$ & $(0.1813)$ \\
\hline \multirow[t]{2}{*}{$\ln \left(\right.$ Chinese Aid Capital $\left._{\mathrm{t}-2}\right)$} & $-0.2147^{*}$ & -0.1836 \\
\hline & $(0.1190)$ & $(0.1983)$ \\
\hline$N$ & 792 & 792 \\
\hline
\end{tabular}

Notes: Dependent variable: Binary conflict indicator (100 if $\mathrm{BRD} \geq 5,0$ if $\mathrm{BRD}<5)$. The sample includes African countries for the sampling period of 1995-2012 for the World Bank and 20002012 for Chinese Aid. Conflicts are considered for the World Bank from 1996 to 2013 and for Chinese aid from 2002 to 2014 due to the lag structure. Both regressions include year and country fixed effects as well as time trends. Time trends include linear countryspecific time trends. Column (1) refers to aid and its effect in the capital regions, whereas column (2) refers to aid and its effect in non-capital regions. Standard errors in parentheses are clustered at the country level. ${ }^{*} p<0.1,{ }^{* *} p<0.05,{ }^{* * *} p<0.01$ 
Aid and conflict at the subnational level

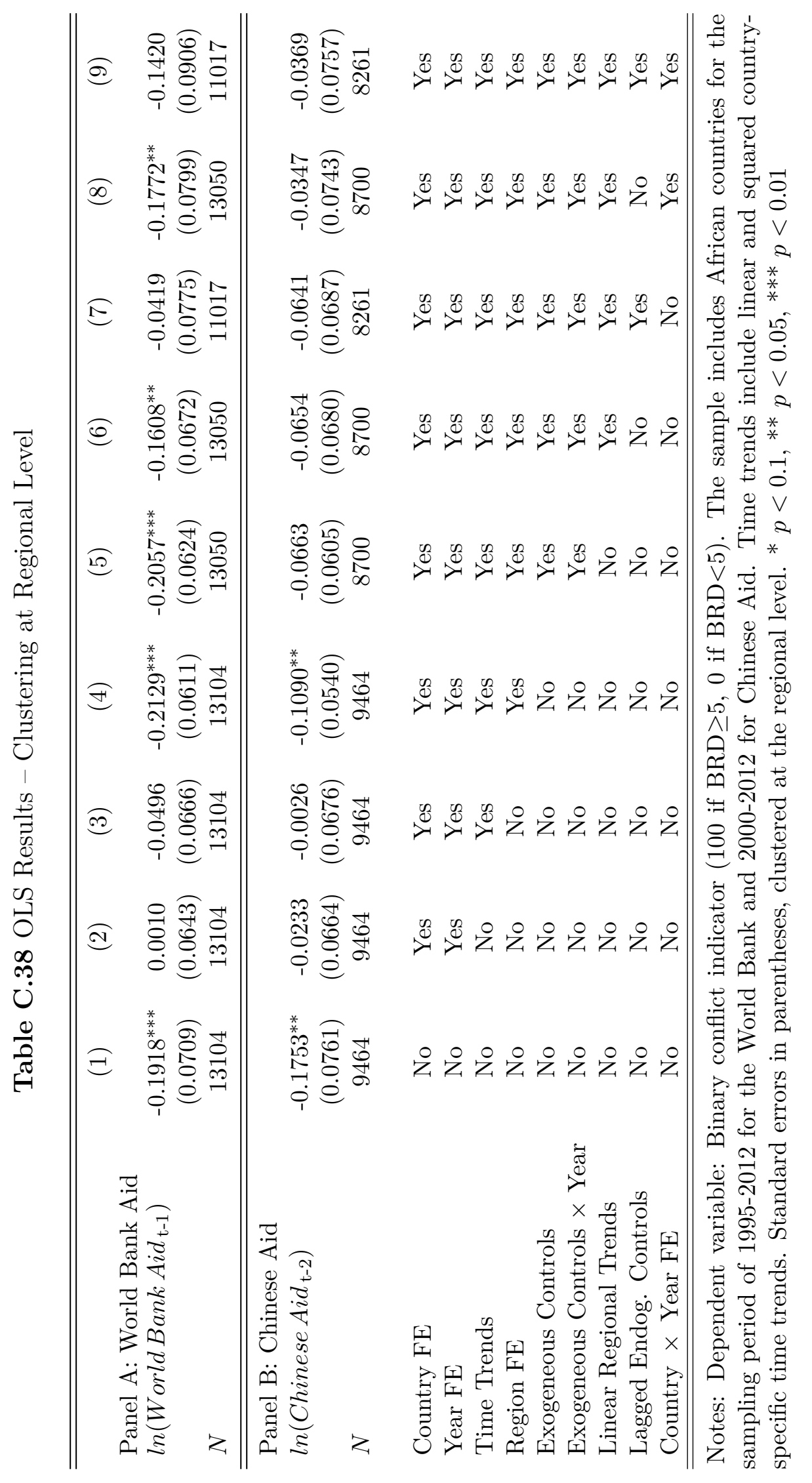


Aid and conflict at the subnational level

Table C.39 IV Results - Clustering at Regional Level

\begin{tabular}{|c|c|c|}
\hline & $(1)$ & $(2)$ \\
\hline \multicolumn{3}{|l|}{$\begin{array}{l}\text { Panel A: World Bank Aid } \\
\text { IV Second stage: IDA Position }\end{array}$} \\
\hline $\ln \left(\right.$ World Bank Aid $\left.\mathrm{t}_{\mathrm{t}-1}\right)$ & $\begin{array}{l}-0.1014 \\
(0.3276)\end{array}$ & $\begin{array}{l}-0.2252 \\
(0.3899)\end{array}$ \\
\hline $\mathrm{N}$ & 12325 & 12325 \\
\hline Kleibergen-Paap underidentification test $\mathrm{p}$-value & 0.000 & 0.000 \\
\hline Kleibergen-Paap weak identification F-statistic & 237.269 & 132.466 \\
\hline \multicolumn{3}{|l|}{ Panel B: Chinese Aid } \\
\hline \multicolumn{3}{|l|}{ IV Second Stage: Chinese Steel } \\
\hline $\ln ($ Chinese Aid $\mathrm{t}-2)$ & $\begin{array}{l}-0.4509 \\
(0.6147)\end{array}$ & $\begin{array}{l}-0.4276 \\
(0.8096)\end{array}$ \\
\hline Kleibergen-Paap underidentification test $\mathrm{p}$-value & 0.000 & 0.000 \\
\hline Kleibergen-Paap weak identification F-statistic & 28.972 & 18.960 \\
\hline Exogeneous Controls & Yes & Yes \\
\hline Exogeneous Controls $\times$ Year & Yes & Yes \\
\hline Linear Regional Trends & Yes & Yes \\
\hline Country-Year FE & No & Yes \\
\hline
\end{tabular}

Notes: Dependent variable: Binary conflict indicator $(100$ if $\mathrm{BRD} \geq 5,0$ if $\mathrm{BRD}<5)$. The sample includes African countries for the sampling period of 1995-2012 for the World Bank and 2000-2012 for Chinese Aid. Both regressions include year and region fixed effects as well as time trends. Time trends include linear and squared country-specific time trends. The constituent term of the probability is depicted in Appendix Table C.7. Standard errors in parentheses, clustered at the regional level.

${ }^{*} p<0.1,{ }^{* *} p<0.05, * * * p<0.01$ 
Aid and conflict at the subnational level

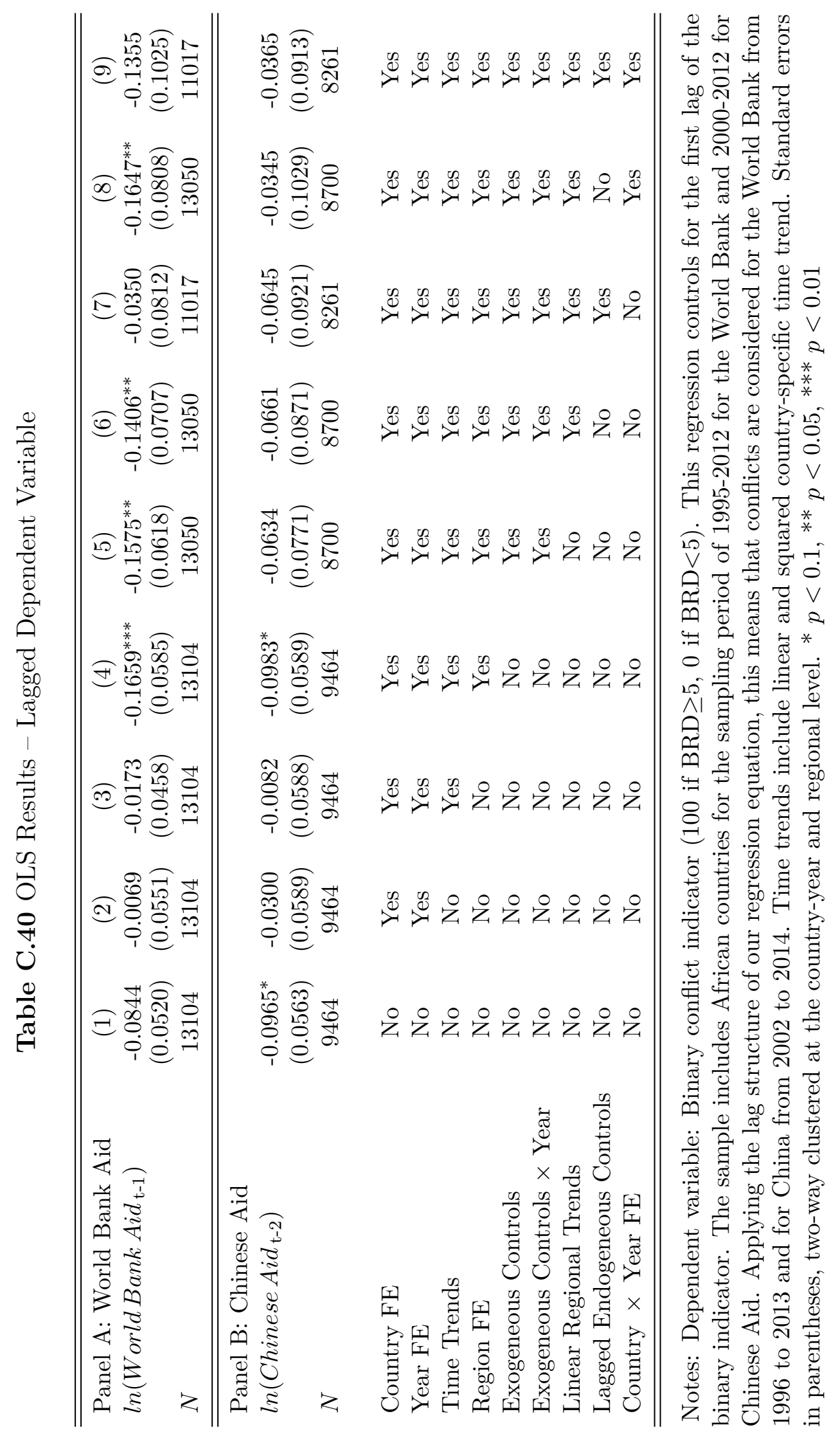


Aid and conflict at the subnational level

Table C.41 Robustness - Poisson Pseudo-Maximum Likelihood

\begin{tabular}{lccc}
\hline \hline & $(1)$ & $(2)$ & $(3)$ \\
Panel A: World Bank Aid & & & \\
main & & & \\
$\ln \left(\right.$ World Bank Aid $\left._{\mathrm{t}-1}\right)$ & -0.0005 & 0.0178 & -0.0171 \\
& $(0.0063)$ & $(0.0149)$ & $(0.0173)$ \\
$N$ & 6246 & 1476 & 7344 \\
\hline \hline Panel B: Chinese Aid & & & \\
main & & & \\
$\ln \left(\right.$ Chinese Aid t-2 $\left._{1}\right)$ & $-0.0128^{*}$ & 0.0023 & $-0.0328^{*}$ \\
& $(0.0076)$ & $(0.0131)$ & $(0.0189)$ \\
$N$ & 3783 & 962 & 4589 \\
& & & \\
\hline \hline
\end{tabular}

Notes: Dependent variables: In column (1) a binary conflict indicator ( 100 if $\mathrm{BRD} \geq 5,0$ if $\mathrm{BRD}<5$ ), in column (2) a binary indicator if any event of non-lethal pro-government violence took place, in column (3) a continuous measure of logged battle-related deaths. The sample includes African countries for the sampling period of 1995-2012 for the World Bank and 2000-2012 for Chinese Aid. All regressions include year fixed effects. Standard errors in parentheses, clustered at the regional level. ${ }^{*} p<0.1,{ }^{* *} p<0.05,{ }^{* * *} p<0.01$ 
Aid and conflict at the subnational level

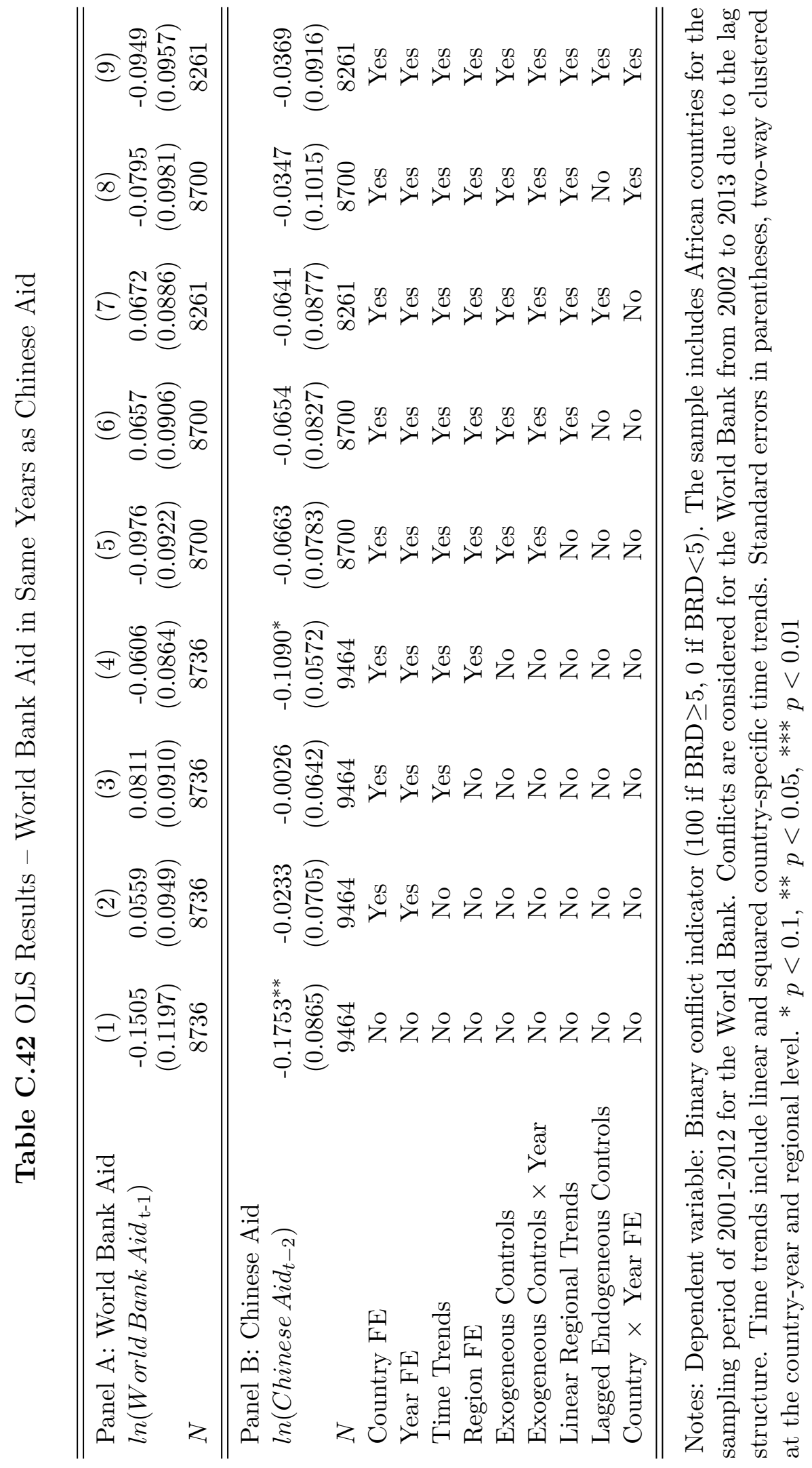


Aid and conflict at the subnational level

Table C.43 IV Results - World Bank Aid in Same Years as Chinese Aid

\begin{tabular}{|c|c|c|}
\hline & (1) & $(2)$ \\
\hline \multicolumn{3}{|l|}{$\begin{array}{l}\text { Panel A: World Bank Aid } \\
\text { IV Second stage: IDA Position }\end{array}$} \\
\hline $\ln \left(W \operatorname{orld} B\right.$ Bank $\left.A_{i d} d_{\mathrm{t}-1}\right)$ & $\begin{array}{l}-0.6227 \\
(1.0568)\end{array}$ & $\begin{array}{l}-2.3417 \\
(1.6897)\end{array}$ \\
\hline Kleibergen-Paap underidentification test p-value & 0.000 & 0.005 \\
\hline Kleibergen-Paap weak identification F-statistic & 22.619 & 6.960 \\
\hline \multicolumn{3}{|l|}{ IV First stage: IDA Position } \\
\hline IDA $_{\text {Position }} \mathrm{t}-1 \times$ Cum. Prob $_{\mathrm{t}-2}$ & $\begin{array}{c}57.2759^{* * *} \\
(12.0429)\end{array}$ & $\begin{array}{r}63.9080^{* * *} \\
(24.2241)\end{array}$ \\
\hline$N$ & 7975 & 7975 \\
\hline \multicolumn{3}{|l|}{ Panel B: Chinese Aid } \\
\hline $\ln \left(\right.$ Chinese Aid $\left.\mathrm{t}_{\mathrm{t}-2}\right)$ & $\begin{array}{l}-0.4509 \\
(0.6168)\end{array}$ & $\begin{array}{l}-0.4276 \\
(0.8068)\end{array}$ \\
\hline $\mathrm{N}$ & 7975 & 7975 \\
\hline Kleibergen-Paap underidentification test p-value & 0.000 & 0.000 \\
\hline Kleibergen-Paap weak identification F-statistic & 22.468 & 16.456 \\
\hline \multicolumn{3}{|l|}{ IV First stage: Chinese Steel } \\
\hline Steel Prod detrend $\mathrm{t}_{\mathrm{t}-3} \times$ Cum. Prob $_{\mathrm{t}-3}$ & $\begin{array}{c}-70.8763^{* * *} \\
(14.9526)\end{array}$ & $\begin{array}{c}-60.6567^{* * *} \\
(14.9524)\end{array}$ \\
\hline$N$ & 7975 & 7975 \\
\hline Exogeneous Controls & Yes & Yes \\
\hline Exogeneous Controls $\times$ Year & Yes & Yes \\
\hline Linear Regional Trends & Yes & Yes \\
\hline Country-Year FE & No & Yes \\
\hline
\end{tabular}

Notes: Dependent variable: Binary conflict indicator (100 if $\mathrm{BRD} \geq 5,0$ if $\mathrm{BRD}<5)$. The sample includes African countries for the sampling period of 2001-2012 for the World Bank and 2000-2012 for Chinese Aid. Both regressions include year and region fixed effects as well as time trends. Time trends include linear and squared country-specific time trends. The constituent term of the probability is depicted in Appendix Table C.7. Standard errors in parentheses, two-way clustered at the country-year and regional level.

${ }^{*} p<0.1,{ }^{* *} p<0.05,{ }^{* * *} p<0.01$ 
Aid and conflict at the subnational level

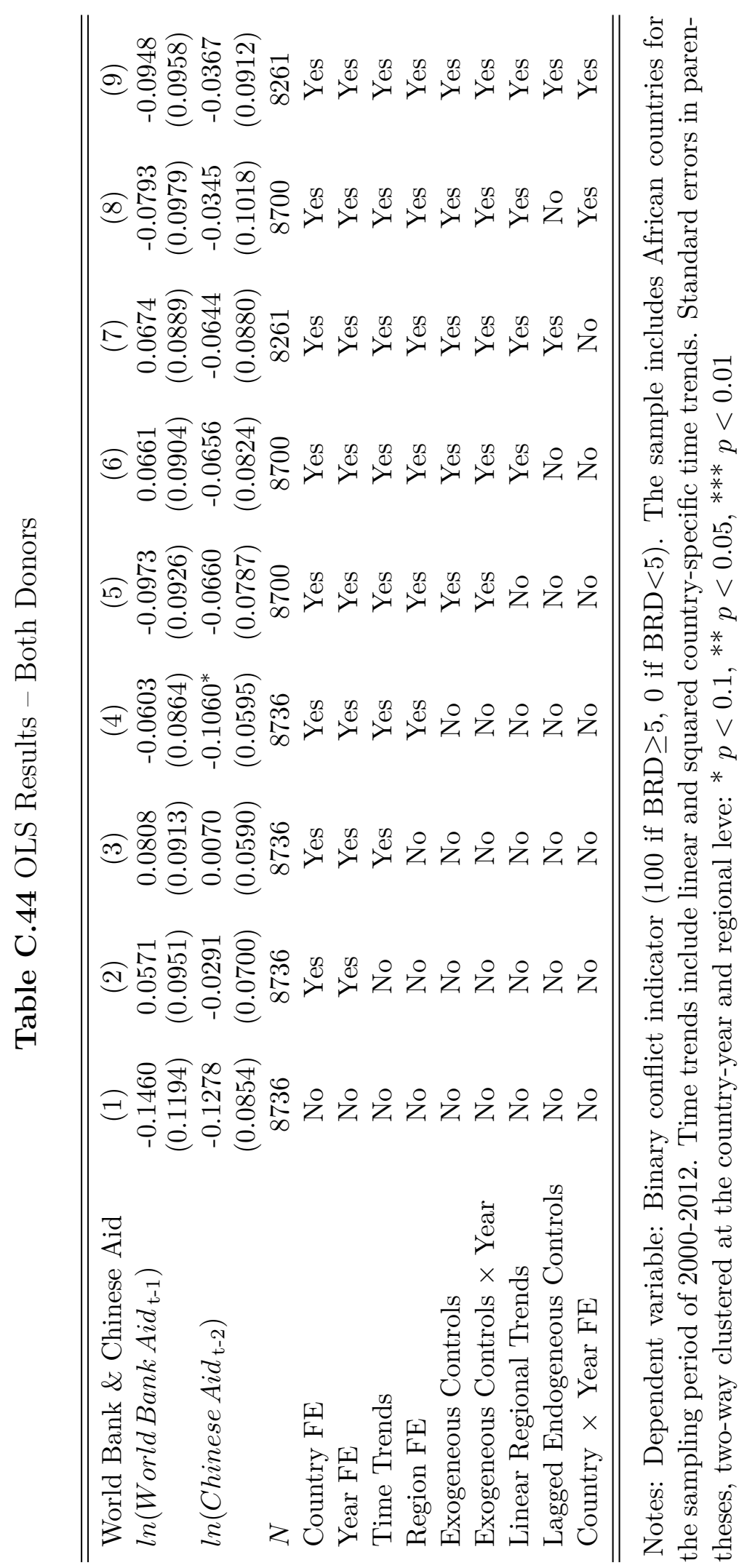


Aid and conflict at the subnational level

Table C.45 IV Results - Both Donors

\begin{tabular}{|c|c|c|}
\hline & $(1)$ & $(2)$ \\
\hline \multicolumn{3}{|l|}{ IV Second stage: IDA Position } \\
\hline $\ln \left(\right.$ World Bank Aid $\left._{\mathrm{t}-1}\right)$ & $\begin{array}{l}-0.7692 \\
(1.0994)\end{array}$ & $\begin{array}{l}-2.4159 \\
(1.7067)\end{array}$ \\
\hline $\ln ($ Chinese Aid $\mathrm{t}-2)$ & -0.4485 & -0.4033 \\
\hline & $(0.6271)$ & $(0.8310)$ \\
\hline Kleibergen-Paap underidentification test p-value & 0.000 & 0.004 \\
\hline Kleibergen-Paap weak identification F-statistic & 12.042 & 3.511 \\
\hline \multicolumn{3}{|l|}{ IV First stage: IDA Position } \\
\hline ID A Position $_{\mathrm{t}-1} \times$ Cum. Prob Pr-2 $_{\mathrm{t}}$ & $\begin{array}{c}57.3141^{* * *} \\
(12.0387)\end{array}$ & $\begin{array}{c}63.8098^{* * *} \\
(24.1928)\end{array}$ \\
\hline Steel Prod detrend $\mathrm{t}-3 \times$ Cum. Prob ${ }_{\mathrm{t}-3}$ & $\begin{array}{l}-0.5590 \\
(4.6845)\end{array}$ & $\begin{array}{l}-0.5283 \\
(4.3082)\end{array}$ \\
\hline$N$ & 7975 & 7975 \\
\hline \multicolumn{3}{|l|}{ IV First stage: Chinese Steel } \\
\hline IDA $_{\text {Position }} \mathrm{t}-1 \times$ Cum. Prob $t-2$ & $\begin{array}{c}-18.0734^{*} \\
(9.3582)\end{array}$ & $\begin{array}{c}-9.5155 \\
(12.7548)\end{array}$ \\
\hline Steel Prod detrend $\mathrm{t}_{\mathrm{t}-3} \times$ Cum. $_{\text {Prob }}{ }_{t-3}$ & $\begin{array}{c}-70.7017^{* * *} \\
(14.9511)\end{array}$ & $\begin{array}{c}-60.7419^{* * *} \\
(14.9668)\end{array}$ \\
\hline$N$ & 7975 & 7975 \\
\hline Exogeneous Controls & Yes & Yes \\
\hline Exogeneous Controls $\times$ Year & Yes & Yes \\
\hline Linear Regional Trends & Yes & Yes \\
\hline Country-Year FE & No & Yes \\
\hline
\end{tabular}

Notes: Dependent variable: Binary conflict indicator (100 if $\mathrm{BRD} \geq 5,0$ if $\mathrm{BRD}<5)$. The sample includes African countries for the sampling period of 2000-2012. Both regressions include year and region fixed effects as well as time trends. Time trends include linear and squared country-specific time trends. The constituent term of the probability is depicted in Appendix Table C.7. Standard errors in parentheses, two-way clustered at the country-year and regional level.

${ }^{*} p<0.1,{ }^{* *} p<0.05,{ }^{* * *} p<0.01$ 


\title{
Chapter 4
}

\section{What Makes a Successful Development Intervention? The Theory of Planned Behavior - An Application to Implementation Research}

Joint work with Jana C. Kuhnt, Katharina Richert and Sebastian Vollmer

\begin{abstract}
The success of development interventions crucially depends on their uptake in the targeted population. We investigate incentives for uptake of those interventions, making use of a framework grounded in psychological theory: "The Theory of Planned Behavior." The framework suggests three determinants for intervention uptake: personal attitudes, the social influence of important others and the perceived ease of intervention use. We use the setup of two randomized controlled trials in Indonesia and Pakistan to test the theoretical framework. Our findings show that the proposed determinants are indeed associated with increased uptake. We investigate further on the determinant personal attitudes by conducting a framed field experiment in Indonesia. The experiment shows that the study population in the Indonesian context exhibits higher levels of support for the project if the participation of international actors is highlighted. Consequently, our results encourage development research and cooperation, first, to consider the determinants suggested by the "Theory of Planned Behavior" in the design of interventions in order to increase uptake. Second, depending on the country context and previous experience, explicitly framing participation of well-esteemed partners in the conducted project might be a cost-effective way to achieve behavioral change.
\end{abstract}



The Theory of Planned Behavior - An Application to Implementation Research

\subsection{Introduction}

A large focus in the literature studying development cooperation naturally lies on its effectiveness. On the macroeconomic cross-country level, the effectiveness of aid is studied to an impressive extent, while results are still inconclusive (Burnside and Dollar, 2000, Easterly et al., 2004). In focus of the literature typically stand donor characteristics (Berthélemy, 2006: Minasyan et al., 2017), recipient characteristics (e.g., Dollar and Pritchett, 1998; Rajan and Subramanian, 2008), or certain types of development assistance (e.g., Dreher et al., 2008; Clemens et al., 2012; Roodman, 2015). Much less attention is drawn to the specific implementation features of development interventions, which might likewise and very likely predict success or failure of interventions. Take for instance two very similar interventions on HIV/Aids education for young people in Uganda from Kinsman et al. (2001) and Karim et al. (2009). While Karim et al. (2009) show quite positive effects of the intervention on female participants with regard to increased condom use, Kinsman et al. (2001) see almost no effect of their large-scale intervention. Can we accordingly assume that HIV/Aids education works in all evaluated eight districts, but Masaka, where Kinsman et al. (2001) conducted their study? Alternatively in 2009, but not in 2001? Possible, but unlikely. The probability is higher that the implementation strategy, which Karim et al. (2009) tested, was more successful in achieving behavioral change than the approach evaluated by Kinsman et al. (2001) in the given setting. However, what makes a successful development intervention? At the heart of development interventions is regularly the aim to change human behaviorgenerally as a mediator to reach a certain goal (e.g., increased use of condoms to reduce sexually transmitted diseases). Limited participation or support from the respective study population challenges these interventions (e.g., Banerjee et al., 2010, Cole et al. 2013). In this chapter, we want to address the puzzle of success and failure of interventions and examine incentivizing factors for intervention uptake. What we have in mind here, is a framework, guiding researchers and practitioners in designing successful interventions. A systematic and deep understanding of what drives behavioral change in response to development activities is in high demand and studies partly acknowledge this by building a theory of change (Nayiga et al., 2014, Rogers, 2014). However, the application of a general framework is missing (Duflo et al., 2007; World Bank, 2015b). Instead, most interventions in development economics still predominantly rely on monetary incentives to increase uptake. Other important drivers of human behavior have attracted limited attention (Kettle et al., 2016). This is the case, despite insights from behavioral economics stressing the importance of non-monetary incentives that shape human motivation and behavior (e.g., Gneezy et al., 2011; Bowles and Polania-Reyes, 2012), and scholarly work showing that these factors play a role in the successful design of interventions (e.g., Banerjee et al., 2010; Cole et al., 2013; Ashraf et al., 2014) 1

\footnotetext{
${ }^{1}$ These factors "disturbing" the rational decision-making are acknowledged by economists (here often-called psychological biases and cognitive limitations) and insights from behavioral economics are increasingly applied to public policy (e.g., Behavioral Insights Team in the UK; Mind, Behavior and Development Unit at the World Bank; Madrian (2014)).
} 
The Theory of Planned Behavior - An Application to Implementation Research

We make use of a psychological theory called the "Theory of Planned Behavior" (TPB), which provides a straightforward framework to identify and respond to facilitating and hindering factors related to human behavior. The framework rests upon three determining factors that influence a person's behavior (Fishbein and Ajzen, 1980 , Ajzen, 1985). The first determinant is the personal attitude towards the behavior, which refers to the degree to which a person has a favorable or unfavorable evaluation of performing the behavior in question. A certain attitude (e.g., dis-/trust) is mostly acquired through knowledge or learning, which can be influenced by various factors, including information or previous experience (Perugini and Bagozzi, 2001, Vogel and Wanke, 2016). The second predictor termed "subjective norm" reflects the social influence felt by the individual. It refers to the perceived social pressure to perform or not to perform the behavior. The third behavioral determinant is the degree of "perceived behavioral control," which refers to the perceived own control over the behavior, i.e., ease or difficulty in its performance (Armitage and Conner, 2001). Generally speaking, individuals are more likely to intend a certain behavior if they judge it beneficial (attitude toward behavior), if they think important others want them to do it (subjective norm), and if they feel, they are able to do it (perceived behavioral control). Importantly, the TPB links its three predictors to intended behavior, which is the immediate antecedent and, thus, a close predictor of an individual's actual behavior (Ajzen, 1991; Bilic, 2005).

The TPB is currently the most widely used and accepted social cognition model across disciplines and researchers (e.g., Ogden, 2003, Hobbis and Sutton, 2005, McEachan et al., 2011) and seems particularly suitable to development economics. This is the case as there is a substantial body of literature which shows the applicability of the TPB to a wide variety of behaviors in different cultural and geographical settings including high and low income countries (e.g., Protogerou et al., 2012; Kiene et al., 2014; Walrave et al., 2014; Hsu et al., 2017; Kassim et al., 2017). The TPB's predictive power was for instance shown in different settings with regard to technology, health-care, consumption choices, voting or education (Blue, 1995; Armitage and Conner, 2001; Bilic, 2005, Barnard-Brak et al., 2010, Cheon et al., 2012; Cooke et al., 2014: Appleby et al., 2016: Landmann et al., 2017) ${ }^{2}$ To the best of our knowledge, however, the framework has not yet been used in implementation research to guide interventions in the field of development economics.

We apply the TPB to a real-world intervention, which we conducted ourselves. More specifically, we consider the introduction of the World Health Organization (WHO)'s Safe Childbirth Checklist (SCC) within two randomized controlled trials (RCTs) in Pakistan's Khyber Pakhtunkhwa province (Kuhnt and Vollmer, 2018) and Indonesia's Aceh province (Diba et al. 2018). Evidently, the checklist can only be effective if health personnel complies with the intervention and actually uses the SCC. Hence, the behavior in question is the uptake (use) of the checklist during deliveries. Based on the

\footnotetext{
${ }^{2}$ Studies also looked into long-term predictions of the TPB. While the predictive power oftentimes drops with time, the TPB is still able to predict behavior for time periods as long as 15 years (e.g., McEachan et al., 2011; Fichten et al., 2016).
} 
The Theory of Planned Behavior - An Application to Implementation Research

TPB determinants, we analyze incentivizing factors. In addition, we will strengthen the analysis by looking into one specific parameter that is likely to influence the behavioral reaction towards development programs. Recently, studies have started to shed light on softer preconditions for the support of interventions: the implementer's characteristics (e.g., Cilliers et al., 2015; Findley et al., 2017). These fall into our determinant attitude towards the behavior, because they influence trust levels. As this determinant is particularly well in control of implementers, the realization of potential incentives should be comparably easy and promising. Accordingly, we deepen our analysis of the determinant attitude towards checklist use by conducting a framed field experiment. Within the context of the Indonesian SCC trial, we assess whether health personnel's attitude and support towards checklist use changes conditional on whether the participation of local or international agents in the study is highlighted. ${ }^{3}$

Our results show that the TPB can indeed help in disentangling the puzzle about intervention success and failure and consequently serve as a guideline in determining and shaping factors affecting intervention uptake. In both country settings, all three proposed TPB determinants are positively related to the uptake of the intervention. A focus on the implementation design on stimulating these factors is thus likely to increase the success of interventions through increased support and consequently higher participation rates among the targeted population. Furthermore, our framed field experiment indicates that the change in attitudes due to the salience of international involvement in projects seems to have advantages over solely locally organized programs in the Indonesian context. The population under study shows higher trust and support for interventions with international involvement. Previous exposure to both international and local implementers drives those positive behavioral reactions towards international research projects.

The chapter is structured as follows: Section 4.2 links the "Theory of Planned Behavior" to our intervention and describes our research design and data. Section 4.3 elaborates on the methods used, and the results are described in Section 4.4. Section 4.5 discusses the generalizability and policy relevance of the results and concludes the study.

\subsection{Research Design and Data}

The interventions used in this study address safe childbirth. For a detailed description of the interventions, see the evaluation articles of the main RCTs (Diba et al., 2018, Kuhnt and Vollmer, 2018). Two-thirds of mother and newborn deaths globally occur due to causes, which could largely be prevented if well-established essential practices were followed (WHO, 2018). However, the gap between the knowledge about what should be done to ensure safe deliveries and what is actually done is large. Following the ideas of the rational choice theory that describes independent agents striving to maximize their utility (Simon and Feldman, 1959), the deviation should be a matter of information or knowledge availability, assuming that incentives to ensure the well-being

\footnotetext{
${ }^{3}$ For a visualization of our study design, see Figure D.2
} 
The Theory of Planned Behavior - An Application to Implementation Research

of the patient are functioning (e.g., humanity; prestige or punishment and investigation in case of death of mother or child). The WHO Safe Childbirth Checklist (SCC) initiative aims at providing health personnel with a checklist to be used around the delivery process entailing the essential practices addressing the major risk factors for mothers and children in low and middle income countries. Experience from other medical fields suggests that checklists could be a promising tool to motivate health personnel to follow essential practices and tackle the know-do gap. Checklists compress and bundle the necessary information into easy-to-use actionable items and herewith reduce a possible "information overload" (e.g., Workman et al., 2007; Borchard et al. 2012 Haugen et al., 2015). Insights from behavioral economics suggest that human behavior is bounded by limitations of the working memory. In situations characterized by high levels of cognitive load - the amount of mental activity imposed - the successful execution of certain tasks might be interrupted or impaired (e.g., Croskerry, 2002; Burgess, 2010; Hoffman et al., 2011; Deck and Jahedi, 2015, Lichand and Mani, 2016). Checklists can be especially helpful to reduce additional cognitive load and allow a reduction of complexity of the task at hand by reminding the user of the essential steps to follow.

Using cluster randomized controlled trials, we evaluated the SCC in 32 health facilities in Indonesia, as well as in 17 health facilities and among 149 individual health providers in Pakistan. In both countries, the intervention we conducted was very similar. The treatment (SCC) was randomly introduced to approximately half of the health providers to causally identify the effect of the intervention on studied outcomes. The randomization took place at the facility level. Hence, all staff working in the same facility were jointly allocated to either treatment or control group.

\subsubsection{The TPB in the Setting of the SCC Intervention}

In this section, we apply the logic of the Theory of Planned Behavior to the SCC intervention. This identifies the TPB determinants as illustrated in Figure 4.1. In the logic of Ajzen (1991) the attitude towards the checklist, the subjective norm of health personnel and the perceived behavioral control about checklist use will jointly determine whether health staff intends to use the checklist, which finally leads to whether the checklist is actually used during deliveries. We will go into more detail in the following.

The puzzle of this study is as follows: If health personnel know that the checklist entails necessary essential practices supporting the safety of deliveries, why would they decide not to use the checklist. This is where we apply the TPB to carve out how the perception about the checklist's usefulness and relevance ("Attitude towards the Behavior"), support, and peer-pressure among staff members ("Subjective Norm"), as well as perceived ability to use the checklist ("Perceived Behavioral Control"), shape intended ("Intentions") and actual uptake ("Behavior"). Specifically, the know-do gap can be translated into the TPB determinants: The easiest explanation of why people would not use the checklist is because they do not know its benefits. The research design assured that all health personnel is informed about the checklist's benefits. Knowing 
The Theory of Planned Behavior - An Application to Implementation Research

Figure 4.1 Applying the TPB to the SCC Intervention

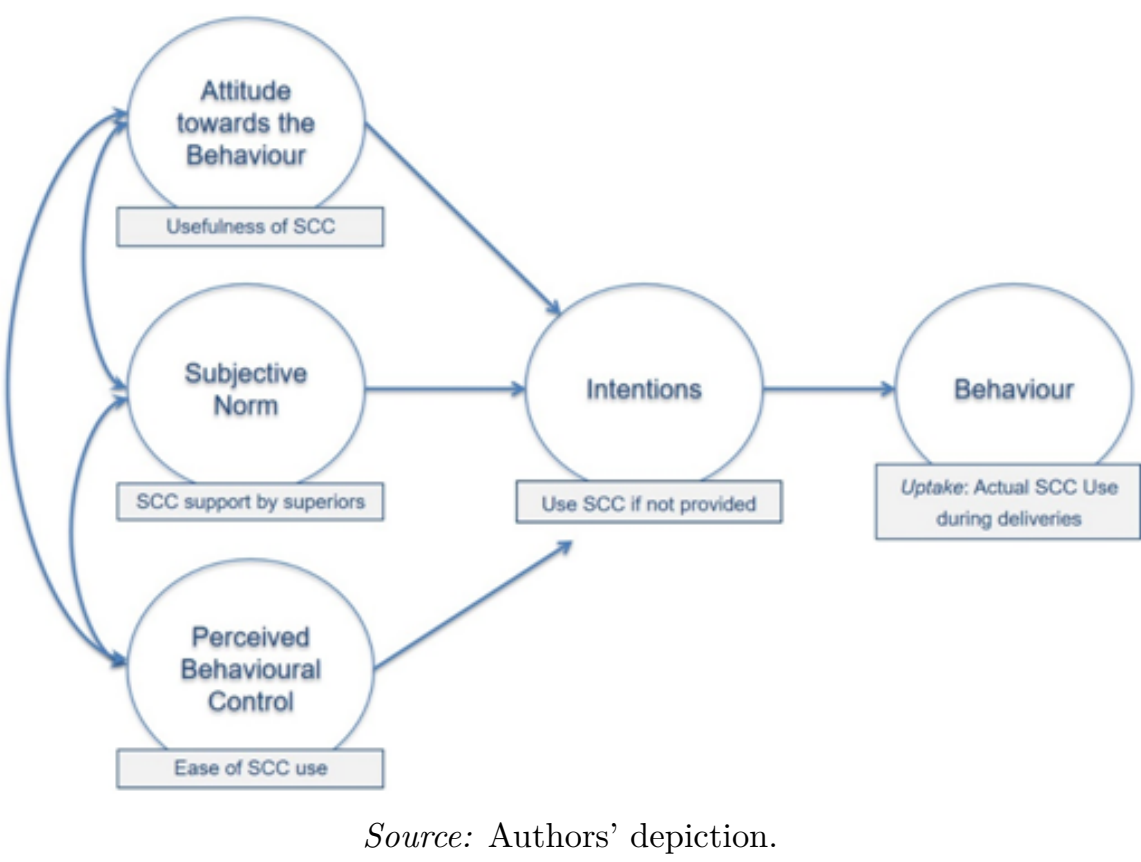

Note: Own illustration based upon Ajzen (1991).

the benefits, however, presumes that health personnel also believed in the information attained. Trusting in the checklist would therefore be a first important precondition for checklist uptake (attitude towards the behavior). On the perspective of the do-side from the know-do gap, people might still not use the checklist as they feel unable to use it (perceived behavioral control) or not obliged to do so (subjective norm). Using the real-world setting of the SCC interventions in Indonesia and Pakistan, we are able to empirically test the influence of the TPB determinants on intended and actual use of the SCC..$^{4}$ Of all TPB determinants, the attitude towards the behavior building on how trust-worthy the intervention is perceived seems to be particularly well in control of the intervention implementer. We therefore elaborate additionally on this determinant within our field experiment.

\section{Data: Measuring TPB Determinants and Outcomes}

We measured our data through surveys with health personnel and clinical observations of the delivery process. Our TPB determinants were collected through survey questions and serve as explanatory variables in our analysis. We conducted surveys at the health

\footnotetext{
${ }^{4}$ Theoretically, opportunity costs of using the SCC might be an impeding factor. However, monetary costs are very low and non-monetary components are implicitly part of attitudes and subjective norms.
} 
The Theory of Planned Behavior - An Application to Implementation Research

facilities in Indonesia and Pakistan at the beginning and the end of the interventions. Importantly, the data for the TPB analysis were only collected for the respondents working in treatment facilities, as at the time of the endline survey health staff in control facilities had not been in contact with the SCC. Hence, asking about the perceptions of the SCC would not have been possible and limits our sample to those interviewed at treatment facilities. This leaves us with 79 respondents in Pakistan and 163 health workers in Indonesia 5 Including only the treatment facilities, gives us a non-random sample limiting causal inference, which is discussed below.

The numerous applications of the TPB to a wide array of contexts ease the measurement of TPB determinants (e.g., French and Hankins, 2003, McEachan et al., 2011). [ $^{6}$ We were thus able to follow the respective literature when formulating survey questions. The first determinant attitude towards the behavior, here towards the use of the SCC, we prompt by asking the respondents to judge the usefulness of the SCC in their professional context (based upon Kam et al. (2012)). Subjective norm would translate into the degree of support by health practitioners' superiors. Perceived behavioral control takes into account how easy the health practitioners judge the checklist to be applicable in their daily work routine. The judgment on the three TPB determinants was generally very positive. For all three determinants and in both contexts the respondents provide a rating of five on a scale ranging from one to six, where six corresponds to "fully agree.' 7 However, Appendix Tables D.4 and D.5 indicate some distinct variation, which we exploit in our analysis. Beyond the main TPB variables, surveys included demographic background information, which serves as control variables.

Following the TPB, the three components then influence whether health staff intends to use the checklist and, ultimately, if they actually use it during deliveries conducted (see Figure 4.1). Intentions to use the checklist and actual checklist use represent our outcome measures. We investigated respondents' intended behavior towards the SCC use, by asking whether they intend to continue using the SCC after termination of

\footnotetext{
${ }^{5}$ The Pakistani health staff worked at 70 different providers (including individual providers but also larger health facilities). While we surveyed every individual provider, we increased the number of interviews at health facilities proportionally with their number of delivery staff to get a more nuanced picture within larger teams. The Indonesian trial involved interviews at 16 health facilities.

${ }^{6}$ It has to be noted that the TPB can be applied in various ways, which is likely to influence its effects (Lugoe and Rise, 1999). In order to increase the TPB's explanatory power and flexibility to address also varying intentions and behavior, several studies extended the original framework by further constructs and components (e.g., Conner and Armitage, 1998, Perugini and Bagozzi, 2001; Armitage and Conner, 2001; Bilic, 2005, Cheon et al., 2012). We will stick to the original theory when applying it to development economics, while we acknowledge the propositions made to deepen or broaden the TPB. Especially, the consideration of other contextual factors offers interesting routes for further research, e.g., in the framework the comprehensive action determination model (Klöckner and Blöbaum, 2010).

'As the distribution of the TPB determinants is heavily right-skewed, we assessed robustness using a binary indicator if respondents chose the top category. Results remain robust and are available upon request.
} 
The Theory of Planned Behavior - An Application to Implementation Research

Figure 4.2 Intentions to use the Safe Childbirth Checklist

a) Intentions - Indonesia

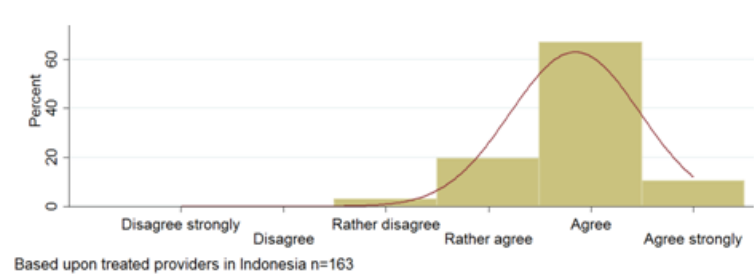

Source: Authors' calculation based on survey data. b) Intentions - Pakistan

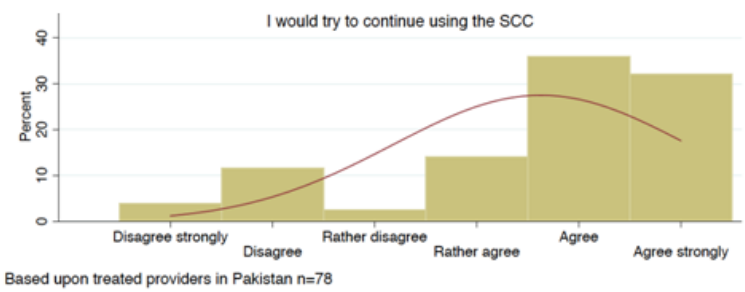

Figure 4.3 Actual use of the Safe Childbirth Checklist
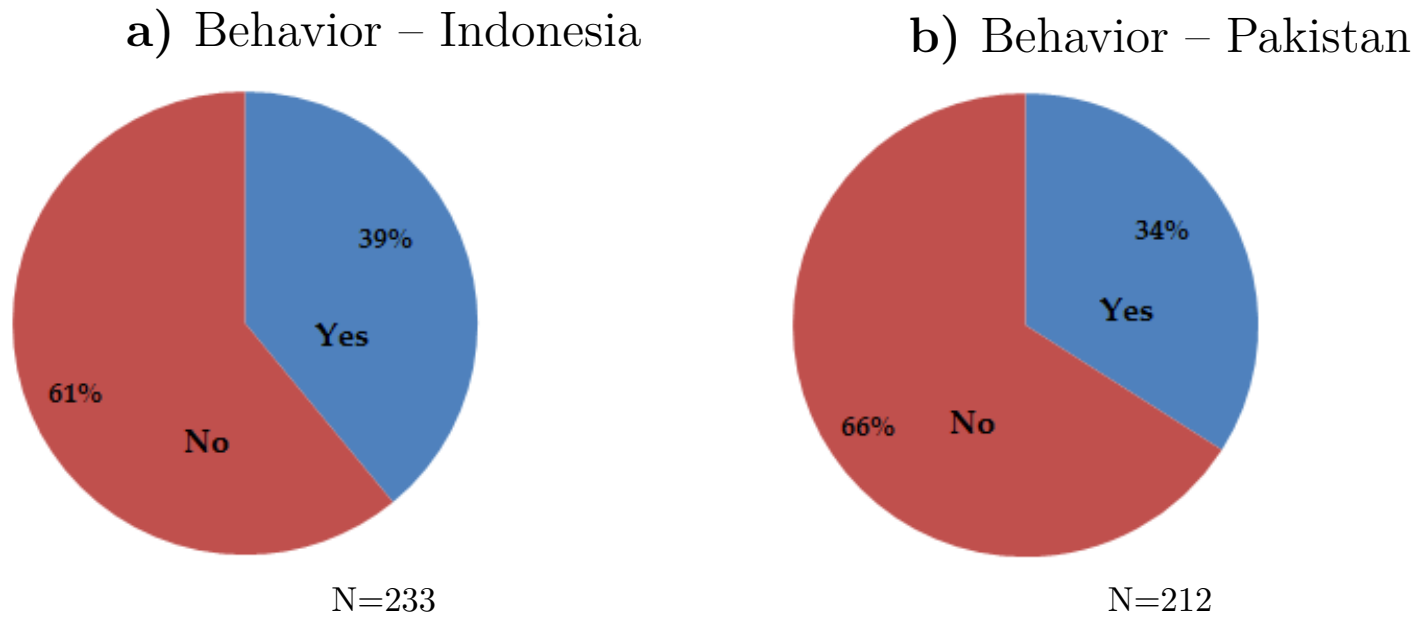

Source: Authors' calculation based on clinical observations.

the study applying a 6-point Likert scale. ${ }^{8}$ Descriptive statistics show that the SCC is generally valued by the practitioners in Indonesia and Pakistan (Figure 4.2). Yet, there is some distinct variation within and across the settings. Additionally, Figure 4.3 describes the actual SCC use by health practitioners in Indonesia and Pakistan. It indicates a limited uptake and, hence, a potential gap between intended and actual use. Therefore, it is important to examine the factors that possibly constrain the behavior more carefully. $9^{9}$

To also assess the actual use of the SCC, we additionally conducted standardized clinical observations in a subsample of the health facilities. Trained observers doc-

\footnotetext{
${ }^{8}$ As an additional outcome measure we asked participants whether they would recommend the SCC to colleagues. Results are available upon request. (2018).

${ }^{9}$ More detail on the data collected can be found in Kuhnt and Vollmer (2018) and Diba et al.
} 
The Theory of Planned Behavior - An Application to Implementation Research

umented the delivery processes and marked whether the attending health staff had used the checklist.10 This information was collected for 212 deliveries at 9 treatment providers in Pakistan and 233 deliveries at 15 treatment facilities in Indonesia. ${ }^{11}$

All measures (except for the actual behavior measure through clinical observations) are perception-based and, hence, subjective indicators. While this sheds light on subjective experiences, these questions are more difficult to compare across individuals and are subject to social desirability bias. ${ }^{12}$ However, evidence from TPB studies suggests that self-reported behavior can have higher explanatory power for intended behavior than objective measures as the latter can hardly reflect intentions, which are by nature subjective (e.g., Armitage and Conner, 2001; McEachan et al., 2011).

\subsubsection{What Shapes Attitudes? A Framing Experiment}

We investigate further on the TPB determinant attitudes towards the behavior in a framed field experiment, as this is particularly in control of intervention implementers. If we can identify positive incentives with our analysis, those should be comparably easy to implement and therefore promising to actually materialize in improved uptake. Precisely, the experiment aims at shedding more light on what influences people's trust in the intervention. For practical reasons, we conducted the experiment within the Indonesian trial only 13

Experimental evidence within the context of the SCC intervention strengthens the real world applicability and external validity. It has been prominently voiced that these types of experiments are a valuable and important tool to generate policy-relevant insights, e.g., by better understanding structural parameters obtained from experimental interventions like RCTs (Duflo et al., 2007; Viceisza, 2015). The experiment is, hence, not only designed to inform our specific intervention but to generate insights for international development research and practice in more general terms.

Recent literature suggests that our channel in focus - attitudes towards the behavior - in implemented interventions is influenced by characteristics of the implementers themselves. International and local actors mostly implement development interventions jointly. These might include non-governmental organizations (NGOs), governmental agencies, or profit-oriented service providers. Also, the growing number of impact evaluations in the domain of development economics, are often implemented by a research

\footnotetext{
${ }^{10}$ Checklist use was either defined by whether the practitioners picked up the checklist during or directly after care, or whether the checklist poster was observed during the delivery process. To hang up a checklist poster in the delivery room for simultaneous consultation formed part of our intervention.

${ }^{11}$ In Pakistan, our observations capture 50 percent of all monthly conducted deliveries at the observed health facilities as well as 94 percent of all monthly conducted deliveries at observed individual providers. In Indonesia, the fraction relates to 64 percent of all monthly conducted deliveries at observed health facilities.

${ }^{12}$ The social desirability bias describes the bias respondents can have in their responses due to the desire to act in a socially acceptable manner (Kemper et al., 2014).

${ }^{13}$ Due to the sampling of individual midwives in Pakistan, the organizational burden and anonymity concerns prevented us from carrying out the experiment in both contexts.
} 
The Theory of Planned Behavior - An Application to Implementation Research

team working at an institution of higher education in a high income country that collaborates with varying intensity with local partners of low and middle income countries to evaluate development policies or programs (Cameron et al., 2016). ${ }^{14}$ Based on insights from previous studies, we propose that the implementer's local or international background might influence the participants' attitude towards the intervention.

Scholarly work has identified several driving factors explaining this phenomenon. Cilliers et al. (2015) show that the presence of a foreigner versus a local as a thirdparty bystander positively affects the contributions of participants in a dictator game in Sierra Leone and identify two potential channels: Firstly, an increase in contributions to impress the foreigner and, secondly, reduced contributions in areas that were previously exposed to the aid-industry. In the latter locations, they show that participants more frequently believed that the game tested their need for aid, and subsequently contributed less. Findley et al. (2017) find that the support of Ugandans for foreignfunded as compared to national government-funded programs is substantially larger. They stress the importance of general levels of confidence and trust towards the implementing agents for the support of projects. Dietrich and Winters (2015), as well as Winters et al. (2017) show more specifically that respondents link higher quality perceptions to donors rather than to the national government. This relates to the general debate on how aid can be delivered most successfully, and whether foreign funding undermines state legitimacy (e.g., Dietrich et al., 2018). Previous involvement and experiences with the respective agents might play a substantial role in shaping those attitudes and support vis-à-vis implementers' projects. In this vein, Dietrich and Winters (2015) condition their experimental effect on previous political participation and Milner et al. (2016) find that the support for foreign-funded as compared to national government funded programs is substantially larger, if participants are in favor of opposition parties, and had negative experiences with the government in the past 15 Here, the authors, especially, stress the role of corruption and clientelism (e.g., Milner et al. 2016, Findley et al., 2017).16 In contrast, the "home bias"-phenomenon suggests that participants have more trust in locals than in internationals as cultural proximity could increase people's trust (e.g., Fuchs and Gehring, 2017).

To the best of our knowledge, the described strand of the literature is currently limited to state versus non-state actors. However, against the background of the numerous international development cooperation projects and in light of the increasing number of large research projects as outlined above, it is important to understand whether the

\footnotetext{
${ }^{14}$ Cameron et al. (2016) find that in a random sample of development evaluation studies more than 50 percent of first authors were affiliated to an institution in North America or Europe. More specifically in our Indonesian context, seven out of nine RCTs in Indonesia registered with the "American Economic Association: RCT Registry," had an US-based principal investigator and only one out of nine was led by an Indonesian researcher (American Economic Association, 2018).

15 Milner et al. (2016) also assess sub-group effects with regard to gender, education, poverty, media exposure, geographic region, experience with aid, type of donor and political connections, but find mainly insignificant results.

${ }^{16}$ Although not testing it explicitly, Findley et al. (2017) name perceptions on accountability, capacities, and level of control as further potential channels.
} 
The Theory of Planned Behavior - An Application to Implementation Research

origin of the program implementer also matters, irrespective of an affiliation to the state. To this question, we dedicate our framed field experiment.17

\section{Experimental Design}

In the aggregate, our experiment compares whether the salience of international versus local program implementers affects support for the respective project. Stressing certain aspects of a particular situation among otherwise equivalent descriptions can lead to very different perceptions and behavioral reactions (Tversky and Kahneman, 1981; Kahneman, 2003, Johnson and Goldstein, 2003, Hossain and List, 2012; Payne et al., 2013). The result is what is called the framing effect. ${ }^{18}$ Stressing certain aspects invokes different associations and leads to different evaluations by the decision maker. Framing effects have been incorporated into theories on human behavior to explain deviations from rational choices (e.g., prospect theory). Their application to real-world decision-making can have important practical implications. Based upon their own intervention, Bertrand et al. (2006) specifically point out that framing might be a particularly cost-effective way to increase interventions' uptake, which we aim to test here.

We make use of the randomized phase-in design of the SCC intervention in Indonesia. Within the endline survey of the larger RCT project, we performed the experiment with midwives at control facilities that neither have received the SCC nor were in contact with the implementation team. Within this group of midwives, we used a between-subject design and randomly assigned the study participants to two different framing information on the actually conducted SCC intervention: The first framing information stressed the involvement of international actors in the SCC program, while the second made the participation of local counterparts more salient (see Figure D.2 in the Appendix for an overview over the study design). ${ }^{19}$. We use the fact that the SCC evaluation has been implemented jointly by both - international and local - actors and therefore, highlight different attributes of the project. We then investigated the

\footnotetext{
${ }^{17}$ We follow the classification of experiments proposed by Harrison and List (2004).

${ }^{18}$ The framing effect became popular through its essential role in Kahneman and Tversky's prospect theory (Kahneman and Tversky, 1979) in which they describe gambles either by their loss or gain probability. There are three different types of framing approaches that have been described and used in the literature: Most prominently and widely researched is the risky choice framing (risk of losing vs. risk of winning) as introduced by Kahneman and Tversky (1979). Attribute framing makes certain characteristics of a choice or good more salient (ground beef that is 75 percent lean vs. 25 percent fat). Lastly, goal framing where either punishment or reward is emphasized (Behavioral Science Solution, 2018). Since then, framing experiments have been extensively applied in medical sciences both in hypothetical (Wilson et al. . 1987) and real contexts, often related to message framing experiments, e.g., with regard to smoking cessation, HIV screening as well as skin and breast cancer prevention (Kalichman and Coley, 1995, Detweiler et al., 1999, Schneider et al., 2001, Toll et al., 2007).

${ }^{19}$ The framing experiment does not include a control group as development programs are always either conducted exclusively locally or have an international component. We believe that it is very unlikely that the implementer's identity is unknown to program participants, although salience might differ.
} 
The Theory of Planned Behavior - An Application to Implementation Research

participants' respective behavior towards the intervention by assessing the support for the SCC project. Since we randomized participants into different treatment groups, we can make causal inference on how the origin of implementers affects behavioral reactions (i.e., different levels of support for the SCC intervention).

In a short pre-experimental survey, we collected background information, including socio-economic and contextual work characteristics, of each participant 20 In appreciation of participants' survey participation, each respondent received a voucher for a phone credit top-up worth 25,000 IDR (approx. 1.75 US\$). Afterwards, the enumerators offered the respondents to participate in the experiment. ${ }^{21}$ Lastly, we conducted a short post-experimental survey, including questions capturing potential framing mechanisms and additional control variables, like the experience of current financial distress.

The "experimental commodity" was derived from the on-going RCT intervention on the SCC. First, the idea and structure of the SCC was explained to the participants. Afterwards, they were presented with one of the two framings that selectively either stressed the involvement of "local" or "international" actors respectively, in the SCC intervention. ${ }^{22}$ A qualitative investigation was conducted prior to the experiment to ensure that the correct terms were used to describe "local" versus "international" agents.23

Our framing information reads as follows:

"Among other researchers, [INTERNATIONAL/LOCAL] researchers took an active role in introducing the checklist to 17 facilities in Aceh province. The research team received approval from the provincial health office of Aceh. However, no funding was provided by the provincial health office. [LOCAL/INTERNATIONAL] research assistants and [INTERNATIONAL/LOCAL] health professionals with a lot of experience in delivery services were important partners and greatly supported the project."

\footnotetext{
${ }^{20}$ This survey was included in the endline survey of the larger SCC intervention.

${ }^{21}$ All respondents chose to continue the survey and participated in the following framing experiment.

${ }^{22} \mathrm{As}$ it is likely that respondents equate an international actor to a donor, we specifically addressed the relevant actors as researchers and professionals in our framing component.

${ }^{23}$ For this purpose, we talked to health-care providers from different facilities, which were not part of the sampled institutions. In the Acehnese setting "local" is understood as "Acehnese" identity, whereby "Indonesian" would be an external concept. Certainly, it would have been of large interest to examine the difference between local and Indonesian implementers. However, due to power constraints, we decided to focus on this more specific framing without splitting the group and reducing the sample. The distinctness of "Acehnese" and "Indonesian" is also underlined by the fact that a small set of respondents named Indonesia and certain provinces as international countries. To deepen our understanding of the term "international" in the Acehnese context, we asked respondents to name the three countries, they first think of when hearing this term (see Figure D.3 in the Appendix). There is a large consensus among respondents regarding the main countries associated with "international," namely Germany (24 percent), Malaysia (19 percent), USA (13 percent), Australia (8 percent). The high prominence of Germany among the foreign countries named, could first - of course - be attributed to the fact that parts of the implementing researchers, were German. Second, it is likely that Germany is indeed particularly present to the Acehnese people as it was the largest European donor after 2004's Tsunami (BBC, 2005). Moreover, Germany's reconstruction efforts were characterized by a strong focus on health interventions (German Federal Ministry for Economic Cooperation and Development (BMZ), 2005).
} 
The Theory of Planned Behavior - An Application to Implementation Research

In order to be able to draw broader conclusions and to generalize the findings to different types of interventions, we named different actors (e.g., researchers, practitioners). To prevent potential effects through assumptions on political involvement, we specifically address the role of the provincial health office in the information given to the study participants. Further, to counter potential bias through speculations on the financial capabilities of different actors, we stress that funding of the intervention is ensured irrespective of the framing given to the participant. For the detailed experimental protocol see Appendix 4.A.1. We hypothesize that the level of support would significantly differ between the local and the international framing. Following the literature, there are arguments for directive effects on both sides, which leads us to handle the issue as an empirical question.

\section{Experimental data}

In total, the experiment was conducted with 236 female midwives from the SCC intervention's control group. The average study participant was 33 years old (minimum: 21 years, maximum 50 years), had 10 years of work experience (minimum: 0 years; maximum 28 years) and 15 years of education (minimum: 12 years; maximum 17 years) (see Table D.1 in the Appendix). Participants in the experiment were comparable in their characteristics to health workers of the main RCT study (see Appendix Table D.3) ${ }^{24}$ Individual characteristics and further contextual variables are balanced across framings indicating that the randomization was successful (Appendix Table D.1). In our main analysis, we focus on those participants that have not been in prior contact with the SCC as 27.92 percent of the respondents state that they were previously exposed to the SCC ${ }^{25}$ As we cannot infer how much these respondents know about the SCC intervention and how intense the exposure was, excluding them is the more conservative choice. ${ }^{26}$ This reduces our sample to 173 participants ${ }^{27}$ Balance on important covariates is still given in this reduced sample (see Appendix Table D.2). Previous SCC exposure was equally distributed across the framing treatments, ruling out selection concerns and enabling us to interpret the estimates causally.

We proxy SCC support by asking the respondents whether they would contribute

\footnotetext{
${ }^{24}$ Health workers in the treatment group seem to have experienced on average five more months of education (Appendix Table D.3.

${ }^{25}$ Although the respective facilities were not exposed to the SCC, reasons for previous exposure might be a second job at another (treatment) facility (11.11 percent of respondents have a second job) or communication with other health practitioners within the district. Contact to midwives from other facilities is also significantly correlated with prior checklist contact.

${ }^{26}$ As a robustness check, we also report the full sample results including a prior contact binary variable in the regression model in Appendix Table D.12. However, as we assume a large heterogeneity of exposure - health practitioners with a job at another facility might have worked with the SCC, others might have just heard the name of the SCC from colleagues - we prefer the reduced sample for our main results.

${ }^{27}$ Due to two outcome measures that could not be matched to respondents and four respondents that refrained from answering on control questions, the sample is reduced to $\mathrm{n}=165$ in our main specifications.
} 
The Theory of Planned Behavior - An Application to Implementation Research

parts of the money they had received through the voucher for phone credit top-up in appreciation of their survey participation to buy checklist copies, which would then support the implementation of the SCC in other anonymous health facilities within the province ${ }^{28}$ The contribution was made anonymously. After the experiment, all participants received a debriefing. ${ }^{29}$ To create transparency on the use of the collected funds, we publicly made information on total amounts available after the end of the study and informed the participant about this procedure. In addition to this traditional monetary outcome, we also collected measures suggested by other disciplines. Psychologists commonly assess the respondent's behavior through time investments (Wildschut et al. 2014). Actual behavior measured by contributing money may be strongly influenced by general or situational economic living conditions of respondents. In case respondents face strong economic constraints, small or zero contributions might reflect a high neediness rather than lack of support for the intervention. Hence, we asked the participant's willingness to invest additional time to practice checklist use during regular working weeks. Further, in order to counter potential social desirability bias, we asked the participants to estimate the average monetary contribution of colleagues in other health facilities in the province. Those elicitation exercises based on introspection have been shown to reduce potential conformity bias in the experimental literature (Trautmann and van de Kuilen, 2015). We focus on the traditionally employed monetary outcome as due to the costs incurred by the respondent this is likely to be the strongest measure, while the additional outcomes are presented in the Appendix. Summary statistics for all measures employed can be found in Appendix Table D.4 for Indonesia and D.5 for Pakistan.

In the post-experimental survey, we asked several questions on potential mechanisms to explain differential preferences towards implementers. Following Milner et al. (2016), we measured participants' level of trust towards different actors (international/local actors) and towards the previously named countries that they understood by the term "international." We used 4-point Likert scales. In addition, we asked participants whether they have previously participated in interventions by international or local experts or researchers, respectively. In the Acehnese health sector, 10 percent (17.5 percent) of the surveyed providers have previously participated in research projects by international (local) actors. Those interactions date back significantly before our intervention as only 2.5 percent of the respondents faced international research projects

\footnotetext{
${ }^{28}$ If they wanted to contribute, we offered them five options from 5,000 to 25,000 IDR (equivalent to $0.4-1.9 \mathrm{US} \$$ ) due to pragmatic reasons of specific top-up values.

${ }^{29}$ After the debriefing, we offered participants to change their monetary contribution. 39 (16.5 percent) participants made use of this option. Generally, this led to an increase in contributions by on average one category (about 4200 IDR), but the amount is not contingent on the framing applied. The main analysis focuses on the pre-debriefing contribution, as we are interested in the framing effect.
} 
The Theory of Planned Behavior - An Application to Implementation Research

in their facility during the previous two years. ${ }^{30}$

\subsection{Method}

In the first part of our regression analysis we address the role of the TPB determinants for intended behavior with regard to checklist use. Our regression line for intended behavior reads as follows:

$$
y_{i}=\alpha+\beta_{i} \text { TPBdeterminant } i+\beta_{k} \sum_{k} X_{i}+\epsilon_{i}
$$

As throughout the study, we estimate models for Indonesia and Pakistan separately using ordinary least squares (OLS) regressions. Our level of analysis is the individual health worker $i$ (79 respondents for Pakistan and 163 individuals for Indonesia). $y_{i}$ determines our outcome variable, which measures intended behavior employing 6-point

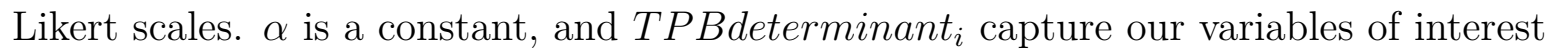
(also using 6-point Likert scales) via our three perception measures for the three TPB pillars: Attitudes, subjective norms, and perceived behavioral control ${ }^{31}$ In adjusted regressions we add $\sum_{k} X_{i}$, which represents our set of $k$ control variables. These include a binary variable indicating the location of the facility (rural versus urban), a variable capturing the district where the provider is located, the level of service provision, which is proxied by a dummy for $24 / 7$ opening hours, and a variable indicating the type of facility ${ }^{32}$ The idea is that those time-invariant facility characteristics might affect the drivers of the TPB. Perceived behavioral control could be affected by staffing and equipment, which is captured by the facility type and geographical remoteness (district dummies and rural/urban distinction) as well as the $24 / 7$ service provision. Remoteness, services and facility type also influence the safety culture, which affects provider's attitudes and the subjective norms of superiors towards the SCC.

Our second part of regressions is the equivalent to the first but changes the outcome variable to birth observations $j$ measuring the actual behavior. Here, $y_{j}$, is a binary variable equalling one, if the checklist was used by the health worker during the delivery. As we cannot link each delivery to the specific health workers' responses, we

\footnotetext{
${ }^{30}$ To investigate additional potential mechanisms, we also collected information on perceived corruption, sufficient funding capabilities, accountability, skills, and control to implement interventions. All this data were collected after the experiment was conducted in order to not affect our main outcome measures. However, this procedure comes with the trade-off of potential justification bias, where individuals would adapt their answers ex-post to justify the previously indicated support. We indeed find that the framing statistically significantly affects some of these variables. Hence, in order to avoid bad control issues, we focus on those variables not significantly affected: Participation in international or local projects, trust in internationals, trust in named foreign countries and trust in locals. We use these later in our regression analysis.

${ }^{31}$ Further, we also estimated regressions with an alternative coding for robustness, where we defined a dummy variable with the value one for the highest category and zero otherwise. Results are robust and available upon request.

${ }^{32}$ Our sample included a wide heterogeneity of facilities from primary to tertiary health providers.
} 
The Theory of Planned Behavior - An Application to Implementation Research

take averages of attitudes, subjective norms and perceived behavioral control per health facility. This would provide us with an intuition of more supportive environments being associated with more or less take-up ${ }^{33}$ The control variables $X_{j}$ stay the same as in regression line 4.1 .

Following the clustered setup of the intervention, in all specifications, we cluster the error terms at the facility level to account for joint correlation within the clusters 34 We employed Likert scales to all perception-based survey questions, which are relatively continuous measures. Hence, we consider them as continuous variables in the estimations, which is the preferred method of analysis proposed in the literature (Pasta, 2009) ${ }^{35}$ As our sample is restricted to our treatment group and includes, thus, a non-random set of individuals, estimations are not derived within the randomization framework and do not allow a causal interpretation. Nonetheless, controlling for several potentially confounding variables, we will receive informative correlations about how behavioral processes are associated with intervention uptake.

The third part of our regression analysis concerns the experimental data. Our analysis of the experiment aims to identify the existence of a systematic difference in the support for our intervention by health practitioners, conditional on whether the local or international implementation was more salient. Our results are based on the following regression equation:

$$
y_{i}=\alpha+\beta_{1} \text { framing }_{i}+\beta_{2} \text { framing }_{i} * c_{i}+\beta_{3} c_{i}+\beta_{m} \sum_{m} C_{i}+v_{i}
$$

In our most parsimonious model, $y_{i}$ is the outcome variable, indicating the support of the SCC by health worker $i . \alpha$ is a constant, and framing $_{i}$ is a binary variable, which equals one if the respondent was exposed to an international, and zero for a local framing. Moreover, heterogeneous effects are assessed by the inclusion of an interaction between the framing and channel $c_{i}$, which is prior participation in international or local projects. In adjusted regressions we add $\sum_{m} C_{i}$, which is our set of control variables. The controls include a variable indicating the respective facility type, where the participant is employed. Research from different facility types indicates very heterogeneous uptake and different attitudes of the respondents towards the tool (Semrau et al., 2017; Kabongo et al., 2017; World Health Organization, 2018). Moreover, we

\footnotetext{
${ }^{33}$ As our analysis, thus, involves different aggregation levels and our measure of intention and actual behavior capture slightly different concepts, we do not estimate a model on the direct link between intentions and behavior.

${ }^{34}$ Due to a limited number of clusters we also present results with wild bootstrapped standard errors following Cameron et al. (2008) for all our baseline models in the Appendix. However, this is only possible for the unadjusted regressions (without controls). When bootstrapping standard errors in models with control variables, we face problems of overfitting. This is the case as our controls consist mainly of dummy or categorical variables, which reduce variation among our relatively small number of observations too strongly to calculate meaningfully adjusted standard errors. Accordingly, we prefer to present regressions without bootstrapped standard errors in our main models.

${ }^{35}$ We also assessed the feasibility of continuous items with a scale from 0 to 100 , but learned that those were harder to comprehend for respondents.
} 
The Theory of Planned Behavior - An Application to Implementation Research

add a binary variable marking whether the respondent experienced financial problems within the past days as this might affect monetary contributions ${ }^{36}$ Further, to control for a potential social desirability bias, we measured social conformity following the social desirability scale developed by Kemper et al. (2014). This measure was adopted to the Acehnese context and we transformed its five items into a composite index ${ }^{37}$ We control also for the subjective perception regarding the amount of paperwork during deliveries, which was motivated by an often-experienced perception during implementation that the new tool adds to the already existing paperwork. Finally, $v_{i}$ describes the residual. Errors are clustered at the facility level to take into account similarities within teams. We are, thus, mainly interested in the effect sizes of $\beta_{1}$ and $\beta_{2}{ }^{38}$

\subsection{Results}

\section{Main results: TPB determinants and SCC support}

For all three TPB determinants, attitudes, subjective norms, and perceived behavioral control, in both study sites, we find that coefficients point towards a consistently similar direction. Tables 4.1 and 4.2 display the regression results of the intended and actual SCC uptake for the data from Pakistan and Indonesia. While the first row always presents the unadjusted coefficients, the second displays results adjusted for control variables as described in Section 4.3. Results show that respondents who express a strongly positive attitude towards the SCC are also more likely to intend to use the new tool even if it is not freely provided to them anymore (columns (1a) to (2b)). In Pakistan and Indonesia the coefficients are positive and statistically significant (ranging from the 1-percent to 5-percent level).

\footnotetext{
${ }^{36}$ Previous research on the SCC has shown differential effects of the checklist across different healthcare facility settings. Applicability to the respective work environment is likely to be influenced by factors like team size, resource access, or delivery load. Related research has similarly controlled for a constructed wealth index (e.g., Cilliers et al. 2015).

${ }^{37}$ We adapted the social desirability measures to the respective context in cooperation with Indonesian counterparts. For instance, one of the items reads "I have occasionally thrown litter away in the countryside or on to the road." As environmental concerns are less salient in the Acehnese context than religious concerns, we changed the item to "When I had the chance to donate for religious purposes, I always contributed a lot." The full set of questions we used for the construction of the social desirability index are displayed in Appendix 4.A.1.

${ }^{38}$ Estimates using ordered probit regressions are shown for robustness in the Appendix. For the ease of interpretation, we prefer to present OLS results in the main part.
} 
The Theory of Planned Behavior - An Application to Implementation Research

Table 4.1 Theory of Planned Behavior - Intended SCC uptake

\begin{tabular}{|c|c|c|c|c|}
\hline & \multicolumn{4}{|c|}{$\begin{array}{c}\text { Intended Behavior } \\
\text { Would use SCC even if copies are not provided } \\
1 \text { "disagree strongly" }-6 \text { "agree strongly" } \\
\text { Pakistan }\end{array}$} \\
\hline & (1a) & $(1 b)$ & $(2 \mathrm{a})$ & $(2 \mathrm{~b})$ \\
\hline \multicolumn{5}{|l|}{ Attitudes: } \\
\hline p-value & $\begin{array}{c}0.984^{* * *} \\
(0.000)\end{array}$ & $\begin{array}{c}0.818^{* * *} \\
(0.000)\end{array}$ & $\begin{array}{c}0.454^{* * *} \\
(0.004)\end{array}$ & $\begin{array}{c}0.309^{* *} \\
(0.012)\end{array}$ \\
\hline Adjusted $R^{2}$ & 0.187 & 0.254 & 0.114 & 0.272 \\
\hline $\mathrm{N}$ & 79 & 79 & 163 & 163 \\
\hline \multicolumn{5}{|l|}{ Subjective Norms: } \\
\hline p-value & $\begin{array}{c}0.143 \\
(0.115)\end{array}$ & $\begin{array}{c}0.164^{*} \\
(0.060)\end{array}$ & $\begin{array}{c}0.536^{* * *} \\
(0.007)\end{array}$ & $\begin{array}{c}0.316^{* * *} \\
(0.001)\end{array}$ \\
\hline Adjusted $R^{2}$ & 0.008 & 0.304 & 0.132 & 0.261 \\
\hline $\mathrm{N}$ & 58 & 58 & 163 & 163 \\
\hline \multicolumn{5}{|c|}{$\begin{array}{l}\text { Perceived Behavioral Control: } \\
\text { Ease of SCC in work environment: } 1 \text { "very difficult" }-6 \text { "very easy" }\end{array}$} \\
\hline p-value & $\begin{array}{c}0.439 * * * \\
(0.003)\end{array}$ & $\begin{array}{c}0.366^{* *} \\
(0.029)\end{array}$ & $\begin{array}{c}0.261^{*} \\
(0.090)\end{array}$ & $\begin{array}{c}0.023 \\
(0.863)\end{array}$ \\
\hline Adjusted $R^{2}$ & 0.128 & 0.211 & 0.048 & 0.222 \\
\hline $\mathrm{N}$ & 78 & 78 & 163 & 163 \\
\hline Control variables & No & Yes & No & Yes \\
\hline Mean of dep. var. & 4.628 & 4.628 & 4.847 & 4.847 \\
\hline Median of dep. var. & 5 & 5 & 5 & 5 \\
\hline SD of dep. var. & 1.452 & 1.452 & 0.634 & 0.634 \\
\hline
\end{tabular}

Note: All regressions are based upon the treated providers. Adjusted regressions (b) additionally control for a variable indicating the facility type, a binary variable indicating rural/urban location, a variable indicating the district and a binary variable indicating whether the facility is open $24 / 7$. Standard errors (SE) are clustered at the facility level. Asterisks indicate p-values according to: ${ }^{*} \mathrm{p}<0.1,{ }^{* *} \mathrm{p}<0.05,{ }^{* * *} \mathrm{p}<0.01$. 
The Theory of Planned Behavior - An Application to Implementation Research

Table 4.2 Theory of Planned Behavior - Actual SCC uptake

Was SCC actively used or looked at during delivery?

$$
\text { Pakistan Indonesia }
$$

(1a) (1b) (2a) (2b)

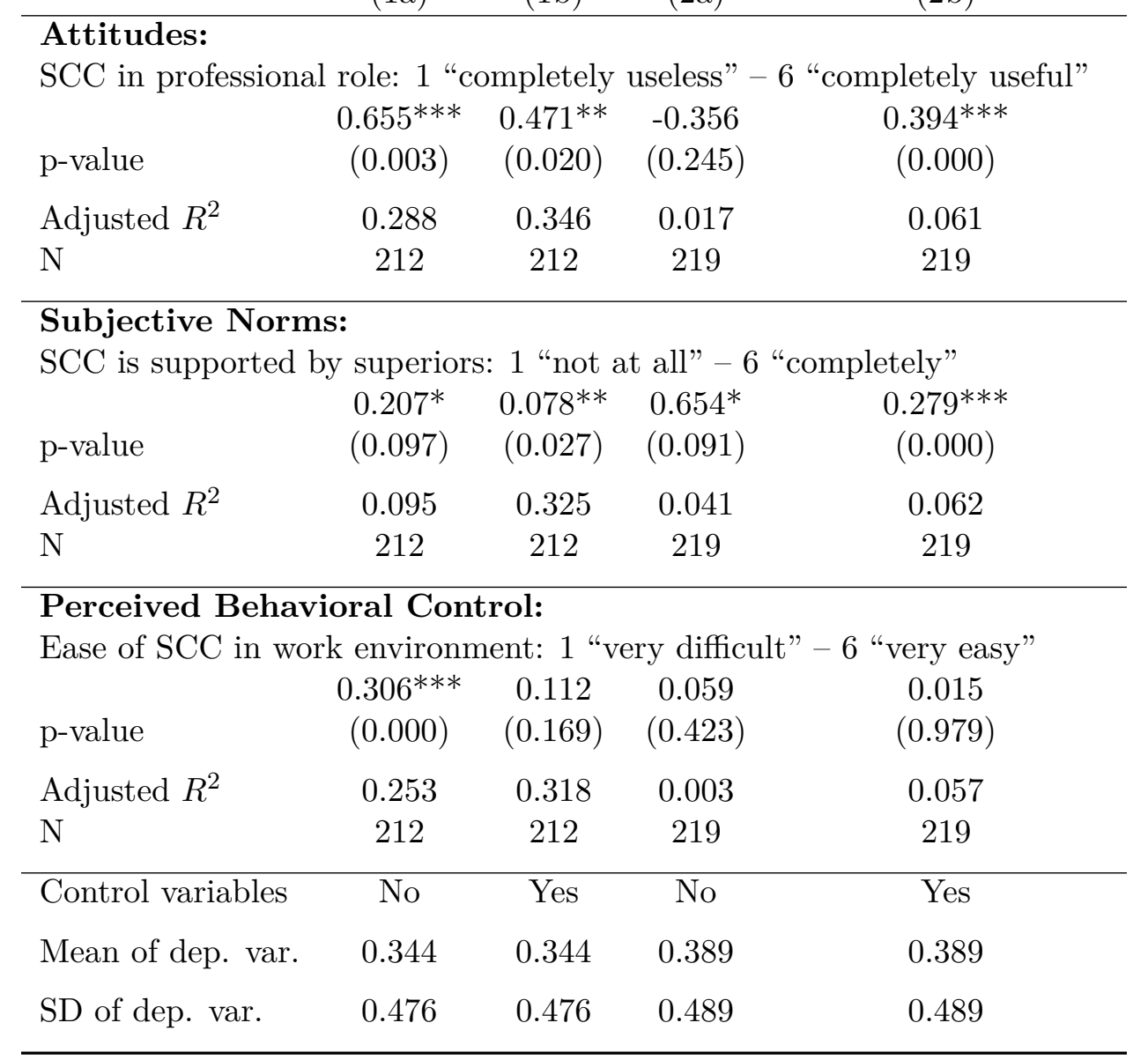

Note: All regressions are based upon the treated providers. Adjusted regressions (b) additionally control for a variable indicating the facility type, a binary variable indicating rural/urban location, a variable indicating the district and a binary variable indicating whether the facility is open $24 / 7$. Standard errors (SE) are clustered at the facility level. Asterisks indicate p-values according to: ${ }^{*} \mathrm{p}<0.1,{ }^{* *} \mathrm{p}<0.05,{ }^{* * *} \mathrm{p}<0.01$.

This is also supported by the actual SCC use (in Table 4.2 columns (3a) to (4b)). The stronger the positive stance towards the checklist, the more often health staff actively uses the SCC during the delivery process. If the SCC is perceived to be more useful (attitude), its actual use among Indonesian health workers increases by 39.4 percentage points and among Pakistani practitioners by 47.1 percentage points. Further, we find consistently positive coefficients in both countries with respect to the support of superiors for the new tool (social norms). While it seems to play an 
The Theory of Planned Behavior - An Application to Implementation Research

important role for intended and actual SCC uptake in Indonesia, it is less important for intended behavior as compared to the actual SCC use in the Pakistani setting. This can be explained by different samples across our outcome measures. While the actual behavioral outcome was mainly collected for health practitioners working in facilities, the sample measuring the intended SCC uptake is dominated by individual health workers (like community midwives). Hence, for them the opinion of superiors is less of a concern but rather the perceived usability (perceived behavioral control). In this regard, we see that the ease of use is a statistically significant predictor of intended SCC use in Pakistan (at the 5 percent level in the adjusted regression), while it is positive but not statistically significant in the Indonesian context or for actual SCC uptake in both countries ${ }^{39}$ These results - though not allowing the establishment of a causal pathway - give a consistent indication: Influencing the TPB determinants into the respective positive direction, is associated with increased intended and actual uptake of the SCC. The regressions without controls in the (a)-columns indicate that the TPB determinants capture 5 to 13 percent of the variation in intentions among Indonesian respondents, and 0.3 to 4 percent of the variation in actual behavior (measured by the adjusted R-squareds between 0.048 and 0.132). Adjusted R-Squareds for the Pakistani case are exceeding those from Indonesia and the TPB determinants explain 0.8 to 19 percent of the variation in intentions. The explanatory power for actual behavior lies between 10 and 29 percent. Hence, the three TPB determinants are important predictors for intended and actual behavioral outcomes, here the use of the SCC.

Differences in the adjusted R-Squareds across TPB determinants are well in line with qualitative evidence. Indonesian coaches, who assisted health personnel in using the checklist, were seldomly asked for help regarding the content of the SCC, which corresponds to the ease of use of this intervention. In contrast, the assessment of the supervisor seems to play an important role in the hierarchically structured Indonesian society. This is also borne out by inter-facility staff meetings and midwives' correspondence with coaches in Indonesia, stressing the salience of supervisors and colleagues reminding each other to use the checklist regularly. In the Pakistani case, we see the strongest explanatory power for the determinants attitudes and control and far behind for norms (12 to 19 percentage points difference). In line with explanations from above, the effect is likely to be driven by the sample of community midwives, who work rather self-employed and do not depend on superiors' norms, accordingly.

Both sets of results imply that in both countries, specifically, attitudes are crucial in shaping intentions and actual behavior. As indicated in the previous literature review, perceptions about the implementer can be strong predictors in shaping intentions and behavior. This is assessed in the subsequent section.

\footnotetext{
${ }^{39}$ As outlined above, we use wild cluster bootstrapped standard errors as robustness tests in samples with a small number of clusters (9 in Pakistan and 15 in Indonesia). Results are displayed in Appendix Table D.6 showing that results are by and large robust to this standard error adjustment. When we generate a dummy variable as an outcome, equaling one for the highest category only (thus, if respondents "fully agree" to "Would try to use SCC even if copies are not provided") results are qualitatively unchanged (see Appendix Table D.7).
} 
The Theory of Planned Behavior - An Application to Implementation Research

\section{Main results: framing experiment}

Table 4.3 displays the main results of the framing experiment conducted in Indonesia. We only include our main outcome measure (monetary investment) here, while results of the alternative outcomes are presented in the Appendix (Table D.11) ${ }^{40}$ The first column presents the unadjusted results, whereas the second column gives the results adjusted for additional control variables. ${ }^{41}$ We limit our sample to those respondents who were not exposed to the SCC prior to this experiment. Full sample regression results controlling for prior contact, are shown in the Appendix (Table D.12) and are comparable to the findings presented in the main part. ${ }^{42}$ As a conservative robustness check, we also present random inference based p-values 43 In unadjusted regressions, the international framing has a positive but at conventional levels insignificant effect on financial contributions of respondents. Once adjusting for control variables, this coefficient turns significant at the $5 \%$ level. Respondents facing an international framing contribute on average more money in support of the SCC project than their counterparts being confronted with the local framing. In the adjusted specification, their contribution is 1,284 IDR higher 44

\footnotetext{
${ }^{40}$ Similarly, we present estimates using ordered probit regressions in the Appendix Table D.15. Results are qualitatively unchanged to OLS regressions.

${ }^{41}$ In line with the randomized setup of the study, results are robust to the inclusion of further covariates, which increases the precision of estimates. The full specification including all control variables is presented in the Appendix Table D.9

${ }^{42}$ As a further robustness check we estimate a regression, which controls for an interaction of the framing with the indicator for past contact. Individuals with prior contact to the checklist might not have had contact with the research team and could, hence, still be receptive to the framing. First, including this group is more conservative as the framing should have a lower effect on the persons that are acquainted to the SCC and induce, thus, a downward bias. Second, individuals with prior contact to the checklist might react heterogeneously due to more comprehensive information. Table D.13 depicts the corresponding results. While the framing indicator decreases slightly in size, but stays significant in the adjusted regressions, there is no significantly different treatment effect for those respondents with past contact.

${ }^{43}$ Randomization inference takes the randomization explicitly into account and follows R.A. Fisher's idea of statistical inference via permutation tests of treatment allocation (Young, 2017). The idea is to assume uncertainty about the treatment allocation and compare the actual treatment allocation to possible alternative allocations.

${ }^{44}$ One's willingness to support an intervention might also be strongly determined by the beliefs about others' contribution. However, reporting one's perception about others might be subject to conformity bias, especially, in the Indonesian society, where a large focus is put on keeping one's face. Elicitation exercises based on introspection have been shown to reduce potential conformity bias in the experimental literature (Trautmann and van de Kuilen, 2015). Moreover, we use the outcome variable elicitation as a control variable in a further robustness test (see Appendix Table D.10). As expected, elicitation shows to be highly significant and positive, while the framing effect holds.
} 
The Theory of Planned Behavior - An Application to Implementation Research

Table 4.3 Framing Experiment - Main Results

\begin{tabular}{lcc}
\hline \multicolumn{3}{l}{ Financial Contribution in support of SCC project (in IDR) } \\
& (a) & (b) \\
\hline Framing: 1 = "international" & 557.6236 & $1,283.7717^{* *}$ \\
p-value & $(0.396)$ & $(0.021)$ \\
RI p-value & $(0.450)$ & $(0.057)$ \\
N & 165 & 165 \\
Control variables & No & Yes \\
Mean of dep. var. & $4,757.576$ & $4,757.576$ \\
SD of dep. var. & $4,711.366$ & $4,711.366$ \\
\hline
\end{tabular}

Note: All specifications are based upon the sample limited to those respondents without prior SCC contact. Specifications (b) include a variable indicating the facility type, a binary variable indicating if the respondent had financial problems, a composite index of social desirability variables and a variable indicating the subjective perception of the amount of paperwork. The same regression with wild cluster bootstrapped SE can be found in Appendix Table D.8. for which significance levels hold. RI p-values are computed with a permutation test based on Hess (2017). Asterisks indicate p-values based on standard errors clustered at the facility level: ${ }^{*} \mathrm{p}<0.1,{ }^{* *} \mathrm{p}<0.05,{ }^{* * *} \mathrm{p}<0.01$.

These results are supported by the alternative outcome measures presented in Appendix Table D.11. Our alternative outcome measures are first, whether respondents would recommend the SCC to fellow colleagues, second, whether they would be willing to invest additional time for the SCC project, third, how high they estimate the average contribution by others and fourth an index of all four outcome measures, using principal component analysis (PCA). Estimates in Table D.11 show robustly positive coefficients, when controls are included and reach statistical significance for recommending the SCC to others and for the PCA-index. Here, however, the financial contribution is the variable that explains the major part of the variation in the index. Hence, our results suggest that the intervention is increasingly supported by the respondents, if it is perceived as an internationally-led endeavor. The representativeness of the experiment is supported by the balance of important individual and contextual characteristics between the experimental sample and the larger sample of the SCC intervention.

\section{Channels: previous exposure}

In order to understand in more detail why respondents show stronger support towards projects implemented by international actors as compared to local implementers, we investigate a mechanism that could influence the attitude of respondents. Previous exposure is one prominent factor determining attitudes. Hence, it might play a role 
The Theory of Planned Behavior - An Application to Implementation Research

whether respondents have been in contact with locally or internationally-led research projects in the past. Their respective experiences are likely to influence their present attitudes and reactions to the intervention.

Descriptive correlations (see Appendix Table D.14) indicate that first-hand experiences - both with local and international research programs - are associated with positive perceptions towards the corresponding implementer - though no claims regarding the causal direction can be made here. Hence, it seems that those positive experiences affect not only the respective implementer but also the support for other actors. 45 It is, therefore, of particular interest to examine the interaction of the international or local framing with previous exposure to the respective implementing agent.

Figure 4.4 displays the point estimates and confidence intervals for the interaction of our experimental framing with the binary variables indicating if respondents already participated in international or local research projects. In order to facilitate interpretation the different options were coded as categories and should be interpreted as the difference from the base category "No Experience with International Experts - No Experience with Local Experts - No International Framing." As before, the framing indicator equals one for the international framing treatment and zero for the local framing treatment. For the experience indicators, one corresponds to experience with the respective actor and zero to no experience.

While the randomization ensured that the framing could be considered as exogenous, project participation is potentially endogenous regarding other traits of the surveyed respondent. However, as recent research by Bun and Harrison (2018) and Nizalova and Murtazashvili (2016) indicates, the interaction of an exogenous and an endogenous variable can be considered as exogenous, when controlling for the endogenous variable. Exogeneity rests on the assumption that the treatment is not correlated with neither previous project participation nor omitted variables, which is arguably the case due to the experimental random assignment ${ }^{46}$ Moreover, balancing tests provided in Tables D.1 and D.2 underscore that previous participation is balanced across both framing treatments.

Green bars in Figure 4.4 indicate the coefficients of regressions without covariates and orange bars the adjusted point estimates. Regarding confidence intervals, thick bars refer to the $10 \%$ and thin bars to the $5 \%$ interval. As we are interested in the framing effect, the results are ordered to compare respondents with similar previous experience (e.g., participation in international/local projects) across framings.

\footnotetext{
${ }^{45}$ The results in Table D.14 also hold if including as control variable local or international participation, respectively, and if standard errors are bootstrapped. The majority of respondents, who participated in international projects also participated in local projects, but not vice versa.

${ }^{46}$ Nonetheless, one needs to be aware that, especially, with a limited sample size omitted variables might not be homogenously distributed and, hence, it is not inherently clear, which other factors are correlated with our interaction variable of interest.
} 
The Theory of Planned Behavior - An Application to Implementation Research

Figure 4.4 Framing Experiment - Previous Experience

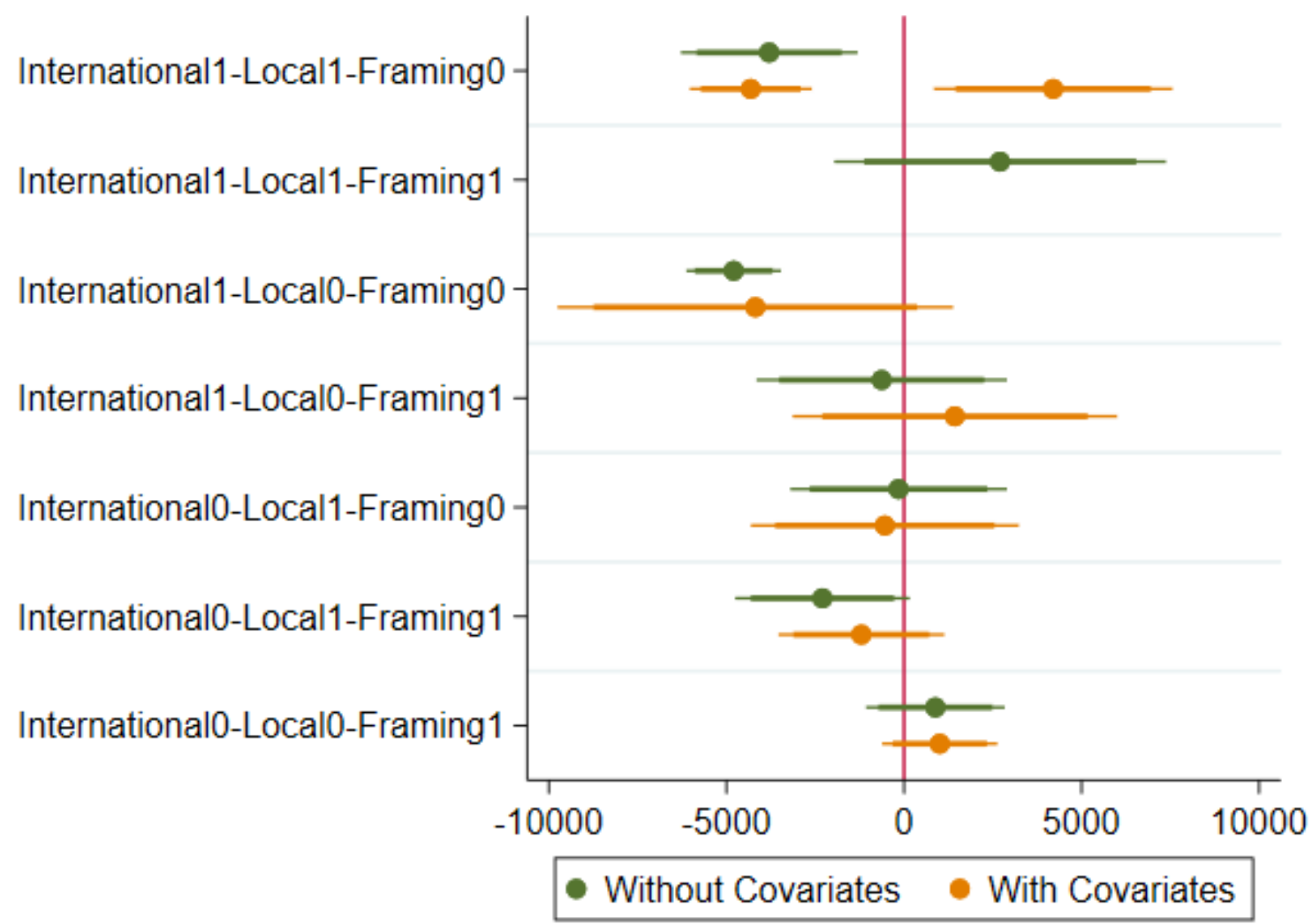

Note: While "Int1" refers to previous experience with international projects, "Loc1" refers to projects with local implementers. "Fra1" indicates the international framing as described above. Covariates include a variable indicating the facility type, a binary variable indicating if the respondent had financial problems, a composite index of social desirability variables and a variable indicating the subjective perception of the amount of paperwork. The comparison group had no prior experience with either actor and faced a local framing. Errors are clustered at the facility level. The thick bars refer to the $10 \%$ and the thin bars to the $5 \%$ confidence interval. The corresponding point estimates are depicted in Table D.17 
The Theory of Planned Behavior - An Application to Implementation Research

The Figure indicates a distinct pattern for midwives, who have been exposed both to an international and local research project in the past. Our results indicate a lower contribution of 6,500-8,500 IDR (e.g., 0.45-0.65 US\$) if those midwives face the local framing (p-value: 0.023 without control variables; p-value: 0.000 with control variables) ${ }^{47}$ In contrast, this implies that the attitude towards the intervention is significantly more positive if respondents knowing both international and local researchers are framed internationally. For respondents with international and local experience we find the only significant group-wise difference between individuals with comparable experience.

However, if respondents who face the local framing were only exposed to international and not to local projects, they do contribute less than the baseline group if we do not condition on covariates (p-value: 0.0113 ). The other categories do neither indicate significant group-wise differences nor deviations from the baseline category. Thus, the results from Figure 4.4 suggest that the positive effects of the international framing are driven by previous experience with the respective implementer. The reduced willingness to contribute to local projects is most pronounced if respondents have participated both in local and international projects.

The positive attitudes towards international projects might, however, depend on the local context as every country will have its specifics in experiences with and attitudes towards the local and international community. The Acehnese context is a very interesting case to study as to its large exposure to various international as well as local actors in the aftermath of the Tsunami 2004, which caused more than 130,000 deaths in the country. Due to previous experiences with both local and international implementers, the assessment of attitudes towards the different implementers is facilitated. However, this context of ultimate human emergency, might have induced a more positive attitude towards the international assistance and could make the interpretation specific to the context 48

Qualitative data based on 66 surveys with health practitioners suggest that positive attitudes towards internationals are mostly linked to perceptions of better knowledge and more structured implementation approaches (based on the open question: "Please describe your experience working with international teams. What did you find surprising?"). This is in line with the positive and significant correlation of the international framing with positive perceptions of international control capabilities and skills of local implementers (Appendix Table D.16) and corresponds to higher trust levels after

\footnotetext{
${ }^{47}$ Although this amount seems small, it corresponds to one meal or half an hour of work of a midwife in the local context.

${ }^{48}$ Despite the individual tragedies, parts of the population perceived the natural disaster as a chance to restart, as the successful reconstruction efforts coincided with the cessation of the Aceh insurgency after almost 30 years of combat. Moreover, Aceh might be specific due to its strong Muslim heritage and introduction of Islamic law in 2006.
} 
The Theory of Planned Behavior - An Application to Implementation Research

previous project participation (see Appendix Table D.14). ${ }^{49}$

Taken together, those results, first, suggest to consider the previous experience of the targeted population, when aiming to achieve high project uptake and accordingly frame development policies. Second, they call for caution when thinking about scalability of projects by the local government if piloted by internationals. Third, they underline the need to implement development policies prudently. Both actions from internationals and locals might affect subsequent take-up and success of other projects.

\subsection{Discussion and Conclusion}

Evidence from behavioral economics supports the importance of non-monetary incentives, trust, or peer effects to explain human behavior. These insights are also of utmost importance to the design of interventions in development economics. This chapter makes use of the Theory of Planned Behavior (TPB) - a well-established theory originating from social psychology. The framework offers a systematic approach to explain and influence supportive human behavior by considering three determinants: A positive attitude towards the behavior or intervention, supporting subjective norms, and a high degree of perceived behavioral control. We provide evidence of the positive association of these mechanisms with the uptake of a program by studying participants in two different cultural contexts. Using the settings of two randomized controlled trials in Pakistan and Indonesia, we show that a more positive attitude towards the new tool (here the Safe Childbirth Checklist (SCC)), more salient subjective norms in favor of the intervention, and greater perceived behavioral control to actively use and implement the checklist were associated with increased intended and actual use of the checklist. Applying the TPB in two diverse study contexts strengthens the claim of generalizability of the results. Previous studies on the TPB also support its broad applicability to explain and influence human behavior. However, it is important to note that we left the random setting for the TPB analysis and, hence, our study does not allow us to infer causal effects of the TPB on intended and actual behavioral reactions.

Recent evidence shows the importance of implementers' characteristics in shaping behavior towards an intervention and it is likely that this affects the TPB determinant attitude towards the behavior. Hence, we further investigate how the salience of the implementer's background, in particular, whether a project is led by an international or local agent, influences the participants' support for the project. The implementer's background is particularly interesting with regard to increasing experimental research in low and middle income countries, which is often a collaboration between international and local researchers and practitioners. The results of the framed field experiment in

\footnotetext{
${ }^{49}$ We asked midwives if they would attribute certain characteristics rather to local or international researchers (e.g., skills, corruption, financial capabilities) in order to carve out how those channels might affect support for the intervention. Those questions were asked intentionally after collecting the outcomes in order to not confound the results. However, this comes with the risk of justification bias, indicated by the significant framing effects in Table D.16. Hence, we did not use those channels for further analysis. Yet, they might be still informative in terms of general attribute ascription.
} 
The Theory of Planned Behavior - An Application to Implementation Research

Indonesia indicate that respondents are more supportive towards interventions (measured through monetary support) implemented by international actors as compared to solely locally led projects. This finding is in line with previous research on behavioral reactions towards international and multilateral donor agencies (e.g., Milner et al., 2016; Winters et al., 2017). Even though research projects might be characterized by different conditions than practical development cooperation, our results could be important for potential replication or scaling of interventions by local actors that were previously implemented by international agents. Extra effort might be needed to generate a positive, supportive behavior towards the intervention if solely implemented by local agents (or probably vice-versa in countries with higher trust in local than international implementers). Generally, trust towards both groups is high in the Indonesian case. Interestingly, those respondents that have already been exposed to previous internationally-led research interventions take a more positive stance towards future international projects. This relationship cannot be established for those who already participated in local research projects. Overall, the results suggest that previous experience with the respective agents influences the attitude and support for future interventions. This underscores the importance of responsible conduction of interventions.

The chapter also stresses the effect of the salience of project implementers to influence support and contribution towards an intervention in case trust levels towards the implementer are high. However, experiences with local and international actors might differ across contexts. For this reason, our results can be considered as one of the first steps of evaluating the TPB and, more specifically, attitudes towards implementers, experimentally. This way, we provide evidence in favor of an active consideration of the TPB determinants in the design and implementation of interventions to increase uptake, cooperative behavior, and general support by the targeted population. Certainly, researchers and practitioners will already have intuitively taken determinants of the TPB into account when designing their intervention. In our study, however, we argue for a systematic application of the TPB to increase interventions' success. A qualitative investigation prior to the project implementation and close cooperation with people knowing the local context to identify behavioral, normative, and control beliefs (that underlie the TPB determinants) within the study sample is recommended (Protogerou et al., 2012). Following the logic of the TPB, changing the respective beliefs ("attitudes") in the appropriate direction will increase supportive behavior towards the intervention (Hobbis and Sutton, 2005). What is more, considering above "subjective norms" and "perceived behavioral control," further contextual and habitual factors in the framework of related theories, can help to get a more elaborate understanding what determines successful uptake of interventions. Further research needs to contribute to a clearer understanding by randomly altering these determinants or replicating results in different settings. This way, important knowledge can be gained to improve not only research interventions, but also practical development cooperation in more general terms. 
The Theory of Planned Behavior - An Application to Implementation Research

\section{A Appendix}

\section{A.1 Experimental Protocol}

\section{General Remarks 50}

If respondent asks you something, kindly answer by mentioning that you are only involved as an enumerator in the project and that you do not have any information on the Safe Childbirth Checklist. Furthermore, please connect the respondent with the contact number, which has been stated before. Of course if there are misunderstandings, you should repeat the provided information. However, please do not explain the information in different words.

Part A "Now, we would like to present you a new tool and would like to learn about your opinion towards it." [Before the start of the experiment (after the completed survey); give the 25,000 IDR voucher to the respondent] "This is in appreciation of your time. Thank you very much. Subsequently, we will provide you with some information on a new tool for health-care in Aceh province. After this, you can decide whether you want to take the money for yourself or if you want to contribute some for the implementation of this tool."

Part B [Enumerator: Please, read this introduction out aloud and clear.] "During complex events, like performing a surgery or a delivery, people can be forgetful or might be distracted by other emergencies or duties. This can potentially have terrible consequences, in the worst case losing the patient. Research proofs that checklists can save lives and prevent these mistakes. Like a surgeon is responsible for patients' lives in the operation theater, the delivery team can have great impact on the safety of mothers and babies. We would like to present you a new tool, which was developed especially for your everyday work: The Safe Childbirth Checklist. It comprises 30 easy to use items. The checklist begins with the admission of the patient and ends with the discharge of mother and baby from the hospital. In each delivery, the doctor or midwife fills in one checklist for every patient. You will fill in the checklist step by step and the checklist will remind you to perform the important steps during delivery. If you would like to know more about the checklist, here it is." [Enumerator: Please hand a checklist copy over to the doctor or midwife.] "For example, the checklist reminds you to perform easy things, which are nevertheless very important like hand washing." [Enumerator: Show item "Confirm supplies are available to clean hands and wear gloves for each vaginal exam." on checklist] "The checklist also reminds you to share important information with patients, including danger signs." [Enumerator: Show item "Danger Signs" on checklist to the midwife or doctor] "All these steps are already part of the study curriculum. Hence, every checklist item is easy to understand. Generally, most of the health workers already practice these important steps in the delivery process.

\footnotetext{
${ }^{50}$ The Indonesian version of the experimental protocol is available upon request.
} 
The Theory of Planned Behavior - An Application to Implementation Research

The checklist just has the purpose to remind you of all the important steps during the delivery process. Especially, when health practitioners are under a lot of pressure, e.g., during night shifts or if complications arise, it can be very helpful. For instance, a research study has proven that during surgeries simple checklists can help to reduce death rates even by almost half."

Part C "Among other researchers, [INTERNATIONAL/LOCAL] researchers took an active role in introducing the checklist to 17 facilities in Aceh province. The research team received approval from the provincial health office of Aceh. However, no funding was provided by the provincial health office. [LOCAL/INTERNATIONAL] research assistants and [INTERNATIONAL/LOCAL] health professionals with a lot of experience in delivery services were important partners and greatly supported the project."

Part D "I will now read to you information about the funding of the Safe Childbirth study conducted by the [INTERNATIONAL/LOCAL] researchers. The following is a page of paper containing information on the checklist." [Enumerator: Please hand over the SCC leaflet to the participant]

Figure D.1 SCC Leaflet

\section{Page 1}

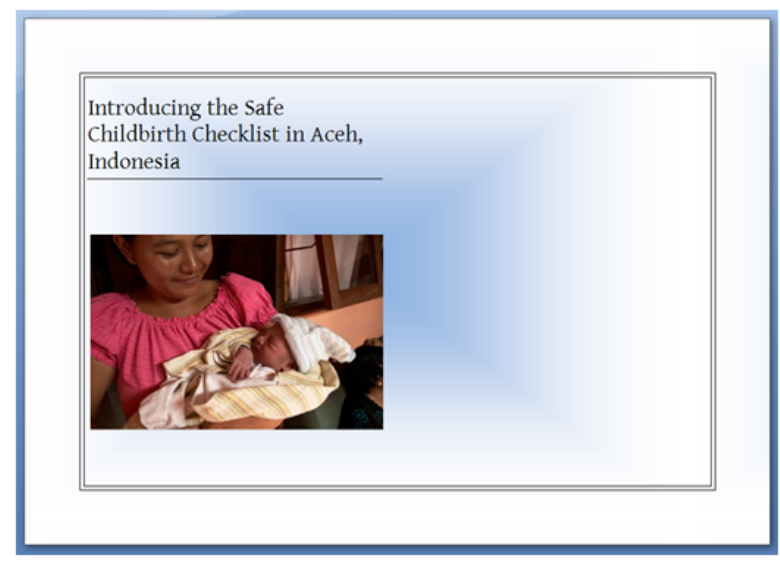

Page 2

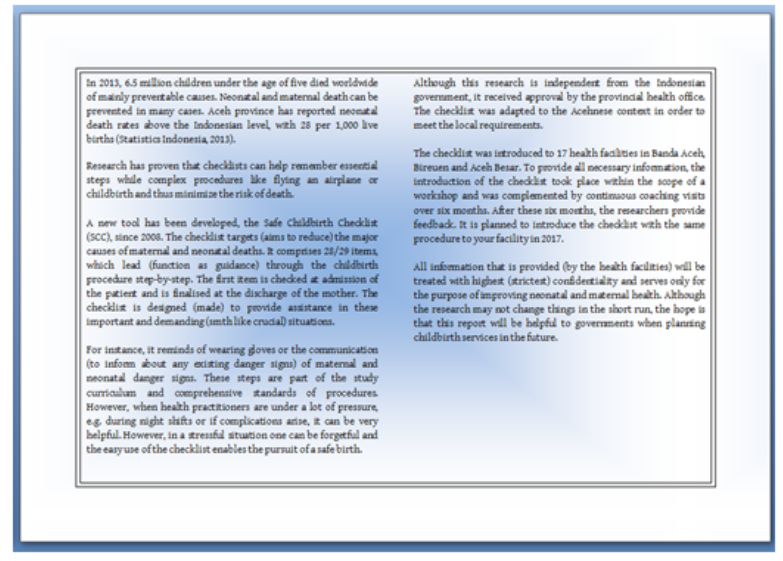

Source: Authors' own depiction.

"The funds for the study have been used to implement the Safe Childbirth Checklist in 17 health facilities in Aceh province during October 2016. Funds are still available to introduce the checklist to 16 further facilities. The budget is enough to provide the 17 health facilities over six months with checklist copies. Therefore, every delivery during these six months can be conducted with the checklist. After this survey ends, the first six months of the checklist implementation are also over. There will be no 
The Theory of Planned Behavior - An Application to Implementation Research

funds remaining to provide additional checklists to those 17 health facilities, where the checklist was already introduced before."

Part E "The researchers are collecting funds to be able to provide checklist copies at those health facilities. Are you willing to support the activity? Remember that the money collected will exclusively be used to provide checklist copies to the health facilities. The total amount of money that was contributed by all donors together will be made transparent. After finalizing the data collection, the amount of money collected will be published openly in every participating facility of this research. If you would like to support the activity, please decide on the amount of money you would like to contribute and note it down on the voucher. You can choose to not contribute at all, or you can give 5,000; 10,000; 15,000; 20,000 or 25,000 IDR. Every contribution can help to conduct more deliveries with a Safe Childbirth Checklist. When you are done, please put the voucher in the envelope and seal it. If you do not wish to contribute anything, please put the number 0 on the voucher. In the end, only the aggregate amount of contributions from all participating facilities will be announced. Your individual contribution will be treated confidentially."

Part F [Enumerator: Read this introduction out aloud to the participant] "During the following task you have to estimate the most chosen answer, which neither refers to the total amount nor the average. We have asked also other health practitioners / workers in the district how much is their willingness to contribute to the provision of checklist copies. Which amount do you think was contributed to the checklist copies by your colleagues per person at other facilities? This estimation is not at all related to your personal opinion. Instead, we would like you to estimate which amount of contribution that was given by most of the other health practitioners per person. For this question, if you assessed the most chosen amount per person correctly, you will be given an additional 10,000 IDR. If you estimated the right amount, the 10.000 IDR will be topped up to your phone credit together with the voucher within the next few days. The other health practitioners also had to choose to contribute $0 ; 5,000 ; 10,000 ; 15,000$; 20,000 or 25,000 IDR. Which category do you think was the most frequently chosen by the health workers? / Which amount do you think most other health workers chose to contribute per person?"

Part G "Your facility is one of the other 16 facilities, where the research team would like to implement the Safe Childbirth Checklist. Experience shows that checklist use needs to be practiced with coaches regularly in order to make deliveries safer. How committed are you in investing your time to practice the use of the checklist in every week?"

Debriefing "Thank you very much for your participation. We asked you previously several questions. The aim is to find out what is your opinion about [local/international] 
The Theory of Planned Behavior - An Application to Implementation Research

researchers and how this opinion influences your motivation to use the Safe Childbirth Checklist. The checklist was previously pilot tested in other countries around the world. This way the most crucial practices during child delivery were identified. The research collaboration was led by the Harvard School of Public Health and the World Health Organization. Local researchers from Syiah Kuala University worked together with international researchers to adapt the checklist to the local context. Both parties hope that the Safe Childbirth Checklist can be implemented sustainably to serve as a tool for safe deliveries in Aceh province. If these information change your attitude towards contributing to the checklist copies in any way, you are free to change your indicated contribution." [Enumerator: If the respondent decides to change his/her contribution, please hand the envelope back.]

Social desirability index We modify social desirability questions developed by Kemper et al. (2014) to reflect social desirability norms in the Acehnese context. The social desirability index was constructed by adding up the top categories (5 and 6) indicated in the subsequent questions.

\section{Items}

\section{Answers}

1. "In an argument, I always remain objective and not become emotional."

2. "Even if I am sad, I always smile when talking to others."

3. "When talking to someone older, I always listen carefully to what $\mathrm{s} / \mathrm{he}$ says."

4. "When I had the chance to donate for religious purposes, I always contributed a lot."

5. "Sometimes I only help people if I hope to get something in return."

1. Disagree strongly

2. Disagree

3. Rather disagree

4. Rather agree

5. Agree

6. Agree strongly

7. Not applicable 
The Theory of Planned Behavior - An Application to Implementation Research

\section{A.2 Figures}

Figure D.2 Study Design Flow Chart

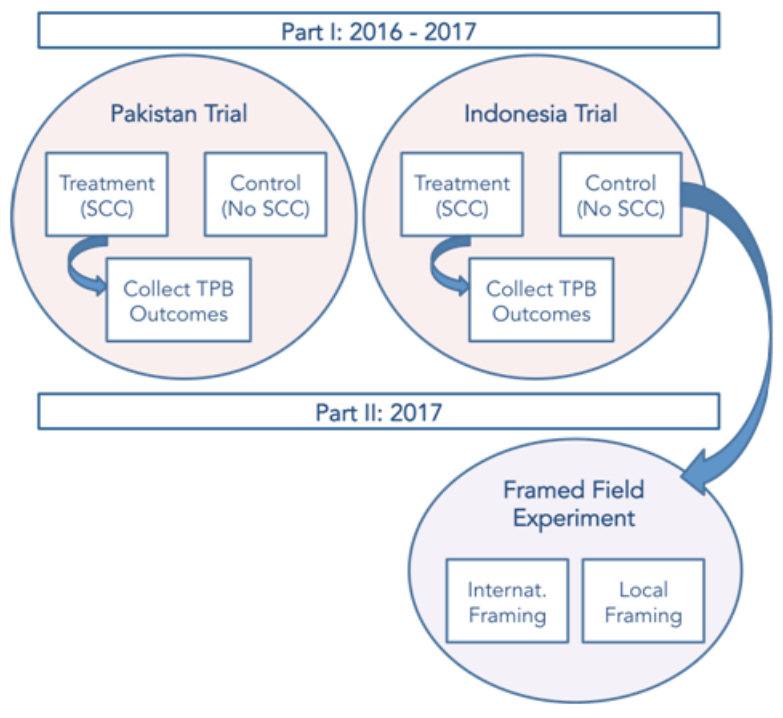

Source: Authors' depiction.

Figure D.3 Distribution of "International" Country Perceptions

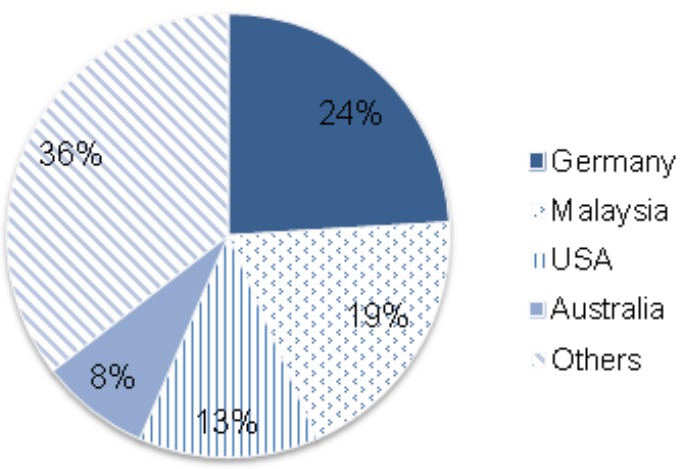

Note: Based on "If you think of activities, programs or projects by internationals, which countries come first to your mind?" 
The Theory of Planned Behavior - An Application to Implementation Research

\section{A.3 Tables}

Table D.1 Experimental Balance - Full Sample

\begin{tabular}{|c|c|c|c|c|c|c|c|c|}
\hline & $\begin{array}{c}\text { Full } \\
\mathrm{N}\end{array}$ & $\begin{array}{l}\text { Full } \\
\text { Mean }\end{array}$ & $\begin{array}{l}\text { Full } \\
\text { SD }\end{array}$ & $\begin{array}{c}\text { Control } \\
\text { Mean }\end{array}$ & $\begin{array}{c}\text { Control } \\
\text { SD }\end{array}$ & $\begin{array}{l}\text { Treat } \\
\text { Mean }\end{array}$ & $\begin{array}{c}\text { Treat } \\
\text { SD }\end{array}$ & $\begin{array}{l}\mathrm{p} \text {-value } \\
\text { difference }\end{array}$ \\
\hline Facility Type & 236 & 1.538 & - & 1.690 & - & 1.433 & - & $0.021^{* *}$ \\
\hline Gender $(1=\mathrm{m}, 2=\mathrm{f})$ & 236 & 2.000 & - & 2.000 & - & 2.000 & - & - \\
\hline Age (Years) & 236 & -33.314 & 7.493 & 33.650 & 7.806 & 33.112 & 7.316 & 0.593 \\
\hline Education (Years) & 236 & 15.051 & 0.527 & 15.020 & 0.603 & 15.067 & 0.462 & 0.619 \\
\hline Experience (Years) & 236 & 9.576 & 7.271 & 9.690 & 7.736 & 9.537 & 6.979 & 0.886 \\
\hline Sufficient income & 236 & 3.208 & 1.008 & 3.160 & 1.012 & 3.246 & 1.014 & 0.526 \\
\hline Financial problems & 236 & 1.678 & - & 1.720 & - & 1.642 & - & $0.081^{*}$ \\
\hline Strategic donation & 236 & 4.657 & 1.264 & 4.710 & 1.225 & 4.627 & 1.296 & 0.564 \\
\hline Social acc. Index & 236 & 3.411 & 0.838 & 3.450 & 0.821 & 3.381 & 0.857 & 0.513 \\
\hline Social acc. \# 1 & 236 & 4.966 & 0.690 & 5.000 & 0.778 & 4.940 & 0.622 & 0.480 \\
\hline Social acc. \# 2 & 236 & 4.568 & 1.027 & 4.600 & 0.932 & 4.545 & 1.101 & 0.650 \\
\hline Social acc. \# 3 & 236 & 5.343 & 0.558 & 5.310 & 0.506 & 5.366 & 0.595 & 0.172 \\
\hline Social acc. \# 4 & 233 & 4.644 & 1.074 & 4.694 & 1.069 & 4.602 & 1.087 & 0.475 \\
\hline Social acc. \# 5 & 236 & 2.229 & 1.254 & 2.250 & 1.298 & 2.216 & 1.235 & 0.784 \\
\hline Paperwork: too much & 236 & 2.814 & 1.343 & 3.000 & 1.497 & 2.664 & 1.195 & 0.173 \\
\hline Routines ease work & 236 & 5.153 & 0.734 & 5.150 & 0.626 & 5.179 & 0.764 & 0.660 \\
\hline Previous SCC experience & 236 & 2.564 & 1.831 & 2.500 & 1.795 & 2.627 & 1.871 & 0.536 \\
\hline Previous SCC use & 236 & 0.547 & - & 0.540 & - & 0.560 & - & 0.772 \\
\hline Access to resources & 236 & 3.470 & 0.517 & 3.530 & 0.502 & 3.425 & 0.526 & $0.080^{*}$ \\
\hline Team effic. indicator & 236 & 5.246 & 0.513 & 5.220 & 0.462 & 5.261 & 0.547 & 0.570 \\
\hline Part. in loc. projects & 236 & 1.831 & - & 1.870 & - & 1.806 & - & 0.235 \\
\hline Part. in int. projects & 236 & 1.898 & - & 1.880 & - & 1.910 & - & 0.511 \\
\hline Part. in donor projects & 236 & 1.907 & - & 1.920 & - & 1.896 & - & 0.511 \\
\hline
\end{tabular}

Note: Based upon the full sample with $\mathrm{N}$ denoting the number of observations, SD gives the standard deviation. Standard Deviations are not depicted for binary outcomes. Proportions in the two groups are significantly different from each other. Asterisks indicate p-values based on standard errors clustered at the facility level: ${ }^{*} \mathrm{p}<0.1,{ }^{* *} \mathrm{p}<0.05,{ }^{* * *} \mathrm{p}<0.01$. 
The Theory of Planned Behavior - An Application to Implementation Research

Table D.2 Experimental Balance - Reduced Sample

\begin{tabular}{|c|c|c|c|c|c|c|c|c|}
\hline & $\begin{array}{c}\text { Full } \\
\mathrm{N}\end{array}$ & $\begin{array}{l}\text { Full } \\
\text { Mean }\end{array}$ & $\begin{array}{l}\text { Full } \\
\text { SD }\end{array}$ & $\begin{array}{c}\text { Control } \\
\text { Mean }\end{array}$ & $\begin{array}{c}\text { Control } \\
\text { SD }\end{array}$ & $\begin{array}{l}\text { Treat } \\
\text { Mean }\end{array}$ & $\begin{array}{l}\text { Treat } \\
\text { SD }\end{array}$ & $\begin{array}{l}\text { p-value } \\
\text { difference }\end{array}$ \\
\hline Facility Type & 170 & 1.500 & - & 1.618 & - & 1.409 & - & $0.050^{*}$ \\
\hline Gender $(1=m, 2=f)$ & 170 & 2.000 & - & 2.000 & - & 2.000 & - & - \\
\hline Age (Years) & 170 & 32.359 & 6.997 & 33.118 & 7.680 & 31.774 & 6.395 & 0.232 \\
\hline Education (Years) & 170 & 14.994 & 0.516 & 14.974 & 0.565 & 15.011 & 0.478 & 0.742 \\
\hline Experience (Years) & 170 & 8.888 & 7.094 & 8.974 & 7.494 & 8.849 & 6.824 & 0.908 \\
\hline Sufficient Income & 170 & 3.200 & 1.069 & 3.118 & 1.083 & 3.269 & 1.065 & 0.348 \\
\hline Financial problems & 170 & 1.741 & - & 1.763 & - & 1.720 & - & 0.396 \\
\hline Strategic donation & 170 & 4.606 & 1.411 & 4.658 & 1.381 & 4.581 & 1.440 & 0.613 \\
\hline Social acc. Index & 170 & 3.329 & 0.827 & 3.316 & 0.852 & 3.344 & 0.814 & 0.808 \\
\hline Social acc. \# 1 & 170 & 5.000 & 0.738 & 4.987 & 0.887 & 5.011 & 0.599 & 0.834 \\
\hline Social acc. \# 2 & 170 & 4.459 & 1.142 & 4.461 & 1.026 & 4.462 & 1.239 & 0.991 \\
\hline Social acc. \# 3 & 170 & 5.429 & 0.584 & 5.408 & 0.521 & 5.452 & 0.634 & 0.436 \\
\hline Social acc. \# 4 & 167 & 4.545 & 1.063 & 4.649 & 1.065 & 4.457 & 1.063 & 0.239 \\
\hline Social acc. \# 5 & 170 & 2.118 & 1.286 & 2.184 & 1.334 & 2.065 & 1.258 & 0.375 \\
\hline Paperwork: too much & 170 & 2.906 & 1.364 & 3.145 & 1.547 & 2.720 & 1.174 & 0.150 \\
\hline Routines ease work & 170 & 5.100 & 0.727 & 5.079 & 0.648 & 5.151 & 0.722 & 0.471 \\
\hline Previous SCC experience & 170 & 2.765 & 1.983 & 2.632 & 1.945 & 2.882 & 2.026 & 0.298 \\
\hline Previous SCC use & 170 & 0.541 & & 0.553 & - & 0.538 & - & 0.854 \\
\hline Access to resources & 170 & 3.441 & 0.498 & 3.513 & 0.503 & 3.387 & 0.490 & $0.060^{*}$ \\
\hline Team effic. indicator & 170 & 5.200 & 0.443 & 5.158 & 0.434 & 5.226 & 0.445 & 0.459 \\
\hline Part. in loc. projects & 170 & 1.829 & - & 1.868 & - & 1.796 & - & 0.131 \\
\hline Part. in int. projects & 170 & 1.918 & - & 1.895 & - & 1.935 & - & 0.272 \\
\hline Part. in donor projects & 170 & 1.935 & - & 1.934 & - & 1.935 & - & 0.959 \\
\hline
\end{tabular}

Note: Based upon the reduced sample excluding observations with prior contact to the checklist. N denotes the number of observations, SD gives the standard deviation. Standard Deviations are not depicted for binary outcomes. Proportions in the two groups are significantly different from each other. Asterisks indicate $\mathrm{p}$-values based on standard errors clustered at the facility level: ${ }^{*} \mathrm{p}<0.1,{ }^{* *} \mathrm{p}<0.05,{ }^{* * *} \mathrm{p}<0.01$. 
The Theory of Planned Behavior - An Application to Implementation Research

Table D.3 Experimental Balance - Reduced Sample \& SCC intervention

\begin{tabular}{lcccccccc}
\hline & $\begin{array}{c}\text { Full } \\
\text { N }\end{array}$ & $\begin{array}{c}\text { Full } \\
\text { Mean }\end{array}$ & $\begin{array}{c}\text { Full } \\
\text { SD }\end{array}$ & $\begin{array}{c}\text { Control } \\
\text { Mean }\end{array}$ & $\begin{array}{c}\text { Control } \\
\text { SD }\end{array}$ & $\begin{array}{c}\text { Treat } \\
\text { Mean }\end{array}$ & $\begin{array}{c}\text { Treat } \\
\text { SD }\end{array}$ & $\begin{array}{c}\text { p-value } \\
\text { difference }\end{array}$ \\
\hline Facility Type & 335 & 1.676 & - & 1.859 & - & 1.503 & - & $0.002^{* * *}$ \\
Gender $(1=m, 2=f)$ & 335 & 1.994 & - & 1.988 & - & 2.000 & - & 0.150 \\
Age (Years) & 335 & 32.529 & 0.403 & 32.706 & 0.606 & 32.379 & 0.539 & 0.687 \\
Education (Years) & 335 & 15.195 & 0.064 & 15.405 & 0.121 & 14.994 & 0.040 & $0.001^{* * *}$ \\
Experience (Years) & 335 & 8.928 & 0.404 & 8.969 & 0.600 & 8.905 & 0.547 & 0.937 \\
Resource Access & 335 & 3.486 & 0.027 & 3.534 & 0.039 & 3.444 & 0.038 & 0.102 \\
Team Efficacy & 335 & 5.240 & 0.025 & 5.282 & 0.036 & 5.195 & 0.034 & $0.081^{*}$ \\
\hline
\end{tabular}

Note: "Full Sample" refers to the pooled Indonesian SCC intervention (treatment and control group), "SCC Intervention" to the treatment group of the SCC intervention, and "Experiment" to the SCC intervention's control group where the framing experiment was conducted (excluding those with prior SCC contact). N denotes the number of observations, SD gives the standard deviation. SDs are not depicted for binary outcomes. Proportions in the two groups are significantly different from each other. Asterisks indicate $\mathrm{p}$-values based on standard errors clustered at the facility level: ${ }^{*} \mathrm{p}<0.1,{ }^{* *} \mathrm{p}<0.05,{ }^{* * *} \mathrm{p}<0.01$. 
The Theory of Planned Behavior - An Application to Implementation Research

Table D.4 Summary Statistics for Indonesian data

\begin{tabular}{lccccc}
\hline & Full & Full & Full & Full & Full \\
& N & Max & Min & Mean & SD \\
Actual Behavior: & & & & & \\
\hline Active SCC Use & 219 & 1 & 0 & 0.389 & 0.489 \\
Intended Behavior & & & & & \\
\hline Would try to use SCC even if copies not provided & 163 & 6 & 3 & 4.847 & 0.634 \\
Would recommend the SCC to fellow colleagues & 163 & 6 & 2 & 5.092 & 0.495 \\
Using the SCC in my professional role is & 163 & 6 & 4 & 5.325 & 0.483 \\
Ease to use SCC in work environment & 163 & 6 & 4 & 5.141 & 0.565 \\
SCC supported by superiors & 163 & 6 & 4 & 5.828 & 0.439 \\
Urban (1) - Rural (2) & 163 & 2 & 1 & 1.515 & 0.501 \\
CEmONC Service Provision 24/7 & 163 & 1 & 0 & 0.178 & 0.384 \\
Facility Type: Community Health Centre & 163 & 1 & 0 & 0.589 & 0.494 \\
Facility Type: Public Hospital & 163 & 1 & 0 & 0.135 & 0.343 \\
Facility Type: Private Hospital & 163 & 1 & 0 & 0.190 & 0.394 \\
Facility Type: Private Midwife Clinic & 163 & 1 & 0 & 0.086 & 0.281 \\
District: Aceh Besar & 163 & 1 & 0 & 0.276 & 0.448 \\
District: Banda Aceh & 163 & 1 & 0 & 0.331 & 0.472 \\
District: Bireuen & 163 & 1 & 0 & 0.393 & 0.490 \\
\hline & & & & & \\
\hline
\end{tabular}


The Theory of Planned Behavior - An Application to Implementation Research

Table D.5 Summary Statistics for Pakistani data

\begin{tabular}{lccccc}
\hline & Full & Full & Full & Full & Full \\
Actual Behavior: & Nax & Min & Mean & SD \\
Active SCC Use & 212 & 1 & 0 & 0.344 & 0.476 \\
Intended Behavior & & & & & \\
\hline & & & & & \\
Would try to use SCC even if copies are not provided & 78 & 6 & 1 & 4.628 & 1.452 \\
Would recommend the SCC to fellow colleagues & 78 & 6 & 1 & 5.141 & 1.090 \\
Using the SCC in my professional role is & 79 & 6 & 1 & 5.380 & 0.821 \\
Ease to use SCC in work environment & 79 & 6 & 1 & 4.962 & 1.305 \\
SCC is supported by superiors & 58 & 6 & 1 & 5.155 & 1.508 \\
Urban (1) - Rural (2) & 80 & 1 & 0 & 0.813 & 0.393 \\
Open 24/7 & 80 & 1 & 0 & 0.150 & 0.359 \\
Facility Type: Health Facility & 80 & 1 & 0 & 0.2125 & 0.412 \\
Facility Type: Community Midwife & 80 & 1 & 0 & 0.5625 & 0.500 \\
Facility Type: Lady Health Visitor & 80 & 1 & 0 & 0.225 & 0.420 \\
District: Haripur & 80 & 1 & 0 & 0.450 & 0.501 \\
District: Nowshera & 80 & 1 & 0 & 0.550 & 0.501 \\
\hline
\end{tabular}


The Theory of Planned Behavior - An Application to Implementation Research

\section{Additional Results - Theory of Planned Behavior}

Table D.6 TPB - Intentions and Behavior: Wild Bootstrapped SE

\begin{tabular}{|c|c|c|c|}
\hline & $\begin{array}{c}\text { Intended SCC Use: } \\
\text { Indonesia } \\
(1 \mathrm{a}) \\
\end{array}$ & $\begin{array}{c}\text { Actual SCC Use: } \\
\text { Pakistan } \\
(2 \mathrm{a}) \\
\end{array}$ & $\begin{array}{c}\text { Actual SCC Use: } \\
\text { Indonesia } \\
(2 \mathrm{~b}) \\
\end{array}$ \\
\hline \multicolumn{4}{|l|}{ Attitudes: } \\
\hline \multicolumn{4}{|c|}{ SCC in professional role: 1 "completely useless" -6 "completely useful" } \\
\hline & $0.454^{* * *}$ & $0.655^{* * *}$ & -0.364 \\
\hline WB p-value & $(0.004)$ & $(0.000)$ & $(0.505)$ \\
\hline \multicolumn{4}{|l|}{ Subjective Norms: } \\
\hline \multicolumn{4}{|c|}{ SCC is supported by superiors: 1 "not at all" -6 "completely" } \\
\hline & $0.536^{*}$ & 0.207 & 0.642 \\
\hline WB p-value & $(0.072)$ & $(0.320)$ & $(0.503)$ \\
\hline \multicolumn{4}{|c|}{ Perceived Behavioral Control: } \\
\hline \multicolumn{4}{|c|}{ Ease of SCC in work environment: 1 "very difficult" - 6 "very easy" } \\
\hline & 0.261 & $0.306^{* * *}$ & 0.038 \\
\hline WB p-value & $(0.102)$ & $(0.000)$ & $(0.432)$ \\
\hline $\mathrm{N}$ & 163 & 212 & 218 \\
\hline Control variables & No & No & No \\
\hline Mean of dep. var. & 4.847 & 0.344 & 0.389 \\
\hline Median of dep. var. & 5 & - & - \\
\hline SD of dep. var. & 0.634 & 0.476 & 0.489 \\
\hline
\end{tabular}

Note: Intended SCC Use was measured via the question "Would you try to use SCC even if copies are not provided anymore? (1 disagree strongly - 6 agree strongly)." Actual SCC Use was meassured via trained observers and is coded as a binary outcome variable. All regressions are based upon the treated providers. Standard errors (SE) are clustered at the facility level and wild cluster bootstrapped due to the small number of clusters (15 facilities), following Cameron et al. (2008). No bootstrapping is provided for intended SCC use in Pakistan as a sufficient number of clusters (70) was sampled. Asterisks indicate p-values according to:

${ }^{*} \mathrm{p}<0.1,{ }^{*} \mathrm{p}<0.05,{ }^{* * *} \mathrm{p}<0.01$. 
The Theory of Planned Behavior - An Application to Implementation Research

Table D.7 TPB - Binary Outcome

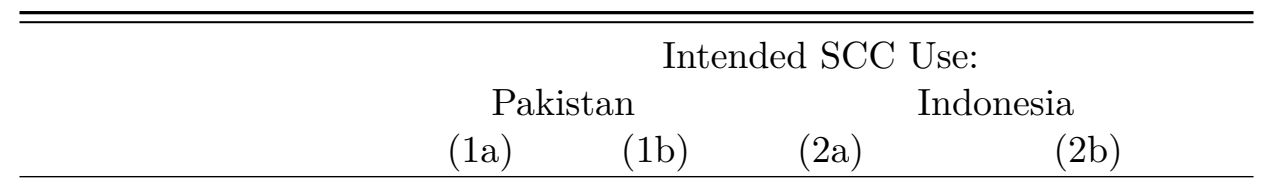

Attitudes:

SCC in professional role: 1 "completely useless" -6 "completely useful"

$\begin{array}{lcccc} & 0.930^{* * *} & 0.704^{* *} & 0.451^{* * *} & 0.317^{* *} \\ \text { p-value } & (0.007) & (0.025) & (0.006) & (0.013)\end{array}$

\section{Subjective Norms:}

SCC is supported by superiors: 1 "not at all" -6 "completely"

$\begin{array}{ccccc} & 0.508 & 0.244 & 0.700^{* * *} & 0.444^{* * *} \\ \text { p-value } & (0.118) & (0.475) & (0.009) & (0.003)\end{array}$

\section{Perceived Behavioral Control:}

Ease of SCC in work environment: 1 "very difficult" - 6 "very easy"

\begin{tabular}{lcccc} 
p-value & $0.763^{* *}$ & $0.675^{* *}$ & 0.303 & -0.057 \\
& $(0.011)$ & $(0.041)$ & $(0.166)$ & $(0.746)$ \\
\hline $\mathrm{N}$ & 78 & 78 & 163 & 163 \\
Control variables & No & Yes & No & Yes \\
Mean of dep. var. & 4.628 & 4.628 & 4.847 & 4.847 \\
Median of dep. var. & 5 & 5 & 5 & 5 \\
SD of dep. var. & 1.452 & 1.452 & 0.634 & 0.634 \\
\hline
\end{tabular}

Note: All regressions are based upon the treated providers. Adjusted regressions (b) additionally control for a variable indicating the facility type, a binary variable indicating rural/urban location, a variable indicating the district and for the Pakistani data a binary variable indicating whether the facility is open 24/7. Standard errors (SE) are clustered at the facility level. Asterisks indicate p-values according to: ${ }^{*} \mathrm{p}<0.1,{ }^{*} \mathrm{p}<0.05,{ }^{* * *} \mathrm{p}<0.01$. 
The Theory of Planned Behavior - An Application to Implementation Research

\section{Additional Results - Framing Experiment}

Table D.8 Framing Experiment - Wild Bootstrapped SE

\begin{tabular}{lcc}
\hline \multicolumn{2}{l}{ Financial Contribution in support of SCC project (in IDR) } \\
& (a) & (b) \\
\hline Framing: 1="internat." & 557.624 & $1,283.772^{* *}$ \\
WB p-value & $(0.404)$ & $(0.032)$ \\
N & 165 & 165 \\
Control variables & no & Yes \\
Mean of dep. var. & $4,757.576$ & $4,757.576$ \\
SD of dep. var. & $4,711.366$ & $4,711.366$ \\
\hline
\end{tabular}

Note: See Table 4.3 Standard errors (SE) are clustered at the facility level and wild boostrapped due to limited cluster number (13) for the specifications indicated as "WB p-values," following Cameron et al. (2008). Asterisks indicate p-values according to: ${ }^{*} \mathrm{p}<0.1,{ }^{* *} \mathrm{p}<0.05,{ }^{* * *} \mathrm{p}<0.01$.

Table D.9 Framing Experiment - Covariates

\begin{tabular}{lccccc}
\hline & $\begin{array}{c}\text { Recom- } \\
\text { mendation }\end{array}$ & $\begin{array}{c}\text { Time } \\
\text { Investment }\end{array}$ & $\begin{array}{c}\text { Own } \\
\text { Contribution }\end{array}$ & Elicitation & PCA \\
\hline Public Hospital & -0.063 & -1.044 & $-3,444.525^{* * *}$ & 415.641 & $-0.710^{*}$ \\
p-value & $(0.595)$ & $(0.073)$ & $(0.0000)$ & $(0.816)$ & $(0.064)$ \\
WB p-value & $(0.651)$ & $(0.134)$ & $(0.002)$ & $(0.695)$ & $(0.200)$ \\
Private Hospital & -0.217 & 0.826 & $-1,093.573$ & $1,162.358$ & 0.042 \\
p-value & $(0.296)$ & $(0.265)$ & $(0.667)$ & $(0.337)$ & $(0.923)$ \\
WB p-value & $(0.302)$ & $(0.344)$ & $(0.541)$ & $(0.454)$ & $(0.873)$ \\
Social Acc. Index & $0.132^{*}$ & $0.934^{* * *}$ & $825.220^{*}$ & -81.462 & $0.446^{* * *}$ \\
p-value & $(0.071)$ & $(0.000)$ & $(0.091)$ & $(0.704)$ & $(0.002)$ \\
WB p-value & $(0.082)$ & $(0.000)$ & $(0.114)$ & $(0.637)$ & $(0.000)$ \\
Paperwork: too much & $-0.149^{* * *}$ & $-0.637^{* * *}$ & $-978.225^{* * *}$ & $-599.969^{* *}$ & $-0.443^{* * *}$ \\
p-value & $(0.003)$ & $(0.000)$ & $(0.002)$ & $(0.019)$ & $(0.000)$ \\
WB p-value & $(0.004)$ & $(0.002)$ & $(0.002)$ & $(0.012)$ & $(0.004)$ \\
\hline
\end{tabular}

Note: All specifications are based upon the sample limited to those respondents without prior SCC contact (refer to Table D.11). Community health clinics (puskesmas) constitute the comparison group regarding the facility type. SE are clustered at the facility level. We present results based on clustered SE indicated as "p-values" and wild bootstrapped due to limited cluster number (13) for the specifications indicated as "WB p-values," following Cameron et al. (2008). Asterisks indicate p-values according to: ${ }^{*} \mathrm{p}<0.1,{ }^{* *} \mathrm{p}<0.05,{ }^{* * *} \mathrm{p}<0.01$. 
The Theory of Planned Behavior - An Application to Implementation Research

Table D.10 Framing Experiment - Elicitation as Control

\begin{tabular}{lc}
\hline Financial Contribution in support of SCC project (in IDR) \\
\hline Framing: 1="internat." & $852.610^{*}$ \\
p-value & $(0.064)$ \\
Elicited Contribution of Others & $0.5000^{* * *}$ \\
p-value & $(0.002)$ \\
N & 165 \\
Mean of dep. var. & $4,757.576$ \\
SD of dep. var. & $4,711.366$ \\
\hline
\end{tabular}

Note: See Table 4.3 Moreover, the elicited contribution of health practitioners from other facilities is added as a control variable. Standard errors (SE) are clustered at the facility level. Asterisks indicate p-values according to: ${ }^{*} \mathrm{p}<0.1,{ }^{*} \mathrm{p}<0.05,{ }^{* * *} \mathrm{p}<0.01$.

When being financially incentivized to assess the potential answer of an anonymous third person, opportunity costs of not revealing the own true assessment increase. We, thus, incentivized respondents with an additional pay-off of 10,000 IDR to estimate the average contribution category of respondents at other facilities. In a resource constrained setting the beliefs about the willingness of others to contribute could provide more accurate information about preferences as they are less subject to idiosyncratic financial situations of respondents. 
The Theory of Planned Behavior - An Application to Implementation Research
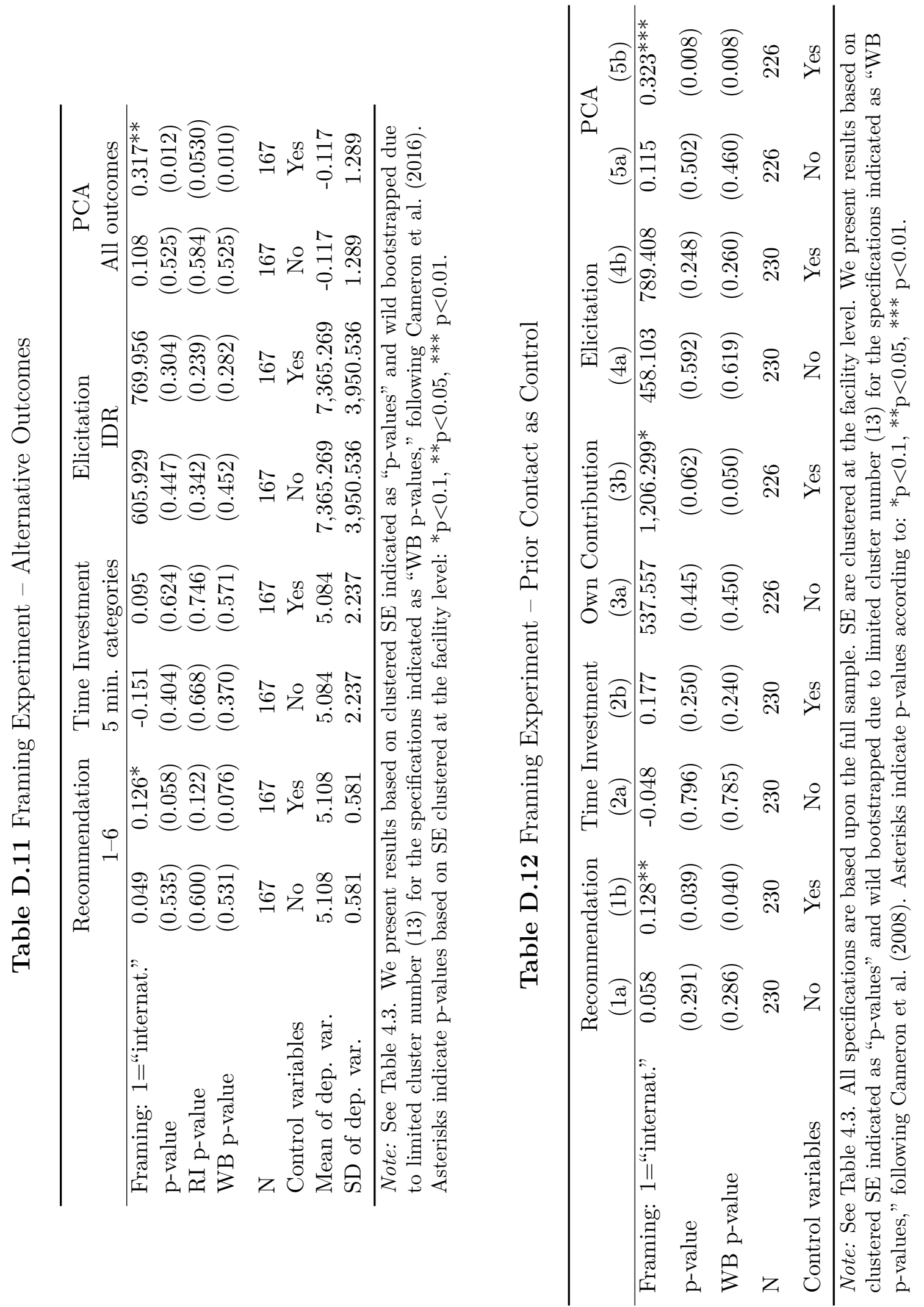
The Theory of Planned Behavior - An Application to Implementation Research

Table D.13 Framing Experiment - Interaction with Prior Contact

\begin{tabular}{lcc}
\hline \multicolumn{2}{l}{ Financial Contribution in support of SCC project (in IDR) } \\
& 557.624 & $1,164.830^{* *}$ \\
\hline Framing: 1="internat." & $(0.395)$ & $(0.033)$ \\
p-value & 225.973 & 627.961 \\
Prior Contact $\times$ Local Framing & $(0.835)$ & $(0.547)$ \\
p-value & 706.522 & $1,955.229$ \\
Prior Contact $\times$ International Framing & $(0.547)$ & $(0.105)$ \\
p-value & 226 & 226 \\
N & No & Yes \\
Control variables & $4,757.576$ & $4,757.576$ \\
Mean of dep. var. & $4,711.366$ & $4,711.366$ \\
SD of dep. var. &
\end{tabular}

Note: See Table 4.3 The base category is No Prior Contact and Local Framing. Asterisks indicate $\mathrm{p}$-values based on standard errors clustered at the facility level: ${ }^{*} \mathrm{p}<0.1,{ }^{* *} \mathrm{p}<0.05,{ }^{* * *} \mathrm{p}<0.01$.

Table D.14 Association between Previous Project Participation and Trust

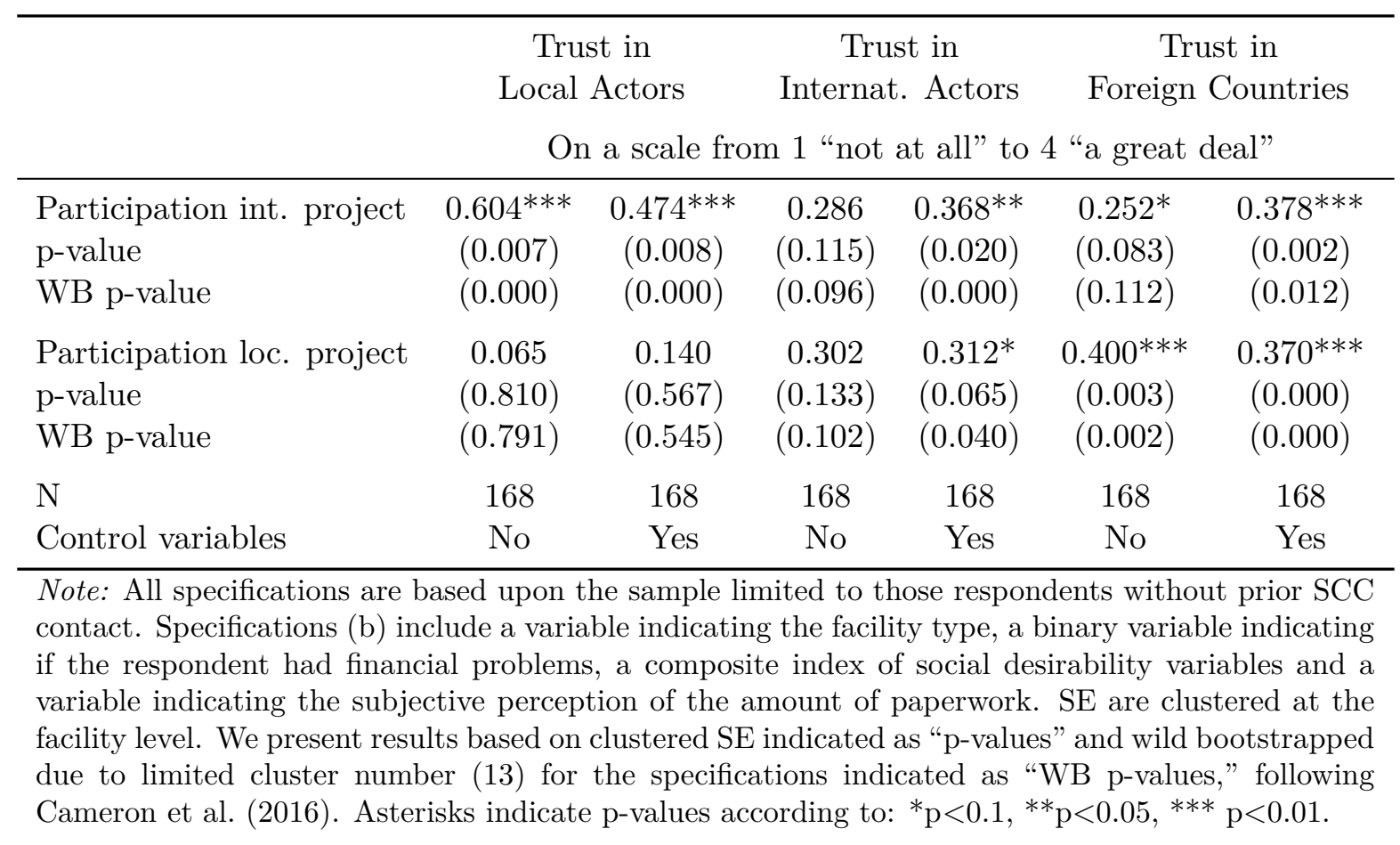


The Theory of Planned Behavior - An Application to Implementation Research
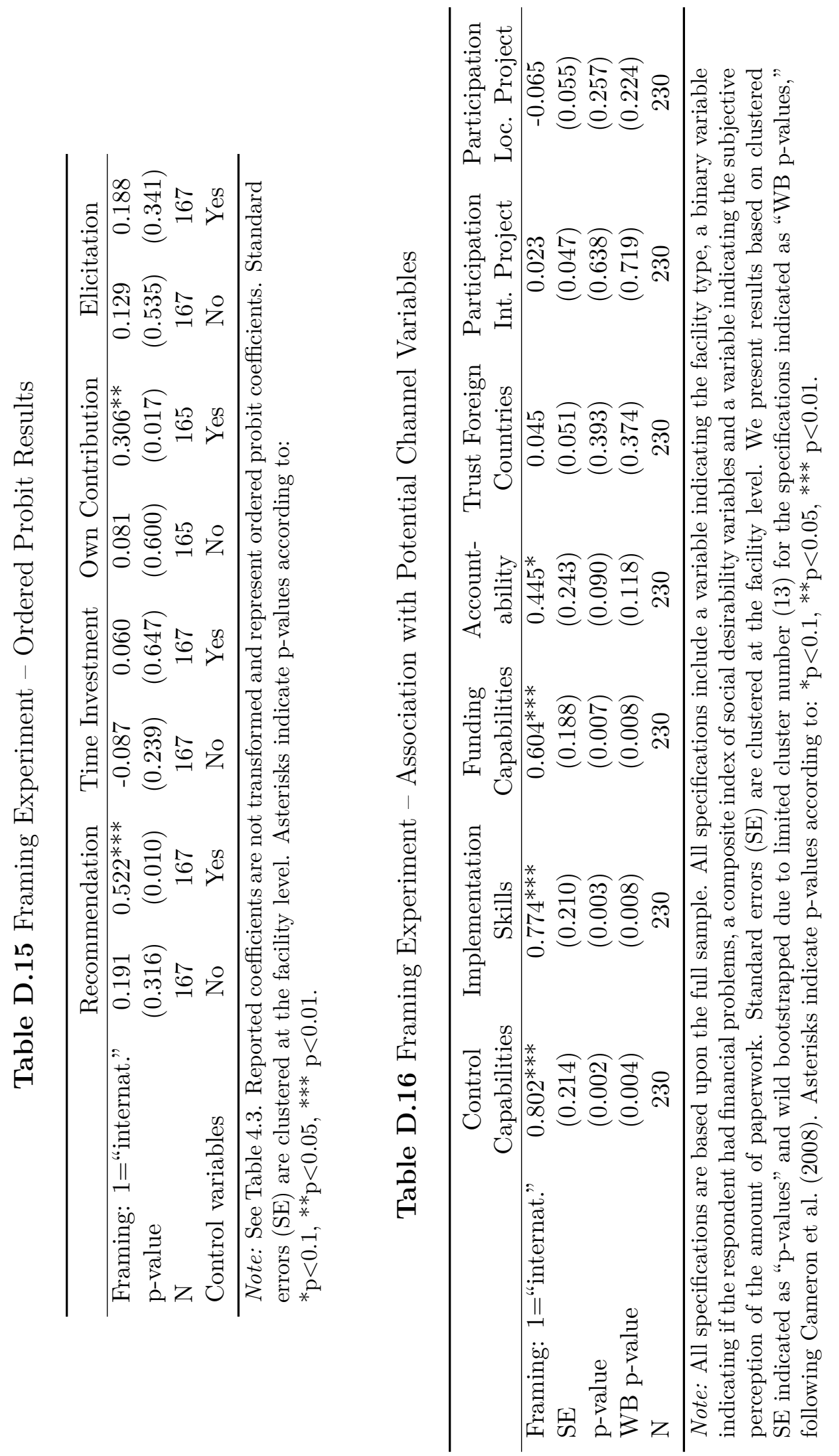
The Theory of Planned Behavior - An Application to Implementation Research

Point Estimates - Previours Experience Table D.17 displays the results for the interaction of our experimental framing with the binary variables indicating if respondents already participated in international or local research projects. While the randomization ensured that the framing could be considered as exogenous, project participation is potentially endogenous regarding other traits of the surveyed respondent. However, as recent research by Nizalova and Murtazashvili (2016) and Bun and Harrison (2018) indicates, the interaction of an exogenous and an endogenous variable can be considered as exogenous, when controlling for the endogenous variable ${ }^{51}$ Moreover, balancing tests provided in Table 4.3 and D.17 underscore that previous participation is balanced across both framing treatments. The results in columns (1a-b) are structured to compare respondents with similar previous experience (participation in international/local projects) across framings. The corresponding comparison group are locally framed respondents, who did neither participate in a local nor in an international project. Row I and II show that if a person had been exposed both to an international and local research project in the past, their contribution is approx. 6,500-8,500 IDR (e.g., 0.450.65 US\$) higher if framed international. Thus, the effect of the attitude towards the intervention in the unadjusted and adjusted specification is significantly higher if respondents knowing both implementers are framed internationally (p-value: 0.025 and 0.000, respectively). Respondents who previously participated in local projects do not contribute different amounts of money when faced with an international framing. However, if respondents were only exposed to international projects in the past, they do contribute significantly less if locally framed, both significant with and without adjusting for controls (p-value: 0.012 and 0.052, respectively). Finally, row VII does not depict any significant framing effects, if respondents did not have any prior experience. Those estimates suggest that the positive effects of the international framing are driven by previous experience with the respective implementer. The reduced willingness to contribute to local projects is most pronounced if respondents have participated both in local and international projects.

\footnotetext{
${ }^{51}$ Nonetheless, one needs to be aware that, especially, with a limited sample size omitted variables might not be homogenously distributed and, hence, it is not inherently clear, which other factors are correlated with our interaction variable of interest.
} 
The Theory of Planned Behavior - An Application to Implementation Research

Table D.17 Framing Experiment - Previous Experience (Point Estimates)

Outcome: Financial Contribution in support of SCC (in IDR)

(a)

(b)

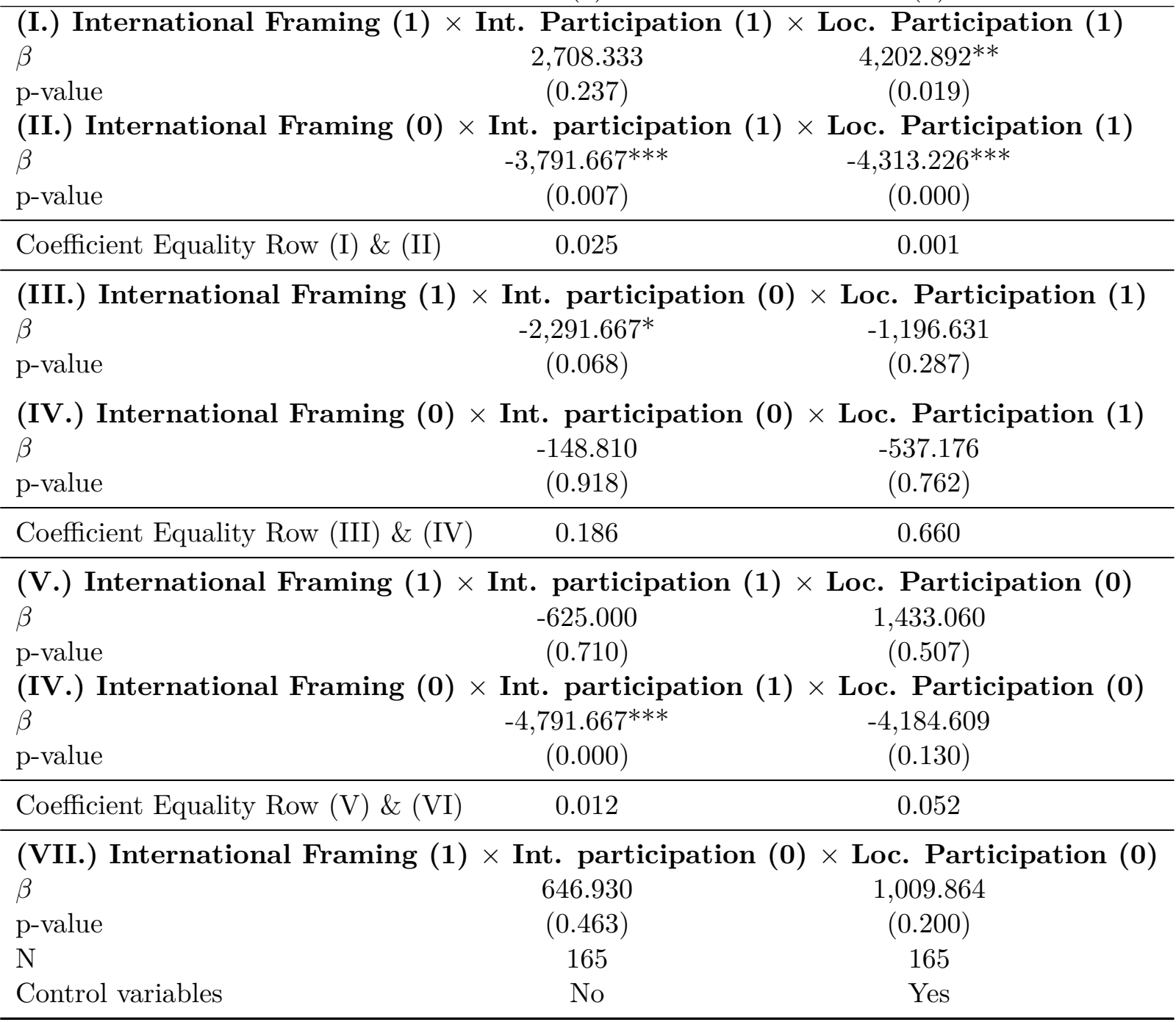

Note: See Table 4.3 Standard errors (SE) are clustered at the facility level. Asterisks indicate p-values according to: ${ }^{*} \mathrm{p}<0.1,{ }^{* *} \mathrm{p}<0.05,{ }^{* * *} \mathrm{p}<0.01$. 



\section{Bibliography}

Abman, R. and C. Carney (2018). Agricultural productivity and deforestation: Evidence from input subsidies and ethnic favoritism in Malawi. Unpublished Manuscript available at: https://www.dropbox.com/s/mleewu3o68in0kj/ agricultural-productivity-deforestation.pdf? $d l=0$.

Acemoglu, D., T. Verdier, and J. A. Robinson (2004). Kleptocracy and divide-and-rule: A model of personal rule. Journal of the European Economic Association 2(2-3), 162192.

Acemoglu, D. and P. Yared (2010). Political limits to globalization. American Economic Review 100(2), 83-88.

Adida, C. L., K. E. Ferree, D. N. Posner, and A. L. Robinson (2016). Who's asking? Interviewer coethnicity effects in African survey data. Comparative Political Studies 49(12), 1630-1660.

Adler, R., G. Huffman, A. Chang, R. Ferraro, P. Xie, J. Janowiak, B. Rudolf, U. Schneider, S. Curtis, D. Bolvin, A. Gruber, J. Susskind, and P. Arkin (2003). Global Precipitation Climatology Project (GPCP): Monthly Precipitation Analysis (1979Present), Version 2. Earth System Research Laboratory, National Oceanic and Atmospheric Administration. Available at https://www.esrl.noaa.gov/psd/data/gridded/ data.gpcp.html, last accessed 10 October, 2018.

Afrobarometer (2018). Afrobarometer: Merged rounds 1-6. Technical report, Afrobarometer. Available at http://www.afrobarometer.org.

AidData (2017). World Bank Geocoded Research Release Level 1. Version 1.4.2 Geocoded Dataset. Technical report, Williamsburg, VA and Washington, DC.

Aidt, T. S. and M. Gassebner (2010). Do autocratic states trade less? The World Bank Economic Review 24(1), 38-76.

Ajzen, I. (1985). From Intentions to Actions: A Theory of Planned Behavior. In J. Kuhl and J. Beckmann (Eds.), Action-control: From cognition to behavior, Chapter 2, pp. 11-39. Heidelberg, Berlin: SSSP Springer Series in Social Psychology. 


\section{Bibliography}

Ajzen, I. (1991). The theory of planned behavior. Organisational Behaviour and Human Decision Processes 50, 179-211.

Aker, J. C., M. W. Klein, S. A. O'Connell, and M. Yang (2014). Borders, ethnicity and trade. Journal of Development Economics 10\%, 1-16.

Akiyama, T. and D. F. Larson (1994). Adding up problem: Strategies for primary commodity exports in Sub-Saharan Africa. World Bank Policy Research Working Paper 1245.

Alesina, A., W. Easterly, and J. Matuszeski (2011). Artificial states. Journal of the European Economic Association 9(2), 246-277.

Alesina, A. and E. L. Ferrara (2005). Ethnic diversity and economic performance. Journal of Economic Literature 43(3), 762-800.

Alesina, A., J. Harnoss, and H. Rapoport (2016). Birthplace diversity and economic prosperity. Journal of Economic Growth 21(2), 101-138.

Alesina, A., S. Michalopoulos, and E. Papaioannou (2016). Ethnic inequality. Journal of Political Economy 124(2), 428-488.

Alkire, S. and M. E. Santos (2014). Measuring acute poverty in the developing world: Robustness and scope of the multidimensional poverty index. World Development 59, 251-274.

Altonji, J. G. and D. Card (1991). The effects of immigration on the labor market outcomes of less-skilled natives. In Immigration, Trade, and the Labor Market, pp. 201-234. University of Chicago Press.

Altonji, J. G., T. E. Elder, and C. R. Taber (2005). Selection on observed and unobserved variables: Assessing the effectiveness of catholic schools. Journal of Political Economy 113(1), 151-184.

American Economic Association (2018). AEA RCT Registry. Available at https:// www.socialscienceregistry.org/, last accessed 10 September, 2018.

Anderson, K., G. Rausser, and J. Swinnen (2013). Political economy of public policies: insights from distortions to agricultural and food markets. Journal of Economic Literature 51(2), 423-477.

Angrist, J. D. and J.-S. Pischke (2009). Mostly Harmless Econometrics. An Empiricist's Companion. Princeton, New Jersey: Princeton University Press.

Appleby, B., C. Roskell, and W. Daly (2016). What are health professionals' intentions toward using research and products of research in clinical practice? A systematic review and narrative synthesis. Nursing open 3(3), 125-139. 


\section{Bibliography}

Armitage, C. J. and M. Conner (2001). Efficacy of the Theory of Planned Behaviour: A meta-analytic review. British Journal of Social Psychology 40, 471-499.

Ashraf, N., E. Field, and J. Lee (2014). Household bargaining and excess fertility: An experimental study in Zambia. American Economic Review 104(7), 2210-2237.

Asmus, G., V. Eichenauer, A. Fuchs, and B. Parks (2017). India's Development Cooperation Worldwide, Version 0.1 (beta release). Mimeo.

Autor, D. H., D. Dorn, and G. H. Hanson (2013). The China syndrome: Local labor market effects of import competition in the United States. American Economic Review 103(6), 2121-2168.

Azevedo, J. (2011). wbopendata: Stata module to access World Bank databases, Statistical Software Components.

Baghdadi, L., I. Martínez-Zarzoso, and H. Zitouna (2013). Are RTA agreements with environmental provisions reducing emissions? Journal of International Economics 90(2), 378-390.

Balassa, B. (1965). Trade liberalization and revealed comparative advantage. Manchester School of Economic and Social Studies 33(2), 99-123.

Baldwin, R. and J. Lopez-Gonzalez (2015). Supply-chain trade: A portrait of global patterns and several testable hypotheses. The World Economy 38(11), 1682-1721.

Ballard-Rosa, C., M. Malik, S. Rickard, and K. Scheve (2017). The economic origins of authoritarian values: Evidence from local trade shocks in the United Kingdom. Unpublished Manuscript available at https://www.researchgate.net/publication/ 320044830_The_Economic_Origins_of_Authoritarian_Values_Evidence_from _ Local_Trade_Shocks_in_the_United_Kingdom.

Banerjee, A., E. Duflo, R. Glennerster, and D. Kothari (2010). Improving immunisation coverage in rural India: Clustered randomised controlled evaluation of immunisation campaigns with and without incentives. BMJ 340, 1-9.

Baranov, V., S. R. Bhalotra, P. Biroli, and J. Maselko (2017). Maternal depression, women's empowerment, and parental investment: Evidence from a large randomized control trial. Technical Report 11187, IZA Discussion Papers.

Barnard-Brak, L., H. Burley, and S. M. Crooks (2010). Explaining Youth Mentoring Behavior using a Theory of Planned Behavior Perspective. International Journal of Adolescence and Youth 15(4), 365-379.

Barrett, C. B., L. Christiaensen, M. Sheahan, and A. Shimeles (2017). On the structural transformation of rural Africa. World Bank Policy Research Working Paper 7938. 


\section{Bibliography}

Barron, P., R. Diprose, and M. J. Woolcock (2011). Contesting development: Participatory projects and local conflict dynamics in Indonesia. New Haven, Connecticut, United States: Yale University Press.

Barsbai, T., H. Rapoport, A. Steinmayr, and C. Trebesch (2017). The effect of labor migration on the diffusion of democracy: evidence from a former Soviet Republic. American Economic Journal: Applied Economics 9(3), 36-69.

Bartik, T. J. (1991). Who benefits from state and local economic development policies? WE Upjohn Institute for Employment Research.

Baskaran, T., B. Min, and Y. Uppal (2015). Election cycles and electricity provision: Evidence from a quasi-experiment with Indian special elections. Journal of Public Economics 126, 64-73.

Bassnet, Y. (2011). Taking stock of aid for trade. Available at https://www.odi.org/ comment/5871-taking-stock-aid-trade, last accessed August 18, 2018.

Bates, R. H. (1989). Beyond the Miracle of the Market: The Political Economy of Agrarian Development in Kenya. Cambridge: Cambridge University Press.

Bates, R. H. and S. Block (2009). Political economy of agricultural trade interventions in Africa. Agricultural Distortions Working Paper 87, World Bank.

Bates, R. H. and S. Block (2010). Agricultural trade interventions in Africa. In K. Anderson (Ed.), In The Political Economy of Agricultural Price Distortions. Cambridge University Press.

Bates, R. H. and S. A. Block (2013). Revisiting African agriculture: institutional change and productivity growth. The Journal of Politics 75(2), 372-384.

BBC (2005). Germany takes lead in aid effort. Available at http://news.bbc.co.uk/2/ hi/europe/4148719.stm, last accessed October 4, 2018.

Beath, A., F. Christia, and R. Enikolopov (2012). Winning hearts and minds through development? Evidence from a field experiment in Afghanistan. World Bank Policy Research Working Paper 6129.

Behavioral Science Solution (2018). Framing Effect. Available at https://www. behavioraleconomics.com/resources/mini-encyclopedia-of-be/framing-effect, last accessed September 29, 2018.

Beine, M., F. Docquier, and H. Rapoport (2008). Brain drain and human capital formation in developing countries: winners and losers. The Economic Journal 118(528), $631-652$.

Bellemare, M. F. (2015). Rising food prices, food price volatility, and social unrest. American Journal of Agricultural Economics 97(1), 1-21. 


\section{Bibliography}

Berman, E., J. H. Felter, J. N. Shapiro, and E. Troland (2013). Modest, secure, and informed: Successful development in conflict zones. American Economic Review: Papers and Proceedings 103(3), 512-517.

Berman, E., J. N. Shapiro, and J. H. Felter (2011). Can hearts and minds be bought? the economics of counterinsurgency in Iraq. Journal of Political Economy 119(4), $766-819$.

Berman, N. and M. Couttenier (2015). External shocks, internal shots: The geography of civil conflicts. Review of Economics and Statistics 97(4), 758-776.

Berman, N., M. Couttenier, D. Rohner, and M. Thoenig (2017). This mine is mine! How minerals fuel conflicts in Africa. American Economic Review 107(6), 1564-1610.

Berthélemy, J.-C. (2006). Bilateral donors' interest vs. recipients' development motives in aid allocation: Do all donors behave the same? Review of Development Economics 10(2), 179-194.

Bertrand, M., S. Mullainathan, and E. Shafir (2006). Behavioral Economics and Marketing in Aid of Decision Making Among the Poor. Journal of Public Policy $\&$ Marketing 25(1), 8-23.

Bezemer, D. and D. Headey (2008). Agriculture, development, and urban bias. World Development 36(8), 1342-1364.

Bilic, B. (2005). The Theory of Planned Behaviour and Health Behaviours: Critical Analysis of Methodological and Theoretical Issues. Hellenic Journal of Psychology 2, 243-259.

Binswanger, H. P. and K. Deininger (1997). Explaining agricultural and agrarian policies in developing countries. Journal of Economic Literature 35(4), 1958-2005.

Bjørnskov, C. and M. Rode (2018). Regime types and regime change: A new dataset, Version 2.1. Available at http://www.christianbjoernskov.com/wp-content/uploads/ 2018/03/Codebook-BR-dataset.pdf.

Blue, C. (1995). The Predictive Capacity of the Theory of Reasoned Action and the Theory of Planned Behavior in Exercise Research: An integrated Literature Review. Research in Nursing and Health 18, 105-121.

Bluhm, R., A. Dreher, A. Fuchs, B. Parks, A. Strange, and M. J. Tierney (2018). Connective financing: Chinese infrastructure projects and the diffusion of economic activity in developing countries. AidData Working Paper (64).

Bluhm, R., M. Gassebner, S. Langlotz, and P. Schaudt (2016). Fueling conflict? (De) escalation and bilateral aid. CESifo Working Paper Series No. 6125. 


\section{Bibliography}

Bommer, C., A. Dreher, and M. Perez (2018). Regional and ethnic favoritism in the allocation of humanitarian aid. CESifo Working Paper 7038.

Bommer, C., E. Heesemann, V. Sagalova, J. Manne-Goehler, R. Atun, T. Bärnighausen, and S. Vollmer (2017). The global economic burden of diabetes in adults aged 20-79 years: a cost-of-illness study. The lancet Diabetes \&f endocrinology 5(6), 423-430.

Borchard, A., D. L. B. Schwappach, A. Barbir, and P. Bezzola (2012). A systematic review of the effectiveness, compliance, and critical factors for implementation of safety checklists in surgery. Annals of Surgery 256(6), 925-933.

Bourguignon, F. and S. R. Chakravarty (2003). The measurement of multidimensional poverty. The Journal of Economic Inequality 1(1), 25-49.

Bowles, S. and S. Polania-Reyes (2012). Economic incentives and social preferences: substitutes or complements? Journal of Economic Literature 50(2), 368-425.

Brakman, S., H. Garretsen, and T. Kohl (2018). Consequences of Brexit and options for a "Global Britain". Papers in Regional Science 97(1), 55-72.

Bräutigam, D. (2011). Aid with Chinese characteristics: Chinese foreign aid and development finance meet the OECD-DAC aid regime. Journal of International Development 23(5), 752-764.

Brooks, D. H. and D. Hummels (2005). Infrastructure's Role in Lowering Asia's Trade Costs: Building for Trade. Edward Elgar Publishing.

Bruederle, A. and R. Hodler (2017). The effect of oil spills on infant mortality: Evidence from Nigeria. CESifo Working Paper 6653.

Bueno De Mesquita, B. (2005). The logic of political survival. MIT press.

Bun, M. J. and T. D. Harrison (2018). OLS and IV estimation of regression models including endogenous interaction terms. Econometric Reviews 113(522), 1-14.

Burgess, D. J. (2010). Are providers more likely to contribute to healthcare disparities under high levels of cognitive load? How features of the healthcare setting may lead to biases in medical decision making. Medical Decision Making 30(2), 246-257.

Burgess, R., R. Jedwab, E. Miguel, A. Morjaria, and G. Padró i Miquel (2015). The value of democracy: evidence from road building in Kenya. American Economic Review 105(6), 1817-1851.

Burnside, C. and D. Dollar (2000). Aid, Policies, and Growth. American Economic Review $90(4), 847-868$.

Calì, M. and D. W. te Velde (2011). Does aid for trade really improve trade performance? World Development 39(5), 725-740. 


\section{Bibliography}

Cameron, A. C., J. B. Gelbach, and D. L. Miller (2008). Bootstrap-based improvements for inference with clustered errors. The Review of Economics and Statistics $90(3)$, $414-427$.

Cameron, A. C., J. B. Gelbach, and D. L. Miller (2011). Robust inference with multiway clustering. Journal of Business \& Economic Statistics 29(2), 238-249.

Cameron, D. B., A. Mishra, and A. N. Brown (2016). The growth of impact evaluation for international development: How much have we learned? Journal of Development Effectiveness 8(1), 1-21.

Caselli, F., M. Morelli, and D. Rohner (2015). The geography of interstate resource wars. Quarterly Journal of Economics 130(1), 267-315.

Cederman, L.-E., H. Buhaug, and J. K. Rød (2009). Ethno-nationalist dyads and civil war: A GIS-based analysis. Journal of Conflict Resolution.

Cederman, L.-E., L. Girardin, and J. Wucherpfennig (2014). Exploring Inequality and Ethnic Conflict: EPR-ETH and GROWup. Boulder, CO: Paradigm Publishers.

Cederman, L.-E., K. S. Gleditsch, and H. Buhaug (2013). Inequality, grievances, and civil war. Cambridge, UK:Cambridge University Press.

Cederman, L.-E., N. B. Weidmann, and N.-C. Bormann (2015). Triangulating horizontal inequality: Toward improved conflict analysis. Journal of Peace Research 52(6), 806-821.

Cederman, L.-E., N. B. Weidmann, and K. S. Gleditsch (2011). Horizontal inequalities and ethnonationalist civil war: A global comparison. American Political Science Review 105 (3), 478-495.

Cheibub, J. A., J. Gandhi, and J. R. Vreeland (2010). Democracy and dictatorship revisited. Public choice 143(1-2), 67-101.

Cheon, J., S. Lee, S. M. Crooks, and J. Song (2012). An investigation of mobile learning readiness in higher education based on the theory of planned behavior. Computers and Education 59(3), 1054-1064.

Child, T. B. (2018). Conflict and counterinsurgency aid: Drawing sectoral distinctions. Journal of Development Economics.

Christian, P. and C. Barrett (2017). Revisiting the effect of food aid on conflict: A methodological caution. World Bank Policy Research Working Paper 8171.

CIDOB (2018). Biografías líderes políticos. Available at https://www.cidob.org/en/ biografias_lideres_politicos_only_in_spanish, last accessed September 10, 2018. 


\section{Bibliography}

CIESIN (2016). Documentation for the gridded population of the world, version 4. NASA Socioeconomic Data and Applications Center (SEDAC). Available at http://sedac.ciesin.columbia.edu/data/collection/gpw-v4/documentation, last accessed October 10, 2018.

Cilliers, J., O. Dube, and B. Siddiqi (2015). The white-man effect: How foreigner presence affects behavior in experiments. Journal of Economic Behavior and Organization 118, 397-414.

Clemens, M. A., S. Radelet, and R. Bhavnani (2012). Counting chickens when they hatch: The short term effect of aid on growth. Economic Journal 90(2000), 1-33.

Cogneau, D. and R. Jedwab (2012). Commodity price shocks and child outcomes: the 1990 cocoa crisis in Cote d'Ivoire. Economic Development and Cultural Change 60(3), $507-534$.

Cole, S., X. Giné, J. Tobacman, P. Topalova, R. M. Townsend, and J. Vickery (2013). Barriers to household risk management: Evidence from India. American Economic Journal: Applied Economics 5(1), 104-135.

Collier, P. and A. Hoeffler (2004). Greed and grievance in civil war. Oxford Economic Papers 56(4), 563-595.

Conner, M. and C. J. Armitage (1998). Extending the Theory of Planned Behavior: A Review and Avenues for Further Research. Journal of Applied Social Psychology 28(15), 1429-1464.

Cooke, R., M. Dahdah, P. Norman, and D. P. French (2014). How well does the Theory of Planned Behaviour predict alcohol consumption? A systematic review and metaanalysis. Health Psychology Review 10(2), 148-167.

Croicu, M. and R. Sundberg (2015). UCDP Georeferenced Event Dataset Codebook Version 4.0. Journal of Peace Research 50(4), 523-532.

Croicu, M. and R. Sundberg (2016). UCDP GED Codebook Version 5.0. Technical report, Department of Peace and Conflict Research, Uppsala University.

Croskerry, P. (2002). Achieving quality in clinical decision making: cognitive strategies and detection of bias. Academic Emergency Medicine 9(11), 1184-1204.

Crost, B., J. Felter, and P. Johnston (2014). Aid under fire: Development projects and civil conflict. American Economic Review 104(6), 1833-1856.

Crost, B., J. H. Felter, and P. B. Johnston (2016). Conditional cash transfers, civil conflict and insurgent influence: Experimental evidence from the Philippines. Journal of Development Economics 118, 171-182. 


\section{Bibliography}

Curto-Grau, M., A. Solé-Ollé, and P. Sorribas-Navarro (2018). Does electoral competition curb party favoritism? American Economic Journal: Applied Economics (forthcoming).

Data in Space (2018). Regional Development Indicators (RDI) - Africa, Version 0.1. Available at https://datainspace.org/, last accessed July 28, 2018.

Daudin, G., M. Morys, and K. H. O’Rourke (2008). Globalization, 1870-1914. University of Oxford - Department of Economics Discussion Paper Series (395).

De Luca, G., R. Hodler, P. A. Raschky, and M. Valsecchi (2018). Ethnic favoritism: An axiom of politics? Journal of Development Economics 132, 115-129.

De Ree, J. and E. Nillesen (2009). Aiding violence or peace? The impact of foreign aid on the risk of civil conflict in sub-Saharan Africa. Journal of Development Economics 88(2), 301-313.

Deck, C. and S. Jahedi (2015). The effect of cognitive load on economic decision making: A survey and new experiments. European Economic Review 78, 97-119.

Demmler, K. M., S. Klasen, J. M. Nzuma, and M. Qaim (2017). Supermarket purchase contributes to nutrition-related non-communicable diseases in urban Kenya. PloS one 12(9), 1-18.

Denning, G., P. Kabambe, P. Sanchez, A. Malik, R. Flor, R. Harawa, P. Nkhoma, C. Zamba, C. Banda, and C. Magombo (2009). Input subsidies to improve smallholder maize productivity in Malawi: Toward an African Green Revolution. PLoS biology $7(1), 2-10$.

Detweiler, J. B., B. T. Bedell, P. Salovey, E. Pronin, and A. J. Rothman (1999). Message framing and sunscreen use: Gain-framed messages motivate beach-goers. Health Psychology 18(2), 189-196.

Diao, X., M. McMillan, and D. Rodrik (2017). The recent growth boom in developing economies: A structural change perspective. NBER Working Paper 23132.

Diba, F., I. Ichsan, M. Muhsin, M. Marthoenis, H. Sofyan, S. Susanti, M. Andalas, K. Richert, L. Kaplan, Samadi, and S. Vollmer (2018). Analysis of the Impact and Effectiveness of Safe Childbirth Checklists on the Quality of Care and Birth Outcomes in Health Facilities in Aceh Province, Indonesia - A Randomized Controlled Trial. Mimeo.

Dickens, A. (2018). Ethnolinguistic favouritism in African politics. American Economic Journal: Applied Economics 10(3), 370-402.

Dietrich, S., M. Mahmud, and M. S. Winters (2018). Foreign Aid, Foreign Policy, and Domestic Government Legitimacy: Experimental Evidence from Bangladesh. The Journal of Politics 1(80), 133-148. 


\section{Bibliography}

Dietrich, S. and M. S. Winters (2015). Foreign aid and government legitimacy. Journal of Experimental Political Science 2(2), 164-171.

Dixit, A. and J. Londregan (1996). The determinants of success of special interests in redistributive politics. The Journal of Politics 58(4), 1132-1155.

Dollar, D. and L. Pritchett (1998). Assessing Aid - What Works, What Doesn't, and Why. World Bank Policy Research Report 1.

Dorward, A. and E. Chirwa (2011). The Malawi agricultural input subsidy programme: 2005/06 to 2008/09. International Journal of Agricultural Sustainability 9(1), 232247.

Doucouliagos, H. and M. Paldam (2008). Aid effectiveness on growth: A meta study. European Journal of Political Economy 24(1), 1-24.

Doucouliagos, H. and M. Paldam (2009). The aid effectiveness literature: The sad results of 40 years of research. Journal of Economic Surveys 23(3), 433-461.

Dreher, A. (2006). Does globalization affect growth? Evidence from a new index of globalization. Applied Economics 38(10), 1091-1110.

Dreher, A., V. Z. Eichenauer, and K. Gehring (2018). Geopolitics, aid, and growth: The impact of UN security council membership on the effectiveness of aid. The World Bank Economic Review.

Dreher, A., A. Fuchs, R. Hodler, B. Parks, P. A. Raschky, and M. J. Tierney (2016). Aid on demand: African leaders and the geography of China's foreign assistance. AidData Working Paper 3 (Revised).

Dreher, A., A. Fuchs, B. Parks, A. M. Strange, and M. J. Tierney (2017). Aid, China, and growth: Evidence from a new global development finance dataset. AidData Working Paper 46.

Dreher, A., A. Fuchs, B. Parks, A. M. Strange, and M. J. Tierney (2018). Apples and dragon fruits: the determinants of aid and other forms of state financing from China to Africa. International Studies Quarterly 62(1), 182-194.

Dreher, A. and N. Gaston (2008). Has globalization increased inequality? Review of International Economics 16(3), 516-536.

Dreher, A., V. Lang, P. Rosendorff, and J.-R. Vreeland (2018). Buying Votes and International Organizations: The Dirty-Work Hypothesis. Mimeo.

Dreher, A. and S. Langlotz (2017). Aid and growth. New evidence using an excludable instrument. Economics Discussion Paper 635, Heidelberg University. 


\section{Bibliography}

Dreher, A., S. Langlotz, and S. Marchesi (2017). Information transmission and ownership consolidation in aid programs. Economic Inquiry 55(4), 1671-1688.

Dreher, A. and S. Lohmann (2015). Aid and growth at the regional level. Oxford Review of Economic Policy 31(3-4), 420-446.

Dreher, A., P. Nunnenkamp, and R. Thiele (2008). Does aid for education educate children? Evidence from panel data. World Bank Economic Review 22(2), 291-314.

Dreher, A., J.-E. Sturm, and J. R. Vreeland (2009). Development aid and international politics. Journal of Development Economics 88(1), 1-18.

Dube, O. and J. F. Vargas (2013). Commodity price shocks and civil conflict: Evidence from Colombia. Review of Economic Studies 80(4), 1384-1421.

Duflo, E., R. Glennerster, and M. Kremer (2007). Chapter 61 Using Randomization in Development Economics Research: A Toolkit. Handbook of Development Economics 4 (07), 3895-3962.

Easterly, B. W., R. Levine, and D. Roodman (2004). Aid, Policies, and Growth: Comment. American Economic Review 94 (3), 774-780.

Eck, K. (2012). In data we trust? A comparison of UCDP, GED, and ACLED conflict events datasets. Cooperation and Conflict 47(1), 124-141.

Eck, K. and L. Hultman (2007). One-sided violence against civilians in war: Insights from new fatality data. Journal of Peace Research 44(2), 233-246.

Ejdemyr, S., E. Kramon, and A. L. Robinson (2018). Segregation, ethnic favoritism, and the strategic targeting of local public goods. Comparative Political Studies 51(9), $1111-1143$.

Englmaier, F. and T. Stowasser (2017). Electoral cycles in savings bank lending. Journal of the European Economic Association 15(2), 296-354.

Esteban, J., L. Mayoral, and D. Ray (2012). Ethnicity and conflict: An empirical study. American Economic Review 102(4), 1310.

Fafchamps, M. (2000). Ethnicity and credit in African manufacturing. Journal of Development Economics 61(1), 205-235.

Fan, Y. and H. Van den Dool (2008). A global monthly land surface air temperature analysis for 1948-present. Journal of Geophysical Research: Atmospheres 113(D1).

FAO (2018). FAOStat. Available at http://www.fao.org/faostat/en/\#data, last accessed September 28, 2018. 


\section{Bibliography}

Fearon, J. D. and D. D. Laitin (2003). Ethnicity, insurgency, and civil war. American Political Science Review 97(01), 75-90.

Fearon, J. D. and D. D. Laitin (2011). Sons of the soil, migrants, and civil war. World Development 39(2), 199-211.

Fichten, C., T. Heiman, M. Jorgensen, M. N. Nguyen, A. Havel, L. King, J. Budd, and R. Amsel (2016). Theory of Planned Behavior Predicts Graduation Intentions of Canadian and Israeli Postsecondary Students with and without Learning Disabilities/Attention Deficit Hyperactivity Disorder. International Journal of Higher Education 5(1), 208-219.

Findley, M. G., A. S. Harris, H. V. Milner, and D. L. Nielson (2017). Who Controls Foreign Aid? Elite versus Public Perceptions of Donor Influence in Aid-Dependent Uganda. International Organization (October 2015), 1-31.

Fishbein, M. and I. Ajzen (1980). Understanding Attitudes and Predicting Social Behavior (Revised ed.). Prentice-Hall.

Franck, R. and I. Rainer (2012). Does the Leader's Ethnicity Matter? Ethnic Favoritism, Education, and Health in Sub-Saharan Africa. American Political Science Review 106(2), 294-325.

French, D. P. and M. Hankins (2003). The expectancy-value muddle in the theory of planned behaviour - and some proposed solutions. British Journal of Health Psychology 8, 37-55.

Fuchs, A. and K. Gehring (2017). The home bias in sovereign ratings. Journal of the European Economic Association 15(6), 1386-1423.

Fuchs, A. and K. C. Vadlamannati (2013). The needy donor: An empirical analysis of India's aid motives. World Development 44, 110-128.

Galiani, S., S. Knack, L. C. Xu, and B. Zou (2017). The effect of aid on growth: Evidence from a quasi-experiment. Journal of Economic Growth 22, 1-33.

Gehring, K., S. Kienberger, and S. Langlotz (2018). Stimulant or depressant? Resourcerelated income shocks and conflict. University of Heidelberg Department of Economics Discussion Paper Series No. 652.

Gehring, K. and V. Lang (2018). Stigma or cushion? IMF programs and sovereign creditworthiness. University of Zurich CIS Working Paper No. 98.

Gehring, K., K. Michaelowa, A. Dreher, and F. Spörri (2017). Aid fragmentation and effectiveness: What do we really know? World Development 99, 320-334.

Gereffi, G. and K. Fernandez-Stark (2016). Global value chain analysis: a primer (Second ed.). Duke CGGC (Center on Globalization, Governance \& Competitiveness). 


\section{Bibliography}

German Federal Ministry for Economic Cooperation and Development (BMZ) (2005). Review of German Government Funding for the Tsunami Relief Operations.

Gibson, C. and M. J. Woolcock (2005). Empowerment and local level conflict mediation in Indonesia: A comparative analysis of concepts, measures, and project efficacy, Volume 3713. World Bank Publications.

Giuliano, P. and N. Nunn (2018). Ancestral characteristics of modern populations. Economic History of Developing Regions 33(1), 1-17.

Gneezy, U., S. Meier, and P. Rey-Biel (2011). When and Why Incentives (Don't) Work to Modify Behavior. Journal of Economic Perspectives 25(4), 191-210.

Goldsmith-Pinkham, P., I. Sorkin, and H. Swift (2018). Bartik instruments: What, when, why, and how. NBER Working Paper 24408.

Gollin, D. (2014). The Lewis model: A 60-year retrospective. Journal of Economic Perspectives 28(3), 71-88.

Grossman, H. I. (1991). A general equilibrium model of insurrections. The American Economic Review, 912-921.

Grossman, H. I. (1992). Foreign aid and insurrection. Defence and Peace Economics 3(4), 275-288.

Guttman, N. B. (1999). Accepting the standardized precipitation index: A calculation algorithm. JAWRA Journal of the American Water Resources Association 35(2), $311-322$.

Hanna, R., E. Duflo, and M. Greenstone (2016). Up in smoke: the influence of household behavior on the long-run impact of improved cooking stoves. American Economic Journal: Economic Policy 8(1), 80-114.

Harms, P. and P.-G. Méon (2018). Good and useless FDI: The growth effects of greenfield investment and mergers and acquisitions. Review of International Economics 26(1), 37-59.

Harrison, G. W. and J. A. List (2004). Field Experiments. Journal of Economic Literature 42(4), 1009-1055.

Haugen, A. S., E. Søfteland, S. K. Almeland, N. Sevdalis, B. Vonen, G. E. Eide, M. W. Nortvedt, and S. Harthug (2015). Effect of the World Health Organization checklist on patient outcomes: a stepped wedge cluster randomized controlled trial. Annals of surgery 261(5), 821-828.

Hausmann, R., J. Hwang, and D. Rodrik (2007). What you export matters. Journal of Economic Growth 12(1), 1-25. 


\section{Bibliography}

Hausmann, R., L. Pritchett, and D. Rodrik (2005). Growth accelerations. Journal of Economic Growth 10(4), 303-329.

Head, K., T. Mayer, and J. Ries (2010). The erosion of colonial trade linkages after independence. Journal of International Economics 81(1), 1-14.

Hegre, H. and N. Sambanis (2006). Sensitivity analysis of empirical results on civil war onset. Journal of conflict resolution 50(4), 508-535.

Henderson, J. V., T. Squires, A. Storeygard, and D. Weil (2017). The global distribution of economic activity: Nature, history, and the role of trade. Quarterly Journal of Economics 133(1), 357-406.

Henderson, J. V., A. Storeygard, and D. N. Weil (2012). Measuring economic growth from outer space. American Economic Review 102(2), 994-1028.

Hendrix, C. S. and S. Haggard (2015). Global food prices, regime type, and urban unrest in the developing world. Journal of Peace Research 52(2), 143-157.

Hess, S. (2017). Randomization inference with Stata: A guide and software. Stata Journal 17(3), 630-651.

Hijmans, R., N. Garcia, J. Kapoor, A. Rala, A. Maunahan, and J. Wieczorek (2012). Global Administrative Areas, Version 2.8.

Hirshleifer, J. (1989). Conflict and rent-seeking success functions: Ratio vs. difference models of relative success. Public Choice 63(2), 101-112.

Hirshleifer, J. (1995). Anarchy and its breakdown. Journal of Political Economy 103(1), $26-52$.

Hobbis, I. C. A. and S. Sutton (2005). Are Techniques Used in Cognitive Behaviour Therapy Applicable to Behaviour Change Interventions Based on the Theory of Planned Behaviour? Journal of Health Psychology 10(1), 7-18.

Hodler, R. and P. A. Raschky (2014). Regional favoritism. Quarterly Journal of Economics 129(2), 995-1033.

Hoffman, M., V. Mukete, J. Szmanda, and C. Witt (2011). The effect of increased stress levels on memory test performance. Unpublished manuscript available at https://www.google.com/search?q=The+effect+of+increased+stress+levels+on+ memory+test+performance+hoffmann\&ie $=$ utf-8\&oe $=$ utf-8\&client $=$ firefox-b- $1-a b$.

Hossain, T. and J. A. List (2012). The behavioralist visits the factory: Increasing productivity using simple framing manipulations. Management Science 58(12), 21512167. 


\section{Bibliography}

Hsu, C. L., C. Y. Chang, and C. Yansritakul (2017). Exploring purchase intention of green skincare products using the Theory of Planned Behavior: Testing the moderating effects of country of origin and price sensitivity. Journal of Retailing and Consumer Services 34, 145-152.

Hultman, L., J. Kathman, and M. Shannon (2014). Beyond keeping peace: United Nations effectiveness in the midst of fighting. American Political Science Review 108(4), $737-753$.

Humphrey, C. and K. Michaelowa (2018). China in Africa: Competition for traditional development finance institutions? AidData Working Paper Series 61.

Idemudia, U. (2009). Oil extraction and poverty reduction in the Niger delta: A critical examination of partnership initiatives. Journal of Business Ethics 90(1), 91-116.

IFPRI (2013). Agricultural incentives. Available at http://www.ag-incentives.org/ indicator/nominal-rate-protection, last accessed September 30, 2018.

ILO (2013). Employment in Africa: Think agriculture! Available at http://www.ilo. org/global/about-the-ilo/newsroom/news/WCMS_203469/lang--en/index.htm, last accessed July 18, 2018.

IMF (2018). IMF Primary Commodity Prices. Available at https://www.imf.org/ external/np/res/commod/index.aspx, last accessed October 2, 2018.

Iwanowsky, M. (2018). The effects of migration and ethnicity on African economic development. Unpublished Mansucript available at http://www.mathiasiwanowsky. com/Migration_and_Trade.pdf.

Johnson, E. J. and D. Goldstein (2003). Do Defaults Save Lives? Science 302(5649), $1338-1339$.

Kabongo, L., J. Gass, B. Kivondo, N. Kara, K. Semrau, and L. R. Hirschhorn (2017). Implementing the WHO Safe Childbirth Checklist: lessons learnt on a quality improvement initiative to improve mother and newborn care at Gobabis District Hospital, Namibia. BMJ Open Quality 6(2), 1-8.

Kahneman, D. (2003). Maps of Bounded Rationality: Psychology for Behavioral Economics. The American Economic Review 93(5), 1449-1475.

Kahneman, D. and A. Tversky (1979). Prospect Theory: An Analysis of Decision under Risk. Econometrica $47(2), 263-291$.

Kalichman, S. C. and B. Coley (1995). Context framing to enhance HIV-antibodytesting messages targeted to African American women. Health Psychology 14(3), $247-254$. 


\section{Bibliography}

Kam, L., V. E. Knott, C. Wilson, and S. K. Chambers (2012). Using the Theory of Planned Behavior to understand health professionals' attitudes and intentions to refer cancer patients for psychosocial support. Psycho-Oncology 21, 316-323.

Kanwar, S. (2012). Intellectual property protection and technology licensing: the case of developing countries. The Journal of Law and Economics 55(3), 539-564.

Karim, A. M., T. Williams, L. Patykewich, D. Ali, C. E. Colvin, J. Posner, and G. Rutaremwa (2009). The impact of the African youth alliance program on the sexual behavior of young people in Uganda. Studies in Family Planning 40(4), 289306.

Kasara, K. (2007). Tax me if you can: Ethnic geography, democracy, and the taxation of agriculture in Africa. American Political Science Review 101(1), 159-172.

Kassim, K. A., L. Arokiasamy, M. H. M. Isa, and C. H. Ping (2017). Intention to Purchase Safer Car: an Application of Theory of Planned Behavior. Global Business \& Management Research 9(1), 188-197.

Keefer, P. (2007). Clientelism, credibility, and the policy choices of young democracies. American Journal of Political Science 51(4), 804-821.

Keefer, P. and S. Khemani (2014). Radio's impact on preferences for patronage benefits. World Bank Policy Research Working Paper 5559.

Kemper, C. J., C. Beierlein, D. Bensch, A. Kovaleva, and B. Rammstedt (2014). Soziale Erwünschtheit-Gamma (KSE-G) (Version 1.0). ZIS - GESIS Leibniz Institute for the Social Sciences. GESIS.

Kettle, S., M. Hernandez, S. Ruda, and M. Sanders (2016). Behavioral interventions in tax compliance: evidence from Guatemala. World Bank Policy Research Working Paper 7690.

Keynes, J. M. (1933). National self-sufficiency. The Yale Review 22(4), 755-769.

Kiene, S. M., S. Hopwood, H. Lule, and R. K. Wanyenze (2014). An empirical test of the Theory of Planned Behaviour applied to contraceptive use in rural Uganda. Journal of Health Psychology 19(12), 1564-1575.

Kinsman, J., J. Nakiyingi, A. Kamali, L. Carpenter, M. Quigley, R. Pool, and J. Whitworth (2001). Evaluation of a comprehensive school-based AIDS education programme in rural Masaka, Uganda. Health Education Research 16(1), 85-100.

Kis-Katos, K., J. Pieters, and R. Sparrow (2018). Globalization and social change: Gender-specific effects of trade liberalization in Indonesia. IMF Economic Review (forthcoming). 


\section{Bibliography}

Kishi, R. and C. Raleigh (2015). Chinese aid and Africa's pariah states. Mimeo.

Klasen, S. (2000). Measuring poverty and deprivation in South Africa. Review of Income and Wealth 46(1), 33-58.

Klöckner, C. A. and A. Blöbaum (2010). A comprehensive action determination model: Toward a broader understanding of ecological behaviour using the example of travel mode choice. Journal of Environmental Psychology 30(4), 574-586.

Kruse, H. W. and I. Martínez-Zarzoso (2016). Transfers in the gravity equation: The case of foreign aid. CEGE Discussion Paper 288.

Kuhnt, J. and S. Vollmer (2018). Implementing the WHO safe childbirth checklist in Pakistan: Can a simple checklist reduce maternal and neonatal health outcomes? Mimeo.

Lagon, M. P. (1992). The International System and the Reagan Doctrine: Can Realism Explain Aid to "Freedom Fighters"? British Journal of Political Science 22(1), 39-70.

Lammersen, F. and M. Roberts (2015). Aid for trade 10 years on: Keeping it effective. OECD Development Policy Papers 1.

Landmann, D., C. J. Lagerkvist, and V. Otter (2017). Determinants of smallholder farmers intention to use smartphones - evidence from rural India. In A. Ruckelshause, A. Meyer-Aurich, W. Lentz, and B. Theuvsen (Eds.), Informatik in der Land-, Forstund Ernährungswirtschaft 2017, Bonn, pp. 93-96. Gesellschaft für Informatik e.V.

Lang, V. (2016). The economics of the democratic deficit: The effect of IMF programs on inequality. Heidelberg University Discussion Paper 617.

Lang, V. F. and M. M. Tavares (2018). The Distribution of Gains from Globalization. IMF Working Paper 18/54.

Larch, M. and J. Wanner (2017). Carbon tariffs: An analysis of the trade, welfare, and emission effects. Journal of International Economics 109, 195-213.

Lebovic, J. H. and E. Voeten (2009). The cost of shame: International organizations and foreign aid in the punishing of human rights violators. Journal of Peace Research $46(1), 79-97$.

Lewis, A. W. (1954). Economic development with unlimited supplies of labor. The Manchester School 22, 139-91.

Lexis Nexis (2018). Academic Search. Available at https://www.lexisnexis.com, last accessed September 28, 2018. 


\section{Bibliography}

Lichand, G. and A. Mani (2016). Cognitive droughts. CAGE Online Working Paper Series 298.

Limao, N. and A. J. Venables (2001). Infrastructure, geographical disadvantage, transport costs, and trade. The World Bank Economic Review 15(3), 451-479.

Lipton, M. (1977). Why poor people stay poor: a study of urban bias in world development. London:Temple Smith; Australian National University Press.

Lugoe, W. and J. Rise (1999). Predicting Intended Condom Use among Tanzanian Students using the Theory of Planned Behaviour. Journal of Health Psychology 4(4), 497-506.

Madrian, B. C. (2014). Applying Insights from Behavioral Economics to Policy Design. NBER Working Paper 20318.

Martínez-Zarzoso, I., F. Nowak-Lehmann D., M. Parra, and S. Klasen (2014). Does aid promote donor exports? Commercial interest versus instrumental philantropy. Kyklos 67(4), 559-587.

McEachan, R. R. C., M. Conner, N. J. Taylor, and R. J. Lawton (2011). Prospective prediction of health-related behaviours with the Theory of Planned Behaviour: A meta-analysis. Health Psychology Review 5(2), 97-144.

McGuirk, E. and M. Burke (2017). The economic origins of conflict in Africa. NBER Working Paper 23056.

McMillan, M. (2001). Why kill the golden goose? A political-economy model of export taxation. Review of Economics and Statistics 83(1), 170-184.

McMillan, M. S., D. Rodrik, and Í. Verduzco-Gallo (2014). Globalization, structural change and productivity growth: with an update on Africa. World Development 63, $11-32$.

Michalopoulos, S. (2012). The origins of ethnolinguistic diversity. American Economic Review 102(4), 1508-1539.

Michalopoulos, S. and E. Papaioannou (2016). The long-run effects of the scramble for Africa. American Economic Review 106 (7), 1802-1848.

Miguel, E., S. Satyanath, and E. Sergenti (2004). Economic shocks and civil conflict: An instrumental variables approach. Journal of Political Economy 112(4), 725-753.

Milanovic, B. (2007). Global inequality, Chapter "Patterns and explanations", pp. 2649. Polity Cambridge and Malden, MA. 


\section{Bibliography}

Milner, H. V., D. L. Nielson, and M. G. Findley (2016). Citizen preferences and public goods: comparing preferences for foreign aid and government programs in Uganda. The Review of International Organizations 11(2), 219-245.

Minasyan, A., P. Nunnenkamp, and K. Richert (2017). Does Aid Effectiveness Depend on the Quality of Donors? World Development 100, 16-30.

Monfreda, C., N. Ramankutty, and J. A. Foley (2008). Farming the planet: 2. Geographic distribution of crop areas, yields, physiological types, and net primary production in the year 2000. Global biogeochemical cycles 22(1), 1-19.

Morelli, M. and D. Rohner (2015). Resource concentration and civil wars. Journal of Development Economics 117, 32-47.

Müller, A. and U. Pape (2018). Broken promises: Evaluating an incomplete cash transfer program. Unpublished Manuscript.

Murdock, G. P. (1959). Africa: its peoples and their culture history. New York: United States; McGraw-Hill.

Naím, M. (2007). Rogue aid. Foreign Policy (159), 96.

Natural Earth (2018). Natural earth - free vector and raster map data. Available at https://www.naturalearthdata.com, last accessed September 3, 2018.

Nayiga, S., D. DiLiberto, L. Taaka, C. Nabirye, A. Haaland, S. G. Staedke, and C. I. Chandler (2014). Strengthening patient-centred communication in rural Ugandan health centres: A theory-driven evaluation within a cluster randomized trial. Evaluation $20(4), 471-491$.

Nielsen, R. A., M. G. Findley, Z. S. Davis, T. Candland, and D. L. Nielson (2011). Foreign aid shocks as a cause of violent armed conflict. American Journal of Political Science 55(2), 219-232.

Nizalova, O. Y. and I. Murtazashvili (2016). Exogenous treatment and endogenous factors: Vanishing of omitted variable bias on the interaction term. Journal of Econometric Methods 5(1), 71-77.

North, D. C. (1991). Institutions. Journal of Economic Perspectives 5(1), 97-112.

Nowak-Lehmann D., F., I. Martínez-Zarzoso, D. Herzer, S. Klasen, and A. Cardozo (2013). Does foreign aid promote recipient exports to donor countries? Review of World Economics $149(3)$, 505-535.

Nunn, N. and N. Qian (2014). US Food Aid and Civil Conflict. American Economic Review $104(6), 1630-1666$. 


\section{Bibliography}

Nunn, N. and L. Wantchekon (2011). The Slave Trade and the Origins of Mistrust in Africa. American Economic Review 101(7), 3221-3252.

OECD (2008). The Paris declaration on aid effectiveness and the Accra agenda for action. Available at https://www.oecd.org/dac/effectiveness/34428351.pdf, last accessed September 27, 2018.

OECD (2015). OECD Creditor Reporting System. Available at https://stats.oecd.org/ Index.aspx?DataSetCode=CRS1, last accessed November 5, 2015.

OECD (2017). OECD Query Wizard. Available at https://stats.oecd.org/qwids, last accessed September 27, 2018.

OECD, WTO (2013). Aid for trade at a glance - 2013, Chapter Boosting Value Chains via Regional Aid for Trade, pp. 119-144.

Ogden, J. (2003). Some problems with social cognition models: a pragmatic and conceptual analysis. Health Psychology 22, 424-428.

Olson, M. (1993). Dictatorship, democracy, and development. American Political Science Review 87(3), 567-576.

Østby, G. (2008). Polarization, horizontal inequalities and violent civil conflict. Journal of Peace Research 45(2), 143-162.

Oster, E. (2017). Unobservable selection and coefficient stability: Theory and evidence. Journal of Business \& Economic Statistics, 1-18.

Pack, H. and J. R. Pack (1993). Foreign aid and the question of fungibility. The Review of Economics and Statistics 75(2), 258-265.

Padró i Miquel, G. (2007). The control of politicians in divided societies: the politics of fear. The Review of Economic Studies 74(4), 1259-1274.

Page, J. (2012). Can Africa industrialise? Journal of African Economies 21 (Suppl. 2), ii $86-$ ii 124.

Pasta, D. J. (2009). Learning when to be discrete: Continuous vs. categorical predictors. In SAS Global Forum, Number 248.

Payne, J. W., N. Sagara, S. B. Shu, K. C. Appelt, and E. J. Johnson (2013). Life expectancy as a constructed belief: Evidence of a live-to or die-by framing effect. Journal of Risk and Uncertainty 46(1), 27-50.

Perugini, M. and R. P. Bagozzi (2001). The role of desires and anticipated emotions in goal-directed behaviours: Broadening and deepening the theory of planned behaviour. 40, 79-98. 


\section{Bibliography}

Pettersson, J. and L. Johansson (2013). Aid, aid for trade, and bilateral trade: An empirical study. The Journal of International Trade 85 Economic Development 22(6), 866-894.

Piketty, T. (2016). We must rethink globalization, or Trumpism will prevail. Available at https://www.theguardian.com/commentisfree/2016/nov/16/ globalization-trump-inequality-thomas-piketty, last accessed September 25, 2018.

Posner, D. N. and D. J. Young (2007). The institutionalization of political power in Africa. Journal of Democracy 18(3), 126-140.

Protogerou, C., A. J. Flisher, L. E. Aar, and C. Mathews (2012). The theory of planned behaviour as a framework for predicting sexual risk behaviour in sub-Saharan African youth: A critical review. Journal of Child and Adolescent Mental Health 24(1), 15-35.

Rajan, R. G. and A. Subramanian (2008). Aid and Growth: What Does the CrossCountry Evidence Really Show? Review of Economics and Statistics 90(4), 643-666.

Rajan, R. G. and A. Subramanian (2011). Aid, Dutch Disease and Manufacturing Growth. Journal of Development Economics 94 (1), 106-118.

Raleigh, C., A. Linke, H. Hegre, and J. Karlsen (2010). Introducing ACLED-armed conflict location and event data. Journal of Peace Research 47(5), 651-660.

Rauch, J. E. and V. Trindade (2002). Ethnic Chinese networks in international trade. Review of Economics and Statistics 84(1), 116-130.

Riley, S. J., S. D. De Gloria, and R. Elliot (1999). A Terrain Ruggedness Index That Quantifies Topographic Heterogeneities. Intermountain Journal of Sciences 5(1-4), 23-27.

Rodrik, D. (1998). Has globalization gone too far? Challenge 41(2), 81-94.

Rodrik, D. (2013). Unconditional convergence in manufacturing. The Quarterly Journal of Economics 128(1), 165-204.

Rodrik, D. (2016). Premature deindustrialization. Journal of Economic Growth 21(1), $1-33$.

Rogers, P. (2014). Theory of change. UNICEF Methodological Briefs 2, UNICEF. Available at https://www.unicef-irc.org/publications/ 747-theory-of-change-methodological-briefs-impact-evaluation-no-2.html, last accessed September 27, 2018.

Roodman, D. (2015). A Replication of "Counting Chickens When They Hatch" (Economic Journal 2012). Public Finance Review 43(2), 256-281. 


\section{Bibliography}

Salehyan, I. and C. Hendrix (2017). Social Conflict Analysis Database (SCAD) Version 3.3 Codebook. Technical report.

Salehyan, I., C. S. Hendrix, J. Hamner, C. Case, C. Linebarger, E. Stull, and J. Williams (2012). Social Conflict in Africa: A New Database. International Interactions 38(4), $503-511$.

Schneider, T. R., P. Salovey, A. M. Apanovitch, J. Pizarro, D. McCarthy, J. Zullo, and A. J. Rothman (2001). The effects of message framing and ethnic targeting on mammography use among low-income women. Health Psychology 20(4), 256-266.

Schneider, U., A. Becker, P. Finger, A. Meyer-Christoffer, B. Rudolf, and M. Ziese (2015). GPCC Full Data Reanalysis Version 7.0 at $0.5^{\circ}$ : Monthly Land-Surface Precipitation from Rain-Gauges built on GTS-based and Historic Data.

Semrau, K. E., L. R. Hirschhorn, M. Marx Delaney, V. P. Singh, R. Saurastri, N. Sharma, D. E. Tuller, R. Firestone, S. Lipsitz, N. Dhingra-Kumar, et al. (2017). Outcomes of a coaching-based WHO Safe Childbirth Checklist program in India. New England Journal of Medicine 37r(24), 2313-2324.

Sen, A. (1993). Capability and Well-Being. Oxford: Clarendon Press.

Sexton, R. (2016). Aid as a tool against insurgency: Evidence from contested and controlled territory in Afghanistan. American Political Science Review 110(4), 731.

Simon, H. A. and J. Feldman (1959). Theories of Decision-Making in Economics and Behavioral Science. Source: The American Economic Review 49(3), 253-283.

Sokoloff, K. L. and S. L. Engerman (2000). Institutions, factor endowments, and paths of development in the new world. Journal of Economic perspectives 14(3), 217-232.

Sow, M. (2018). Figures of the week: Africa's intra- and extra-regional trade. Available at https://www.brookings.edu/blog/africa-in-focus/2018/03/29/ figures-of-the-week-africas-intra-and-extra-regional-trade/, last accessed September $7,2018$.

Storeygard, A. (2016). Farther on down the road: Transport costs, trade and urban growth in Sub-Saharan Africa. The Review of Economic Studies 83(3), 1263-1295.

Strandow, D., M. Findley, D. Nielson, and J. Powell (2011). The UCDP-AidData Codebook on Geo-Referencing Foreign Aid. Version 1.1. Technical report, Uppsala Conflict Data Program.

Strange, A. M., A. Dreher, A. Fuchs, B. Parks, and M. J. Tierney (2017). Tracking underreported financial flows: China's development finance and the aid-conflict nexus revisited. Journal of Conflict Resolution 61(5), 935-963. 


\section{Bibliography}

Sundberg, R. and E. Melander (2013). Introducing the UCDP georeferenced event dataset. Journal of Peace Research 50(4), 523-532.

te Velde, D. W. (2007). Regional Aid for Trade. ILEAP Negotiation Advisory Brief 12.

Temple, J. and N. Van de Sijpe (2017). Foreign aid and domestic absorption. Journal of International Economics 108, 431-443.

Toll, B. A., S. S. O’Malley, N. A. Katulak, R. Wu, J. A. Dubin, A. Latimer, B. Meandzija, T. P. George, P. Jatlow, J. L. Cooney, et al. (2007). Comparing gain-and loss-framed messages for smoking cessation with sustained-release bupropion: a randomized controlled trial. Psychology of Addictive Behaviors 21(4), 534-544.

Tollefsen, A. F., H. Strand, and H. Buhaug (2012). PRIO-GRID: A unified spatial data structure. Journal of Peace Research 49(2), 363-374.

Trautmann, S. T. and G. van de Kuilen (2015). Belief Elicitation: A Horse Race among Truth Serums. Economic Journal 125(589), 2116-2135.

Trionfetti, F. (2017). An anatomy of the transfer problem. Mimeo.

Tversky, A. and D. Kahneman (1981). The framing of decisions and the psychology of choice. Science 211 (4481), 453-458.

Uchida, H. and A. Nelson (2009). Agglomeration index: Towards a new measure of urban concentration. UNU-WIDER Working Paper 2010/29.

Van de Walle, N. (2003). Presidentialism and clientelism in Africa's emerging party systems. The Journal of Modern African Studies 41(2), 297-321.

Van der Ploeg, F. (2011). Natural resources: curse or blessing? Journal of Economic Literature 49(2), 366-420.

van Weezel, S. (2015). A spatial analysis of the effect of foreign aid in conflict areas. AidData Working Paper 8.

Viceisza, A. C. (2015). Creating a Lab in the Field: Economics Experiments for Policymaking. Journal of Economic Surveys 30(5), 835-854.

Vicente, P. C. and L. Wantchekon (2009). Clientelism and vote buying: lessons from field experiments in African elections. Oxford Review of Economic Policy 25(2), $292-305$.

Vijil, M. and L. Wagner (2012). Does aid for trade enhance export performance? Investigating the infrastructure channel. The World Economy 35(7), 838-868.

Vogel, T. and M. Wanke (2016). Attitudes and Attitude Change (Second ed.). London and New York: Routledge. 


\section{Bibliography}

Vogt, M., N.-C. Bormann, S. Rüegger, L.-E. Cederman, P. Hunziker, and L. Girardin (2015). Integrating data on ethnicity, geography, and conflict: The ethnic power relations data set family. Journal of Conflict Resolution 59(7), 1327-1342.

Walrave, M., W. Heirman, and L. Hallam (2014). Under pressure to sext? Applying the theory of planned behaviour to adolescent sexting. Behaviour 85 Information Technology 33(1), 85-97.

Weidmann, N. B., J. K. Rød, and L.-E. Cederman (2010). Representing ethnic groups in space: A new dataset. Journal of Peace Research 47(4), 491-499.

WHO (2018). Newborns: Reducing mortality. Available at http://www.who.int/ news-room/fact-sheets/detail/newborns-reducing-mortality, last accessed September 10, 2018.

Wildschut, T., M. Bruder, S. Robertson, W. A. van Tilburg, and C. Sedikides (2014). Collective nostalgia: A group-level emotion that confers unique benefits on the group. Journal of Personality and Social Psychology 107(5), 844-863.

Williams, M. J. (2017). The political economy of unfinished development projects: corruption, clientelism, or collective choice? American Political Science Review 111(4), $705-723$.

Wilson, D. K., R. M. Kaplan, and L. J. Schneiderman (1987). Framing of decisions and selections of alternatives in health care. Social Behaviour 2(1), 51-59.

Winters, M. S., S. Dietrich, and M. Mahmud (2017). Perceptions of Foreign Aid Project Quality in Bangladesh. Research and Politics 4 (4), 1-6.

WITS (2018). World Integrated Trade Solutions Database. Available at https://wits. worldbank.org/, last accessed September 26, 2018.

Wooldridge, J. M. (2015). Control functions methods in applied econometrics. Journal of Human Resources 50(2), 420-445.

Workman, M., M. F. Lesser, and J. Kim (2007). An exploratory study of cognitive load in diagnosing patient conditions. International Journal for Quality in Health Care 19(3), 127-133.

World Bank (2015a). Management's discussion \& analysis and financial statements. Available at https://ida.worldbank.org/sites/default/files/images/ida_ financial_statements_jun_15.pdf, last accessed September 27, 2018.

World Bank (2015b). World Development Report 2015 - Mind, Society, and Behavior. Washington, DC: World Bank.

World Bank (2017a). Migration and remittances. Mirgration and Development Brief 27. 


\section{Bibliography}

World Bank (2017b). World bank group finances - IDA: Commitments, gross disbursements, and net disbursements. Available at https://finances.worldbank.org/dataset/ IDA-Commitments-Gross-Disbursements-and-Net-Disbur/tark-i8qh/data, last accessed October 3, 2018.

World Bank (2018a). Doing Business 2018. Available at http://www.doingbusiness. org/, last accessed September 27, 2018.

World Bank (2018b). Global Economic Monitor (GEM). Available at https://data. world/worldbank/global-economic-monitor, last accessed September 30, 2018.

World Bank (2018c). Supporting Africa's transformation: Regional integration and cooperation assistance strategy. Africa Regional Integration Strategy Progress Report 121912-AFR.

World Bank (2018d). World Development Indicators. Available at https://data. worldbank.org/indicator, last accessed September 25, 2018.

World Health Organization (2018). Experiences with the WHO Safe Childbirth Checklist from around the world. Available at http://www.who.int/patientsafety/ implementation/checklists/scc-photostory/en, last accessed October 3, 2018.

World Steel Association (2009). Statistical yearbook 2009. Annual Report, Worldsteel Committee on Economic Studies, Brussels, Belgium.

World Steel Association (2014). Statistical yearbook 2014. Annual Report, Worldsteel Committee on Economic Studies, Brussels, Belgium.

WTO (2005). Aid for trade capacity in poorer countries up by 50 per cent since Doha. Available at https://www.wto.org/english/news_e/pres05_e/pr427_e.htm, last accessed August 18, 2018.

WTO (2013). Countries of the Central African Economic and Monetary Community (CEMAC). Trade Policy Review - Report by the WTO Secretariat WT/TPR/S/285.

Wucherpfennig, J., N. B. Weidmann, L. Girardin, L.-E. Cederman, and A. Wimmer (2011). Politically Relevan Ethnic Groups across space and time: Introducing the GeoEPR dataset. Conflict Management and Peace Science 28(5), 423-437.

Yotov, Y. V., R. Piermartini, J.-A. Monteiro, and M. Larch (2016). An Advanced Guide to Trade Policy Analysis: The Structural Gravity Model. Geneva: WTO publications.

Young, A. (2017). Channelling Fisher: Randomization Tests and the Statistical Insignificance of Seemingly Significant Experimental Results. Available at http://personal. lse.ac.uk/YoungA/ChannellingFisher.pdf, last accessed September 27, 2018.

Zylberberg, E. (2013). Bloom or bust? A global value chain approach to smallholder flower production in Kenya. Journal of Agribusiness in Developing and Emerging Economies 3(1), 4-26. 



\section{Acknowledgments}

Many people have supported me in the process of writing these chapters and without their help, this thesis would not exist. First, I am very grateful to Axel Dreher my principal supervisor - whose provision of academic freedom and an "open door" policy for PhD students I highly valued. In this regard, Axel contributed largely to the development of this thesis by providing comprehensive feedback on the chapters and always being open for discussions on methods as well as general concepts of the political drivers of economic development. Equally, I enjoyed the great chair activities and found it highly beneficial that Axel encouraged the cooperation with other researchers. Axel provided me with the unique opportunity to be both a member of his chair in Heidelberg and the research training group "Globalization and Development" in Hannover and Göttingen. Being affiliated with Göttingen also provided me with the opportunity to be co-supervised by Stephan Klasen, who actively supported me throughout the process and impressed me by his ability to instantly grasp the strengths and weaknesses of research projects. Further, I was inspired by his motivation to give young researchers constructive feedback and contributing to their professional development. Moreover, the thesis strongly benefited from the comments of my third supervisor Martin Gassebner and I very much enjoyed the hospitality at his chair in Hannover. Equally, I valued Krisztina Kis-Katos critical comments during seminars pushing one to think a step further. I was very happy when she agreed without hesitation to become my third examiner.

With regard to the chapters of this thesis, I consider myself very lucky to have worked with so many gifted co-authors, from whom I learned a great deal. This ranges from Hendrik's critical theoretical thoughts and Melvin's programming skills, as well as Kai's scientific curiosity to Jana's and Katharina's intrinsic motivation for development. Moreover, Sebastian Vollmer fostered my interdisciplinary interest in health economics. All of them made my PhD an invaluable learning experience. In this regard, I am very grateful to Tristan and Inma, who encouraged me to go on and do a PhD after my master studies.

Besides co-authorship, my doctoral studies would not have been the same without the inspiring colleagues from Göttingen, Hannover and Heidelberg. The courses organized by Melanie and Björn for the research training group helped me to gain a thorough understanding of diverse fields in economics. However, without Bruno, Cara, Christian, Esther, Ghida, Helke, Hendrik, Jana, Manuel, Marlene, Marcello, Melvin, 


\section{Acknowledgments}

Paul, Reinhard, Sebastian, Simone, Slava, Stefanos, Tabea, Theres, and Wiebke courses and seminars would not only have been very challenging, but also definitely less fun. I would also like to thank Friederike, who organized many great seminars on behalf of the research group, providing us $\mathrm{PhD}$ students with diverse opportunities for academic exchange. It is also great to see that the research group continues its work involving a new cohort - its members Lukas and Johannes already provided valuable comments on this thesis. Of course, I also enjoyed the many coffee and lunch breaks with the colleagues in Heidelberg, including Alexander, Alexandra, Andreas, Angelika, Christopher, David, Gerda, John, Katharina, Michael, Onno, Rajesh, Sarah, Sebastian, Sven, Valentin, Vera, and Zain. More specifically, I very much appreciated Andreas' academic guidance starting from the first meeting and admired Rajesh's interest in all fields of economics. While Angelika's and Gerda's good mood cheered up many breaks and chair events, John and Sven reminded me that running and going out make for a good work life balance. Sebastian and Valentin showed me how important conferences are to sustain academic exchange, even if most of them only take place once a year. Sarah and Zain helped me to not lose faith during the last weeks of the dissertation. The joint work with Katharina in Indonesia and Heidelberg sustained and fostered my interest in development cooperation and impact evaluation.

Also administrative hurdles can be equally a challenge, too. Had it not been for Christiane Fuhlrott, Kerstin Renziehausen, Heike Kullmann and Freya Schadt, I would have stopped researching and would still be working on the accounting for the travel expenses. Similarly, if Lisa Rogge and Vivien Hülsen had not supported us in Indonesia, we would still be checking survey answers. If I hadn't had all my colleagues' encouragement, I might have given up halfway (or even during the last weeks).

Here, I also have to thank our Indonesian colleagues Farah Diba, Dr. Ichsan, Dr. Marthoenis, Dr. Suryane, Dr. Muhsin, Dr. Hizir Sofyan, and Professor Samadi for their hospitality during our research on the Safe Childbirth Checklist, as well as the student assistant team around Hujjatul Balighah, Putri Cynthia Eka, Mutia Elviani, Masyitah Masyitah and Teddy Thaher, who taught us so much about the local context. All of them made it an unforgettable experience, which involved many challenges demonstrating the limits but mostly the great opportunities of international cooperation.

Although I would not have liked to miss these first-hand experiences of globalization, it was important for me to keep my local roots. In this regard, I would like to thank Annabell, who helped me to focus on the important issues and keep a balance between my $\mathrm{PhD}$ and life in general. I also owe a great deal to my friends Frauke, Nico and Philip, who hosted me several times in Göttingen and made it possible for me to work on my dissertation in two places. Finally, I would like to thank my sisters as well as my parents, who were encouraging me throughout my studies. They provided me with good advice, discussed research questions over dinner and if they would not have picked me up from the train station uncountable times, I would be lost somewhere between Göttingen and Osterode. Their support was invaluable. 


\section{Acknowledgments}

Acknowledgements - Chapter 1: We would like to thank Ron Davies, Luca de Benedictis, Axel Dreher, Stephan Klasen, Sarah Langlotz, Holger Strulik, Inma Martínez-Zarzoso, Dennis P. Quinn, Simon Quinn, participants at the ETSG 2016 conference, the 9th FIW conference in Vienna, the International Development Economics Workshop 2016 in Clermont-Ferrand, the Beyond Basic Questions Workshop 2016 in Salzburg, members of the Research Training Group Globalization and Development in Göttingen and Hannover, as well as Seminar Participants at Heidelberg University for valuable suggestions and comments. Harrison Bardwell supported us as a proofreader. We thank the German Research Foundation (DFG) for financial support.

Acknowledgements - Chapter 2: I thank Richard Bluhm, Christian Bjørnskov, Christian Bommer, John Cruzatti, Bruno Gabriel Witzel de Souza, Axel Dreher, Krisztina Kis-Katos, Stephan Klasen, Sven Kunze, Sarah Langlotz, Johannes Matzat, Angelika Müller, Dennis P. Quinn, Katharina Richert, Manuel Santos Silva, and Holger Strulik for valuable suggestions and comments. Moreover, I received valuable feedback from members of the Research Training Group Globalization and Development in Göttingen and Hannover, as well as Seminar Participants at Heidelberg University and at the 2018's Beyond Basic Questions Workshop. Theresa Geyer, Lena Gempke and Vivien Hülsen provided superb research assistance. Furthermore, Harrison Bardwell supported me as a proofreader. I thank the German Research Foundation (DFG) for financial support.

Acknowledgements - Chapter 3: We thank Richard Bluhm, Axel Dreher, Martin Gassebner, John Hoddinott, Christopher Kilby, Stephan Klasen, Stephen Knack, Stephan Kyburz, Steffen Lohmann, Franziska Luig, Tania Masi, Katharina Michaelowa, Richard Nielsen, Paul Schaudt, Arthur Silve, Philip Verwimp, Lukas Wellner and Tore Wig for valuable comments. Moreover, this work benefited from input provided at seminars in Groningen, Göttingen, Heidelberg, Hannover and Zürich, the Beyond Basic Questions conference at Lago di Garda, the 2017's General Conference of the European Political Science Association, the 2017's Jan Tinbergen Conference organized by the Network of European Peace Scientists, the EUDN PhD Workshop 2017 in Wageningen, the Annual Meeting of the International Political Economy Society 2017, the Northeast Universities Development Consortium Conference NEUDC 2017, the HiCN Conference 2017, the 2017 PRIO Workshop in Addis Abeba, the European Public Choice Society Meeting 2018, the CSAE Conference 2018 and the 2018 Silvaplana Workshop on Political Economy. Bradley Parks kindly shared data on the IDA's funding position. We are grateful to Michele McArdle and Tatiana Orozco, who provided excellent research assistance and support, as well as to Harrison Bardwell for proofreading. 


\section{Acknowledgments}

Acknowledgements - Chapter 4: We thank Manuela De Allegri, Britta Augsburg, Stephan Brenner, Martin Bruder, Erwin Bulte, Wändi Bruine de Bruin, Simone Dietrich, Siobhan Doria, Axel Dreher, Kerstin Grosch, York Hagmayer, Marcela Ibañez, Ghida Karbala, Rossa O'Keeffe-O'Donovan, Christian König, Dirk Landmann, Friederike Lenel, David McKenzie, Anna Merkel, Atika Pasha, Jan Priebe, Gert Pönitzsch, Holger Rau, Miriam Romero, Robert Schmidt, Santiago Saavedra, Sebastian Schneider, Simone Schotte, Reinhard Weisser, Hendriek Yopin, and colleagues from the chair in Heidelberg as well as the participants of seminars at Heidelberg University and the University of Göttingen and the members of the Research Training Group 1723 "Globalization and Development" for valuable feedback on the design and implementation of the field experiment conducted in Indonesia. Moreover, we are grateful for the proofreading of Harrison Bardwell and highly valued the excellent research assistance in Indonesia and Pakistan. 